\title{
Revisión del género Valeriana (Valerianaceae) en Sudamérica austral
}

\section{Revision of genus Valeriana (Valerianaceae) in Southern South America}

\author{
AdRIANA KUTSCHKER \\ Facultad de Ciencias Naturales, Universidad Nacional de la Patagonia San Juan Bosco, Ruta 259 - Km 4, 9200 Esquel- \\ Chubut, Argentina. \\ adrikut@gmail.com
}

\begin{abstract}
RESUMEN
El género Valeriana es el más diverso de la familia Valerianaceae y se encuentra ampliamente distribuido en las zonas templadas del hemisferio norte, África y Sudamérica, presentando en la región andina un importante centro de diversificación secundaria. Este trabajo comprende la revisión de las especies de Sudamérica austral sobre la base de material de Argentina y Chile desde los $33^{\circ} \mathrm{S}$ hasta $\operatorname{los} 55^{\circ} \mathrm{S}$. Se describen 40 especies de Valeriana de esta región, se citan ilustraciones ya publicadas y se incluye una clave para identificarlas. Se incluyen sinonimias nuevas basadas en el estudio de los tipos nomenclaturales y se lectotipifican varios taxones. Se hace referencia a las características distintivas de cada especie, su fenología, distribución geográfica y hábitat, material adicional examinado y afinidades taxonómicas. Se amplía la distribución geográfica de algunas especies y se citan nuevos registros para Argentina y Chile.
\end{abstract}

Palabras clave: Argentina, Chile, taxonomía, Valeriana, sinónimos, lectotipificación.

\begin{abstract}
The genus Valeriana is the most diverse of the Valerianaceae family and is widely distributed in temperate northern hemisphere, Africa and South America, presenting in the Andean region an important center of secondary diversification. This work includes the review of species of southern South America based on material from Argentina and Chile south of latitude $33^{\circ} \mathrm{S}$. Forty species of Valeriana are described for this region, references of published illustrations are given and a key is provided for their identification. New synonymies and lectotypes based on the study of type material are included. Notes on phenology, geographic distribution and habitat, additional material examined, distinguishing characters and taxonomic affinities are also given. Some species had not been reported previously for Argentina or Chile.
\end{abstract}

KEYwords: Argentina, Chile, taxonomy, Valeriana, synonims, lectotyfication.

\section{INTRODUCCIÓN}

La versión más reciente del sistema de clasificación de angiospermas basado en criterios filogenéticos (APG III 2009) incluyó a los géneros de la familia Valerianaceae dentro de la familia Caprifoliaceae, pertenecientes al Orden Dipsacales. Si bien esta familia ampliada está bien caracterizada, la mitad de los clados que incluye están pobremente caracterizados morfológicamente (APG III 2009). En este trabajo se mantiene la posición taxonómica de la familia Valerianaceae según Backlund y Pyck (1998) y sobre la base de los trabajos filogenéticos de Bell (2004), Hidalgo et al. (2004) y Bell y Donoghue (2005).

La familia Valerianaceae incluye alrededor de 400 especies que se distribuyen en todo el mundo, a excepción de Australia y las islas del Pacífico. El género Valeriana es el más diversificado y de mayor distribución dentro de esta familia, estando muy bien representado en la región andina de América del Sur. Las Valerianáceas están representadas en la flora argentina por 3 géneros: Valerianella Mill., Valeriana L. y Stangea Graebn; presentando Valeriana un total de 48 especies. En Chile esta familia incluye los mismos géneros presentes en Argentina y Valeriana es el más numeroso con 43 especies (Kutschker 2008a). Asimismo el género está bien representado en Perú con 73 especies, 45 de ellas endémicas; en Ecuador con 35, de las cuales 8 son endémicas; en Venezuela 2 especies, sin endemismos; Brasil con 17 especies (Bell 2003) y en Colombia se registran 28 especies (Mejía Piñeros et al. 2005).

A pesar de que existen revisiones de la familia Valerianaceae para la Argentina (Borsini 1942, 1944, 1946, 1960, 1962) y Chile (Gay 1847, Reiche 1902, Borsini 
1966), el género Valeriana en particular nunca fue tratado de manera conjunta para Chile y Argentina con un criterio fitogeográfico que permita considerar estas áreas adyacentes como un continuo, donde existe un importante número de especies compartidas por ambos países.

El objetivo de este estudio es realizar una revisión taxonómica y resolver la nomenclatura de las especies de Sudamérica austral, sobre la base de material de Argentina y Chile, al sur del paralelo $33^{\circ}$. Esto facilitará la identificación de la mayoría de las especies de la región templada de América del Sur, donde el género presenta un importante centro de diversificación secundaria. Se detalla la historia taxonómica de Valeriana y se discuten diferentes clasificaciones infragenéricas. Se describen el género y las especies aceptadas, su nomenclatura y sinonimias, y se hace referencia también a los caracteres distintivos, la distribución geográfica y afinidades taxonómicas. Se incluye una clave artificial para la determinación de los diferentes taxones.

Inicialmente el estudio incluyó un total de 44 especies, 18 de las cuales eran compartidas por ambos países. La exhaustiva recopilación de información taxonómica sobre las distintas especies y el análisis morfológico, en particular de hojas y frutos, permitió confirmar la posición taxonómica de la mayoría de las especies presentes en la región. Las especies V. crispa Ruiz \& Pav. y V. stricta Clos son citadas por primera vez para Argentina y $V$. boelckei Borsini para Chile. Se establecieron 6 nuevas sinonimias, V. floribunda Phil., V. oreocharis Phil. y V. lobata (Hook. \& Arn.) Höck que corresponden a sinónimos de $V$. crispa Ruiz \& Pav.; V. pilosa Phil. y V. germainii Briq. sinónimo de $V$. polemoniifolia Phil., y $V$. maipoana Rav. sinónimo de $V$. lepidota Clos; por otro lado se excluyó la especie V. magna Clos, considerada dudosa para Chile (Borsini 1966), lo que redujo el número de especies estudiadas a 40 . De éstas 34 se encuentran en Chile, 25 en Argentina, con 19 especies distribuidas en ambos países. Se amplían las distribuciones geográficas de V. boelckei, V. chilensis, V. crispa, V. fonckii, V. macrorhiza y V. stricta.

HISTORIA TAXONÓMICA Y DELIMITACIÓN DEL GÉNERO La denominación de Valerianaceae fue realizada por Batsch (1802) e incluía inicialmente una serie de géneros que no pertenecían a la misma; luego el concepto de la familia fue enmendado por Dumortier (1829), acotando las especies que la integraban. Los botánicos anteriores a Tournefort (1719) designaban a las especies de Valerianáceas como Nardus y $P h u$, y fue este autor quien las dividió en dos géneros: Valeriana y Valerianella. Estos fueron unificados por Linné, conservando el nombre de Valeriana, y publicados en su Species Plantarum, ed. $1^{\circ}, 31$ (1753). El lectotipo para el género fue seleccionado por Hitchcock (1929). Con posterioridad a Linné muchos fueron los autores que trataron el género Valeriana, entre ellos: Adanson (1764), Necker (1791), Moench (1794), Persoon (1805), De Candolle (1805,
1830), Dufresne (1811), Kunth (1819), Weddell (1859), Höck (1882, 1897, 1901), Graebner (1906), quienes además crearon nuevos géneros dentro de la familia Valerianaceae.

Miller (1754) separó nuevamente las especies sin pappus en el género Valerianella y a partir de éste se separaron tres nuevos géneros: Fedia Gaertn., enmendado por Moench, nom. cons., Patrinia Juss. y Plectritis (Lindl.) DC. Persoon (1805) dividió a la familia en sólo dos géneros: Valeriana y Phyllactis, incluyendo en este último a todas las especies con hojas radiadas. Lo mismo hizo Kunth (1819), quien redujo el número de géneros a Valeriana y Fedia. Weddell (1859) reconoció los mismos géneros que Persoon, pero se basó en las características del cáliz en la fructificación y creó divisiones dentro de Valeriana según sus formas vegetativas.

En base a la presencia de giba o espolón en las flores, al número de estambres y de lóculos en el fruto con desarrollo o no de pappus, De Candolle (1805) reconoce cuatro géneros, Valeriana, Centranthus, Fedia y Valerianella. Más tarde el mismo autor $(1830,1832)$ suma 7 géneros a los ya definidos: Patrinia, Nardostachys, Dufresnia, Astrephia, Plectritis, Triplostegia y Betckea. Al género Valeriana lo divide en 3 secciones, basándose en la morfología de flores y hojas: Phyllactis, Aretiastrum y Phu, esta última la más extensa y que incluía las especies de Europa y América.

Bentham y Hooker (1873-1876) y Höck $(1882,1901)$ reconocieron nueve y ocho géneros respectivamente dentro de las Valerianáceas; este último autor utilizó como criterios de diferenciación las formas de vida, número de estambres y morfología del fruto. Graebner (1906) subdividió a Valerianaceae en tres tribus, que comprendían 14 géneros en total, 7 de los cuales eran reconocidos para Sudamérica (Valeriana L., Phyllactis Pers., Aretiastrum DC., Belonanthus Graebn., Phuodendron Graebn., Stangea Graebn. y Astrephia Dufr.). Stuckert y Briquet (19161919) en su contribución a las Valerianáceas de Argentina consideraron sólo tres géneros, uno de ellos Valeriana. Borsini $(1942,1944)$ en sus trabajos sobre la sistemática de las Valerianáceas de Argentina y basándose especialmente en la morfología del fruto, reconoció los siguientes géneros: Plectritis, Centranthus, Valerianella, Valeriana y Stangea, transfiriendo a Phyllactis a la categoría de subgénero.

Las revisiones más actuales corresponden a Weberling (1970), quien conservó las tribus Patrinieae Höck y Triplostegieae Höck tal como las definiera Graebner (1906), y redujo a tres las subtribus que integran la tribu Valerianeae Höck., con un total de 13 géneros en la familia. Eriksen (1989) a diferencia de Graebner (1906) y Weberling (1970) reconoce a Phyllactis Pers. como un subgénero de Valeriana L., y a su vez considera a los géneros Aretiastrum (DC.) Spach, Astrephia Dufr., Belonanthus Graebn. y Stangea Graebn. como secciones de Valeriana. Backlund (1996) conserva las tribus, subtribus y los 14 géneros establecidos por Graebner (1906), y varios autores han agrupado a los 
taxones exclusivamente sudamericanos en Valeriana L., reduciendo el número de géneros a ocho (Larsen 1986, Eriksen 1989).

Muchos de los géneros en que se ha subdividido a la familia Valerianaceae han sido considerados en algún momento especies o secciones de Valeriana L., elevándose su estatus a género; se ha dado también el proceso inverso, por el cual algunos géneros pasaron a constituir subgéneros o secciones. Esto refleja la complejidad para establecer una clasificación adecuada que incluya la gran diversidad de especies, particularmente en Sudamérica.

\section{RELACIONES INTRAGENÉRICAS}

De Candolle (1830) subdividió a Valeriana en 3 secciones, basándose en las formas vegetativas y estructura de las hojas: Phyllactis (según el concepto de Persoon y con corola 3-fida), Aretiastrum (caracterizada por su corola 4-5 fida) у $P h u$ (corola 5-fida), que corresponde a la sección más extensa y que incluye la mayoría de las especies de América. Esta última sección a su vez la divide en grupos informales basados en las características del tallo (herbáceo, fruticoso, voluble) y el tipo de hojas (basales y caulinares enteras o divididas; basales enteras y caulinares divididas). Estos aspectos también fueron contemplados por Gay (1847) y Weddell (1859) para agrupar a diferentes especies de Chile.

Höck (1882) dividió al género en siete secciones, criterio seguido también por Graebner (1906), quien agrega una sección más, y Stuckert \& Briquet (1916-1919), quienes consideraron cuatro de estas secciones para las Valerianas de Argentina: Euvaleriana, Hybocarpos, Valerianopsis y Aretiastrum.

Borsini (1944), de acuerdo al desarrollo del cáliz en la madurez, subdividió al género Valeriana en dos subgéneros: Phyllactis y Valeriana. Eriksen (1989), basándose en las divisiones establecidas por Graebner (1906), consideró que no existe evidencia (morfológica, anatómica, química) que sustente la preservación de los 6 géneros relacionados con Valeriana en Sudamérica (Aretiastrum, Astrephia, Belonanthus, Phuodendron, Phyllactis y Stangea) y por lo tanto, a los efectos de mantener cierta uniformidad a nivel genérico, los mismos deben ser considerados secciones de Valeriana.

Este autor propuso una nueva subdivisión del género Valeriana y para ello se basó especialmente en la reducción del número de esporangios de las anteras en la mayoría de las especies de Sudamérica. Según su criterio, Valeriana comprende dos subgéneros: Valeriana y Phyllactis. El primero, caracterizado por presentar anteras tetraesporangiadas, comprende a su vez tres secciones: sección Valeriana que incluye las especies del Viejo Mundo y América del Norte; sección Porteria a la que pertenecen las especies de Venezuela, y sección Astrephia con una especie de los Andes occidentales. El subgénero Phyllactis, enmendado por el autor, incluye todas las especies con anteras biesporangiadas, distribuidas en Sudamérica; abarca 17 secciones y constituye una división aún incompleta. La separación en los subgéneros Valeriana y Phyllactis realizada por Borsini (1966) y Eriksen (1989) está basada en un único carácter utilizado por cada autor, presencia o ausencia de pappus (Borsini 1966) y anteras bi o tetraesporangiadas (Eriksen 1989), los cuales no delimitan los mismos grupos. Los datos obtenidos por Bell y Donoghue (2005), en relación a las implicancias taxonómicas de estudios filogenéticos en Valerianaceae, apoyan las conclusiones de estos autores respecto a que los taxones sudamericanos podrían ser tratados como Valeriana. Sin embargo, cuestionan la significancia taxonómica de los caracteres morfológicos por ellos utilizados. Sugieren además que se requieren datos adicionales, no solamente más caracteres sino también más taxones, para entender mejor la evolución de los caracteres dentro de este grupo tan diverso morfológicamente.

Área de ESTUdio

El área de estudio comprende la región austral de América del Sur, desde $\operatorname{los} 33^{\circ}$ a $55^{\circ} \mathrm{S}$ aproximadamente. En Argentina incluye la provincia de Mendoza hasta Tierra del Fuego, abarcando las provincias patagónicas en toda su extensión (entre los $62^{\circ}$ y $74^{\circ} \mathrm{O}$ ). En Chile se extiende desde la Región de Valparaíso en el norte hasta la Región de Magallanes en el extremo sur, desde la costa pacífica hasta la Cordillera de los Andes (Fig. 1).

La selección del área para el presente estudio se basó por un lado en las características climáticas, con temperaturas medias anuales inferiores a $12{ }^{\circ} \mathrm{C}$ y precipitaciones medias superiores a los $100 \mathrm{~mm}$ anuales, factores que conjuntamente con el relieve determinan la vegetación de la región, la que se corresponde con Sudamérica templada. Por otro lado el área seleccionada está limitada en su sector norte por la diagonal árida de Sudamérica, la cual ha actuado como barrera y filtro a través de la historia evolutiva-biogeográfica de la flora del Cono Sur (Aizen \& Ezcurra 1998, Villagrán \& Hinojosa 2005). Esta diagonal árida es una franja continua de clima árido que se extiende a lo largo de los Andes, desde el oeste de Venezuela y el noroeste de Chile, hasta el noreste de Patagonia argentina (Villagrán \& Hinojosa 1997, 2005, Ezcurra 2002, Hinojosa 2004) y coincide a su vez con la zona de transición sudamericana, donde se superponen elementos bióticos de las regiones Neotropical y Andina (Morrone 2001, Ruggiero \& Ezcurra 2003, Morrone 2004) y su formación puede considerarse como un evento vicariante que ha frenado la dispersión entre las biotas andina y neotropical (Morrone 2004). Adicionalmente, las formaciones vegetales xerófitas a lo largo de esta franja climática desconectan la región de los bosques del sur de Sudamérica de las restantes formaciones forestales del continente (Villagrán \& Hinojosa 2005). En estas zonas de transición deberían esperarse variaciones marcadas en la riqueza de especies, así como también cambios rápidos en las áreas de distribución geográfica de las 
especies o una combinación de ambos procesos (Ruggiero \& Ezcurra 2003).

\section{MATERIALES Y MÉTODOS}

El estudio taxonómico se realizó sobre la base de material de los principales herbarios de Chile y Argentina (BA, BAB, BCRU, CONC, LP, SGO, SI) y fotografías del herbario de Kew (K), Glasgow (GL), Missouri Botanical Garden (MO) y Universidad de Montpellier (MPU) (abreviaturas según el Index Herbariorum). Se cita todo el material examinado, el cual es representativo de la distribución y diversidad de cada especie en la región. La identificación de las especies se hizo por comparación con material tipo o fotografías del mismo, lo mismo que la resolución de los sinónimos nomenclaturales. Las fotografías de ejemplares tipo de herbarios europeos de la colección del Field Museum de Chicago se designan con la abreviatura "fot. F" y el número de la colección fotográfica. Este estudio incluyó la revisión de más de 1.000 ejemplares de herbario, de los cuales aproximadamente 70 correspondieron a ejemplares tipo (incluidas fotografías). Los tipos estudiados se marcan con el signo ! después de la sigla del herbario donde se encuentran.
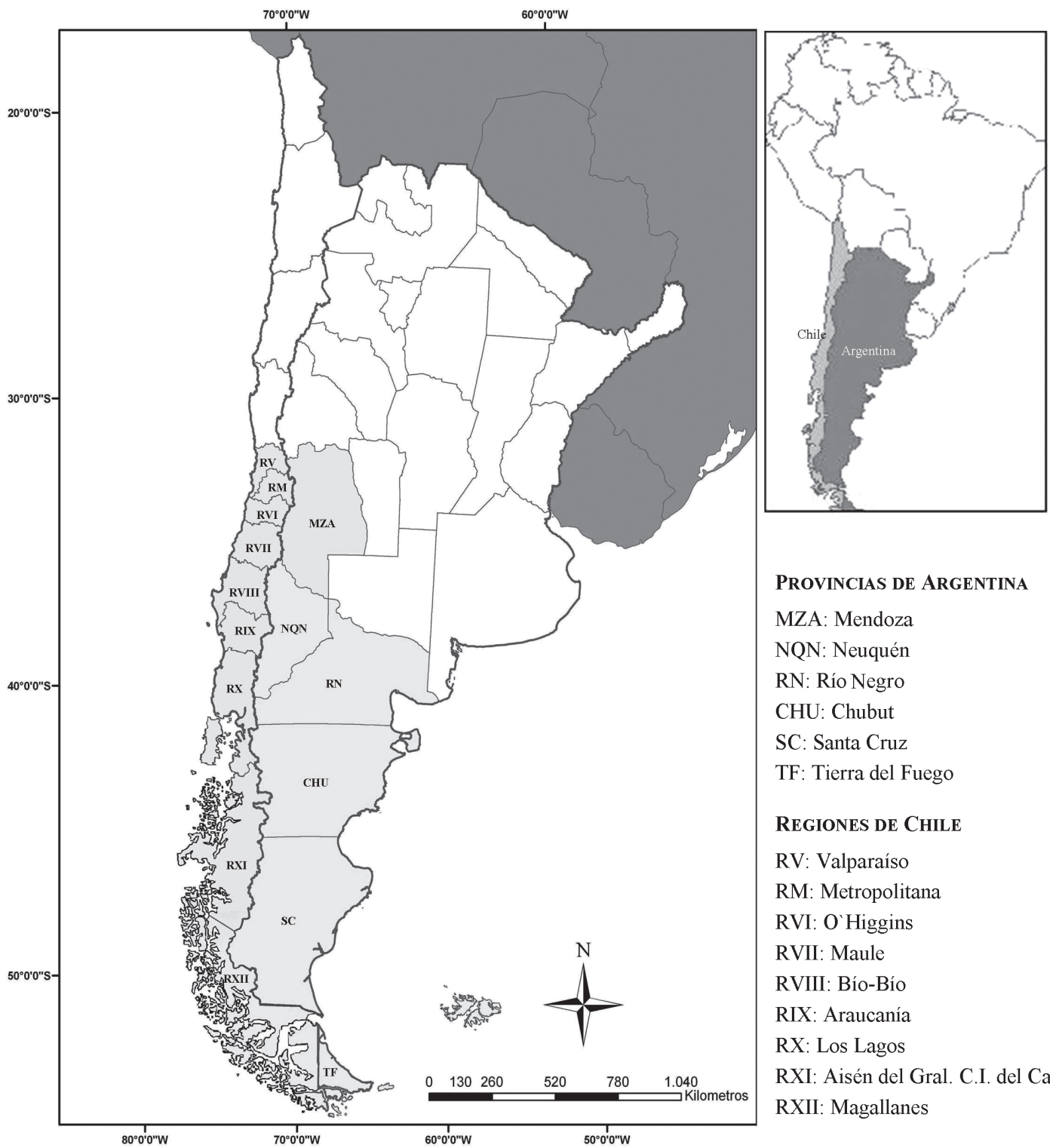

\section{ProvinCias de ARgentina}

MZA: Mendoza

NQN: Neuquén

RN: Río Negro

CHU: Chubut

SC: Santa Cruz

TF: Tierra del Fuego

\section{Regiones de CHILE}

RV: Valparaíso

RM: Metropolitana

RVI: O'Higgins

RVII: Maule

RVIII: Bío-Bío

RIX: Araucanía

RX: Los Lagos

RXI: Aisén del Gral. C.I. del Campo

RXII: Magallanes

FIGURA 1. Mapa donde se indican las provincias argentinas y regiones de Chile incluidas en el presente estudio.

FIGURE 1. Map indicating the Argentina provinces and Chile regions included in this study. 
TABLA I. Tipos de inflorescencia presentes en las especies de Valeriana estudiadas, que se describen teniendo en cuenta caracteres cualitativos.

TABLE I. Inflorescence types present in the Valeriana species studied, they are described considering qualitative features.

\begin{tabular}{lccccc}
\hline \multicolumn{1}{c}{ TIPO DE INFLORESCENCIA } & \multicolumn{4}{c}{ CARACTERÍsTiCAS } \\
\cline { 2 - 6 } & LoNGITUD & ANCHO & CONTINUIDAD & RoBusteZ & CANTIDAD FLORES \\
\hline Paniculiforme (Fig. 4a) & alargada & amplia & discontinua & robusta/grácil & densi/paucifloras \\
Espiciforme (Fig. 4b) & alargada & amplia & continua/discontinua & robusta & densifloras \\
Capituliforme (Fig. 4c) & corta & angosta & continua & robusta & paucifloras \\
Glomeruliforme (Fig. 4d) & alargada & angosta & discontinua & robusta & densifloras \\
\hline
\end{tabular}

En la revisión realizada por Borsini para las especies de Chile (1966), la autora designó lectotipos a ejemplares que debieron ser considerados como holotipos, en función de existir sólo un ejemplar citado en la descripción original. En este trabajo se cambiaron estas designaciones cuando correspondió, se lectotipificaron tres especies y neotipificaron diez especies. Asimismo se establecieron nuevas sinonimias y se extendieron las áreas de distribución de varias especies en base a los registros de los herbarios, en algunos casos debido a determinaciones erróneas previas de las especies.

\section{RESULTADOS}

El género Valeriana $\mathrm{L}$. se caracteriza por la variación en la forma de crecimiento, la altura de la planta y la morfología de distintos órganos tanto vegetativos (raíz, tallos, hojas) como reproductivos (flores, fruto). La diversidad morfológica del género Valeriana ha sido tratada por varios autores (Gay 1847, Reiche 1902, Graebner 1906, Borsini 1944, 1966, 1999). Se describen aquí sus caracteres morfológicos, en especial aquéllos con valor taxonómico, en particular hojas y frutos, que permiten la separación de las distintas especies de Argentina y Chile.

\section{НÁвIто}

Las valerianas incluyen especies anuales ( $V$. crispa, $V$. grandifolia, V. samolifolia, $V$. sphaerocarpa, V. virescens), pero la mayoría corresponden a hierbas perennes, a veces algo leñosas en la base. Su altura varía notablemente desde los 4 $\mathrm{cm}$ ( $V$. sedifolia) hasta los $2 \mathrm{~m}$ ( $V$. virescens); en general son plantas erguidas, a excepción de $V$. scandens, única especie voluble de Argentina que no está incluida en el presente estudio. Las especies altoandinas son de escaso porte y adquieren formas arrosetadas ( $V$. boelckei, $V$. chilensis, $V$. descolei, V. dinorrhiza, V. macrorhiza; V. philippiana, $V$. radicalis, $V$. ruizlealii), son acaules en algunos casos $(V$. moyanoi, V. sedifolia,). En algunas especies la presencia de rizomas muy extendidos y ramificados facilita su propagación vegetativa, como en $V$. chilensis, $V$. fonckii, $V$. hebecarpa y V. philippiana, entre otras (Kutschker 2009).

\section{RAÍCES Y TALLOS}

Las raíces son fibrosas, con ramificaciones engrosadas o bien raicillas filiformes como en $V$. laxiflora. Su tamaño es variable, siendo bastante reducidas en las especies anuales. Los tallos son herbáceos, a veces subleñosos, simples o ramificados como en $V$. dinorrhiza, $V$. chilensis, $V$. fonckii, $V$. graciliceps y $V$. peltata. La mayoría son cilíndricos o bien tetrágonos como en $V$. chilensis, $V$. dinorrhiza, $V$. grandifolia, $V$. leucocarpa, $V$. velutina, $V$. polemoniifolia y $V$. virescens. Pueden ser lisos o estriados; glabros, pubescentes o hirsutos, con pelos simples o glandulosos. En muchas especies los entrenudos son cortos, comprimidos, lo que conduce a la formación de una roseta basal de hojas. Las especies perennes presentan rizomas con distinto grado de desarrollo, forma y consistencia. Hay rizomas carnosos y de considerable tamaño ( $V$. boelckei, $V$. carnosa y $V$. dinorrhiza), otros son leñosos y tortuosos ( $V$. chilensis, $V$. fonckii, $V$. hebecarpa, $V$. philippiana), o carnosos pero de menor desarrollo $(V$. bridgesii, V. hyalinorrhiza, V. laxiflora, V. lapathifolia, V. moyanoi, V. obtusifolia) (Kutschker 2009).

HoJAs

Las hojas son opuestas o dispuestas en verticilos $(V$. sedifolia), desde pocos milímetros hasta $35 \mathrm{~cm}$ (V. carnosa, $V$. ruizlealii, $V$. lapathifolia), y carecen de estípulas. Pueden ser enteras o divididas, sésiles o pecioladas. Las inferiores, generalmente arrosetadas, presentan láminas enteras $(V$. boelckei, V. borsinii, V. carnosa, V. fonckii, V. macrorhiza, $V$. munozii, V. radicalis,), pinnatipartidas ( $V$. clarionifolia, V. verticillata, V. philippiana), pinnatisectas (V. crispa, V. polemoniifolia, $V$. stricta), y pinnatilobadas ( $V$. laxiflora, $V$. hornschuchiana); pueden ser ovadas, obovadas, lanceoladas, espatuladas, cordadas (V. lapathifolia), con los bordes enteros ( $V$. borsinii, $V$. leucocarpa, $V$. macrorhiza, $V$. radicalis), dentados (V. carnosa, V. clarionifolia, V. crispa), crenados ( $V$. virescens), lacerados ( $V$. bracteosa), sinuados o lobulados. La superficie puede ser glabra o pubescente, y la consistencia membranácea (V. lapathifolia, $V$. virescens), carnosa ( $V$. carnosa, $V$. chilensis, $V$. moyanoi), subcoriácea (V. clarionifolia) o papirácea ( $V$. laxiflora). El pecíolo puede ser de menor, igual o mayor longitud que la lámina, 
glabro o pubescente, más o menos aplanado, ensanchado en la base, y a veces acanalado ( $V$. chilensis). Las hojas superiores también pueden ser enteras o divididas, mucho más reducidas y en general sésiles.

La morfología de las hojas constituye uno de los aspectos más variables en el género Valeriana, esto se manifiesta en el marcado polimorfismo foliar intraespecífico e interespecífico, algunos de cuyos ejemplos se grafican en las figuras 2 y 3 . En el primer caso se grafica la morfología foliar de 24 especies de Valeriana, abarcando un amplio espectro de hojas que caracterizan a este género. La Figura 3 ilustra las hojas inferiores de $V$. laxiflora, que muestra las diferentes formas que adoptan las hojas en distintas etapas del desarrollo o bien simultáneamente en la misma planta.

ARQuiteCtura DE LA INFLORESCENCIA

La estructura de la inflorescencia de las Valerianáceas en general, incluyendo algunas especies de Valeriana, ha sido descripta por Borsini (1944), Larsen (1986) y Weberling (1961, 1965, 1983). El tipo de inflorescencia básico de Valeriana podría definirse como una inflorescencia monotélica truncada (Weberling 1961). A pesar de la pérdida de flores terminales en algunos ejes se ha comprobado, a través de estudios comparativos, que la naturaleza monotélica permanece. Esta estructura de ejes truncados es denominada tírsica y por ello se hace referencia a un tirso como la inflorescencia característica del género Valeriana. Larsen (1986: 429, Fig. 1A) define el término paracladio para indicar las ramas laterales que repiten la estructura del eje principal del sistema de floración. Considera que el término inflorescencia en sentido amplio designa cualquier agrupación de flores, por lo cual utiliza la denominación de sinflorescencia para indicar una agregación bastante densa de paracladios. Estos son agrupados en distintas generaciones, cada una de las cuales forma una sinflorescencia central o circular en la parte apical del brote. Cada sinflorescencia es desplazada hacia la periferia del brote por una nueva foliación.

Más allá de la complejidad estructural que presenta la inflorescencia básica de Valeriana, aquí se describieron e ilustraron de manera simplificada teniendo en cuenta la forma o aspecto general de las mismas (Tabla I) y se las designó como paniculiformes, presente en la mayoría de las especies (Fig. 4a), cimas espiciformes ( $V$. chilensis, $V$. macrorhiza, $V$. moyanoi) (Fig. 4b), capituliformes ( $V$. descolei, $V$. boelckei, $V$. sedifolia) (Fig. 4c), glomeruliformes discontinuas ( $V$. dinorrhiza, V. polystachya, V. ruizlealii) (Fig. 4d).

En relación al tamaño de la inflorescencia o su caracterización en contraídas o laxas, depende del estado fenológico de la planta, por lo cual no constituye un buen carácter para diferenciar las distintas especies; no así la forma, que si bien es semejante en muchas especies, en algunos casos permite separarlas correctamente ( $V$. boelckei, V. moyanoi, V. polystachya, V. ruizlealii).
BRÁCTEAS Y BRACTÉOLAS

Una de las características de la familia en general es la presencia de brácteas y bractéolas supernumerarias, opuestas entre sí. Aquí se sigue el concepto de Larsen (1986), quien define a las brácteas como aquellas estructuras asociadas a un órgano (paracladio, flor), pero que no están situadas en el eje principal, y solamente aquellos profilos de las flores los cuales no sustentan ningún otro órgano son denominados bractéolas o brácteas floríferas. Tanto brácteas como bractéolas, son polimorfas y decrecen en tamaño, desde la base al ápice de la inflorescencia. Pueden ser enteras o divididas, de forma linear, lanceolada, oblonga, obovada, auriculada, decusadas, a veces formando una vaina basal breve entre sí y con el tallo. Pueden ser glabras o pubescentes, con pelos simples o glandulosos, especialmente en el margen y la parte axilar de las mismas.

FLOR

Las flores son pequeñas, de pocos milímetros, a excepción de $V$. fonckii que alcanza los $10 \mathrm{~mm}$. Pueden ser unisexuales $(V$. munozii, V. sedifolia), hermafroditas ( $V$. borsinii, $V$. fonckii, $V$. polemoniifolia, $V$. samolifolia, $V$. vaga), polígamo ginodioicas (V. bracteosa, V. clarionifolia, V. crispa, V. descolei, V. philippiana, V. polysatchya, V. virescens), polígamo trioicas $(V$. dinorrhiza, V. ruizlealii). En general las flores hermafroditas son de mayor tamaño que las femeninas.

CÁliz

Presentan un cáliz glabro o pubescente, soldado por su base a la parte superior del ovario ínfero. Puede ser entero, cilíndrico, crateriforme o urceolado, a veces dentado irregularmente ( $V$. macrorhiza) o ausente, no transformado en pappus a la madurez (V.descolei, V. dinorrhiza, V. munozii, V.ruizlealii), o bien en la mayoría de las especies enrollado en las flores, siendo acrescente y persistente en el fruto transformado en un pappus plumoso; el mismo está constituido por setas subuladas, en número de 6 a 22. La completa reducción del cáliz habría evolucionado repetidamente de manera independiente en varios géneros de la familia y dentro de Valeriana. Por esto a nivel genérico y entre especies el desarrollo o no del cáliz no sería considerado un carácter taxonómico fiable (Eriksen 1989).

\section{Corola}

La corola es membranosa, glabra o pubescente en la parte interior y/o exterior, está dividida en 5 lóbulos, ovados u oblongos, y es de forma campanulada, infundibuliforme o tubuloso-infundibuliforme. Puede estar provista de una giba cerca de la base, de desarrollo variable, que a veces presenta papilas en la parte interna y le da un aspecto carnoso. Las corolas pueden ser blancas, rosadas y amarillas, siendo el blanco el color más frecuente; en algunas especies puede observarse una gradación del blanco al rosado o flores blancas con tintes rosados, como en el caso de Valeriana 
carnosa, V. clarionifolia y V. moyanoi. Corolas amarillas se observaron en $V$. chilensis, habiéndose citado este color solamente para los géneros Patrinia y Aretiastrum dentro de las Valerianáceas (Eriksen 1989). La forma, tamaño y color de las flores poseen valor taxonómico limitado dentro del género Valeriana.

\section{Nectarios}

Las flores presentan los nectarios ubicados dentro del tubo de la corola, usualmente asociados a la giba. Este tipo de flores son polinizadas por insectos relativamente pequeños, como mosquitos y moscas (Eriksen 1989).

\section{AndRoceo}

Presenta 3 estambres, aunque muy raramente pueden observarse especies de Valeriana con 4 a 5 estambres. Los mismos están insertos en la corola, a distintas alturas del tubo. Pueden ser inclusos o exertos. Las anteras son bitecas, ovoides o elipsoides, con 2 ó 4 sacos polínicos o microsporangios, y dehiscentes por dos hendiduras longitudinales; los filamentos son libres, subulados.

\section{Polen}

Las Valerianáceas se caracterizan por presentar una escasa variación en el tipo de polen (Clarke 1978, Patel \& Skvarla 1979, Diez 1987, Meyer 1991). La mayoría de los géneros tienen polen tricolpado, isopolar, radialmente simétrico y esférico a prolado o suboblado; la superficie de la exina es usualmente espinulada o verrugosa. Los granos de polen poseen tamaño variable ( 27 a $78 \mu \mathrm{m}$ en eje polar) y presentan formas y número de aperturas similares en los diferentes grupos. Si bien la ornamentación y la estructura de la pared varían, no permiten establecer límites genéricos claros (Clarke 1978). Los principales tipos de granos de polen característicos de las Valerianáceas pueden ser encontrados dentro del género Valeriana (Larsen 1986).

A pesar de la aparente uniformidad del polen de las Valerianáceas, ciertos autores han distinguido varios tipos que perrniten agrupar sus taxones de acuerdo a sus caracteres polínicos. Así, Clarke (1978) separó Valeriana del grupo conformado por Centranthus, Fedia, Plectritis y Valerianella en base a una característica estructural: la presencia o ausencia de columelas ramificadas. Esta ausencia, que se da en Valeriana, está generalmente acompañada por una exina de espesor uniforme en todo el grano, y una esculturación espinulada y muchas veces verrugosa. Esto podría sugerir que los cuatro géneros antes mencionados, con columelas ramificadas y exina engrosada en los polos, derivaron de Valeriana (Eriksen 1989).

Las descripciones existentes sobre el polen en general han sido realizadas a nivel de género (Clarke 1978, Diez 1987, Xena de Enrech et al. 1996), aunque existe un estudio del polen de las Valerianas de América tropical (Meyer 1991). El polen de estas especies de Valeriana posee tamaños similares, el cociente polar/ecuatorial en la mayoría de los casos es de 1,0 a 1,3, aunque puede variar entre 0,7 y 1,6; presenta la pared de los granos de polen divididos en ectexina y endexina, aunque la última no siempre se puede reconocer fácilmente. La ornamentación de la pared puede presentar escabrosidades, espínulas y verrugas. Se ha comprobado la existencia de diferencias intragenéricas en los caracteres de los granos de polen, no así dentro de una misma especie (Meyer 1991). No existen datos sobre el polen de las especies de Sudamérica austral.

\section{GineCeo}

El ovario es ínfero, sésil y está inserto en la axila de dos bractéolas concrescentes. Es tricarpelar y trilocular, aunque sólo uno de los lóculos es fértil y es el que lleva el único óvulo anátropo. El estilo es simple, filiforme y en algunas especies puede estar engrosado en la porción apical. En las flores femeninas es generalmente exerto. El estigma es papiloso, trífido o trilobado.

\section{Frutos y SEMILLAS}

Los frutos del género Valeriana son aquenios, de tamaños y formas variables, y que en su parte apical pueden presentar el cáliz persistente, desarrollado en pappus plumoso, o completamente ausente (Borsini 1944, 1966, Eriksen 1989). Los aquenios maduros presentan un rango de tamaño de 1 a $9 \mathrm{~mm}$ (excluido el pappus); los más pequeños corresponden a $V$. hebecarpa $(1-1,5 \mathrm{~mm})$ y $V$. grandifolia (1,2-1,5 mm) y el más grande a $V$. boelckei $(7-9 \mathrm{~mm})$. En relación a la forma los frutos pueden ser ovoides, elipsoides, lageniformes, piriformes, triquetros o globosos; en tanto su superficie puede ser totalmente glabra o pubescente en una o ambas caras (ventral y/o dorsal). Por otro lado, los frutos pueden ser uniloculares, es decir compuestos por un solo lóculo fértil ( $V$. dinorrhiza, $V$. polystachya, $V$. radicalis, $V$. samolifolia), o triloculares, con un único lóculo fértil y dos lóculos estériles, cuyo grado de desarrollo varía desde lóculos estériles incipientes (V. lapathifolia, $V$. laxiflora, $V$. leucocarpa, $V$. philippiana y $V$. vaga), reducidos a esbozos (V. boelckei, V. bracteosa, V. chilensis, V. clarionifolia, V. graciliceps, $V$. hebecarpa, $V$. hornschuchiana, V. lepidota, $V$. polemoniifolia, $V$. stricta, $V$. valdiviana, $V$. velutina y $V$. virescens), hasta lóculos estériles bien desarrollados como en $V$. bridgesii, V. crispa, V. grandifolia, V. hyalinorrhiza, $V$. obtusifolia, V. peltata, $V$. sphaerocarpa y V. verticillata (Kutschker 2008b).

Esta característica relacionada al grado de desarrollo de los lóculos estériles, como así también al tamaño, forma general, superficie del fruto y la presencia o no de pappus, son caracteres constantes dentro de cada especie y permite diferenciarlas (Kutschker 2008b). Las modificaciones del cáliz y de los lóculos estériles estarían correlacionadas probablemente con el medio de dispersión (Bell 2004, Bell \& Donoghue 2005). Las semillas son piriformes generalmente, péndulas y exalbuminadas, con cotiledones aplanados y carnosos, más largos que la radícula. 

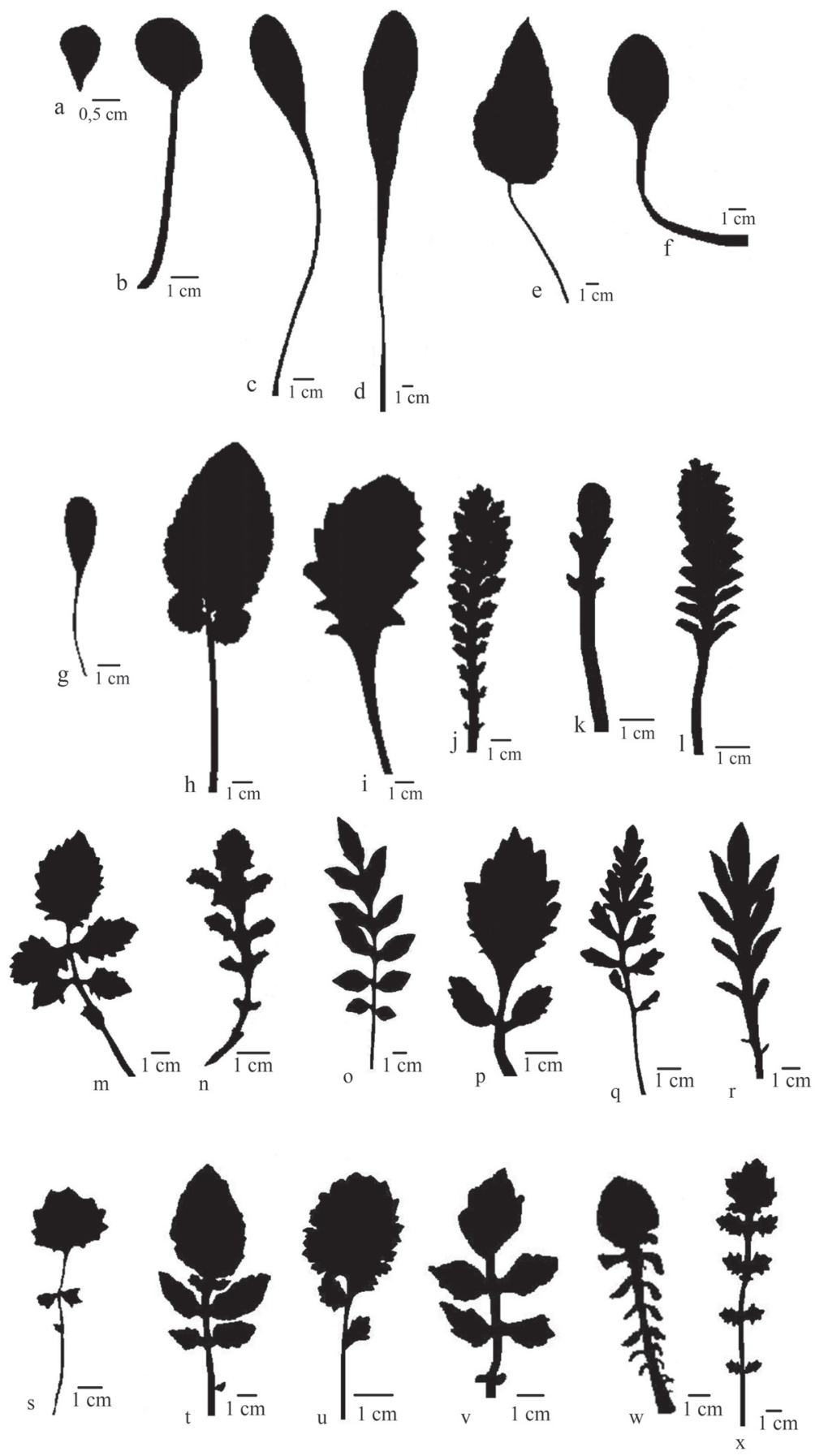

Figura 2. Hojas basales de diferentes especies de Valeriana. a, V. samolifolia (Philippi 998); b, V. boelckei (Rossow 4625); c, V. leucocarpa (Poeppig 847); d, V. borsinii (Rossow 2700); e, V. lapathifolia (Delfin s.n.); f, V. radicalis (Gay 1095); g, V. fonckii (Von Rentzell 6148); h, V. virescens (Kutschker 172); i, V. carnosa (Kutschker 176); j, V. clarionifolia (Kutschker 171); k, V. moyanoi (Kutschker 150); 1, V. philippiana (fot. FM 17864); m, V. crispa (Herb. Philippi 995a); n, V. hyalinorrhiza (Behn s.n.); o, V. polemoniifolia (Reiche s.n.); p, V. hebecarpa (Rossow 4536); q, V. stricta (Geisse s.n.); r, V. polystachya (Valentini 54); s, V. peltata (Gay s.n.); t, V. grandifolia (F. Behn s.n.); u, V. bracteosa (Looser 2090); v, V. velutina (Zoellner 6253); w, V. papilla (Geisse s.n.); x, V. vaga (Bravo 191).

Figure 2. Basal leaves of different species of Valeriana. a, V. samolifolia (Philippi 998); b, V. boelckei (Rossow 4625); c, V. leucocarpa (Poeppig 847); d, V. borsinii (Rossow 2700); e, V. lapathifolia (Delfin s.n.); f, V. radicalis (Gay 1095); g, V. fonckii (Von Rentzell 6148); h, V. virescens (Kutschker 172); i, V. carnosa (Kutschker 176); j, V. clarionifolia (Kutschker 171); k, V. moyanoi (Kutschker 150); 1, V. philippiana (fot. FM 17864); m, V. crispa (Philippi 995a); n, V. hyalinorrhiza (Behn s.n.); o, V. polemoniifolia (Reiche s.n.); p, V. hebecarpa (Rossow 4536); q, V. stricta (Geisse s.n.); r, V. polystachya (Valentini 54); s, V. peltata (Gay s.n.); t, V. grandifolia (F. Behn s.n.); u, V. bracteosa (Looser 2090); v, V. velutina (Zoellner 6253); w, V. papilla (Geisse s.n.); x, V. vaga (Bravo 191). 


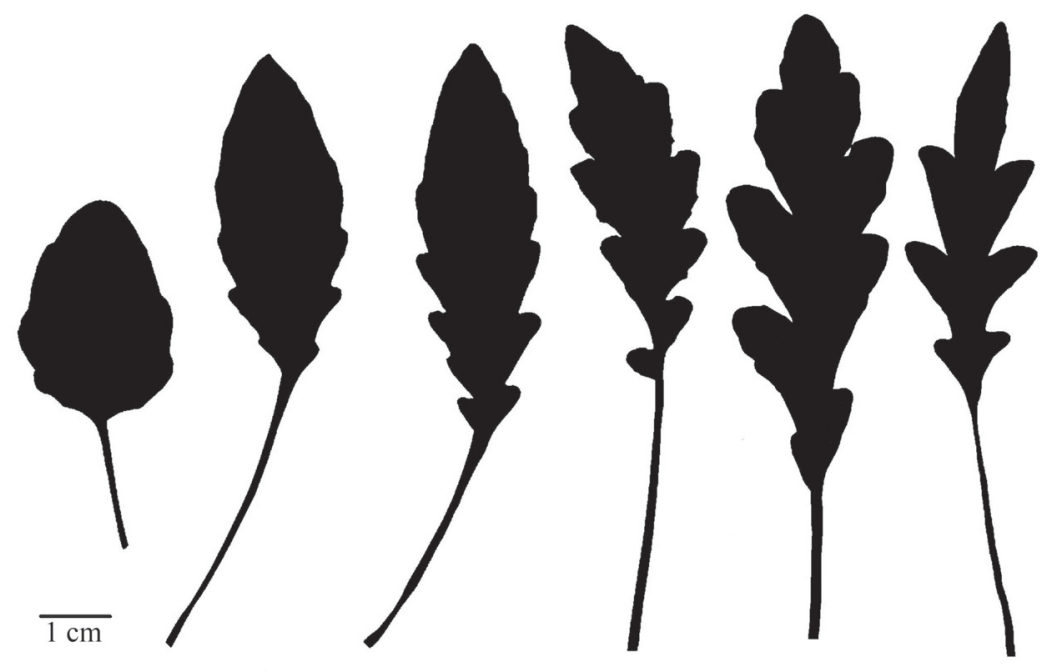

FIGURA 3. Variación de la morfología foliar en Valeriana laxiflora Phil. (Kutschker 227; Mazzucconi 1188).

Figure 3. Variation in leaf morphology of Valeriana laxiflora Phil. (Kutschker 227; Mazzucconi 1188).

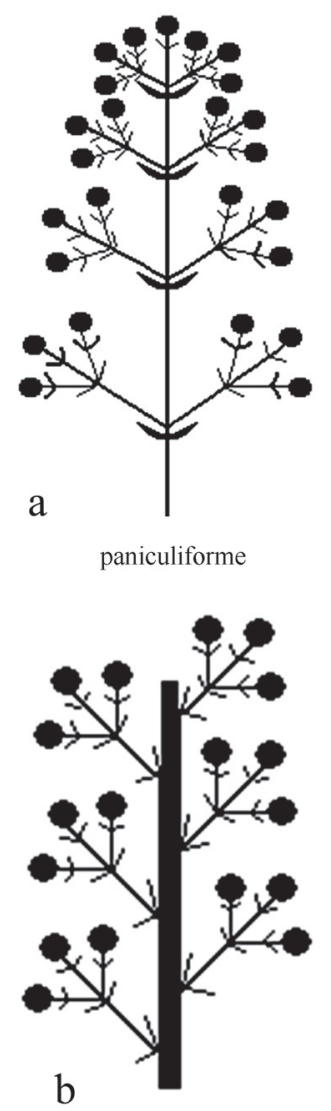

espiciforme

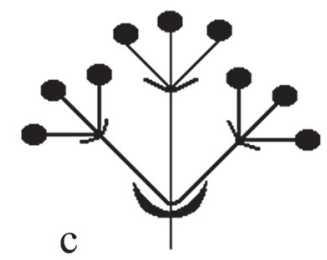

capituliforme

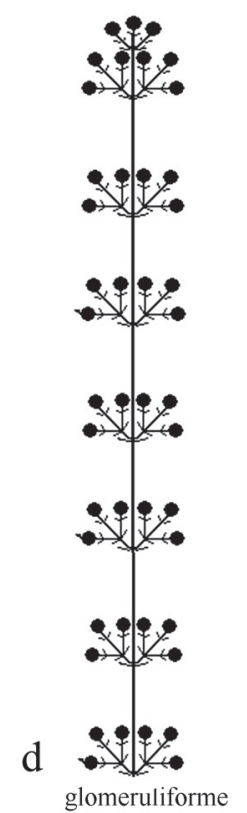

Figura 4. Tipos de inflorescencia que pueden presentar las especies de Valeriana consideradas en este estudio. a, paniculiforme; b, espiciforme; c, capituliforme y d, glomeruliforme.

FiguRE 4. Inflorescence types that may present the Valeriana species included in this study. a, paniculiform; b, spiciform; c, capituliform y d, glomeruliform. 


\section{Cromosomas}

Valeriana muestra un amplio rango de números cromosómicos, conformando series poliploides basadas en los números básicos $\mathrm{X}=7$ y $\mathrm{X}=8$ y sus derivados, esto es $2 \mathrm{n}=14,16,28$, 32,56 , etc. Las especies de Valeriana de América del Norte y del Viejo Mundo raramente exhiben $2 \mathrm{n}=32$, mientras este número domina todos los taxones de Sudamérica, incluyendo el resto de los géneros presentes en esta parte del continente, como son Astrephia, Aretiastrum, Belonanthus, Phyllactis, Phuodendron y Stangea (Eriksen 1989). No existen datos sobre las especies de Sudamérica austral.

\section{TRATAMIENTO TAXONÓMICO}

En Sudamérica austral están representados los subgéneros propuestos por Borsini (1966): Valeriana L. y Phyllactis (Pers.) Borsini y según la clasificación de Eriksen (1989) el subgénero Valeriana sección Astrephia (Dufr.) Eriksen, stat. nov. y el subgénero Phyllactis (Pers.) Borsini emend. Eriksen. El hecho de que estas clasificaciones están basadas en un único carácter, distinto en cada caso, y por otro que no hay coincidencia en los grupos que se forman a partir de ambas propuestas, dificulta acordar con uno de estos criterios.

Si bien los estudios moleculares (Bell 2004, Hidalgo et al. 2004, Bell \& Donoghue 2005) han clarificado en gran medida las relaciones filogenéticas entre diferentes especies de Valeriana de Sudamérica tropical, la intención de este trabajo es aportar una clasificación o agrupamiento que permita reconocer grupos naturales entre las diferentes especies de Sudamérica austral, independientemente de sus relaciones filogenéticas, hasta tanto éstas se estudien. Es por ello que aquí se establecen cuatro grupos informales, en base a la morfología de los frutos y hojas. Se definen así el Grupo I caracterizado por frutos sin desarrollo de los lóculos estériles, pappus plumoso ausente, hojas siempre enteras. El Grupo II incluye las especies sin desarrollo de lóculos estériles, pappus plumoso ausente y hojas divididas. Las especies con distinto grado de desarrollo de los lóculos estériles, pappus plumoso presente y hojas enteras integran el Grupo III; mientras las especies con distinto grado de desarrollo de los lóculos estériles, pappus plumoso presente y hojas divididas conforman el Grupo IV.

La sinonimia de Valeriana que se presenta a continuación solamente incluye los nombres genéricos que han sido utilizados para las especies presentes en Sudamérica austral. Se explicita el nombre de la especie tipo de cada nombre genérico y su sinónimo en Valeriana. Los sinónimos homotípicos se indican con el símbolo $\equiv$, y los basados en tipos diferentes con el símbolo $=$. Después se incluye una descripción del género, una clave y descripciones de todas las especies con su respectivo material estudiado. En el Apéndice 1 se incluye la lista de ejemplares examinados con datos de los coleccionistas, y en el Apéndice 2 se presenta el índice de nombres científicos y vulgares o comunes de las especies estudiadas.
Valeriana L. Sp. P1., $1^{\text {a }}$ ed., 31. 1753. TIPO: (lectotipo, designado por Hitchcock en Prop. Brit. Bot. 117, 1929) Valeriana officinalis L.

Phyllactis Pers., Synopsis Plant. I: 39.1805. TIPO: (lectotipo, designado por Larsen en Nord. J. Bot. 6: 435(2), 1986) Phyllactis rigida Pers. [三Valeriana rigida Ruiz \& Pav.].

Astrephia Dufr., Hist. Nat. et Med. Valér., 1811. TIPO: (lectotipo, designado por Eriksen, Nord. J. Bot. 9 (2), 1989) Astrephia chaerophylloides Sm. [EValeriana chaerophylloides $\mathrm{Sm}$.].

Plectritis (Lindl.) DC. Prodr. 4: 631, 1830. TIPO: Plectritis congesta (Lindl.) DC. [三Valeriana congesta Lindl.].

Betckea DC. Prodr. 4: 642, 1830. TIPO: Betckea samolifolia DC. [ $\equiv$ Valeriana samolifolia (DC.) Colla].

Valerianella (Tourn.) Pollich emend. Moench. Meth. Pl. Horti. Bot. Marburgi 493-4, 1794. TIPO: Valerianella olitoria (L.) Pollich.

Hierbas anuales o perennes, raíces axonomorfas y raicillas filiformes; rizomas de desarrollo variable, aspecto rugoso, carnosos o leñosos. Tallos erectos o ascendentes, raramente volubles, simples o ramificados, cilíndricos o tetrágonos, fistulosos; plantas a veces estoloníferas o cespitosas. Hojas basales y caulinares opuestas, pecioladas o sésiles, sin estípulas, enteras, pinnatífidas, pinnatipartidas, pinnatilobadas o pinnatisectas, las basales a menudo arrosetadas. Inflorescencias cimosas, compuestas, paniculiformes o tirsiformes, a veces con cimas capituliformes globosas, espiciformes o glomeruliformes discontinuas. Brácteas y bractéolas opuestas, herbáceas, glabras o pubescentes; en ocasiones con pelos glandulosos. Flores hermafroditas o unisexuales -plantas hermafroditas, polígamas o dioicas-, asimétricas, pentámeras, epíginas, sentadas. Cáliz variadamente dentado cuando presente, a menudo acrescente y persistente sobre el fruto. Corola gamopétala, cigomorfa o asimétrica, tubulosoinfundibuliforme, infundibuliforme o campanulada, glabra o pubescente en su parte externa y/o interna, blanca o rosada, raramente amarilla; limbo con 5 lóbulos ovados u oblongos; tubo más o menos angosto, recto o curvado, a veces con una giba (contiene el néctar) hacia la mitad o cerca de la base. Androceo con 3 estambres, libres, alternipétalos, insertos en el tubo de la corola, con filamentos glabros o pubescentes, inclusos o exertos; anteras oblongas, glabras, medifijas. Ovario ínfero, tricarpelar y trilocular, con 1 cavidad fértil hacia la cara dorsal conteniendo 1 rudimento seminal anátropo, y 2 cavidades ventrales estériles; estilo filiforme, generalmente exerto, liso; estigma, papiloso, trilobulado o trífido. Fruto aquenio, con un lóculo fértil muy desarrollado 
y 2 lóculos estériles que varían desde ausentes, incipientes, reducidos a esbozos, o bien desarrollados; cáliz persistente a la madurez, transformado en un pappus plumoso o ausente. Semillas con embrión recto, sin endosperma, lisas, no adheridas al pericarpo.

El género Valeriana incluye unas 250 distribuidas en todo el mundo, con excepción de Australia y la mayoría de las islas del Pacífico. Crecen en las regiones templadas del Hemisferio Norte, África y preferentemente en la región andina de Sudamérica, donde presentan un importante centro secundario de diversificación, tanto en el páramo (Eriksen 1989, Mabberley 1990, Bell 2004, Bell \& Donoghue 2005) como en los Andes australes (Kutschker 2009).

Algunas especies nativas de Argentina y Chile con propiedades medicinales son Valeriana carnosa Sm., "ñamkulawen" o "yerba del aguilucho blanco", conocido como el remedio de las siete enfermedades (Gusinde 1936, Martínez Crovetto 1968, Dimitri 1974, 1988, Ratera \& Ratera 1980, Boelcke 1981, Houghton \& Manby 1985, Montecino \& Conejeros 1985, Manfred 1991, De Mösbach 1992, Alonso 1998, Kutschker et al. 2002, Estomba et al. 2005, 2006, Molares et al. 2007, Molares \& Ladio 2008), V. lapathifolia Vahl, "huahuilque" (Hoffmann et al. 1992, Conticello et al. 1997) y V. virescens "liglolkin", utilizada por sus propiedades aromáticas, refrescantes y tónicas (Gusinde 1936). Valeriana macrorhiza DC. se trata de otra especie autóctona de Argentina y Chile, sobre la cual se ha trabajado en el área farmacológica, sin resultados concretos aún (Alonso 1998).

\section{Clave artificial para las especies de Valeriana de Sudamérica austral}

1. Plantas con hojas basales siempre enteras.

2. Frutos sin pappus plumoso.

3. Frutos pubescentes.

4. Hierba de $10 \mathrm{~cm}$ de alt., hojas hasta $5 \mathrm{~cm}$; inflorescencia terminal con tallos floríferos cortos ............... V. descolei

4'. Hierbas hasta $1 \mathrm{~m}$ de alt., hojas de $32 \mathrm{~cm}$, inflorescencia espiciforme..................................................... ruizlealii

3'. Frutos glabros.

5. Planta anual, pocas hojas obovadas que no forman una roseta basal. V. samolifolia

5'. Plantas perennes, hojas espatuladas formando una roseta basal.

6. Inflorescencia terminal contraída. V. munozii

6'. Inflorescencias espiciformes o glomeruliformes.

7. Hierba de $25 \mathrm{~cm}$ de alt., inflorescencia espiciforme V. macrorhiza

7'. Hierba hasta $70 \mathrm{~cm}$ de alt., inflorescencia glomeruliforme discontínua. V. dinorrhiza

2'. Frutos con pappus plumoso.

8'. Hojas membranáceas o papiráceas.

9. Hojas ovadas.

10. Hojas de base escotada, borde entero, discolores; hojas superiores enteras (por excepción divididas).....V. lapathifolia

10'. Hojas con pecíolo de base ensanchada, borde groseramente dentado, concolores; hojas superiores pinnatisectas

9'. Hojas obovadas-oblongas o espatuladas.

11. Hojas obovado-oblongas; flor hermafrodita de $5 \mathrm{~mm}$, infundibuliforme-campanulada; frutos glabros

11'. Hojas espatuladas; flor hermafrodita de 3,5 mm, campanulada; frutos pubescentes.

V. leucocarpa

8. Hojas carnosas/subcarnosas o coriáceas.

12. Plantas en cojín $<5 \mathrm{~cm}$ de alt., hojas lingüiformes, coriáceas, imbricadas

V. borsinii

$1^{\prime}$. Plantas $\geq 5 \mathrm{~cm}$ hasta $90 \mathrm{~cm}$ de alt, hojas no lingüiformes, carnosas $/$ subcarnosas.

13. Hojas obovadas o elípticas, márgenes dentados.

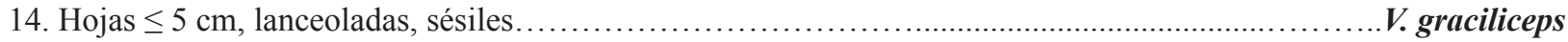

14 . Hojas $>5 \mathrm{~cm}$, obovadas o elípticas, pecioladas.

13'. Hojas espatuladas, márgenes enteros o crenados (raro dentados).

15. Longitud del pecíolo 2 o 3 veces mayor a la lámina, inflorescencias terminales paucifloras

16. Flor hermafrodita de $3 \mathrm{~mm}$, infundibuliforme.............................................................. radicalis

16'. Flor hermafrodita de $1,5 \mathrm{~mm}$, campanulada................................................................... boelckei

15'. Longitud del pecíolo de $\leq$ longitud respecto a la lámina, inflorescencias en panículas densifloras.

17. Flor hermafrodita de $2,2 \mathrm{~mm}$, campanulada.

17'. Flor hermafrodita de hasta $10 \mathrm{~mm}$, infundibuliforme.

1'. Plantas con hojas basales siempre divididas (raramente hojas enteras y divididas en la misma planta). 
18. Frutos sin pappus

V. polystachya

18 '. Frutos con pappus.

19. Frutos en toda su superficie glabros.

20. Hojas con el lóbulo terminal marcadamente mayor que los restantes.

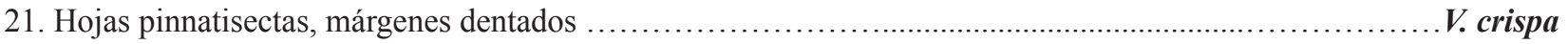

21'. Hojas pinnatipartidas, márgenes crenados o lacerados.

22. Hierbas hasta $40 \mathrm{~cm}$ de alt., inflorescencias densifloras........................................................ obtusifolia

22'. Hierbas hasta $80 \mathrm{~cm}$ de alt., inflorescencias paucifloras........................................................... lepidota

20 '. Hojas con el lóbulo terminal igual o poco mayor que los restantes.

23. Hojas pinnatipartidas o pinnatilobadas.

24. Hojas pinnatilobadas, papiráceas..

V. laxiflora

24'. Hojas pinnatipartidas, subcoriáceas......

V. clarionifolia

23'. Hojas pinnatisectas.

25. Hojas carnosas; frutos lageniformes, papilosos......................................................................... stricta

$25^{\prime}$. Hojas membranáceas, frutos ovoides, muricados.................................................................................. vaga

19'. Frutos con una o todas sus caras pubescentes o hirsutas.

26. Frutos con el lóculo fértil pubescente y los estériles glabros.

27. Hojas con el lóbulo terminal igual o poco mayor que los restantes

V. verticillata

27'. Hojas con el lóbulo terminal marcadamente mayor que los restantes.

28. Lóbulo terminal de forma orbicular o reniforme, de base escotada. V. peltata

28 '. Lóbulo terminal de forma ovada u obovada, sin base escotada.

29. Tallos floríferos cilíndricos; flor hermafrodita de 3,5 $\mathrm{mm}$. V. bridgesii

29'. Tallos floríferos tetrágonos; flor hermafrodita $\leq 3 \mathrm{~mm}$.

30. Hierba anual, hasta $80 \mathrm{~cm}$ de alt.; flor hermafrodita de $2 \mathrm{~mm}$, campanulada

V. grandifolia

$30^{\prime}$. Hierba perenne, hasta $40 \mathrm{~cm}$ de alt.; flor hermafrodita de $3 \mathrm{~mm}$, tubuloso-infundibuliforme ..V. hyalinorrhiza

26'. Frutos pubescentes o hirsutos en toda su superficie.

31. Hojas con el lóbulo terminal marcadamente mayor que los restantes.

32. Plantas perennes; inflorescencias menos desarrolladas, flor hermafrodita de ca. $3 \mathrm{~mm}$

32'. Plantas anuales; inflorescencias muy desarrolladas, flor hermafrodita de 1 a 2,5 mm.

V. bracteosa

33. Frutos globosos, con lóculos estériles bien desarrollados

V. sphaerocarpa

33'. Frutos ovoides o elipsoides, con lóculos estériles reducidos a esbozos.

34. Planta hasta $1 \mathrm{~m}$ de alt.; frutos con pubescencia rala...................................................... valdiviana

34'. Planta hasta $2 \mathrm{~m}$ de alt., frutos densamente hirsutos........................................................ virescens

31 '. Hojas con el lóbulo terminal igual o poco mayor que los restantes.

35. Tallos floríferos tetrágonos.

36. Hojas pinnatipartidas, segmentos lobados, oblongos, borde entero

V. hornschuchiana

36'. Hojas pinnatisectas, segmentos ovados o elípticos, bordes dentados.

37. Hojas com segmentos ovados; flor hermafrodita de $2 \mathrm{~mm}$, campanulada.

V. velutina

37'. Hojas com segmentos elípticos; flor hermafrodita de 1-1,5 mm, infundibuliforme........... . polemoniifolia

35'. Tallos floríferos cilíndricos.

38. Escapo floral simple, carnoso, que nace de la roseta basal de hojas; flor hermafrodita de $8 \mathrm{~mm}$...V. moyanoi 38'. Tallos simples o ramificados; inflorescencia terminal, flor hermafrodita entre 4-6,5 mm.

39. Hojas pinnatisectas, con segmentos obovados, superpuestos.

V. philippiana

39'. Hojas pinnatipartidas; segmentos oblongos, no superpuestos V. papilla

1. Valeriana boelckei Rossow, Parodiana 8 (1): 1-2. 1993. TIPO: Argentina. Neuquén, Dpto. Loncopué: Cerro Butahuao, 13-I-1984, Rossow et al. 1955 (holotipo, $\mathrm{BAB} !)$.

Hierba perenne, de $20-25 \mathrm{~cm}$ alt., glabra. Rizoma hasta $20 \mathrm{~cm}$ long. y $2 \mathrm{~cm}$ diám., vertical, fusiforme, carnoso, con restos de pecíolos secos hacia el ápice. Hojas enteras, láminas de 15-25 x 10-25 mm, ovadas, glabras, carnosas; pecíolos de 4-8 cm, aplanados y ensanchados hacia la base. Hojas superiores enteras, ovadas, sésiles. Inflorescencia terminal con tallos floríferos gruesos, de 5-15 cm long; brácteas y bractéolas hasta $15 \mathrm{~mm}$, gradualmente menores hacia el ápice de la inflorescencia, enteras, obovadas, decusadas, soldadas formando una vaina basal breve, a menudo con pequeños pelos capitados en el margen. Flores hermafroditas pequeñas, corola de $\pm 1,5 \mathrm{~mm}$, campanulada; estambres inclusos, anteras y filamentos de igual longitud; estilo corto. 
Fruto unilocular de $\pm 9 \times 4,5 \mathrm{~mm}$, ovoide a lageniforme, glabro; pappus formado por 17-22 setas plumosas.

ILUSTRACIONES: Rossow, 1993: 4. Borsini, 1999: 451.

CARACTERísticas Distintivas: Rizoma muy desarrollado, napiforme, no ramificado, estriado. Hojas enteras, con lámina ovada y el pecíolo aprox. 4 veces más largo que la lámina. Inflorescencia terminal, pauciflora; fruto glabro de hasta $9 \mathrm{~mm}$, uno de los de mayor tamaño dentro del género.

Fenología: Florece de octubre a diciembre y fructifica en verano, en enero y febrero.

DisTRIBUCIÓN Y HÁBITAT: Especie presente en las montañas del oeste de la provincia de Neuquén hasta Nahuel Huapi por el sur y zona adyacente de Chile. Elevación 1.500-2.000 m s.m.

Hasta la fecha $V$. boelckei había sido citada como endémica de Neuquén (Argentina), sin embargo registré ejemplares recolectados en zonas adyacentes de Chile (IX Región de la Araucanía).

Valeriana boelckei es afín a $V$. carnosa y $V$. fonckii. $V$. carnosa se distingue por sus hojas de mayor tamaño y de bordes marcadamente dentados; sus frutos son más pequeños, con setas en menor número y más cortas. $V$. fonckii se diferencia por presentar rizoma leñoso, tortuoso, ramificado; las hojas espatuladas, con pecíolo de la longitud de la lámina, y frutos de menor tamaño.

Material adicional examinado: ARGEnTINA. Neuquén. Dpto. Loncopué: Chenque Pehuén, Cerro al S del destacamento de Gendarmería, ladera N, \pm 2000 m s.m., 14-I-1982, Rossow et al. 1013 (BAB); Dpto. Los Lagos: PN Nahuel Huapi, Cerro Pelado, 18-II-1995, Ferreyra 396 (BCRU); Dpto. Minas: Huingancó, La Rinconada, 14-II-1990, Correa et al. 9990 (BAB); Dpto. Norquín: camino entre Caviahué y Copahue., 18-II-1992, Rossow \& Gómez 4590 (BAB 138, BAF); Copahue, $\pm 2 \mathrm{~km}$ al O del camping, 18II-1992, Rossow \& Gómez 4625 (BAB 173, BAF). CHILE. IX Región de la Araucanía. Malleco. Pino Hachado, \pm a $100 \mathrm{~m}$ del límite, lado sur del camino, 38³9'S, 7054'W, 1900 m s.m., 11II-1960, Ricardi 5113 (CONC 26089); Lonquimay, Paso Pino Hachado, 38³9'S, 7054'W, 1600 m s.m., 7-II-1991, Ruthsatz 7630 (CONC 135728).

2. Valeriana borsinii Rossow, Parodiana 8 (1): 3-5, fig. 1.1993. TIPO: Argentina. Neuquén, Dpto. Minas: laguna Varvarco Tapia, cañadón al sur de la laguna, 13-II-1985, Rossow \& Gómez Cadret 2700 (holotipo, BAF; isotipo, $\mathrm{BAB} !)$.

Hierba perenne de hasta $110 \mathrm{~cm}$ alt. Rizoma leñoso de $2 \mathrm{~cm}$ diám., con el ápice cubierto por restos de hojas secas. Hojas basales enteras, de $15-25 \times 2-3,5 \mathrm{~cm}$, obovado-oblongas, apenas sinuadas, glabras, membranáceas, atenuadas en un largo pecíolo; 3-4 pares de hojas caulinares de $3-13 \mathrm{~cm}$, unidas por una vaina breve, las inferiores enteras o groseramente dentadas, las superiores pinnatipartidas a pinnatisectas, auriculadas y pubescentes en la base. Tallos floríferos de sección cuadrangular, paucifoliados. Inflorescencias densas. Brácteas hasta $12 \mathrm{~mm}$ y bractéolas hasta $5 \mathrm{~mm}$, oblongas, auriculadas, a veces cortamente bífidas en el ápice, connadas y pubescentes en la base. Flores hermafroditas: corola de 2$3,4 \mathrm{~mm}$, campanulada, gibosa, y con pelos carnosos pequeños en la base; tubo corolino pubescente interiormente, lóbulos ovados. Estambres exertos. Ovario elipsoide; estigma 2-3 lobado. Fruto de $\pm 2,3-2,5 \mathrm{~mm}$, elipsoide o estrechamente ovoide, comprimido, corta y densamente pubescente en ambas caras, finamente papiloso; pappus de $c a .1 \mathrm{~mm}$, formado por 9-10 setas plumosas.

ILUSTRACIONES: Rossow, 1993: 4. Borsini, 1999: 451.

CARACTERÍsticas Distintivas: Hojas basales formando una roseta, enteras, alargadas y atenuadas en un largo pecíolo; las hojas superiores pinnatisectas. Tallo florífero tetrágono. Fruto pequeño, de 2,3-2,5 mm, elipsoide, corta y densamente pubescente en ambas caras.

Fenología: Florece de octubre a diciembre y fructifica en verano, en enero y febrero.

Distribución Y HÁBITAT: Especie endémica del noroeste de la provincia de Neuquén, habita en sectores montañosos, en cañadones.

Valeriana borsinii es afín a V. leucocarpa, de la cual se diferencia por sus frutos corta y densamente pubescentes.

Material adicional examinado: ARGEnTINA. Neuquén. Dpto. Minas: RP 1, La Fragua, 11-XII-1992, Rossow et al. 5521 (BAB, $\mathrm{BAF})$.

3. Valeriana bracteosa Phil., Linnaea 33: 101. 1864-5. TIPO: Chile. Cuesta de Chacabuco, IX-1861, Philippi s.n. (lectotipo, designado por Borsini (1966: 404), SGO 56955 !).

Valeriana rupestris Phil., Anales Univ. Chile 41: 734. 1872. TIPO: Chile. Baños de Cauquenes, X-1887, Philippi s.n. (holotipo, SGO 56949!).

Hierba perenne hasta $1 \mathrm{~m}$ alt., simple o ramificada desde la base. Raíz leñosa de $17 \mathrm{~cm}$ long. x $2 \mathrm{~cm}$ diám.; tallos de base leñosa, con restos foliares. Hojas basales de 4-26 cm, enteras, liradas o pinnatisectas, con segmentos irregulares, enteros o lobados; márgenes sinuados, enteros o dentados; lóbulo terminal más grande, obovado. Hojas superiores pinnatisectas. Inflorescencias de $11-20 \mathrm{~cm}$, densamente 
ramificadas, pubescentes, glandulosas. Brácteas de 10$15 \mathrm{~mm}$, lanceoladas, lineares u oblongas. Bractéolas de 2-3 mm, lineares o filiformes, con pelos glandulosos. Flor hermafrodita: corola de 2,5-3 $\mathrm{mm}$, infundibuliformecampanulada. Estambres inclusos, anteras elipsoides. Flor femenina: corola de $1 \mathrm{~mm}$; lóbulos ovados. Ovario pubescente. Fruto unilocular de 2 x $1 \mathrm{~mm}$, elipsoide, planoconvexo, con esbozos de 2 lóculos estériles en el ápice; hirsuto, con pelos más densos en su cara trinervada; pappus formado por 8-9 setas.

ILUSTRACIONES: Borsini, 1966: 464.

Características distintivas: Hierba de hasta $1 \mathrm{~m}$ alt., hojas generalmente pinnatisectas, con segmentos de bordes irregulares, el terminal notablemente más grande; hojas superiores pinnatisectas. Inflorescencias muy ramificadas; fruto de $2 \mathrm{~mm}$, elipsoide, con lóculos estériles reducidos a esbozos en el ápice de la cara trinervada; hirsuto. Con pappus.

Fenología: Florece de septiembre a octubre y fructifica en diciembre y enero.

DiSTRIBUCIÓN Y HÁBITAT: Especie endémica de las provincias centrales de Chile: Santiago, O'Higgins y Ñuble (Regiones $\mathrm{M}$ hasta VIII), entre los 1.400-1.600 m de altura. Crece en zonas de montaña, en particular en peñascos y grietas de las rocas.

Valeriana bracteosa es afín a $V$. virescens, y se diferencia por presentar inflorescencias menos desarrolladas y frutos elipsoides escasamente hirsutos; además es una especie perenne, mientras que $V$. virescens es anual.

Material adicional examinado: CHILE. Región Metropolitana. Santiago, Cuesta de Chacabuco, Philippi 970 (SGO 43509); Alfalfal, 3330'S, $70^{\circ} 11^{\prime} \mathrm{W}, 1500 \mathrm{~m}$ s.m., IX-1952, Levi 705 (CONC 108249); Quebrada de Peñalolen, 33⒉ $8^{\prime} \mathrm{S}, 70^{\circ} 33^{\prime} \mathrm{W}, 1000$ m s.m., 23-X-1952, Bravo 192 (CONC 108195); Río Colorado, cerca de los Baños de Tupungato, 1500 m s.m., 19-IX-1928, Looser 2090 (SI); Baños de Tupungato, 333' 'S, 7005'W, 1620 m s.m., IX-1928, Garaventa 1484 (CONC 54187). VIII Región del Bío-Bío. Ñuble: Chillán, Philippi s.n. (fot. F 17829 ex B).

4. Valeriana bridgesii Hook. \& Arn., Bot. Misc. 3: 365. 1833. TIPO: Chile. Valparaíso, Cuming 744 (lectotipo, designado por Borsini (1966: 432), GL; isolectotipo, fot. K!).

Valeriana simplex Clos in Gay, Hist. Chile, Bot. 3: 224. 1847. TIPO: Chile. Gay s.n. (lectotipo, designado aquí, $\mathrm{P},=$ fot. F 37128!; isolectotipo, fot. K!).

Valeriana regularis Clos in Gay, Hist. Chile, Bot. 3: 225. 1847. TIPO: Chile. Santiago. 1839. Gay 305 (lectotipo, designado por Borsini (1966: 434), P, = fot. F 37124!; isolectotipo, fot. $\mathrm{K}$ !).
Valeriana phellocarpa Phil., Linnaea 33: 100. 1864. TIPO: Chile. Colchagua, Guzmán s.n. (neotipo, designado aquí, SGO 43458!).

Hierba perenne de 7-60 cm alt., simple o ramificada, glabra o con pelos cortos. Rizoma de 3-4,5 mm diám., ovoide o fusiforme, estriado transversalmente, carnoso. Hojas inferiores enteras, liradas, lobadas hasta pinnatisectas, de 18 × 2-2,5 cm; las divididas con lóbulos de 0,5-2 x 1,5 $\mathrm{cm}$, el terminal de mayor tamaño; márgenes sinuados, crespos, crenulados; membranáceas. Hojas superiores pinnatífidas o pinnatisectas. Inflorescencias de hasta 50 $\mathrm{cm}$, contraídas o laxas; pedúnculos cortamente pubescenteglandulosos. Brácteas de $20 \mathrm{~mm}$, enteras, lineares u oblongas, auriculadas o divididas. Bractéolas de 1,5-15 $\mathrm{mm}$. Flor hermafrodita: corola de 2,5-3,5 mm, tubulosoinfundibuliforme; tubo giboso cerca de la base. Estambres inclusos, filamentos estaminales insertos en la mitad de la corola. Flor femenina: corola de $1 \mathrm{~mm}$, infundibuliforme, lóbulos ovados, obtusos u orbiculares. Ovario elipsoide; estilo exerto; estigma papiloso. Fruto ovoide o elipsoide de 2-2,5 x 1,2 mm; presenta el lóculo fértil pubescente y 2 lóculos estériles globosos, glabros; pappus formado por 10-11 setas.

ILUSTRACIONES: Borsini, 1966: 472.

CARACTERÍsticas Distintivas: Rizoma carnoso, arrugado transversalmente; hojas basales pecioladas, enteras, lobadas hasta pinnatisectas. Inflorescencias muy desarrolladas, casi de la longitud de la planta. Fruto muy característico, formado por 2 lóculos estériles globosos, glabros, desarrollados sobre la cara ventral y dorsal del fértil; y el lóculo fértil plano, pubescente; con pappus.

FenOlogía: Florece de octubre a diciembre y fructifica en verano, en enero y febrero.

DisTRIBUCIÓN Y HÁBITAT: Habita en los cerros de las provincias del norte y centro de Chile (Regiones IV, V, M y VI), entre los 200 y 900 m s.m.

Valeriana bridgesii es afín a $V$. obtusifolia, de la cual se separa por su inflorescencia más desarrollada y por el fruto que tiene el lóculo fértil globoso, mientras en $V$. obtusifolia es plano.

Observación 1: En el caso de Valeriana simplex Clos no designó ejemplar tipo (holotipo), por lo cual se designa aquí como lectotipo a uno de los ejemplares recolectados por Gay (sintipos), que sirvieron de base para la descripción original de la especie. La necesidad de designar un neotipo para Valeriana phellocarpa Phil. se fundamenta en la pérdida del ejemplar de Simons s.n. en el cual se basó la diagnosis de la 
especie. Se seleccionó como neotipo al ejemplar de Guzmán s.n., el cual se ajusta a la descripción original.

Observación 2: Los ejemplares que están en una etapa inicial de fructificación presentan formas de transición de los frutos, siendo uniloculares, planos, pubescentes en su cara uninervada.

Observación 3: Xifreda (1999) la menciona como cita dudosa para la flora argentina. Entre el material examinado en el presente trabajo, $V$. bridgesii no ha sido registrada para la Argentina; tampoco se ha citado su presencia en la literatura.

Material adicional eXaminado: CHILE. IV Región de Coquimbo.

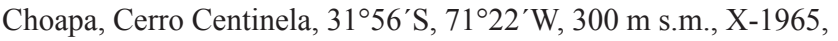
Jiles 4606 (CONC 54332). V Región de Valparaíso. Aconcagua. Purutum, Catapilco, IX-1865, Philippi 990a (SGO 43460); Catapilco, IX-1865, s.col. (SGO 57062); Valparaíso, 1871, Borchers s.n. (SGO 57006); Valparaíso, IX-1879, s.col. (SGO 43496, 57063); Petorca, Zapallar, Tigre, 32 $33^{\prime} \mathrm{S}, 71^{\circ} 28^{\prime} \mathrm{W}, 20 \mathrm{~m}$ s.m., IX-1923, K. Behn s.n. (CONC 21676); Valparaíso, Camino a

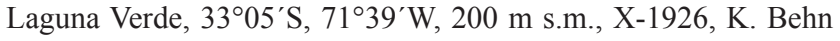

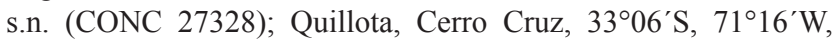
900 m s.m., IX-1927, Garaventa 1202 (CONC 54273); Quillota,

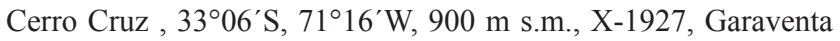
1205 (CONC 54272); Cerro Comunidad, Maitenes, 3259'S, 71 ${ }^{\circ} 15^{\prime} \mathrm{W}$, IX-1928, Garaventa 1309 (CONC 54277); Valparaíso,

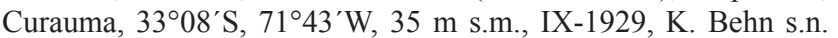
(CONC 21681); Valparaíso, Viña del Mar, $33^{\circ} 02^{\prime} \mathrm{S}, 71^{\circ} 34^{\prime} \mathrm{W}$, 20 m s.m., IX-1932, K. Behn s.n. (CONC 26896). Región Metropolitana. Santiago, San Miguel, X-1880, Navarro s.n. (SGO 43453); Santiago, Renca, Philippi 990b (SGO 43457); Santiago, San Ramón, XI-1883, Philippi 990e (SGO 43459); Santiago, Rinconada Lo Cerda, Quebrada La Plata, 33²9'S, 7054'W, 600 m s.m., X-1961, Schlegel 4061 (CONC 44919); Santiago, Cerros

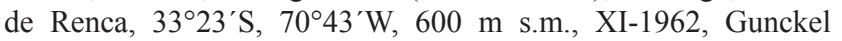
43980 (CONC 108186).

5. Valeriana carnosa Sm., Pl. Icon. Ined. 3:32, tab. 52. 1791. TIPO: Chile. Puerto Prat, región del Cerro de la Última Esperanza, 26-I-1904, Hicken 125 (neotipo designado aquí, SI 22710!).

Valeriana magellanica Lam., Encycl. Meth. 6: 306. 1808. TIPO: Chile. Estrecho de Magallanes, Commerson s.n. (holotipo, P; isotipo, fot. MO!).

Hierba perenne de hasta $80 \mathrm{~cm}$, simple o ramificada desde la base. Rizoma carnosodehasta $50 \mathrm{~cm}$ long., con ramificaciones tenues. Hojas basales enteras, de 6-21 x 3-7 cm, obovadas o elípticas, margen entero o con gruesos dientes, glabras, carnosas; pecíolos de $3-12 \mathrm{~cm}$. Hojas superiores sésiles o pecioladas, de 0,6-4,5 cm, obovadas, oblongas, triangulares o lanceoladas, margen entero o dentado. Inflorescencias axilares o terminales, paniculiformes, laxas. Brácteas de 3-9 mm, enteras, oblongo-lanceoladas, ovadas. Bractéolas de 2,5-4 mm, enteras o auriculadas, oblongo-lanceoladas, agudas, glabras o con pelos largos en los márgenes, en su parte basal. Flor hermafrodita: corola de $4 \mathrm{~mm}$, campanulada o infundibuliforme-campanulada, gibosa en su base; lóbulos oblongos. Estambres inclusos. Flor femenina: corola de 2-3 mm, campanulada; lóbulos ovados. Estilo exerto, engrosado en el ápice. Fruto de 5-7 x 2-3,5 mm, piriforme, con nervaduras gruesas, glabro; pappus formado por 14-15 setas plumosas.

ILUSTRACIONES: Borsini, 1944: tab. 128; 1999: 454.

CARACTERÍSTICAS DISTINTIVAS: Rizoma muy desarrollado, de hasta $50 \mathrm{~cm}$ de longitud; hojas basales y superiores enteras, carnosas, el margen en general presenta gruesos dientes o pequeñas lacinias. Inflorescencias axilares o terminales, laxas; fruto de 5-7,5 x 2-3 mm, piriforme, con lóculos estériles no desarrollados, glabro; con pappus.

FenOlOGíA: Florece de octubre a diciembre y fructifica en verano, en enero y febrero.

DistRIBUCIÓN Y HÁBITAT: En Chile habita en la cordillera austral, desde Maule hasta Tierra del Fuego (Regiones VII, VIII, IX, X, XI y XII); en Argentina en las provincias de Mendoza, Neuquén, Río Negro, Chubut, Santa Cruz y Tierra del Fuego. Elevación: 0-2.500 m s.m. Es una de las especies de más amplia distribución, encontrándose en sitios abiertos de las zonas boscosas de la provincia fitogeográfica Subantártica, en la estepa y en la transición bosque-estepa.

Nombre COMúN Y USOS: Ñancolahuén (yerba del aguilucho blanco), ñamkulawen (lengua mapuche). Utilizada en la medicina popular mapuche y considerada el "remedio que cura las siete enfermedades"; para tratar afecciones de los pulmones, estómago, hígado y riñones, dolor de cintura y espalda, y para el decaimiento (Kutschker et al. 2002).

Valeriana carnosa es afína $V$.fonckii, de la cual se distingue por sus hojas de mayor tamaño, de bordes marcadamente dentados y que no están arqueadas, especialmente en los ejemplares de herbario. Además $V$. carnosa presenta un rizoma carnoso muy desarrollado, mientras en $V$. fonckii es leñoso y su tamaño es mucho menor.

Observación: La descripción de Smith está basada en material coleccionado por Commerson, posiblemente depositado en el Herbario del Museo de Historia Natural de París (P) o de la Universidad de Montpellier (MPU), el cual no ha sido localizado y probablemente esté perdido o destruido. Por este motivo se ha decidido designar un neotipo, el cual corresponde al ejemplar de Hicken 125 depositado en SI.

Material adicional examinado: ARGentina. Chubut. Dpto. 
Biedma: Río San José, comienzos de Península Valdés, en Bahía San José, 18-I-1973, Goodall 4586 (BAB); Dpto. Escalante: R.N. $\mathrm{N}^{\circ} 3,20 \mathrm{~km}$ N Comodoro Rivadavia, 5-XII-1986, Gómez et al. 269 (BAB); Estancia Begoña, $30 \mathrm{~km}$ al NO de Comodoro Rivadavia, 2-XI-1946, Soriano 2020 (BAB); Dpto. Florentino Ameghino: Dique Florentino Ameghino, 20-XII-1981, Cabrera et al. 33304 (SI); A 1 km antes del Dique Florentino Ameghino desde Dolavon, 22-II-1990, Correa et al. 10204 (BAB); Dpto. Futaleufú: Corcovado, Cerro Colorado, 12-I-1948, Krapovickas 4056 (BAB 70532); Lago Amutui Quimei, Presa Futaleufú, 30-XI-1985, Arroyo \& Leuenberger 3406 (BAB); R.P. N ${ }^{\circ} 17$, a $5 \mathrm{~km}$ de Corcovado, 1-II-1990, Correa et al. 10402 (BAB); Esquel, cañadón hacia La Hoya, 881 m s.m., 2-III-2008, Kutschker 801 (BCRU); Dpto. Senguerr: Valle de la Laguna Blanca, 15-XI-1901, Koslowsky 60 (SI); Laguna Blanca, verano 1903-04, Koslowsky 12425 (BAB); Estancia Pepita, 11-II-1945, Soriano 1498 (SI, BAB); Estancia Pepita, 13-II-1947, Soriano 2587 (BAB); Paso Huemules, Estancia La Elida, 21-I-1984, Rossow et al. 2308 (BAB); Dpto. Tehuelches: Lago General Paz, 2-III-1903, Gerling s.n. (SI 14524); Tehuelches, a 20 km de Río Pico, en el camino de lago Vintter, 16I-1948, Krapovickas 4136 (BAB 70528). Mendoza. Alto Valle de El Sosneado, $2700 \mathrm{~m}$ s.m., 19-II-1942, Burkart et al. s.n. (SI 14311); Dpto. San Rafael: Sierra del Nevado, Zanjón del Plateado frente a los Cerros Morados, 1650 m s.m., 8-XII-1973, Boelcke et al. 15725 (BAB). Neuquén. Dpto. Minas: lagunas Epulaufquen, Cerros al NO de las lagunas, 1570-1630 m s.m., 17-I-1964, Boelcke et al. 10970 (BAB); Dpto. Los Lagos: Villa Puerto Manzano, subida al Cerro O'Connor, 1250 m s.m., 1-XII-1969, Diem 3375 (BAB); Dpto. Huiliches: Currhué, subida al Cerro Colohuincul, 24-I-1982, Carrique et al. 1472/1459 (BAB); Dpto. Aluminé: R.P $\mathrm{N}^{\circ} 11,23 \mathrm{~km}$ al $\mathrm{N}$ del Lago Ñorquinco hacia Paso de Icalma, 1800 m s.m., 17-II-1990, Correa et al. 10058 (BAB); Dpto. Norquín: Copahue, \pm 2 km o del camping, 18-II-1992, Rossow \& Gómez Cadret 4620 (BAB). Río Negro. Dpto. Bariloche: PN Nahuel Huapi, Cerro Otto, 1100 m s.m., 7-I-1946, Boelcke 1692 (SI); Cerro Otto, 1300 m s.m., 17-X-1949, Boelcke \& Hunziker 3693 (BAB); PN Nahuel Huapi, S.C. de Bariloche, 800 m s.m., 18-X1949, Boelcke \& Hunziker 3728 (BAB); PN Nahuel Huapi, faldeos Cerro Ventana, 1350 m s.m., 25-X-1949, Boelcke \& Hunziker 3379 (BAB); Cerro Meta, ladera N, 1740 m s.m., 13-II-1994, Ferreyra \& Clayton 293 (BCRU); Cerro Carbón y Estratos, 7-I1996, Ferreyra \& Clayton 438 (BCRU); Cerro López, 16-II-2003, Kutschker 176 (BCRU); Cerro Challhuaco, II-1998, Daniels s.n. (BCRU). Dpto. Valcheta: Somuncurá, Cerro Corona, 24-XI-1975, Correa et al. 6341 (BAB); Cerro Corona ladera S, 13-II-1981, Rossow \& Gómez Cadret 185 (BAB). Santa Cruz. Lago Viedma, I-1916, Witte 46 (SI); Localidad no indicada, Burmeister s.n. (SI 14526); 25 km al sur de Río Gallegos, 22-I-1949, Grondona 2140 (BAB); El Portezuelo, a $20 \mathrm{~km}$ de Chile, 13-XII-1954, Soriano 4792 (BAB); Dpto. Deseado: Cañadón del Veneciano, 12-XI-1965, Correa \& Nicora 3328 (BAB); Puerto Deseado, cañadón próximo a la Estación de Biología Marina, 9-XII-1970, Crespo \& Troncoso 1702 (BAB); Dpto. Güer Aike: entre Dorotea y yacimiento de Río Turbio, 240 m s.m., 8-I-1978, Ambrosetti \& Méndez 667 (BAB); Estancia Cóndor, cerca del casco en ladera S, 9-XII-1976, Seibert et al.-TBPA-Fit. 969 (BAB); Morro Philippi, 14-XII-1976, Seibert et al.-TBPA-Fit. 1117 (BAB); Estancia Glencross, 14-XII-1976, Seibert et al.-TBPA-Fit. 2095 (BAB); Estancia Dos de Enero, Valle de las Chinas, 350-600 m s.m., 7-XII-1978, Pisano \& Cárdenas 4809 (BAB); Estancia La Verdadera Argentina, Cerro de la Virgen,
525 m s.m., 17-I-1977, Arroyo et al.-TBPA-Fit 2177 (BAB); Estancia La Verdadera Argentina, Cerro de la Virgen, 18-I-1977, Arroyo et al.-TBPA-Fit 2238 (BAB); Estancia La verdadera Argentina, Cerro de la Virgen, al N del casco de la estancia, 20-I1977, Arroyo et al. -TBPA-Fit 2273 (BAB); Estancia Las Vizcachas, Cerro Las Vizcachas, 25-I-1977, Arroyo et al. TBPA- Fit. 2433 (BAB); Estancia Las Vizcachas, Cerro Pto. La Piedra, faldeos SE, 26-I-1977, Arroyo et al.-TBPA-Fit 2517 (BAB); Cerro Las Vizcachas, 29-I-1977, Arroyo et al. TBPA-Fit. 2651/2676 (BAB); Estancia Stag River, meseta La Torre, Cerro Punta Gruesa, 940 m s.m., 24-I-1978, Roig et al.-TBPA-Fit 3076/3106 (BAB); Estancia Stag River, meseta La Torre, Cerro Punta Gruesa, 25-I-1978, Roig et al.-TBPA-Fit 2980 (BAB); Estancia Stag River, faldeo meseta La Torre, 670 m s.m., 2-II-1978, Ambrosetti \& Méndez-TBPA-Fit 3526 (BAB); Estancia Stag River, 15-II-1978, Boelcke et al.TBPA-Fit 3256 (BAB); Estancia Stag River, 18-II-1978, Boelcke et al. -TBPA-Fit 3331 (BAB); Valle superior del Río Turbio, cordillera Chica, Cerro Punta Alta 980 m s.m., 5-II-1978, Ambrosetti \& Méndez TBPA-Fit 3739 (BAB); Valle superior Río Turbio, 28-II-1978, Ambrosetti \& Méndez - TBPA-Fit 3369 (BAB); Ruta 3, 50 km camino de Río Gallegos a Las Horquetas, en bajos del brazo sur del río Coig, 26-XI-1963, Correa et al. 2835 (BAB); R.N. $\mathrm{N}^{\circ} 40$ a $10 \mathrm{~km}$ de Cancha Carreras hacia Estancia Tapi Aike y Esperanza, 11-I-1987, Leuenberger \& Arroyo 3656 (BAB); Dpto. Lago Argentino: $10 \mathrm{~km}$ al sur del Hotel Punta del Lago, 270 m s.m., 13-I-1939, Eyerdam et al. 24385 (SI); Lago San Martín, Estancia La Federica, bahía de la Lancha, 23-I-1967, Boelcke et al. 12758 (BAB); El Chaltén, X-1999, s.col. (BAB 92048); Lago Argentino, Punta Gualichu a Punta Bonita, 27-X2002, Guerrido 557 (SI); Lago Argentino, alrededores de la Laguna Huemul, $30 \mathrm{~km}$ al N de El Chaltén por RP 23, 21-I-2003, Belgrano 41 (SI); Dpto. Lago Buenos Aires: meseta del lago, 2 km NO casco Estancia La Vizcaína, 9-XII-1986, Sánchez 476 (BAB); a orillas del Río Zeballos, 29-XI-1990, Correa et al. 10343 (BAB); Dpto. Río Chico: Las Horquetas-Tucu-Tucu, 21-XI-1965, Correa \& Nicora 3543 (BAB). Tierra del Fuego. Tierra del Fuego, Bahía Felipe, 4-XI-1930, Donat 350 (SI); Estancia María Behety, secc. Miranda, 28-I-1955, Soriano 4873 (BAB); Dpto. Río Grande: Estancia El Salvador, 20-XI-1971, Boelcke et al. 15091 (BAB); Cabo Domingo, $17 \mathrm{~km}$ al $\mathrm{N}$ de Río Grande en ladera O, 18-XI1971, Boelcke et al. 15039 (BAB); San Sebastián, 29-I- 1995, Fortunato 4895 (BAB); Estancia San Julio, 280 m s.m., 29-I-1995, Fortunato 4896 (BAB); Dpto. San Sebastián: Estancia Los Flamencos, 12-XI-1970, Goodall 2522 (BAB); Estancia Cullén, 13-XI-1970, Goodall 2548 (BAB); Estancia Los Flamencos, 46 km O de Río Grande, 4-I-1972, Moore \& Goodall 306 (BAB); Dpto. Ushuaia: Punta María, 22-I-1960, Correa \& Perez Moreau 1989 (BAB); Cabo San Pablo, ca. 100 km SE Río Grande, 14-I1968, Moore 1510 (BAB); Cabo San Pablo, Estancia Santa Ana, 2-I-1973, Goodall 4467 (BAB). CHILE. VII Región del Maule. Talca: Laguna del Maule, $36^{\circ} 00^{\prime}$ S, $70^{\circ} 30^{\prime} \mathrm{W}, 2190$ m s.m., I-1961, Schlegel 3489 (CONC 51238); Laguna del Maule, $36^{\circ} 00^{\prime} \mathrm{S}$, $70^{\circ} 30^{\prime} \mathrm{W}, 2200$ m s.m., XII-1969, Zoellner 4495 (CONC 108234); Laguna del Maule, 36 $6^{\circ} 00^{\prime} \mathrm{S}, 70^{\circ} 30^{\prime} \mathrm{W}, 2200 \mathrm{~m}$ s.m., XII-1969, Zoellner 4526 (CONC 108256). VIII Región del Bío-Bío. Nuble: Baños de Chillán, I-1877, s.col. (SGO 57012); Termas de Chillán, 1883, Borchers s.n. (SGO 57014); Termas de Chillán, 1892, s.col. (SGO 57013); Cordillera de Chillán, XII-1899, s. col. (SGO 57087); Baños de Chillán, Nieblas $36^{\circ} 54^{\prime} \mathrm{S}, 71^{\circ} 24^{\prime} \mathrm{W}, 2000 \mathrm{~m}$ s.m., III-1927, Werdermann 1324 (CONC 28972); Nuble. Termas 
de Chillán, $36^{\circ} 54^{\prime} \mathrm{S}, 7^{\circ} 24^{\prime} \mathrm{W}, 2000$ m s.m., I-1940, Pfister s.n (CONC 4150); Termas de Chillán, 3654’ S, 71²4’W, 2000 m s. m., I-1940, Pfister s.n. (CONC 108149); Termas de Chillán, 36 $54^{\circ} \mathrm{S}, 71^{\circ} 24^{\prime} \mathrm{W}, 2000$ m s.m., II-1931, Deltor 2034 (CONC 54263); Termas de Chillán, 365 $54^{\prime} \mathrm{S}, 71^{\circ} 24^{\prime} \mathrm{W}, 2000 \mathrm{~m}$ s.m., I1945, Pfister s.n. (CONC 4159); Termas de Chillán, 3654'S, $71^{\circ} 24^{\prime} \mathrm{W}, 2000$ m s.m., XII-1948, Castillo s.n. (CONC 108139); Termas de Chillán, 36 $54^{\prime} \mathrm{S}, 7^{\circ} 24^{\prime} \mathrm{W}, 2000$ m s.m., I-1967, Schlegel 5834 (CONC 51239); Termas de Chillán, 3654’S, 713' 'W, 1750 m s.m., XII-1972, Zoellner 6696 (CONC 108154); Bío-Bío. Sierra Velluda, $37^{\circ} 29^{\prime} \mathrm{S}, 71^{\circ} 25^{\prime} \mathrm{W}, 1500 \mathrm{~m}$ s.m., XI-1952, Ricardi 2349 (CONC 13190); Bío-Bío. Laguna de la Laja, 37²1' S, 71²2'W, 1000 m s.m., XII-1976, Zoellner 9425 (CONC 108233); Bío-Bío. Volcán Copahue, 3751'S, 71¹0’W, 2500 m s.m., I1896. Neger s.n. (CONC 108155); Cordillera de Antuco, Las Cuevas, I-1887, Rohmer s.n. (SGO 57018). IX Región de la Araucanía. Malleco. Cordillera de las Raíces, 38²6 $\mathrm{S}, 71^{\circ} 29^{\prime} \mathrm{W}$, 1600 m s.m., XII-1971. Montero 8665 (CONC 100863); Cordillera de las Raíces, $1^{\circ}$ Esplanada, $38^{\circ} 26^{\prime} \mathrm{S}, 71^{\circ} 29^{\prime} \mathrm{W}, 1600$ m s.m., XII1976, Montero 10335 (CONC 100864); Cordillera de las Raíces, $2^{\circ}$ arenal, $38^{\circ} 26^{\prime} \mathrm{S}, 71^{\circ} 29^{\prime} \mathrm{W}, 1500$ m s.m., XII-1977, Montero 10734 (CONC 100862); Malleco, Lago Guallatue, 3841'S, 71ํำ' W; 1150 m.s.m, II-1966, Weisser 1542 (CONC 108232); Laguna Icalma, 38 $8^{\circ} 7^{\prime} \mathrm{S}, 7^{\circ} 20^{\prime} \mathrm{W} ; 1300$ m s.m., I-1947, F. Behn s.n. (CONC 7364); Cautín. Volcán Lanín, 39³8'S, 71³0’W; 1500 m s.m., I-1947, F. Behn s.n. (CONC 7412); Malleco, Nahuelbuta, Volckmann s.n. (SGO 43487). XI Región de Aisén. Aisén, Reserva Forestal Coihaique Alto, Laguna Verde, $45^{\circ} 27^{\prime} \mathrm{S}, 71^{\circ} 35^{\prime} \mathrm{W}, 750 \mathrm{~m}$ s.m., XII-1979, Schlegel 7204 (CONC 118575); Aisén, Camino de Coihaique a Balmaceda, $45^{\circ} 45^{\prime} \mathrm{S}, 71^{\circ} 55^{\prime} \mathrm{W}, 1000 \mathrm{~m}$ s.m., XI1954, Pfister s.n. (CONC 18433); Aisén, Región del Lago Buenos Aires, Valle Ibañez, 500 m s.m., 26-I-1939, Von Rentzell 6164 (SGO 117399- SI). XII Región de Magallanes. Última Esperanza, Sierra Baguales, Estancia La Cumbre, 5044'S, 72²2'W, $800 \mathrm{~m}$ s.m., XII-1986, Landero 701 (CONC 93243); Última Esperanza,

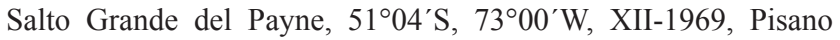
2568 (CONC 34760); Última Esperanza, Sección Lazo, Río Lazo, $51^{\circ} 08^{\prime} \mathrm{S}, 72^{\circ} 49^{\prime} \mathrm{W}, 550 \mathrm{~m}$ s.m., XII-1973, Pisano 4138 (CONC 137729); Última Esperanza, Sierra del Toro, $51^{\circ} 10^{\prime} \mathrm{S}, 7^{\circ} 50^{\prime} \mathrm{W}$, 700 m s.m., I-1992, Kalin Arroyo et al. 44 (CONC 128545); Sierra del Toro, $51^{\circ} 10^{\prime} \mathrm{S}, 72^{\circ} 50^{\prime} \mathrm{W}, 700 \mathrm{~m}$ s.m., II-1992. Kalin Arroyo et al. 69 (CONC 128501); Sierra del Toro, $51^{\circ} 10^{\prime} \mathrm{S}, 72^{\circ} 50^{\prime} \mathrm{W}, 700 \mathrm{~m}$ s.m., II-1992, Kalin Arroyo et al. 90 (CONC 128552); Última Esperanza, Cerros Cueva del Mylodon, 51 ${ }^{\circ} 34^{\prime} \mathrm{S}, 72^{\circ} 36^{\prime} \mathrm{W}, 100 \mathrm{~m}$ s.m., I-1952, Pfister \& Ricardi s.n. (CONC 12088); Magallanes, Escorial Pali Aike, $52^{\circ} 02^{\prime} \mathrm{S}, 69^{\circ} 45^{\prime} \mathrm{W}, 80 \mathrm{~m}$ s.m., XII-1974, Dollenz 203 (CONC 138747); Última Esperanza, PN Torres del Paine, Laguna Azul, 10-XI-1999, s.col. (BAB 92084); Última Esperanza, Morro Chico, 52 ${ }^{\circ} 02^{\prime} \mathrm{S}, 7^{\circ} 26^{\prime} \mathrm{W}$, XII-1954, Magens 19 (CONC 108116); Magallanes, 1864-65, Philippi 986a (SGO 43488); Magallanes, Silla del Diablo, I-1951, Barrientos s.n. (CONC 108117); Magallanes, Punta Arenas, XII-1878, Philippi 986c (SGO 43485); Magallanes, aprox. $75 \mathrm{~km}$ NE de Punta Arenas, cerca del Estrecho de Magallanes, 4-I-1939, Eyerdam et al. 24097 (SI); Magallanes, Chabunco, $53^{\circ} 01^{\prime} \mathrm{S}, 70^{\circ} 50^{\prime} \mathrm{W}, 10 \mathrm{~m}$ s.m., XII-1951, Magens s.n. (CONC 12220); Punta Arenas, Chabunco, $53^{\circ} 01^{\prime} \mathrm{S}$, $70^{\circ} 50^{\prime} \mathrm{W}, 10 \mathrm{~m}$ s.m., I-1952, Barrientos s.n. (CONC 108152); Punta Arenas, $53^{\circ} 10^{\prime} \mathrm{S}, 70^{\circ} 54^{\prime} \mathrm{W}, 20 \mathrm{~m}$ s.m., II-1954, Magens s.n. (CONC 108119); Magallanes, Dpto. Última Esperanza, Ea. Cerro Castillo, Explotadora de Tierra del Fuego, 20-XI-1955, Muñoz P. 4059 (SGO
11842); Magallanes, Puerto Munición, 52¹8'S, 69²4’W, 15 m s. m., I-1962, Ricardi \& Matthei 78 (CONC 54197); Magallanes, Cabo Negro, 52 ${ }^{\circ} 58^{\prime}$ S, $70^{\circ} 51^{\prime}$ W, 15 m s.m., XII-1969, Pisano 2319 (CONC 34291); Dpto. Última Esperanza, $\mathrm{S}^{\circ}$ Baguales, Estancia La Cumbre, 1000 m s.m., 18-XII-1975, Boelcke et al. TBPA-Fit 738 (BAB); Cameron, 5330’ S, 69³9’W, 100 m s.m., II-1951, Barrientos 356 (CONC 108114).

6. Valeriana chilensis Borsini, Lilloa 32: 392. 1966. TIPO: Chile. Talca, Laguna de Maule, 3600'S, 70³0'W, 2000 m s.m., 27-XI-1953, Sparre y Smith 23 (holotipo, CONC 17528 !).

Hierba perenne hasta $35 \mathrm{~cm}$ alt, glabra o con pelos escasos. Rizoma leñoso, horizontal, tortuoso, con corteza agrietada castaña a grisácea. Tallos tetrágonos, grisáceos, con restos de pecíolos en la base y ramificados hacia el ápice. Hojas basales enteras de 1-4 cm, espatuladas, ovadas o suborbiculares; bordes enteros, sinuados o dentados; glabras, carnosas; atenuadas en un pecíolo de 1-4 (6) cm, canaliculado, nervado. Hojas superiores de $10 \times 4 \mathrm{~mm}$, enteras, margen dentado o erosado. Inflorescencias contraídas, densas. Brácteas de 2,5$5 \times 2 \mathrm{~mm}$, oblongas, márgenes enteros. Bractéolas de 1,5-5 x $1 \mathrm{~mm}$. Flor hermafrodita: corola de 2-2,2 mm, campanulada, con giba pequeña cerca de la base; estilo trífido. Estambres inclusos. Fruto unilocular de 2-2,5 x $1 \mathrm{~mm}$, elipsoide, con esbozos de 2 lóculos estériles en el ápice de la cara trinervada; glabro, castaño-amarillento; pappus formado por 11-13 setas plumosas, soldado en el tercio basal.

Ilustraciones: Borsini, 1966: 449; 1999: 454. Rossow, 1993: 7 .

CARACTERísticas Distintivas: Rizoma leñoso, tortuoso; tallos tetrágonos; hojas basales y superiores enteras, ovadas, carnosas, dentadas o sinuadas; inflorescencia terminal, contraída; fruto de 2-2,5 mm, elipsoide, con lóculos estériles reducidos a esbozos en el ápice de la cara trinervada, glabro; con pappus.

FenOlogía: Florece de octubre a diciembre y fructifica en verano, en enero y febrero.

DistribuCiÓN Y HÁBITAT: En Chile ha sido descripta para la Región del Maule (VII), comunas de Talca y Linares, entre los 1050 y 2000 m s.m.; en Argentina se la ha recolectado en la Provincia de Neuquén, al N del Dpto. Minas, y en la Provincia de Chubut, en cerros del Parque Nacional Los Alerces. Habita en zonas montañosas, entre los 1500 y 2000 m s.m.

Valeriana chilensis es afín a $V$. fonckii, de la cual se diferencia por sus pequeñas flores y frutos, y sus hojas e hipsófilos glabros. No presenta las hojas plegadas y arqueadas como $V$.fonckii, especialmente en los ejemplares de herbario. También se asemeja a $V$. macrorhiza en el aspecto general 
de la planta, especialmente de la inflorescencia, pero se distingue por sus hojas ovadas y de pecíolo acanalado, y por el fruto que presenta pappus plumoso. Es afín a $V$. radicalis, de la cual se distingue por presentar frutos más pequeños, ovoides, con esbozos de lóculos estériles presentes, y la flor hermafrodita con estambres inclusos.

Material adicional examinado: ARGEnTINA. Chubut. Dpto. Futaleufú: PN Los Alerces, Cerro El Dedal, 42 ${ }^{\circ} 53^{\prime} \mathrm{S}, 71^{\circ} 38^{\prime} \mathrm{W}$, 24-III-2008, Kutschker 808 (BCRU). Neuquén. Dpto. Minas: destacamento Cerrillos, Cerro Morado, \pm 1600 m s.m., 12-II1985, Rossow \& Gómez Cadret 2663 (BAB); Laguna Varvarco Tapia, cañadón al sur de la laguna, 13-II-1985, Rossow \& Gómez Cadret 2728 (BAB). CHILE. VII Región del Maule. Linares, Reserva Nacional Bellotos del Melado, 35 $51^{\circ} \mathrm{S}, 71^{\circ} 06^{\prime} \mathrm{W}, 1050$ m s.m., 20-XII-1999, Kalin Arroyo et al. 996187 (CONC 149289); Reserva Nacional Bellotos del Melado, ladera con quila, $35^{\circ} 51^{\prime} \mathrm{S}$, 71 ${ }^{\circ} 06^{\prime} \mathrm{W}, 1370$ m s.m., 21-XII-1999, Kalin Arroyo et al. 996312 (CONC 149204); Reserva Nacional Bellotos del Melado, 35 51' S, $71^{\circ} 06^{\prime} \mathrm{W}, 1350$ m s.m., 4-I-2000, Humaña et al. 20013 (CONC 148985).

7. Valeriana clarionifolia Phil., Linnaea 28: 702. 1858. TIPO: Chile. Laguna de Malvarco, I-1856, Germain s.n. (lectotipo, designado por Borsini (1966: 419), SGO 56964!, p.p. $\operatorname{con} V$. pulchella Phil. $=V$. philippiana Briq.).

Valeriana spegazzinii Skottsb., Kungl. Svenska Vetenskapsakad. Handl. 56 (5): 308. 1916. TIPO: Argentina. Chubut, Estancia Maitén, 28-X-1908, Skottsberg s.n. (lectotipo, designado aquí, SGO 58792!).

Valeriana sarcophylla Stuck. \& Briq., Ann. Conserv. Jard. Bot. Genève 20: 431. 1916-9. TIPO: Argentina. Cordillera de Mendoza, Río Salado superior, Infierno Chico, 29-I-1893, Stuckert 7622 (holotipo, G,= fot. F 27206!).

Hierba perenne de hasta $75 \mathrm{~cm}$ alt., glabra, simple o ramificada en la base. Rizoma de $1,5 \mathrm{~cm}$ de diám., rugoso, carnoso, cubierto por restos foliares. Hojas basales pinnatipartidas que no superan los $20 \times 2-3,5 \mathrm{~cm}$; lámina con segmentos ovados, obtusos, disminuyendo de tamaño hacia la base; glabras, coriáceas, lustrosas; pecíolo canaliculado y pubescente en su cara interna. Hojas superiores pinnatisectas de 1,5-4 cm, con lóbulos lineares u oblongos. Inflorescencias con tallos floríferos largos, pauci-densifloras, laxas o contraídas. Brácteas de 4-10 mm, lineares, enteras o dentadas, a veces auriculadas, márgenes con pelos glandulosos. Bractéolas de 3-5 x 0,5$1 \mathrm{~mm}$, oblongo-lineares. Flor hermafrodita: corola de 3$4 \mathrm{~mm}$, infundibuliforme, gibosa en la base. Estambres inclusos. Flor femenina: corola de 3-4,5 mm, campanulada; lóbulos ovados. Ovario oblongo. Fruto de 4-5,5 x 2-2,5 $\mathrm{mm}$, lageniforme, escotado en la base, con las nervaduras marcadas y lóculos estériles reducidos a esbozos en el ápice del fértil, glabro; pappus formado por 11-15 setas plumosas.
ILUSTRACIONES: Borsini, 1944: tab. 131; 1999: 451.

CARActerísticas distintivas: Rizoma corto, carnoso. Las hojas basales son pecioladas, divididas, con 8-9 pares de segmentos que van disminuyendo de tamaño hacia la base; coriáceas, lustrosas; hojas superiores pinnatisectas. Fruto de 4-5,5 mm, lageniforme, glabro; esbozos de lóculos estériles en el ápice de la cara trinervada; con pappus.

Fenología: Florece de octubre a diciembre y fructifica en verano, en enero y febrero.

DisTRIBUCIÓN Y HÁBITAT: Especie nativa que se encuentra en Mendoza y provincias de la región Patagónica hasta Santa Cruz (Argentina). Crece entre los 0 y 2.000 m s.m., en zonas boscosas de montaña (Provincia subantártica) como así también en lomadas de la estepa patagónica (Provincia patagónica), y en la transición entre ambos ambientes. En Chile ha sido citada para la Región de Bío-Bío (Región VIII).

Aspectos ecológicos: Presenta variaciones en la forma y cantidad de lóbulos de las hojas, no así en su consistencia coriácea. La médula del rizoma es amarillenta y el olor penetrante, siendo uno de los más fuertes entre las Valerianas de la región. Generalmente crecen buscando la protección de otras hierbas de mayor porte, arbustos, árboles o rocas.

Nombre COMÚN y usos: Ñanculahuén de monte. Se ha registrado su uso etnomedicinal en Patagonia argentina, con las mismas aplicaciones que Valeriana carnosa (Kutschker et al. 2002, Molares et al. 2007).

Valeriana clarionifolia se asemeja a $V$. verticillata por la forma de sus hojas basales y se diferencia por la consistencia de las mismas y por el fruto que en $V$. clarionifolia es lageniforme y los lóculos estériles del fruto están reducidos a esbozos, mientras que en $V$. verticillata es ovoide y presenta lóculos estériles bien desarrollados.

Observación: Al no designarse un holotipo al momento de la descripción de la especie, fue seleccionado un lectotipo entre los ejemplares citados por Skottsberg en la diagnosis original (sintipos).

Material adicional examinado: ARGENTINA. Chubut. Trayecto Trelew-Tecka, XI-1899, Illín s.n. (BAB); Travesía de Rawson a la Cordillera, 1/30-XI-1903, Illín s.n. (SI 14544); Dpto. Cushamen: al sur cruce R.N. N 40, 26-XI-1983, Correa et al. 8944 (BAB); Dpto. Escalante: Estancia Begoña, $30 \mathrm{~km}$ al NO de Comodoro Rivadavia, 1-XI-1946, Soriano 2007 (BAB); Dpto. Futaleufú: Aeropuerto de Esquel, 12-XII-1981, Cabrera et al. 33093 (SI); entrando hacia Jaramillo, 1-XII-1990, Correa et al. 10400 (BAB); PN Los Alerces, frente al lago Futalaufquen, 2-XII-1990, Correa et al. 10441 (BAB); PN Los Alerces, a $59 \mathrm{~km}$ de Esquel, Lago Futalaufquen camino a lago Menéndez, 25-XI-2006, Morrone 
5668 (SI); PN Los Alerces, sendero entre Lago Menéndez y Lago Cisne, 30-X-2008, Biganzoli 1854 (SI); 20 km al N de Esquel, 24II-1993, Roig. et al. 14659 (BAB); Esquel, cañadón hacia La Hoya, 881 m s.m., 2-III-2008, Kutschker 802 (BCRU); Dpto. Languiñeo: Cerro Kaquel, 130 km SE de Esquel, 3-I-2002, Kutschker 171 (BCRU); Dpto. Tehuelches: 40 km José de San Martín-Pampa de Agnia, 26-XI-1965, Correa \& Nicora. 3663 (BAB); R.P. No 19 , a $21 \mathrm{~km}$ NE de Gobernador Costa, 8-XII-1976, Arroyo et al. 409 (BAB). Neuquén. Dpto. Aluminé: Pulmarí, 8-XII-1981, Cabrera et al. 32930 (SI); 13,5 km al E del lago Ñorquinco hacia Aluminé, 19-I-1982, Rossow et al. 1262 (BAB); R.P. N 23, entre Aluminé y Rahué, cascada al sur de Rahué, 15-XII-1985, Correa et al. 9341 (BAB); Dpto. Los Lagos: Huinca-lu, 11-XI-1966, Vallerini-Suero 1086 (BAB); Estancia Fortín Chacabuco, 22-XI-1967, Correa et al. 3795 (BAB); Dpto. Lácar, \pm 15 km E de San Martín de los Andes, 4XII-1980, Correa et al. 7816 (BAB). Río Negro: PN Nahuel Huapi, S.C. de Bariloche, 800 m s.m., 18-X-1949, Boelcke \& Hunziker 3729 (BAB); Bariloche, detrás del aeropuerto, 31-X-1994, Brion \& Barthelemy s.n. (BCRU). Santa Cruz. Caleta Olivia. 14-X-1929, Donat 190 a (SI); 23-X-1929, Donat 190 b (SI); Dpto. Deseado: Cañadón del Veneciano, 18-XI-1965, Correa et al. 3472. (BAB); Dpto. Lago Argentino: Calafate, 25-XI-1983, Cabrera 34150 (SI); Lago Argentino, Punta Gualichu a Punta Bonita, 27-X-2002, Guerrido 555 (SI); Dpto. Lago Buenos Aires: Los Antiguos, 24XI-1965, Correa et al. 3621 (BAB); camino al Río Jainemeni, 28II-1990, Correa et al. 10322 (BAB); Dpto. Magallanes: Cañadón León, Estancia La Alianza, 1-II-1958, Vervoorst 5744 (BAB). CHILE. VIII Región del Bío-Bío. Bío-Bío, Antuco, Río Los Pinos, 37²9'S, 71³3'W, 30-I-1991, Ruthsatz 7308 (CONC 135843).

8. Valeriana crispa Ruiz \& Pav., Fl. Peruv. Chil. 1: 41. 1798. TIPO: Chile. Valparaíso. Curauma, X-1883, Philippi 995a (neotipo, designado aquí, SGO 43493!).

Astrephia lobata Hook. \& Arn., Bot. Misc. 3: 364-5. 1832-3. Valeriana lobata (Hook. \& Arn.) Höck, Bot. Jahrb. Syst. 3 (1): 53. 1882. TIPO: Chile. Valparaíso, Cuming 571 (lectotipo designado aquí, fot. K!).

Valeriana oreocharis Phil., Linnaea 28: 699. 1858. TIPO: Chile. Cordillera de Linares, I-1856, s. col. (holotipo, SGO 56944!).

Valeriana floribunda Phil., Linnaea 28: 701. 1858. TIPO: Chile. Valparaíso, San Antonio, X-“1883” (1853?), Germain s.n. (probable holotipo, SGO 43494!).

Valeriana excelsa Reiche, Anales Univ. Chile 106: 1018. 1900. TIPO: Chile. Valparaíso. Quintero, al N de Valparaíso, 19-IX-1931, Looser 2088 (neotipo designado aquí, SI!).

Hierba anual hasta $80 \mathrm{~cm}$ alt. Raíz hasta $20 \mathrm{~cm}$ long. y tallos estriados, densamente foliados, glabros o pilosos. Hojas basales enteras o divididas, pecioladas, de 2,5-8 x 1,5-3,5 cm; las enteras con lámina ovada o elíptica; base recta, atenuada o escotada, márgenes gruesamente dentados, membranáceas; las hojas pinnatisectas de ámbito oblongo y segmentos ovadolanceolados, el lóbulo terminal de mayor tamaño. Hojas superiores lirado-pinnatisectas, lóbulos oblongo-lanceolados o lanceolados. Inflorescencias densifloras, pedúnculos glandulosos, de 8-10 cm long. Brácteas de 3-5 mm, oblongo- lanceoladas o lineares, base generalmente auriculada, con abundantes pelos rígidos o glandulosos en sus márgenes y base. Bractéolas de $2 \mathrm{~mm}$, lineares agudas, algo ensanchadas en su base, márgenes y haz con pelos simples o glandulosos. Flor hermafrodita: corola de $2-3 \mathrm{~mm}$, infundibuliformecampanulada, gibosa; estambres inclusos. Flor femenina: corola de $1 \mathrm{~mm}$, campanulada, gibosa; estilo exerto. Fruto trilocular, de 1,5-2 x 1-1,2 mm, ovoide o elipsoide, con 2 lóculos estériles bien desarrollados sobre la cara trinervada del lóculo fértil, con una depresión en la parte media; glabro, papiloso; pappus formado por 7-12 setas plumosas.

ILUSTRACIONES: Borsini, 1966: 449; 1999: 461 (sub. Valeriana oreocharis). Rossow, 1993: 7 (sub. Valeriana oreocharis).

CARacterísticas distintivas: Tallos surcados; las hojas basales enteras o divididas, en este caso presentan el lóbulo terminal de mayor tamaño, con márgenes dentados; hojas superiores lirado-pinnatífidas. Inflorescencia muy desarrollada; brácteas y bractéolas con pelos rígidos o glandulosos en márgenes y base; fruto pequeño, con 3 lóculos bien desarrollados, los estériles separados por un surco; ovoide o elipsoide, glabro; con pappus.

Fenología: Florece de octubre a diciembre y fructifica en verano, enero y febrero.

DistRiBUCiÓN y hÁBITAT: Vive en las provincias del sur y centro de Chile, tanto en áreas andinas como costeras (Regiones IV, V, M, VI, VII, VIII y IX); en Argentina en la provincia de Neuquén, habita en zonas montañosas entre los 1.000 y $2.500 \mathrm{~m}$ s.m.

Valeriana crispa es afín a $V$. valdiviana, ambas especies anuales, de la cual se diferencia por los segmentos de las hojas basales regularmente dentados y por sus frutos con lóculos estériles bien desarrollados, separados por un surco, mientras que $V$. valdiviana presenta segmentos foliares con bordes erosados y frutos con lóculos estériles reducidos a esbozos.

Observación 1: El análisis de ejemplares de Valeriana crispa, $V$. oreocharis y V. floribunda permite establecer que las diferencias entre las tres especies se limitan al tipo de pubescencia de brácteas y bractéolas (presencia de pelos rígidos o glandulosos en base y márgenes) y a la forma del fruto (ovoide o elipsoide). Se observaron muchos ejemplares donde se presenta una combinación de estos caracteres. Se considera que corresponden a una misma especie, que por prioridad debe llevar el nombre Valeriana crispa Ruiz \& Pav. En función de esta nueva sinonimia establecida la especie V. crispa presenta una distribución continua desde Limarí (Región IV: Coquimbo) hasta Cautín (Región IX: Araucanía). 
Observación 2: Hooker y Arnott describieron a Astrephia lobata (tratada por Borsini como Valeriana lobata) basados en dos ejemplares designados como Cuming 571: el $\alpha$ del Herbario de Arnott, depositado en Glasgow (GL) y el $\beta$ del herbario de Hooker, depositado en Kew (K). Borsini (1966: 408) observa, por un lado, que Bentham y Hooker describieron a $V$. lobata como Astrephia lobata, cuando en realidad fueron Hooker y Arnott. Por otro lado, considera que dicha descripción se realizó en base a dos materiales diferentes, Cuming 571 y Bridges 747, pertenecientes al herbario de Arnott depositado en GL. Según su criterio el primer ejemplar correspondía a $V$. lobata (al que define como lectotipo) y el otro a $V$. valdiviana. Lo correcto es que dicha descripción se realizó en base a dos materiales diferentes, pero que correspondían a Cuming 571, depositados en distintos herbarios. Dados estos errores de Borsini, aquí se elige el ejemplar Cuming 571, depositado en K como lectotipo de Astrephia lobata $(=V$. lobata $)$.

Además en el presente trabajo se determina que el ejemplar tipo Cuming 571 depositado en $\mathrm{K}$, sobre el que Hooker y Arnott describieron en parte a Astrephia lobata, corresponde a V. crispa Ruiz et. Pav., por lo cual se considera que tanto Astrephia lobata como V. lobata son sinónimos de V. crispa Ruiz et Pav., por el principio de prioridad.

Observación 3: En el Herbario del Jardín Botánico de New York (NY) se registra como posible ejemplar TIPO de Valeriana crispa a un ejemplar de $V$. crispa Hook. \& Arn. (interpretado como V. crispa Ruiz \& Pav.), que no se ajusta a la descripción de la especie. Por otro lado al no encontrarse el material en el cual Ruiz y Pavón basaron la descripción original de $V$. crispa, se designa aquí un neotipo que corresponde al ejemplar de Philippi 995a. En el caso de Valeriana excelsa ante la pérdida total del material original se designa aquí un neotipo, el cual corresponde al ejemplar Looser 2088.

Material adicional examinado: ARGEnTINA. Neuquén. Dpto. Lácar: PN Lanín, Sección Ñorquinco, cascada al O, Cusato 2966 (BAA). CHILE. IV Región de Coquimbo. Limarí. Las Cardas, $30^{\circ} 18^{\prime} \mathrm{S}, 71^{\circ} 16^{\prime} \mathrm{W}, 500$ m s.m., IX-1950, Jiles 1865 (CONC 54325); Limarí. Parque Nacional Fray Jorge, $30^{\circ} 40^{\prime} \mathrm{S}, 71^{\circ} 40^{\prime} \mathrm{W}, 500 \mathrm{~m}$ s.m., XI-1974, Marticorena et al. 524 (CONC 54188); Limarí. Fray Jorge, $30^{\circ} 40^{\prime} \mathrm{S}, 71^{\circ} 40^{\prime} \mathrm{W}, 450 \mathrm{~m}$ s.m., IX-1960, Schlegel 2846 (CONC 54323); Limarí. Bosque Fray Jorge, $30^{\circ} 40^{\prime} \mathrm{S}, 71^{\circ} 40^{\prime} \mathrm{W}, 450$ m s.m., X-1970, Castillo s.n. (CONC 108275). V Región de Valparaíso. Petorca. Panamericana, $4 \mathrm{~km}$ antes Puente Guaquen, $32^{\circ} 22^{\prime} \mathrm{S}$, 71²4'W, 5 m s.m., X-1971, Marticorena et al. 1272 (CONC

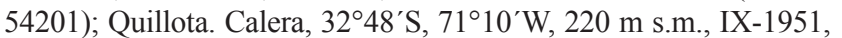
Kunkel 2438 (CONC 108244); Valparaíso. El Olivar, Parque Fauna, $33^{\circ} 02^{\prime} \mathrm{S}, 71^{\circ} 30^{\prime} \mathrm{W}, 150 \mathrm{~m}$ s.m., IX-1987, Poblete 106 (CONC 89015); Valparaíso. Laguna Verde, $33^{\circ} 03^{\prime} \mathrm{S}, 71^{\circ} 42^{\prime} \mathrm{W}, 120 \mathrm{~m}$ s.m., X-1972, Zoellner 6363 (CONC 108248); Valparaíso. Curauma, $33^{\circ} 08^{\prime} \mathrm{S}, 7^{\circ} 43^{\prime} \mathrm{W}, 35 \mathrm{~m}$ s.m., 10-XI-1929, K. Behn s.n. (CONC 21684); Valparaíso. Quintay, $33^{\circ} 10^{\prime} \mathrm{S}, 71^{\circ} 42^{\prime} \mathrm{W}, 10 \mathrm{~m}$ s.m., 11-X1943, K. Behn s.n. (CONC 21683). Región Metropolitana. Santiago.
Cajón del Arrayán, X-1859, Philippi s.n. (SGO 57081); Santiago. San Ramón, X-1879, (Herb. Philippi 991c) (SGO 43514); Santiago. Rinconada de Lo Cerda, 3329' S, 7053'W, 500 m s.m., XII-1961, Schlegel 4171 (CONC 54315); Santiago. Cerro Manquehue, ladera oeste de Quebrada Agua del Palo, $33^{\circ} 21^{\prime} \mathrm{S}, 70^{\circ} 35^{\prime} \mathrm{W}, 1700 \mathrm{~m}$ s.m., 9-XII-1976, Aguilera \& Elgueta s.n. (CONC 100276); Cordillera de Santiago. Cajón del Arrayán, X-1859, (Herb. Philippi 972) (SGO 57008). VI Región de O’Higgins. Cachapoal. Baños de Cauquenes, X-1877 (Herb. Philippi 963) (SGO 43477); Cachapoal. Baños de Cauquenes, s. col. (SGO 57007); Cachapoal. Termas de Cauquenes, Quebrada Huinganes, 34ำ $15^{\prime} \mathrm{S}, 7^{\circ} 34^{\prime} \mathrm{W}, 700$ m s.m., XI-1952, Pfister s.n. (CONC 13145); Colchagua. Camino Vegas del Flaco, Huertecillas, 3450’S, 70³3'W, 1100 m s.m., I-1951, Ricardi 1249 (CONC 10222). VII Región del Maule. Curicó. Andes de Curicó, XI1897, s. col. (SGO 57089); Talca. Constitución, 1-VIII-1899, s.col. (SGO 56987); Talca. Constitución, $35^{\circ} 20^{\prime} \mathrm{S}$, $72^{\circ} 25^{\prime} \mathrm{W}, 30 \mathrm{~m}$ s.m., VIII-1959, Barnier s.n. (CONC 108273); Constitución, 35²0’S, 72²5’W, 26-IX-1921, Baeza s.n. (CONC 108257). VIII Región del Bío-Bío. Ñuble. V-1902, Rivera s.n. (SGO 57091); Nuble. Río Chillán, 16-X-1902, s.col. (SGO 57110); Nuble. Río Chillán, 15-I-1903, s.col. (SGO 57102); Nuble. Río Chillán, 31-X-1903, s.col. (SGO 69601-69605); Concepción. Isla Quiriquina, 36³7'S, 7303 'W, 20 m s.m., 7-XI-1948, Pfister s.n. (CONC 8638-8648); Concepción. Lirquén, $36^{\circ} 43^{\prime} \mathrm{S}, 72^{\circ} 58^{\prime} \mathrm{W}, 15$ m s.m., 11-XII-1950, Ricardi s.n. (CONC 11070); Concepción. Desembocadura del Río Bío-Bío, 3648'S, 73¹0’W, 5 m s.m., 20-X-1976, Rodríguez 1100 (CONC 54309); Concepción. Rocoto, $36^{\circ} 48^{\prime} \mathrm{S}, 7^{\circ} 10^{\prime} \mathrm{W}, 30 \mathrm{~m}$ s.m., 15-XI-1967, Villarroel \& Weldt 108 (CONC 35089); Ñuble. Puente El Roble, en los Cerros, $36^{\circ} 45^{\prime} \mathrm{S}, 7^{\circ} 25^{\prime} \mathrm{W}, 64$ m s.m., 14-XI-1972, Igayman \& Muñoz s.n. (CONC 8648); Concepción. Desembocadura, Rocoto, 36 $48^{\prime} \mathrm{S}, 7^{\circ} 10^{\prime} \mathrm{W}, 30 \mathrm{~m}$ s.m., 16-I-1959, Marticorena et al. s.n. (CONC 25332); Concepción. Ramuncho, 3654'S, 73¹1 'W, 40 m s.m., 10-X-1939, K. Behn s.n. (CONC 21668). IX Región de la Araucanía. Cautín. Lautaro, $38^{\circ} 32^{\prime} \mathrm{S}, 72^{\circ} 26^{\prime} \mathrm{W}, 230$ m s.m., 10-XI1920, Hollermayer 309 (CONC 108122); Cautín. Temuco, Isla del Cautín, 3844'S, 72³3'W, 120 m s.m., 14-XI-1947, Gunckel 36601 (CONC 108265); Cautín. Nueva Imperial, $38^{\circ} 36^{\prime} \mathrm{S}, 72^{\circ} 51^{\prime} \mathrm{W}, 2-\mathrm{XII}-$ 1977, Montero 10543 (CONC 100853); Nueva Imperial, 38³6’S, 7251'W, 8-XII-1977, Montero 10772 (CONC 101075); Balseado Mancul, a $2 \mathrm{~km}$ de la ciudad Mancul, en borde de río, 3-XII-2008, Morrone 6090 (SI).

9. Valeriana descolei Borsini, in Descole, Gen. et Sp. Pl. Arg. 2: 239-341. 1944. TIPO: Argentina. Mendoza, Las Heras, Casa de Piedra, 2700 m s.m., 2-XI-1913, Sanzin 136 (holotipo, LIL; isotipo SI!).

Hierba perenne de 2-10 $\mathrm{cm}$ de alt, ramificada en la base. Tallos rizomatosos cubiertos de restos foliares. Hojas basales enteras, de hasta $5 \mathrm{~cm}$, espatuladas, lámina ovada, obovada u oblonga, nervadura media saliente en el envés, base asimétrica y atenuada hacia el pecíolo, borde entero, hirsuto-pubescentes o subglabras. Pecíolo con la cara superior cóncava, hirsuto-pubescente. Inflorescencias pequeñas, tallos floríferos cortos. Brácteas de 3,5-7 mm de largo, oblongas, concrescentes. Bractéolas de $2 \mathrm{~mm}$ de largo, oblongas, ovadas u obovadas. Flor hermafrodita: corola de 1-2,5 $\mathrm{mm}$, anchamente infundibuliforme, pubescente 
exteriormente; lóbulos oblongos, obtusos; estambres exertos; estigma papiloso. Flor femenina: corola de 1,5-2 $\mathrm{mm}$, campanulada; tubo con una pequeña giba en la mitad; lóbulos obtusos; estilo exerto; estigma recurvo. Fruto de 4-4,5 mm, claviforme, engrosado en el ápice, densamente hirsuto-pubescente, glanduloso en la base; cáliz de borde entero, no desarrollado en pappus plumoso.

ILUSTRACIONES: Borsini, 1944: tab. 147.

Características distintivas: Hierba perenne de pequeño porte; hojas basales espatuladas formando una roseta; la inflorescencia apenas supera la longitud de las hojas y el fruto es claviforme, de 4-4,5 mm, densamente hirsutopubescente, sin pappus plumoso.

Fenología: Florece de octubre a diciembre y fructifica en verano, enero y febrero.

DisTRIBUCIÓN Y HÁBITAT: Especie endémica de Argentina que habita en la provincia de Mendoza, entre los 2.500 y 3.000 m s.m.

Valeriana descolei es afín a $V$. nivalis y $V$. castellanosi (especies del norte de Chile y noroeste de Argentina, no incluidas en el presente estudio), de las cuales se diferencia por sus hojas espatuladas pero no ensanchadas en la base como las otras especies, por la inflorescencia capituliforme laxa y pauciflora y por su fruto que carece de pappus plumoso.

Material adicional examinado: ARGEnTINA. Mendoza. Dpto. Las Heras: La Crucesita, XI- 1936, Semper s.n. (Ruiz 4152); Entre Casa de las Piedras y Cumbres de los Altos Manantiales, 18-I1897, Kurtz 9329a (CORD); Quebrada del Toro, Cerro Pelado, 18/22-I-1897, Kurtz 9414 (CORD).

10.Valeriana dinorrhiza (Griseb.) Höck, in Engler, Bot. Jahrb. 3: 54. 1882. Phyllactis dinorrhiza Griseb., P1. Lorentzianae 113. 1874. TIPO: Argentina. Catamarca, Vayas Altas cerca de Belén, I-1872, Hieronymus 606 (isotipo, BA 42082!).

Hierba perenne de hasta $70 \mathrm{~cm}$ de alt., glabra, densamente ramificada desde la base. Rizoma de 2,5-5 cm diám., carnoso, simple o ramificado, cubierto con restos foliares. Tallos tetrágonos, fistulosos. Hojas basales enteras, hasta 20 x 2-3 cm; láminas espatuladas o lanceoladas, atenuadas en un pecíolo más corto, igual o más largo que el limbo. Hojas superiores de 2,5-7 cm, lineares o lanceoladas, pilosas en las axilas, decusadas, membranáceas; sésiles o cortamente pecioladas. Inflorescencias en racimos espiciformes o glomeruliformes, discontinuas. Brácteas enteras, lanceoladas, base y márgenes glandulosos. Bractéolas de 2-6 mm, lineares, lanceoladas, oblongas, obtusas o irregularmente recortadas. Flor hermafrodita: corola de 2-3 mm, infundibuliforme-campanulada; lóbulos desiguales, ovados, glandulosos en la parte interna de todo el lóbulo o en las axilas; estambres exertos, insertos aprox. en la mitad de la corola; anteras ovoides; estigmas papilosos. Flor femenina: corola de 0,5$1 \mathrm{~mm}$, hipocrateriforme, giba pequeña en la base; estilo filiforme, exerto; estigmas 3, claviforme. Flor masculina: corola de 1,5-3 mm, anchamente infundibuliforme, lóbulos desiguales, obtusos, nerviación marcada, interiormente glandulosos; estambres exertos, anteras con tecas separadas por un conectivo ancho. Fruto de 1,5-2,5 $\mathrm{mm}$, triquetro, elipsoide, glabro; cáliz no desarrollado en pappus plumoso.

ILuSTRACIONES: Borsini, 1944: tab. 149.

CARACTERÍSTiCAS Distintivas: Raíz axilar robusta; tallos tetrágonos, simples, cubiertos con restos de pecíolos en forma de escamas; hojas basales en roseta, espatuladas o lanceoladas; hojas superiores lineares o lanceoladas; inflorescencias en racimos espiciformes o glomeruliformes, discontinuas; flores polígamo trioicas; fruto de 1,5-2,5 mm, triquetro, elipsoide, glabro; sin pappus.

FenOlogía: Florece de diciembre a enero, fructifica a fin de verano.

Distribución Y HÁBITAT: Especie endémica de Argentina, que se distribuye en las provincias de Catamarca, La Rioja, Salta y Tucumán, entre los 2.000-5.000 m s.m.

Valeriana dinorrhiza se asemeja a $V$. macrorhiza en la inflorescencia y el fruto que en ambas especies carece de pappus plumoso, y se diferencia por la mayor altura que alcanza la planta y las hojas que son estrechamente espatuladas o lanceoladas y membranáceas, mientras que en V. macrorhiza son espatuladas y carnosas.

Material adicional examinado: ARGENTINA. Catamarca. Dpto. Andalgalá: 9-II-1916, Jörgensen s.n. (SI). La Rioja. Sierra Famatina, 21-I-1928, Castellanos s.n. (BA). Salta. Pampa Grande, Spegazzini s.n. (LP); Laguna Seca, Cerro del Cajón, $4280 \mathrm{~m}$ s.m., 15-II-1914, Rodríguez 1370 (SI). San Juan. Cordillera de Colangüil, Quebrada del Salto, 16-I-1930, Pérez Moreau s.n. (BA). Tucumán. Dpto. Chicligasta: Estancia Las Pavas, Pto. El Bayo, 3200 m s.m., 12-III-1924, Venturi 3098 (SI); Estancia Santa Rosa, 4000 m s.m., 13-XII-1925, Venturi 4058 (SI); Estancia Las Pavas, 3200 m s.m., 5-XII-1926, Venturi 4695 (SI); Estancia Santa Rosa, 3300 m s.m., 12-I-1927, Venturi 4746 (SI); Dpto. Tafí: Sierras Calchaquíes, Peñas Azules, 3400 m s.m., 29-I-1933, Burkart 5302 (SI); km 82 camino Tucumán-Tafí del Valle-Santa María, $3700 \mathrm{~m}$ s.m., 26-II-1959, Diem 272 (SI); Sierras Calchaquíes, Cerro Bayo, alrededores del Refugio, 4200 m s.m.,15-III-1984, Gómez-Sosa \& Múlgura 201 (SI). 
11. Valeriana fonckii Phil., Anales Univ. Chile 85: 742. 1893-4. TIPO: Chile. Valdivia, Cordillera de Ranco, Huahuin, I-1887, Philippi s.n. (neotipo, designado aquí, SGO 43501!).

Valeriana crenata Phil., Anales Univ. Chile 85: 744. 1893-4. TIPO: Chile. Aisén, Portezuelo Los Mallines, entre los valles Simpson e Ibañez, 1300 m s.m., 25-I-1939, Von Rentzell 6148 (neotipo, designado aquí, SI!, isoneotipo SGO 117551!).

Hierba perenne de hasta $35 \mathrm{~cm}$ alt., muy ramificada; rizomatosa. Tallos fistulosos, paucifoliados, con pelos escasos. Hojas basales en roseta, enteras, hasta $8 \mathrm{~cm}$, espatuladas, márgenes enteros, paucidentados o festoneados, subcarnosas, encorvadas; pecíolo de $2,5 \mathrm{~cm}$. Hojas superiores sésiles, hasta $1 \mathrm{~cm}$, oblongas o lanceoladas, margen entero o dentado, con pelos más abundantes desde su parte media a la base. Inflorescencias terminales glomeruliformes, contraídas. Pedúnculos pubescentes. Brácteas de 6-9 mm, oblongo-lanceoladas. Bractéolas de 3,5-6 mm, oblongas o lanceoladas; brácteas y bractéolas pubescentes en su margen y parte basal. Flor hermafrodita: corola de 5,5$10 \mathrm{~mm}$, infundibuliforme o tubuloso-infundibuliforme, gibosa en la base, pubescente en su parte interna; lóbulos oblongos, interiormente papilosos. Filamentos estaminales pubescentes, exertos; anteras elipsoides; estigmas lamelados. Fruto unilocular de 5-6 x $3 \mathrm{~mm}$, elipsoide, glabro; pappus de $5 \mathrm{~mm}$, formado por $15-16$ setas plumosas.

ILUSTRACIONES: Borsini, 1944: tab. 129; 1999, 454.

CARACTERÍsticas Distintivas: Base leñosa; hojas basales y superiores enteras, espatuladas, subcarnosas, arqueadas en forma de hoz; en general presentan tres pares de hojas caulinares, sésiles, que se disponen de manera más o menos equidistante a lo largo del tallo. Inflorescencias terminales cortas; la corola de la flor hermafrodita es una de las de mayor tamaño entre las especies estudiadas; fruto de 5-6 x 3 mm, elipsoide, glabro; con pappus.

Fenología: Florece de diciembre a enero y fructifica en enero y febrero.

DistriBUCIÓN Y HÁBITAT: En Chile se distribuye en la Cordillera austral, desde Ñuble hasta Aisén (Regiones: VII, VIII, IX, XIV, X y XI); en Argentina, en las provincias patagónicas de Neuquén, Río Negro y Chubut. Habita entre los 1.100-2.300 m s.m., en zonas montañosas con vegetación arbustiva o en sectores boscosos altos y en praderas altoandinas.

Valeriana fonckii es afín a $V$. carnosa, de la cual se diferencia por sus rizomas tortuosos y tallos densamente ramificados; la consistencia, la forma arqueada de sus hojas y la disposición de las hojas caulinares. Además difiere por el tamaño grande de las flores y los estambres exertos en la flor hermafrodita.

Observación: El material utilizado por Philippi para describir a Valeriana fonckii en 1856 no fue encontrado, no existiendo holotipo, isotipos ni paratipos adjudicables a dicha especie. Cualquier ejemplar de Philippi en sus posteriores publicaciones no es parte del material original, por lo tanto el ejemplar citado por Philippi en Anales de la Universidad de Chile (1893-94, 85: 742) no debería considerarse holotipo. Resulta necesario entonces designar un neotipo, para lo cual se selecciona aquí al ejemplar de Philippi s.n. (SGO 43501).

En el caso de Valeriana crenata, la necesidad de designar un neotipo se fundamenta en la pérdida del material original. Se seleccionó como neotipo el ejemplar de Von Rentzell 6148 , que se ajusta a la descripción original de la especie.

Material adicional examinado: ARGENTINA. Chubut. Dpto Futaleufú: PN Los Alerces, Cerro Cocinero, refugio, 17-II-2003, Kutschker 180 (BCRU); Cordón Rivadavia, Cerro Huemules Sur, $42^{\circ} 48^{\prime} \mathrm{S}, 71^{\circ} 29^{\prime} \mathrm{W}, 1368$ m s.m., 16-III-2008, Kutschker 803 (BCRU). CHILE. Neuquén. Dpto. Aluminé: $23 \mathrm{~km}$ al N del lago Norquinco hacia Paso de Icalma, 18-II-1990, Correa et al. 10062 (BAB); Dpto. Huiliches: laderas del Volcán Lanín, 1300-1400 m s.m., 17-II-1974, Correa et al. 5676 (BAB); PN Lanín, Cerro Los Angeles. 20-II-1974, Correa 5828 (BAB); Dpto. Lácar: San Martín de los Andes, Chapelco Chico, 1750 m s.m., 22-I-1974, Gentili 146/147 (BAB); Cordón de Chapelco, refugio, 1750 m s.m., 12-I1977, Gentili s.n. (SI); Chapelco \pm 1800 m s.m., 4-II-1977, Crespo \& Giangualani 2073 (BAB); San Martín de los Andes, cordón Chapelco, 15-II-1979, Rossow et al. 234 (BAB); Cerro Chapelco, 22-I-1981, Rossow \& Gómez Cadret 477 (BAB); San Martín de los Andes, Cerro Chapelco, \pm 1700 m s.m., 26-I-1982, Rossow et al. 1489 (BAB); Cerro Chapelco, 17-XII-1985, Correa et al. 9379 (BAB); Dpto. Los Lagos: laguna Las Monjas, valle alto del arroyo Vinagre, 1550 m s.m., 5-III-1945, Diem 923 (BAB); Refugio filo Cerro Colorado al Cerro Tres Lagunas, 1600-1700 m s.m., 7-I1951, Diem 1766 (SI); PN Nahuel Huapi, refugio Cerro Colorado, 13-II-1953, Boelcke \& Correa 6866 (BAB); PN Nahuel Huapi, Cerro Colu Mahuida, entre Puerto Manzano y Lago Traful, nacimiento arroyo s/nombre, 14-II-1953, Boelcke \& Correa 6942 (BAB); PN Nahuel Huapi, nacientes arroyo Estacada, $1600 \mathrm{~m} \mathrm{~s}$. m., 24-II-1953, Boelcke \& Correa 7173 (BAB); Dpto. Norquín: Copahue, 2000 m s.m., 25-XII-1944, O’Donell 2156(SI); Copahue, Cerro al N de las termas, 12-I-1982, Rossow et al. 851 (BAB); Copahue, Cerro al sur de las termas, 12-I-1982, Rossow et al. 886 (BAB); Copahue, 18-II-1992, Rossow \& Gómez Cadret 4602 (BAB); Copahue, camino al Paso Copahue, 2100-2200 m s.m., 9II-1994, Ezcurra et al. 911 (BCRU); a 1 km de Copahue, hacia el este en dirección a Caviahue, 1-III-1994, Fortunato 4346 (BAB); Serranía al NO del pueblo de Copahue, ca. 2100 m s.m., 16-I-1995, Ezcurra 1281 (BCRU); Volcán Copahue, planicie cerca del camping de la Villa Copahue, 2300 m s.m., 18-I-1995, Chiapella et al. 605 (BCRU); Cerro Bayo, Villa La Angostura, Río Manso Inferior, 1500 m s.m., 20-I-1996, Núñez 175 (BCRU). Río Negro. PN Nahuel Huapi, Cerro López, 1700 m s.m., 13-III-1936, De 
Saint s.n. (SI 146); PN Nahuel Huapi, Río Ñireco, mallines superiores, 1650 m s.m., 12-I-1946, Boelcke 1856 (SI); PN Nahuel Huapi, Picada al Cerro Rigi, 11-I-1952, Boelcke \& Correa 5444 (SI; BAB); PN Nahuel Huapi, Paso de las Nubes, 14-I-1952, Boelcke \& Correa 5572 (SI; BAB); PN Nahuel Huapi, Cerro Tronador, 17-I-1952, Boelcke \& Correa 5638/5688 (SI); PN Nahuel Huapi, subida al Granito, 22-I-1952, Boelcke \& Correa 5916/5935/5950 (BAB, SI); PN Nahuel Huapi, Cerro Catedral, 12II-1955, Troncoso \& Bacigalupo s.n. (SI 18971); Bariloche, Cerro Tronador, 27-XII-1974, Rubulis s.n. (BCRU); Cerro Tronador, con lenga rastrera, 4-I-1975, Rubulis s.n. (BCRU); Cerro López, 20-II1981, Rossow \& Gómez Cadret 380 (BAB); Cerro López, 15-XII1986, Sánchez et al. 753 (BAB); Cerro López, 1720 m s.m., 1-III1993, Ferreyra 35 (BCRU); Cerro Meta, aprox. 1700 m s.m., pedrero orientación E, 22-XII-1993, Ezcurra et al. 715 (BCRU); Cerro Meta, ladera E, aprox. 1750 m s.m., 9-I-1994, Ferreyra 181 (BCRU); PN Nahuel Huapi, Cerro Catedral, refugio Frey, $1750 \mathrm{~m}$ s.m., 14-I-1994, Ferreyra \& Clayton 213 (BCRU); PN Nahuel Huapi, Cerro Tronador, aprox. 1850 m s.m., 23-II-1997, Ezcurra 2267 (BCRU; Cerro Catedral, refugio Frey, 1700-1800 m s.m., 22I-1998, Nuñez 201 (BCRU); PN Nahuel Huapi, Cerro Challhuaco, II-1998, Daniels s.n. (BCRU); Cerro Bonete, Laguna Azul, 1300 m s.m., 13-XII-1998, Grosfeld 558 (BCRU); Bariloche, Cerro Catedral, final del cablecarril, 1800 m s.m., XII-1999, Steccani s. n. (BCRU); Bariloche, Cerro López, I-2000, Puntieri s.n. (BCRU); Bariloche, Cerro Catedral, picada al refugio Frey, 29-XII-2000, Puntieri s.n. (BCRU). VII Región del Maule. Talca, Laguna de Maule, 36 $06^{\circ} \mathrm{S}, 70^{\circ} 30^{\prime} \mathrm{W}, 2000 \mathrm{~m}$ s.m., I-1943, H. Behn s.n. (CONC 6380, 121698, 21699). VIII Región del Bío-Bío. Nuble.

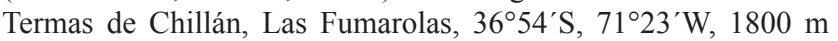
s.m., XI-1990, Taylor et al. 10295 (CONC 123314); Termas de Chillán, 365 $54^{\prime} \mathrm{S}, 7^{\circ} 24^{\prime} \mathrm{W}, 2000$ m s.m., I-1940, Pfister s.n.

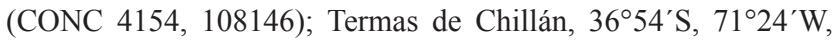
2000 m s.m., I-1945, Pfister s.n. (CONC 4160); Termas de Chillán, Valle de las Nieblas, $36^{\circ} 54^{\prime} \mathrm{S}, 71^{\circ} 31^{\prime} \mathrm{W}, 1950 \mathrm{~m}$ s.m., I-1945, Pfister s.n. (CONC 4163); Camino Termas de Chillán, Valle de las Nieblas, 3654'S, 71³1'W, 2000 m s.m., XI-1990, Von Bohlen 1030 (CONC 131364). IX Región de la Araucanía. Malleco. Termas Río Blanco, 38³4'S, 71³4’W, 1300 m s.m., I-1935, Montero 2052 (CONC 101093); Termas Río Blanco, 38³4’S, 71³4’W, 1700 m s.m., I-1938, Montero 3673 (CONC 101097); Termas Río Blanco, Cerro El Sapo, 38³5'S, 71³7’ W, 1680 m s. m., I-1948, F. Behn s.n. (CONC 7926); Paso Pino Hachado, límite chileno-argentino, $38^{\circ} 39^{\prime} \mathrm{S}, 70^{\circ} 54^{\prime} \mathrm{W}, 1900$ m s.m., I-1977, Marticorena et al. 1411 (CONC 45785); Cautín. Volcán Llaima, $38^{\circ} 41^{\prime} \mathrm{S}, 71^{\circ} 46^{\prime} \mathrm{W}, 1950 \mathrm{~m}$ s.m., I-1995, A. Marticorena et al. 330 (CONC 132795); Paso Pino Hachado, ladera exposición sur, 3840’S, 7054'W, 1920 m s.m., I-1996, A. Marticorena et al. 403 (CONC 135271); Volcán Llaima, Refugio andino, 38 $41^{\prime} \mathrm{S}$, 7148’W, 2000 m s.m., I-1942, Montero 4471 (CONC 101095);

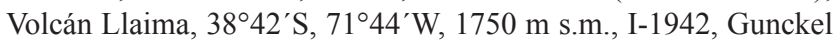
12262 (CONC 108134); Volcán Llaima, 3842’ S, 7144’ W, 1300 m s.m., I-1942, Gunckel 12356 (CONC 108123); Volcán Llaima, $38^{\circ} 42^{\prime} \mathrm{S}, 7^{\circ} 44^{\prime} \mathrm{W}, 950$ m s.m., I-1942, Gunckel 12387 (CONC

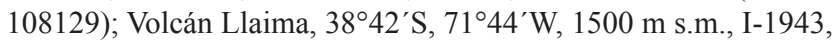
Gunckel s.n. (CONC 108143); Cautín. Parque Los Paraguas,

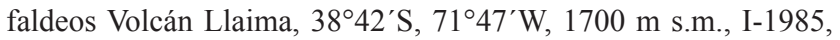
Matthei \& Quezada 170 (CONC 64678); Refugio del Volcán Llaima, 38² $43^{\prime} \mathrm{S}, 71^{\circ} 43^{\prime} \mathrm{W}, 1500 \mathrm{~m}$ s.m., I-1946, Reinicke s.n.

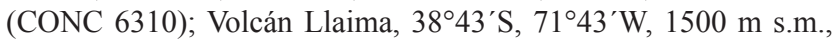

III-1954, Sparre \& Constance 10648 (CONC 17521); Volcán Llaima, 38 $43^{\prime}$ S, $71^{\circ} 43^{\prime} \mathrm{W}, 550 \mathrm{~m}$ s.m., XII-1953, Smith \& Sparre 224 (CONC 17519); Volcán Llaima, 3843’S, 7143’W, I-1937, Hollermayer 412 (CONC 108124); Volcán Llaima, 3843'S, 71²43'W, 1500 m s.m., II-1956, Montero 4901 (CONC 101094); Volcán Llaima, Refugio Forestal, 3843'S, 71 ${ }^{\circ} 43^{\prime} \mathrm{W}, 1500$ m s.m., I-1972, Montero 8609 (CONC 101096); Cautín. Volcán Villarrica, $39^{\circ} 25^{\prime} \mathrm{S}, 7^{\circ} 57^{\prime} \mathrm{W}, 1300 \mathrm{~m}$ s.m., I-1935, Pfister s.n. (CONC 126); Volcán Villarrica, 39²5'S, 7157’W, 1200 m s.m., I-1948, Pfister s.n. (CONC 8165); Curacautín, Río Blanco, 1300 m s.m., 9-I-1935, Montero s.n. (SGO 57010); Malleco. Tolhuaca, s.col. (61120); Cautín. Refugio de El Llaima, 30-XI-1971, Beckett et al. 4346 (SGO 110157); Cautín. Ribera Río Cautín, E de Temuco, Montaldo y Seeger 362 (SGO 113051). XIV Región de Los Ríos. Valdivia, Krause s.n. (SGO 43476); Andes de Valdivia, Pearce 71 (fot. K).). X Región de Los Lagos. Osorno. Cráter Volcán Antillanca, 40 $45^{\prime}$ S, $72^{\circ} 09^{\prime} \mathrm{W}, 1350$ m s.m., I-1961, Ricardi \& Matthei 5236 (CONC 26467); Cráter Volcán Antillanca, $40^{\circ} 45^{\prime} \mathrm{S}, 72^{\circ} 09^{\prime} \mathrm{W}$, 1350 m s.m., II-1967, Ricardi 5314 (CONC 54192); Osorno. Antillanca, $40^{\circ} 45^{\prime} \mathrm{S}, 72^{\circ} 09^{\prime} \mathrm{W}, 1300 \mathrm{~m}$ s.m., I-1954, Sparre \& Smith 372 (CONC 17520); Osorno. Parque Nacional Puyehue, Antillanca, $40^{\circ} 46^{\prime} \mathrm{S}, 7^{\circ} 12^{\prime} \mathrm{W}, 1250 \mathrm{~m}$ s.m., I-1988, Gardner \& Knees 3903 (CONC 107400); Antillanca, 4047'S, 72 ${ }^{\circ} 12^{\prime} \mathrm{W}, 1100$ m s.m., I-1954, Pfister s.n. (CONC 14559); Antillanca, $40^{\circ} 46^{\prime} \mathrm{S}$, $72^{\circ} 12^{\prime} \mathrm{W}, 1100$ m s.m., III-1976, Schlegel 6817 (CONC 44792); Antillanca, desde el Refugio hacia el límite de la vegetación, 24XI-1987, Meza \& Barrera 1529 (SGO 113527); Antillanca, 4045'S, 7209'W, 1350 m s.m., II-1991, Ruthsatz 7777 (CONC 135764); Llanquihue. Cerro Vichadero, Casa Pangue, $41^{\circ} 04^{\prime} \mathrm{S}$, $71^{\circ} 51^{\prime} \mathrm{W}, 1700 \mathrm{~m}$ s.m., I-1953, Pfister s.n. (CONC 13585); Llanquihue. Peulla, Rigi, $41^{\circ} 06^{\prime} \mathrm{S}, 72^{\circ} 02^{\prime} \mathrm{W}, 1250 \mathrm{~m}$ s.m., III1967, Zollitsch 261/285 (CONC 38570, 38569); Palena. Las Escalas, Futaleufú, $43^{\circ} 12^{\prime} \mathrm{S}, 7^{\circ} 50^{\prime} \mathrm{W}, \mathrm{I}-1997$, Hildebrand-Vogel 17 (CONC 141738). XI Región de Aisén. Aisén. Puyuhuapi, $44^{\circ} 21^{\prime}$ S, $72^{\circ} 34^{\prime} \mathrm{W}, 1200 \mathrm{~m}$ s.m., II-1940, Schwabe s.n. (CONC 21697-21700); General Carrera. Cerro Castillo, Río Ibáñez, $46^{\circ} 03^{\prime} \mathrm{S}, 72^{\circ} 08^{\prime} \mathrm{W}, 1200$ m s.m., II-1974, Gunckel 52601 (CONC 108240).

12. Valeriana graciliceps Clos in Gay, Hist. Chile, Bot. 3: 231. 1847. TIPO: Chile. Gay 1096 (lectotipo, designado por Borsini (1966: 422), $\mathrm{P}$, = fot. F 27189!; isolectotipo, fot. $\mathrm{K} !)$.

Valeriana lutescens Phil., Linnaea 28: 699. 1858. TIPO: Chile. Cordillera de Linares, I-1956, Germain s.n. (holotipo, SGO 56956!).

Hierba perenne hasta $70 \mathrm{~cm}$ alt., glabra; tallos jóvenes con nervaduras notables, cubiertas de pelos; de la parte inferior surgen numerosas ramas delgadas y rígidas hacia el ápice. Hojas basales enteras, hasta $3,5 \times 0,7 \mathrm{~cm}$, lanceoladas o angostamente oblongas; márgenes enteros o irregularmente dentados, carnosas. Hojas superiores de $2 \mathrm{~cm}$, lineares, lanceoladas. Inflorescencias laxas, paucifloras, largamente pedunculadas. Brácteas de 4-9 x 1-2 mm, lanceoladas. Bractéolas de 2-4, lineares. Flor hermafrodita: corola de 5-6 mm, infundibuliforme; lóbulos oblongos. Estambres inclusos. Estigmas lineares. Flor femenina: corola de 1,8-2 
$\mathrm{mm}$, tubuloso-campanulada; estilo exerto; estigma trífido. Fruto de 5-5,5 × $3 \mathrm{~mm}$, lageniforme, con lóculos estériles reducidos a esbozos en el ápice de la cara trinervada, glabro; pappus formado por 16-20 setas plumosas.

ILUSTRACIONES: Borsini, 1966: 460.

CARACTERísticasdistintivas:Plantasubleñosa, connumerosas ramas, delgadas, rígidas; hojas basales y superiores enteras, unidas en la base, lanceoladas, carnosas; inflorescencias laxas, con pocas flores, algunas dispuestas en el ángulo de la dicotomía; fruto de $5-5.5 \mathrm{~mm}$, lageniforme, escotado en la base, glabro; con pappus.

Fenología: Florece en diciembre y fructifica en verano, en enero y febrero.

DistRIBUCIÓN Y HÁBITAT: Se distribuye en las provincias centrales de Chile, en Coquimbo, Santiago y Linares (Regiones IV, V, M y VII). Habita en áreas montañosas.

Valeriana graciliceps no presenta afinidades claras con ninguna de las especies aquí analizadas.

Material adicional examinado: CHILE. IV Región de Coquimbo. Coquimbo. Cuncumen, I-1873, Landbeck s.n. (SGO 43441, 57033). V Región de Valparaíso. San Felipe. Laguna de Copiu, 32³6’S, 70³3’W, 3000 m s.m., II-1924, Joseph 2758 (CONC 108182); Los Andes. Los Maitenes, 3242’ S, 70²5'W, 2500 m s.m., XII-1965, Zoellner s.n. (CONC 108242). Región Metropolitana. Santiago. Las Condes, I-1880, Navarro s.n. (SGO 43497); Cordillera de Popeta, I-1881, s.col. (SGO 43440); Peñalolén, 2300 m s.m., 22-I-1928, Looser 861 (SI); Peñalolén, 2300 m s.m., 1-V-1929, Looser 883 (SI); Valle del Río Morales, cerca de Lago Valdés, 2500 m s.m., II-1936, Grandjot s.n. (SGO 57034); San José de Maipo, Cajón de Morales, 3350'S, 7008'W, 3000 m s.m., III-1921, Jaffuel 453 (CONC 54257); Cajón de Morales, 3350’ S, 7005’ W, 2200 m s.m. III/1953. Ricardi 2439 (CONC 13881); Cajón de Morales, 3350’S, $70^{\circ} 05^{\prime} \mathrm{W}, 2400$ m s.m., II-1963, Ricardi et al. 899 (CONC 54280); Cajón del Río Morales, 3330’S, 7000’W, 2750 m s.m., I- 1989, Saavedra \& Pauchard 236 (SGO 132859; CONC 127642); Cordillera

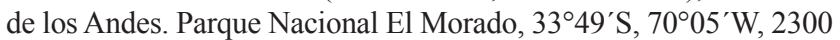
m s.m., 14-I-1991, Teillier et al. 2308 (SGO 132866); Cordillera de Las Arañas, XII-1854, Germain s.n. (SGO 57035); Cordillera

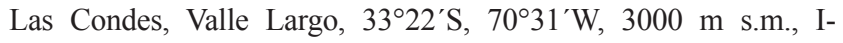
1934, Castillo s.n. (CONC 108172); Cordillera Abanico, 33²9'S, $70^{\circ} 27^{\prime} \mathrm{W}, 2300$ m s.m., XII-1928, Garaventa 1527 (CONC 48806); Lo Valdés, $33^{\circ} 48^{\prime} \mathrm{S}, 7^{\circ} 02^{\prime} \mathrm{W}, 3000$ m s.m., II-1936, Grandjot 1215 (CONC 108173); El Volcán, 3350’S, 7005’W, 2200 m s.m., I-1950, Muñoz s.n. (CONC 108175); San José de Maipo, Cajón de Morales entre Baños Morales y Las Panimávidas, 3348'S, 7004’W, 2000 m s.m., 22-XII-2001, Teillier \& Márquez 5260 (CONC 156616); Santuario de la Naturaleza Yerba Loca, ladera al SE del estero de la Yerba Loca, 2400 m s.m., 331' $6^{\prime}$ S, 70¹8'W, 15-II-1999, Kalin Arroyo \& Humaña 991851 (CONC 167197). VII Región del Maule. Linares. Laguna Dial, 36²5’S, 7055’W, 1520 m s.m., I-1961, Schlegel 3670 (CONC 54319).
13. Valeriana grandifolia Phil., Linnaea 28: 700. 1858. TIPO: Chile. Provincia de Concepción, Talcahuano, XII1856, Philippi s.n. (holotipo, SGO 56948!).

Hierba anual hasta $80 \mathrm{~cm}$ alt. Raíz axonomorfa, con ramificaciones gruesas en el cuello y raicillas filiformes. Tallos tetrágonos, con aristas aladas pilosas. Hojas basales enteras o divididas, de 4-15 x $4 \mathrm{~cm}$; las enteras de lámina oblonga, largamente peciolada; las divididas con 2-5 pares de folíolos de 2,5-10 x 1-4 mm, el terminal más desarrollado, oblongos, ovados, lanceolados o suborbiculares, base decurrente, márgenes sinuados o crenados, haz piloso; pecíolos hasta $12 \mathrm{~cm}$, de base dilatada. Hojas superiores enteras o partidas, con 2-3 pares de segmentos lanceolados, agudos. Inflorescencias muy desarrolladas, hasta $65 \mathrm{~cm}$. Brácteas de $2 \mathrm{~cm}$, oblongas, pubescentes. Bractéolas de 1,5-4 mm, oblongas $u$ ovadas, auriculadas en la base, pubescentes. Flor hermafrodita: corola de $2 \mathrm{~mm}$, campanulada, gibosa, exteriormente pubescente. Estambres inclusos. Flor femenina: corola de 0,8-1 mm, campanulada, pubescente; estilo exerto. Fruto de 1,2-1,5 mm; lóculo fértil plano convexo, densamente pubescente; los estériles bien desarrollados en la parte central del lóculo fértil, y separados por un surco, glabros; pappus formado por 11 setas plumosas.

ILUSTRACIONES: Borsini, 1966: 453.

CARACTerísticas distintivas: Hojas basales y superiores enteras o divididas, en este caso con el segmento terminal de mayor tamaño; inflorescencias muy desarrolladas; brácteas y bractéolas densamente pubescentes; fruto 3-locular, uno de los más pequeños dentro del género, elipsoide; lóculo fértil densamente pubescente y los estériles glabros, bien desarrollados; con pappus.

Fenología: Florece de octubre a diciembre y fructifica en verano, en enero y febrero.

DistRIBUCIÓN: Especie endémica de las provincias del centro y sur de Chile, desde Valparaíso hasta Araucanía (Regiones V, M, VII, VIII y IX).

Valeriana grandifolia se asemeja a $V$. valdiviana por los tallos tetrágonos y la forma de las hojas basales, y se diferencia en el fruto que presenta el lóculo fértil densamente pubescente y los lóculos estériles bien desarrollados, separados por un surco y glabros, mientras en $V$. valdiviana los lóculos estériles están reducidos a esbozos y presentan pubescencia rala. Se parece a $V$. hyalinorrhiza en la morfología del fruto.

Material adicional eXaminado: CHILE. V Región de Valparaíso.

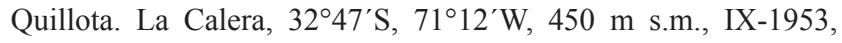


Kunkel s.n. (CONC 108168). Región Metropolitana. San Antonio de las Bodegas, IX-1833, s.col. (SGO 57082); Santiago. Las Vertientes, $33^{\circ} 35^{\prime} \mathrm{S}, 7^{\circ} 27^{\prime} \mathrm{W}, 890$ m s.m., IX-1951, Gunckel 24655 (CONC 108214). VII Región del Maule. Linares. La Mina, Camino al Melado, $35^{\circ} 51^{\prime} \mathrm{S}, 71^{\circ} 08^{\prime} \mathrm{W}, 1500 \mathrm{~m}$ s.m., XII-1953, Ricardi 2808 (CONC 14632); Reserva Nacional Bellotos del

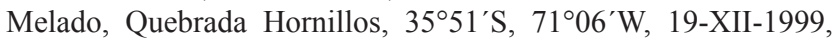
Kalin Arroyo et al. 994946 (CONC 149234); Reserva Nacional Bellotos del Melado, límite del Parque, $35^{\circ} 51^{\prime} \mathrm{S}, 71^{\circ} 07^{\prime} \mathrm{W}, 950 \mathrm{~m}$ s.m., 20-XII-1999, Kalin Arroyo et al. 996197 (CONC 149212). VIII Región del Bío-Bío. Bío-Bío. P.N. Laguna del Laja. Chacay, sector las chilcas, $37^{\circ} 23^{\prime} \mathrm{S}, 7^{\circ} 24^{\prime} \mathrm{W}, 1146 \mathrm{~m}$ s.m., 25-I-2001, Baeza et al. 3415 (CONC 155939); Concepción. Ranquil, Fundo el Milagro, 36 ${ }^{\circ} 41^{\prime} \mathrm{S}, 7^{\circ} 37^{\prime} \mathrm{W}, 200$ m s.m., XI-1953, Sparre 10054 (CONC 17531); Concepción. Boca del Bío-Bío, 36² $48^{\prime} \mathrm{S}, 73^{\circ} 10^{\prime} \mathrm{W}$, 5 m s.m., XI-1935, Pfister s.n. (CONC 3542); Concepción. Universidad de Concepción, 36 $49^{\circ} \mathrm{S}, 7^{\circ} 02^{\prime} \mathrm{W}, 100 \mathrm{~m}$ s.m., XI-1990, Taylor 10234 (CONC 123313); Concepción, 36²9'S, $7^{\circ} 03^{\prime} \mathrm{W}, 10$ m s.m., X-1922, Barros 920 (CONC 108207); Concepción, $36^{\circ} 49^{\prime} \mathrm{S}, 7^{\circ} 03^{\prime} \mathrm{W}, 10 \mathrm{~m}$ s.m., XII-1936, F. Behn s.n. (CONC 21666); Concepción. Nonguén, 36 $50^{\circ} \mathrm{S}$, $73^{\circ} 00^{\prime} \mathrm{W}$, 75 m s.m., XI-1953, Sparre 10013 (CONC 17530); Concepción. Quebrada Cerros La Toma y Buena Vista, 36 $50^{\prime} \mathrm{S}, 7^{\circ} 02^{\prime} \mathrm{W}$, 60 m s.m., 2-XI-1934, Junge s.n. (CONC 5190); Concepción. Hualqui, Pichaco, $36^{\circ} 55^{\prime} \mathrm{S}, 72^{\circ} 50^{\prime} \mathrm{W}, 200$ m s.m., X-1937, Junge s.n. (CONC 7764); Concepción. Cerro Caracol, 3650’ S, $73^{\circ} 02^{\prime} \mathrm{W}, 200$ m s.m., I-1941, F. Behn s.n. (21665); Concepción. La Toma, $36^{\circ} 50^{\prime} \mathrm{S}, 7^{\circ} 02^{\prime} \mathrm{W}, 100 \mathrm{~m}$ s.m., XI-1945, Junge s.n. (CONC 4904); Concepción. San Pedro, 3650’S, 7306’ W, 12 m s.m., XII-1946, Pfister s.n. (CONC 7111); Ñuble. Cordillera de Chillán, Atacalco, $36^{\circ} 53^{\prime} \mathrm{S}, 71^{\circ} 38^{\prime} \mathrm{W}, 650$ m s.m., I-1936, Pfister s.n. (CONC 7727); Termas de Chillán, 365 $54^{\prime} \mathrm{S}, 71^{\circ} 24^{\prime} \mathrm{W}, 2000$ m s.m., I-1940, Pfister s.n. (CONC 4155); Ñuble, Cerro Coiquén frente a Quirihue, cumbre en ladera sur, $900 \mathrm{~m}$ s.m., $36^{\circ} 18^{\prime} \mathrm{S}$, 72²8'W, 3-XII-1998, Matthei 679 (CONC 151723). IX Región de la Araucanía. Malleco. Mininco, 3747'S, $72^{\circ} 28^{\prime} \mathrm{W}, 190 \mathrm{~m}$ s.m. X1953, Kunkel 2441 (CONC 108188); Lumaco, 38 $10^{\circ} \mathrm{S}, 72^{\circ} 54^{\prime} \mathrm{W}$, 75 m s.m. X-1958, Kunkel 552 (CONC 108189).

14. Valeriana hebecarpa DC. Prodr. 4: 638. 1830. TIPO: Chile. Pico del Pilque, Andes Antucensis, I-1829, Poeppig 942 (holotipo, G, = fot. F 20545 ex M!).

Valeriana columbaria Phil., Anales Univ. Chile 85: 747. 1893-4. TIPO: Chile. Baños de Chillán, II-1872, King s.n. (holotipo, SGO 56965!).

Hierba perenne hasta $60 \mathrm{~cm}$ de alt., glabra, muy ramificada. Rizoma vertical, leñoso. Tallos tortuosos, tetrágonos, glabros o con pelos aislados. Hojas basales enteras, lámina de 1-6 cm, ovada o elíptica, márgenes marcadamente sinuados o lobados; papiráceas; pecíolos hasta $8 \mathrm{~cm}$, de base ensanchada y márgenes pubescentes. Hojas superiores pinnatisectas, segmentos oblongos, enteros o aserrados, sésiles. Inflorescencia paniculiforme de hasta $22 \mathrm{~cm}$, laxas. Brácteas de 4-20 mm y bractéolas de 2-4 mm, oblongas o lineares, auriculadas, con pelos simples y capitados. Flor hermafrodita: corola de $2 \mathrm{~mm}$, infundibuliformecampanulada, gibosa, con pelos dispersos en la parte externa e internamente, en la zona de inserción de los estambres. Filamentos estaminales subulados; anteras elipsoides. Flor femenina: corola de $1 \mathrm{~mm}$; lóbulos ovados. Fruto de 1-2 x 1 $\mathrm{mm}$, con un lóculo fértil y dos estériles reducidos a esbozos en su parte apical, angostamente elipsoide, densamente hirsuto; pappus formado por 10-12 setas plumosas.

ILustraciones: Borsini, 1966: 452; 1999: 457. Rossow, 1993: 7.

CARACTERÍSTICAS DISTINTIVAS: Hojas basales enteras, marcadamente sinuadas o lobadas, papiráceas; en general con pecíolos más largos que la lámina, hojas superiores pinnatisectas; inflorescencias hasta $22 \mathrm{~cm}$. Fruto pequeño, con esbozos de dos lóculos estériles en su parte apical, angostamente elipsoide, hirsuto; con pappus.

FenOlOGía: Florece en febrero y marzo.

Distribución: En Chile habita en la cordillera austral (Regiones VIII y IX), frecuente en la provincia de Nuble (Región VIII, Bío-Bío), entre los 1.100-2.000 m s.m.; en Argentina se la encuentra en la provincia de Neuquén, entre los 1000-1500 m s.m.

Valeriana hebecarpa es afín a $V$. laxiflora en cuanto a la morfología y la consistencia de las hojas basales, y se diferencia por el tallo tetrágono y por los frutos de menor tamaño y con una superficie densamente hirsuta.

Material adicional examinado: ARGENTINA. Neuquén. Dpto. Minas: Laguna Epulaufquen, primera terraza basáltica hacia Laguna Chaquira, 11-II-1990, Correa et al. 9916 (BAB); Laguna Epulaufquen, Laguna Negra, 14-II-1992, Rossow \& Gómez Cadret 4536 (BAB). CHILE. VIII Región del Bío-Bío. Ñuble. Baños de Chillán, II-1892, s.col. (SGO 57052); Termas de Chillán, 3654'S, 71²2'W, 2000 m s.m., 15-II-1931, Deltor 2074 (CONC 54264); Termas de Chillán, Valle de las Nieblas, 3654'S, 71³1 'W, 2000 m s.m., I- 1935, Pfister s.n. (CONC 3694; 4149; 7720); Termas de Chillán, $36^{\circ} 54^{\prime} \mathrm{S}, 71^{\circ} 24^{\prime} \mathrm{W}, 2000$ m s.m., III-1942, García s.n. (CONC 108250); Termas de Chillán, 36 $54^{\circ} \mathrm{S}, 71^{\circ} 24^{\prime} \mathrm{W}, 1600 \mathrm{~m}$ s.m., I-1945, Pfister s.n. (CONC 4162); Camino Termas de Chillán, Gruta Los Pangues, 3656'S, 71²7'W, 1200 m s.m., 7-XII-1992, Rodríguez \& Marticorena 3045 (CONC 135088); Nuble. Yungay, Fundo Baquedano - Santa Lucia, $37^{\circ} 05^{\prime} \mathrm{S}, 71^{\circ} 38^{\prime} \mathrm{W}, 1200 \mathrm{~m}$ s.m., II-1957, Artigas s.n. (CONC 19579); Ñuble, desde la Reserva Nacional Nuble a Yungay, salida del túnel, $1210 \mathrm{~m} \mathrm{s.m.,} 37^{\circ} 10^{\prime} \mathrm{S}$, 71³3'W, 18-II-2003, Mihoc et al. 7237 (CONC 164636); Bío-

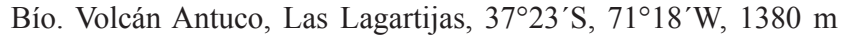
s.m., 19-II-1988, Stuessy \& Baeza 11056 (CONC 110423); Bío Bío, Parque Nacional del Laja, ladera del cerro, 1300 m s.m., $37^{\circ} 25^{\prime} \mathrm{S}, 7^{\circ} 26^{\prime} \mathrm{W}, 18-\mathrm{XI}-2001$, Mihoc 3163 (CONC 159222). IX Región de la Araucanía. Araucanía. Las Cuevas, II-1881, Sage s.n. (SGO 43463); Malleco. Ascenso a Termas de Río Blanco, 38³1'S,

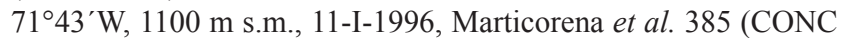
135269); Termas de Río Blanco, $38^{\circ} 34^{\prime} \mathrm{S}, 71^{\circ} 38^{\prime} \mathrm{W}, 1150 \mathrm{~m}$ s.m., I1948, Pfister s.n. (CONC 7882); Ascenso a Termas de Río Blanco, 
1100 m s.m., $38^{\circ} 31^{\prime} \mathrm{S}, 71^{\circ} 43^{\prime} \mathrm{W}, 11-\mathrm{I}-1996$, A. Marticorena et al. 385 (CONC 135269).

15. Valeriana hornschuchiana Walp., Nov. Act. Leop. Carol. 19, Suppl. 1: 357. 1843. TIPO: Chile. Cordillera de San Fernando, Meyen s.n. (holotipo, P, = fot. F 37111!)

Valeriana rotundiloba Clos in Gay, Hist. Fís. Polit. Chile, Bot. 3: 233. 1847. TIPO: Chile. 1839, Gay 1089 (lectotipo, designado por Borsini (1966: 410), P, = fot. F 37125!).

Valeriana bustillosii Phil., Linnaea 33: 104. 1864-5. TIPO: Chile. Cordillera de las Arañas, I-1861, Landbeck s.n. (lectotipo, designado por Borsini (1966: 410), SGO 56954 !).

Hierba perenne de hasta $50 \mathrm{~cm}$ alt., ramificada, glabra. Tallos tetrágonos, rugosos, a veces rojizos y cinéreos. Hojas basales enteras, hasta $4 \mathrm{~cm}$, o generalmente lirado-pinnatipartidas, con segmentos oblongo-lamceolados, ovados o suborbiculares, obtusos, disminuyendo gradualmente de tamaño hacia la base; márgenes enteros, sinuosos, lobados o crenulados; toda la hoja con pelos cortos glandulosos, subcarnosa. Hojas superiores pinnatisectas, segmentos lanceolados, lineares $\mathrm{u}$ oblongos. Inflorescencias axilares y terminales, laxas o contraídas. Brácteas de 4-5 mm, lanceoladas. Bractéolas de 3-4 mm, lanceoladas o lineares. Pedúnculos florales, brácteas y bractéolas con pelos glandulosos. Flor femenina: corola de 2,2 $\mathrm{mm}$, campanulada, gibosa; ovario pubescente; estilo exerto. Fruto 2-2,5 x 1,5 mm, piriforme, papiloso, con pelos cortos en ambas caras; pappus formado por 6-8 setas plumosas.

ILUSTRACIONES: Borsini, 1966: 456.

CARACTERÍsticas Distintivas: tallos subleñosos, rugosos; hojas basales generalmete lirado-pinnatilobadas, 5-6 pares de segmentos polimorfos, que van disminuyendo de tamaño hacia la base; hojas superiores pinnatisectas, ambas cubiertas de pelos cortos glandulosos; fruto de 2-2,5 mm, piriforme, con pubescencia corta en ambas caras; con pappus.

FenOlogía: Florece en noviembre y diciembre, fructifica en enero y febrero.

DisTRIBUCIÓN Y HÁBITAT: En Chile se distribuye en cordilleras de las provincias centrales, entre los 1.220-2.800 m s.m. (Regiones: V, M, VI y VII); en Argentina se encuentra en las montañas de la provincia de Mendoza, habitando entre los 2.500-3.000 m s.m.

Valeriana hornschuchiana presenta hojas basales pinnatipartidas semejantes a $V$. clarionifolia, aunque los bordes de los segmentos en el primer caso son enteros. Se diferencia en los frutos que son más pequeños y con pubescencia corta en ambas caras.
Material adicional examinado: ARGENTINA. Mendoza. Burkart 14309a (SI); Sparre 1622 (LIL). CHILE. V Región de Valparaíso. Aconcagua, Stebb 9046 (SGO 140125). Región Metropolitana: Santiago. San José de Maipo, Cajón del Río Morales, 33³0’S, $70^{\circ} 00^{\prime} \mathrm{W}$, Saavedra \& Pauchard 238 (SGO 133140); Santiago. Fierro Carrera, $33^{\circ} 11^{\prime} \mathrm{S}, 70^{\circ} 20^{\prime} \mathrm{W}$, I-1930, Montero 1024 (CONC 101088); Fierro Carrera, $33^{\circ} 12^{\prime} \mathrm{S}, 70^{\circ} 14^{\prime} \mathrm{W}, 2800 \mathrm{~m}$ s.m., I-1930, Garaventa 519 (CONC 54278); Cordillera de Santiago, 3327' S, $70^{\circ} 40^{\prime} \mathrm{W}, 2700$ m s.m., III-1899, Reiche s.n. (CONC 121061); Santiago, Santuario de la Naturaleza Yerba Loca, lado NO de la vega de las Vacas, 2780 m s.m., 332'' S, 70¹6'W, 7-XI-1998, Kalin Arroyo \& Humaña 980630 (CONC 162930). VI Región. Colchagua. Junta Río Tinguiririca y Río del Azufre, 3449'S, 70³4’W, 1220 m s.m., III-1979, Villagrán \& Kalin Arroyo s.n. (CONC 55942). VII Región del Maule. Curicó. Camino Laguna Teno c/camino a Paso Vergara, km 6, 35 ${ }^{\circ} 10^{\prime} \mathrm{S}, 70^{\circ} 30^{\prime} \mathrm{W}, 2300 \mathrm{~m}$ s.m., III-1967, Marticorena \& Matthei 966 (CONC 54295).

16. Valeriana hyalinorrhiza Ruiz \& Pav., Fl. Peruv. et Chil. 1: 41, tab. 67. 1798. TIPO: Chile. Concepción, Ruiz \& Pavón s.n. (holotipo, MA, = fot. F 18244!).

Hierba perenne hasta $40 \mathrm{~cm}$ alt., hirsuto-pubescente. Rizoma fusiforme, carnoso, con numerosas raicillas. Tallo simple, tetrágono. Hojas basales hasta $6 \mathrm{~cm}$, enteras, espatuladas; o bien pinnatisectas, con segmento terminal más desarrollado, ovado, crenulado, los restantes segmentos de menor tamaño, oblongos, dentados; pelos hirsutos sobre la cara ventral de la lámina, cara dorsal glabra; membranáceas. Hojas superiores pinnatipartidas de 0,8-3,5 cm, atenuadas en la base o sésiles; pecíolo de 1-2 cm, pubescente. Inflorescencia alargada, contraída o laxa. Brácteas de 3-6 mm, partidas de ámbito oblongo, con segmentos lineares filiformes, pubescentes. Bractéolas de 2-3,5 mm, linear-oblongas, base ensanchada generalmente auriculada. Flor hermafrodita: corola de 2-3 mm, tubuloso-infundibuliforme; lóbulos ovados, obtusos u oblongos; estambres inclusos. Flor femenina: de $2 \mathrm{~mm}$, corola campanulada; lóbulos ovados; estilo exerto; estigma trífido. Fruto trilocular, de 2 x $1 \mathrm{~mm}$, lóculo fértil plano, hirsuto; lóculos estériles bien desarrollados, separados por un surco medio, glabros; pappus formado por 9-12 setas plumosas.

ILUSTRACIONES: Borsini, 1966: 465.

CARACTERísticas Distintivas: Tallo florífero tetrágono; hojas basales enteras, espatuladas a pinnatipartidas, lóbulo terminal más desarrollado, y hasta 4-5 pares de segmentos cuyos tamaños van disminuyendo hacia la base; cara dorsal glabra y ventral con pelos hirsutos; hojas superiores pinnatipartidas; inflorescencias alargadas; fruto con lóculo fértil hirsuto, lóculos estériles bien desarrollados, glabros; con pappus.

FenOlogía: Florece en septiembre, octubre y noviembre; fructifica en verano, en diciembre y enero. 
DistribuCiÓN Y HÁBITAT: Se encuentra en las provincias del centro y sur de Chile (Regiones V, M, VI, VII y VIII). Habita en zonas litorales, en llanos herbáceos o sitios arenosos, áridos.

Valeriana hyalinorrhiza es afín a $V$. grandifolia, de la cual se diferencia por ser una especie perenne, por la altura de la planta y el tallo tetrágono, y se asemeja especialmente en la morfología del fruto.

Material adicional eXAminado: CHILE. V Región de Valparaíso. Aconcagua. Catapilco, IX-1865, Philippi 987b (SGO 43438; 57028); Valparaíso, IX-1879, Philippi 978c (SGO 43445);

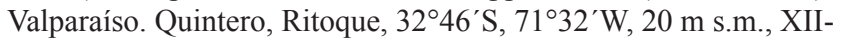
1959, Gunckel 37371 (CONC 108187); Valparaíso. Viña del Mar, detrás del cementerio, $33^{\circ} 02^{\prime} \mathrm{S}, 71^{\circ} 34^{\prime} \mathrm{W}, 20 \mathrm{~m}$ s.m., IX-1923, K. Behn s.n. (CONC 21673; 21675); Valparaíso. Camino a Laguna Verde, $33^{\circ} 05^{\prime}$ S, 71³9'W, 200 m s.m., X-1926, K. Behn s.n. (CONC 21672); Valparaíso. Placilla, $33^{\circ} 07^{\prime} \mathrm{S}, 71^{\circ} 35^{\prime} \mathrm{W}, 360$ m s.m., VIII1956, Schlegel 1131 (CONC 54316); Valparaíso. Viña del Mar, $33^{\circ} 09^{\prime} \mathrm{S}, 70^{\circ} 55^{\prime} \mathrm{W}, 230 \mathrm{~m}$ s.m., X-1933, K. Behn s.n. (CONC 108141). VI Región. Colchagua, Philippi 987a, (SGO 43437); Cachapoal. Rancagua, $34^{\circ} 10^{\prime} \mathrm{S}, 70^{\circ} 45^{\prime} \mathrm{W}, 500 \mathrm{~m}$ s.m., Joseph 4379 (CONC 108142); Cachapoal. Cocalan, $34^{\circ} 11^{\prime} \mathrm{S}, 71^{\circ} 14^{\prime} \mathrm{W}, 400 \mathrm{~m}$ s.m., XI-1913, Baeza s.n. (CONC 108246). VII Región del Maule. Talca. Constitución, XI-1891, s.col. (SGO 61676); Constitución, Maquehua, $35^{\circ} 23^{\prime} \mathrm{S}, 7^{\circ} 17^{\prime} \mathrm{W}, 125$ m s.m., IX-1921, Baeza s.n. (CONC 108247). VIII Región del Bío-Bío. Concepción, X-1890, s.col. (SGO 57055); Concepción. La Toma, 36 $6^{\circ} 50^{\prime} \mathrm{S}, 7^{\circ} 02^{\prime} \mathrm{W}$, 100 m s.m., X-1934, Junge 974 (CONC 108140).

17. Valeriana lapathifolia Vahl, Enum. Plant 2: 11. 1806. TIPO: Estrecho de Magallanes, Commerson s.n. (holotipo, P; isotipo, fot. MPU 12577!).

Valeriana parnasiifolia Sandw., in Hooker, Ic. Plant. tab. 3349. 1837. TIPO: Argentina. Neuquén, Santa Julia, cerca del Lago Huechulaufquen, 1500 m s.m., 24-XII-1926, Comber 895 (holotipo, fot. K!).

Valeriana cordata Griseb., Abh. Ges. Wiss. Göt., 38 (32). 1854. TIPO: Chile. Cordillera de Ranco, Lechler 780 (holotipo, CORD).

Valeriana cordata Phil., Linnaea 28: 697, 1858. TIPO: Chile. Al pie del Volcán Osorno, II-1852, Philippi s.n. (holotipo, SGO 56950!).

Valeriana andonaegui Phil., Anales Univ. Chile 41: 733. 1872. TIPO: Chile. Provincia Llanquihue, Monte Yate, al sur de Puerto Montt, 600 m s.m., 1871, Juliet s.n. (lectotipo, designado por Borsini (1966: 400), SGO 56943!).

Valeriana cordata Griseb. var. dentata Phil., Anales Univ. Chile 85: 742. 1893-4. TIPO: Chile. Provincia de Palena, I-1887, Delfin s.n. (holotipo, SGO 43478!).

Valeriana lindaviana Graeb., Bot. Jahrb. 26: 426. 1899. TIPO: Chile. Valdivia, Hueicolla, XI-1864, Philippi 993 (neotipo, designado aquí, SGO 43516!)

Hierba perenne hasta $1 \mathrm{~m}$ de alt., simple o ramificada, densamente foliada en la base. Rizoma horizontal de hasta aprox. $20 \mathrm{~cm}$, con varios nudos de los que nacen raíces fibrosas. Hojas basales hasta $20 \mathrm{~cm}$, enteras; láminas de 2-14 x 2-9 cm, ovadas, ovado-lanceoladas, oblongas o elípticas; de base recta, escotada o cordiforme; márgenes sinuados o brevemente crenulados; a veces con pelos cortos en toda su superficie; membranáceas, discolores; pecíolos de 4-12 $\mathrm{cm}$, gruesos, ensanchados en la base, pubescentes en sus márgenes y en la base. Hojas superiores hasta $10 \mathrm{~cm}$, oblongas o lanceoladas, por excepción divididas; sésiles o cortamente pecioladas. Inflorescencias hasta $30 \mathrm{~cm}$, contraídas, luego laxas y densifloras; pedúnculos pubescentes. Brácteas de 4-20 x 2-3 mm, oblongas. Bractéolas de 2,5-6 x 0,5-2 mm, lanceoladas, lineares. Brácteas y bractéolas con densos pelos rígidos en su base. Flor hermafrodita: corola de 3,5$5 \mathrm{~mm}$, infundibuliforme-campanulada, gibosa, pubescente; lóbulos oblongos; estambres exertos; ovario oblongo-lineal; estilo exerto; estigmas filiformes, papilosos. Flor femenina: corola de 1,5-2,5 mm, campanulada, gibosa, pubescente internamente en su parte basal; lóbulos ovados u oblongos obtusos; estilo exerto, estigmas lineares. Fruto de 3-4 x 1-1,5 mm, con un lóculo fértil y dos estériles incipientes, elipsoide, escotado en la base, glabro, con tres nervaduras marcadas; pappus formado por 11-16 setas plumosas.

ILUSTRACIONES: Borsini, 1944: tab. 132; 1999: 457.

CARACTERísticas distintivas: Hojas basales enteras, láminas muy desarrolladas, ovadas u ovado-lanceoladas, de base escotada o cordiforme, largamente pecioladas; hojas superiores oblongas o lanceoladas, por excepción divididas, en general sésiles. Hojas notablemente discolores en material de herbario. Inflorescencias, axilares y terminales, contraídas, pedúnculos pubescentes; fruto de 3-4 mm, con un lóculo fértil y dos estériles incipientes, elipsoide, glabro; con pappus.

FenOlogíA: Florece de diciembre a enero, fructifica en febrero y marzo.

DistRIBUCIÓN Y HÁBITAT: Habita en bosques húmedos del sur de Chile, desde Valdivia a Magallanes (Regiones XIV, X, XI y XII); en Argentina en las provincias patagónicas de Neuquén, Río Negro, Chubut y Santa Cruz, en sitios húmedos y sombríos, preferentemente asociada a bosques de lenga (Nothofagus pumilio). Fue recolectada por Gusinde en Tierra del Fuego (Skottsberg 1926), pero no ha sido encontrada posteriormente.

Nombre común y usos: Huahuilque, se señala el uso de esta especie contra la ictericia y catarros intestinales (Juliet 1962).

Valeriana lapathifolia es afín a $V$. chilensis en relación 
a la morfología del fruto, pero se distingue claramente de todas las valerianas por sus hojas membranáceas, discolores, enteras, ovadas y de base entera, escotada o cordiforme.

Observación: En el caso de Valeriana lindaviana la necesidad de designar un neotipo se fundamenta en la pérdida del material original. Se designa aquí como neotipo al ejemplar de Philippi 993.

Material adicional examinado: ARGentina. Chubut. Dpto. Cushamen: lago Esperanza, población Cárdenas, \pm 900 m s.m., 1II-1996, Johnson 629 (BAB); Dpto. Futaleufú: PN Los Alerces, Cerro Alto El Petiso, $42^{\circ} 42^{`}$ S, $71^{\circ} 45^{\prime} \mathrm{W}, 1083$ m s.m., 30-III-2008, Kutschker 812 (BCRU). Santa Cruz. Dpto. Lago Argentino: Lago Argentino, 1958/59, James 774/812 (SI); Lago Argentino, península de Magallanes, 230 m s.m., 15-II-1975, Boelcke et al. 16441 (BAB); PN Los Glaciares, glaciar Ameghino al Spegazzini, verano 1953, Perez Moreau s.n. (BAB); PN Los Glaciares, Lago Argentino, Cerro Mayo, verano 1953, Perez Moreau s.n. (BAB). Neuquén. Dpto. Los Lagos: PN Nahuel Huapi, Los Cántaros, 6-II1952, Boelcke \& Correa 5262 (SI; BAB); Camino a Paso Puyehue, \pm 1100 m s.m., 11-I-1970, Diem 3378 (BAB); Camino a Paso Puyehue, 1300 m s.m., 17-I-1975, Gentili 296 (BAB); Puerto Blest por Cascada Los Cántaros, 14-I-1957, Mazzucconi 1303 (BAB); Villa La Angostura, Cerro Bayo, 1400 m s.m., 20-I-1997, Núñez \& Daniels 162 (BCRU); Cerro Bayo, 20-I-1997, Daniels 44 (BCRU). Río Negro. Cerro Tronador entre Mallín Chileno y refugio, 18-I1952, Boelcke \& Correa 5750 (SI; BAB); PN Nahuel Huapi, Lago Felipe, 26-I-1952, Boelcke \& Correa 6058 (SI; BAB); Cerro Tronador, picada al paso de las Nubes, 980 m s.m., 15-I-1975, Rechencq s.n. (BCRU); Dpto. Bariloche: Puerto Blest, laguna Los Cántaros, 5-III- 1957, Boelcke \& Hunziker 7075 (BAB); Cascada Los Cántaros, picada, 20-XI-1986, Puntieri \& Brion s.n. (BCRU); Puerto Blest, 15-II-1990, Chiapella s.n. (BCRU); PN Nahuel Huapi, lago Frías a Los Clavos, 10-I-1953, Boelcke \& Correa 5406 (BAB); Lago Frías-Cascada La Hilda, 15-II-1948, Dawson \& Schwabe 2760 (BAB); Arroyo Castaño Overo, 2-I-1970, Eskuche 3377 (BAB); Cerro López, 20-II-1981, Gómez Cadret \& Rossow 361 (BAB); Bariloche. Pampa Linda, cerca de Tronador, $850 \mathrm{~m}$ s.m., 20-XII-1973, Rubulis s.n. (BCRU); Bariloche. Picada Salto Las Nalcas, 850 m s.m., 2-I-1975, Rechencq s.n. (BCRU). CHILE. XIV Región de Los Ríos. Valdivia. Pantanos en San Juan, I-1865, Philippi 992b (SGO 43482); Valdivia. Cordillera de Ranco, Cuesta de Ripeta, I-1887, Philippi 2157 (SGO 43495); Cordillera de Ranco, Pearce s.n. (SGO 57001); Cordillera de Ranco, Cuesta de Ripeta, I-1887, Philippi s.n. (SGO 56998); Chiloé. Castro, La Charca, orillas del Río Gamboa, 31-I-1929, Espinosa s.n. (SGO 57045); Chiloé, $30 \mathrm{~km}$ al N de Castro, 23-XI-1971, Beckett et al. 4287 (SGO 94902); Palena. Río Palena, 1885, Hirth s.n. (SGO 57004); Palena. Río Palena, I-II/1887, Delfin s.n. (SGO 43478; 57002; 57047); Península Huequi, Río negro o Melles hasta Laguna Soledad, 920 m s.m., 14-I-1993, Moreira Muñoz s.n. (SGO 128742); Antillanca, a $1 \mathrm{~km}$ desde el Refugio Antillanca hacia Aguas Calientes, 24-XI-1987, Meza \& Barrera 1542 (SGO 113540); Puyehue. Anticura, Salto El Indio, 25-XI-1987, Meza \& Barrera 1575 (SGO 113573); Valdivia. Volcán Quetrupillan, 39²9'S, 71²4' W, 1000 m s.m., III-1971, Oehrens 963 (CONC 108118); Valdivia. Trafún, $39^{\circ} 35^{\prime} \mathrm{S}, 71^{\circ} 47^{\prime} \mathrm{W}, 840$ m s.m., 4-I1969, Montaldo 4616 (CONC 108200); Valdivia. Paso Carririñe,
3948'S, $71^{\circ} 42^{\prime} \mathrm{W}, 1150$ m s.m., I- 1976, Marticorena et al. 641 (CONC 146190); Valdivia. Lago Riñihue, Enco, 3954’S, $72^{\circ} 10^{\prime} \mathrm{W}$, 270 m s.m., I-1957, Montero 5030 (CONC 100866); Valdivia. Volcán Choshuenco, 3956'S, 7204'W, 1100 m s.m., I-1928, Hollermayer s.n. (CONC 56456); Valdivia. Cordillera Pelada de Chaihuin, 39 $57^{\prime} \mathrm{S}, 7^{\circ} 28^{\prime} \mathrm{W}, 500$ m s.m., I-1932, Gunckel 3011 (CONC 108133); La Unión, Cordillera Pelada, al llegar a Hueicolla, 4009'S, 73³9'W, 200 m s.m., 12-XII-1979, Montero 11412 (CONC 100846); Cordillera Pelada, Barra del Río Bueno, $40^{\circ} 10^{\prime} \mathrm{S}$, $73^{\circ} 29^{\prime} \mathrm{W}$, $1000 \mathrm{~m}$ s.m., XII- 1931, Hollermayer 493 (CONC 108144); Cordillera Pelada, La Reina, $40^{\circ} 10^{\prime} \mathrm{S}, 73^{\circ} 29^{\prime} \mathrm{W}, 950 \mathrm{~m}$ s.m., X-1934, Hollermayer 684 (CONC 108156); Cordillera Pelada, de la Costa, $40^{\circ} 10^{\prime} \mathrm{S}, 73^{\circ} 29^{\prime} \mathrm{W}, 950$ m s.m., 30-XI-1934, Hollermayer 699 (CONC 101072); Valdivia. Llancacura, 40¹8' S, 73²4' 'W, 100 m s.m., 10-I-1962, Schlegel 4182 (CONC 54184). X Región de Los Lagos. Osorno. Paso Puyehue, $40^{\circ} 40^{\prime} \mathrm{S}, 71^{\circ} 58^{\prime} \mathrm{W}$, 1200 m s.m., 4-I- 1954, Sparre \& Smith 346 (CONC 17522); Osorno. Entre el refugio y Termas de Puyehue, $40^{\circ} 40^{\prime} \mathrm{S}, 72^{\circ} 10^{\prime} \mathrm{W}$, 1100 m s.m., II-1967, Ricardi 5335 (CONC 54291); Osorno. Parque Nacional Puyehue, 4046’ S, 72¹4’W, 900 m s.m., I-1988, Gardner \& Knees 3817 (CONC 107392); Osorno. Antillanca, $40^{\circ} 47^{\prime} \mathrm{S}, 72^{\circ} 12^{\prime} \mathrm{W}, 1100 \mathrm{~m}$ s.m., I-1954, Sparre \& Smith 391 (CONC 17523); Antillanca, $40^{\circ} 47^{\prime} \mathrm{S}, 72^{\circ} 12^{\prime} \mathrm{W}, 900 \mathrm{~m}$ s.m., III1985, Delgado \& Ramírez s.n. (CONC 65363); Antillanca, 4047S, $72^{\circ} 12^{\prime} \mathrm{W}, 1000 \mathrm{~m}$ s.m., III-1954, Sparre \& Constance 10789 (CONC 17524); Osorno. Parque Nacional Puyehue, $40^{\circ} 47^{\prime} \mathrm{S}$, $72^{\circ} 12^{\prime} \mathrm{W}, 1100$ m s.m., XII-1976, Rodríguez R. 1038 (CONC 54308); Osorno. Antillanca, $40^{\circ} 47^{\prime} \mathrm{S}, 72^{\circ} 13^{\prime} \mathrm{W}, 1100 \mathrm{~m}$ s.m., I1954, Pfister s.n. (CONC 14568); Osorno. Volcán Osorno, 41 ${ }^{\circ} 03^{\prime} \mathrm{S}$, $72^{\circ} 29^{\prime} \mathrm{W}, 1000$ m s.m., I-1971, Weldt \& Rodríguez 819 (CONC 35346); Cerro Vichadero, Casa Pangue, $41^{\circ} 04^{\prime} \mathrm{S}, 71^{\circ} 51^{\prime} \mathrm{W}, 1600$ m s.m., 14-I-1953, Pfister s.n. (CONC 13576); Volcán Osorno, La Picada, $41^{\circ} 05^{\prime} \mathrm{S}, 72^{\circ} 25^{\prime} \mathrm{W}, 1500$ m s.m., XI-1939, Gunckel 9375/9379 (CONC 108137/108212); Llanquihue. Peulla, 31-I1919, Hicken 276 (SI 22714); Peulla, Rigi, $41^{\circ} 06^{\prime} \mathrm{S}, 72^{\circ} 02^{\prime} \mathrm{W}$, 1250 m s.m., III-1967, Zollitsch 284 (CONC 54290); Peulla, $41^{\circ} 06^{\prime}$ S, $72^{\circ} 02^{\prime} \mathrm{W}, 190$ m s.m., 13-I-1953, Pfister s.n. (CONC 13550); Llanquihue. Volcán Calbuco, $41^{\circ} 20^{\prime} \mathrm{S}, 72^{\circ} 37^{\prime} \mathrm{W}, 1000 \mathrm{~m}$ s.m., II-1913, Horst s.n. (CONC 108132); Llanquihue, Volcán Yates, 1200 m s.m., III-1925, Werdermann 658 (SI); Lago de Todos los Santos, Cayutué, I-1922, Wolffhügel s.n. (SI 22712); Chiloé.

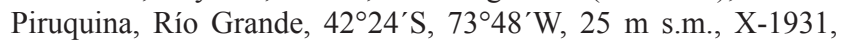
Junge 73 (108136); Chiloé. Tranque Río Gamboa, 42²8'S, $73^{\circ} 47^{\prime} \mathrm{W}, 100$ m s.m., 5-II-1957, Ricardi \& Marticorena 4008 (CONC 24556); Chiloé. Lago Río Negro, $42^{\circ} 42^{\prime} \mathrm{S}, 72^{\circ} 34^{\prime} \mathrm{W}, 200$ m s.m., I-1986, Villagrán et al. 6859 (CONC 76091); Chiloé.

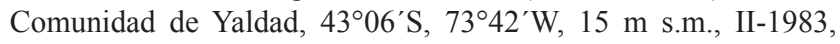
Villagrán 4851 (CONC 55785); Chiloé, Peruquina, Río Grande, 31-X-1931, Junge 73 (SI). XI Región de Aisén. Aisén. Valle Ibáñez, Bajada del Diablo, 540 m s.m., 25-I-1939, Von Rentzell 6141 (SI; SGO 117552); Aisén. Puyuhuapi. 0-200 m s.m., 1-XI-1947, H. Behn 38 (SGO 65493); Aisén. Quitralcó, 15-XII-1947, H. Behn 114 (SGO 65552; CONC 21691); Aisén. Laguna San Rafael, al pie de la montaña, cerca de cascada, al E del Hotel Laguna, 16-I-1959, Muñoz P. 6225 (SGO 119492); Aisén. Puerto Puyuhuapi, 44²0’ S, $72^{\circ} 32^{\prime} \mathrm{W}$, III-1940, Schwabe s.n. (CONC 10705); Puyuhuapi, $44^{\circ} 21^{\prime} \mathrm{S}, 72^{\circ} 34^{\prime} \mathrm{W}, 200 \mathrm{~m}$ s.m., 1-XI-1947, H. Behn s.n. (CONC

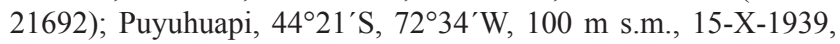
Schwabe 7 (CONC 21687); Aisén. Camino Coihaique a Puerto Aisén, $45^{\circ} 25^{\prime} \mathrm{S}, 7^{\circ} 30^{\prime} \mathrm{W}, 650 \mathrm{~m}$ s.m., XII-1954, Pfister s.n. 
(CONC 18518); Lago General Paz (Palena), 4-III-1909, Gerling s.n. (SI 14530); Aisén. Parque Laguna San Rafael, Río Exploradores,

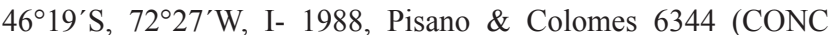
105270); Río Exploradores, $46^{\circ} 25^{\prime} \mathrm{S}, 7^{\circ} 20^{\prime} \mathrm{W}, 30 \mathrm{~m}$ s.m., III1967, Seki 295 (CONC 54311); San Rafael, 46² $40^{\prime} \mathrm{S}, 7^{\circ} 50^{\prime} \mathrm{W}$, 100 m s.m., II-1959, Schlegel 2134 (CONC 54183); Aisén. Parque Nacional Laguna San Rafael - Istmo de Ofqui, 46 ${ }^{\circ} 42^{\prime} \mathrm{S}, 7^{\circ} 06^{\prime} \mathrm{W}$, II-1988, Pisano 6314 (CONC 104548); Istmo de Ofqui, 1-II-1921, Hicken s.n. (SI 14547); Aisén. Laguna San Rafael, borde del Río Lucas, 12-II-1999, Teillier \& Márquez 4282 (CONC 149679). XII Región de Magallanes. Magallanes, laguna El Parrillar, 4-I-1977, Seibert et al. TBPA-fit. 2252 (BAB); Península Roca, seno Resi, 21-I-1978, Pisano TBPA-fit 2784 (BAB); Península Roca, 24-I1978, Pisano TBPA-fit 2871 (BAB); Puerto Toro, 18-I-1977, Moore \& Pisano TBPA-fit 1833 (BAB); Seno Unión, 12-I-1976, Boelcke et al. TBPA-fit 973 (BAB); Lago Porteño, sur del lago Toro, 15-XII-1975, Boelcke et al. TBPA-fit 609 (BAB); Provincia de Magallanes, ca. 15 km sur de Punta Arenas, 6-I-1939, Eyerdam et al. 24129 (SI); Cerro de la Última Esperanza, 10-II-1904, Hicken 95 (SI 22711); Punta Arenas, XII-1878, Philippi 993a (SGO 4351757048); Río de las Minas, 16-II-1908, Skottsberg 142/143 (BA 41787; SGO 58790); Dpto. Última Esperanza: Puerto Bella Vista, 13-I-1977, Moore \& Pisano TBPA-fit 1728 (BAB); Puerto Bella Vista, 5-XII-1979, Roig et al. TBPA-fit. 5117 (BAB); Última Esperanza. Fiordo Falcon, 49 40'S, 7350'W, XII-1988, Pisano 6512 (CONC 105271); Última Esperanza. Fiordo Peel, Río Murtillar, $50^{\circ} 27^{\prime} \mathrm{S}, 73^{\circ} 37^{\prime} \mathrm{W}$, XI-1985, Pisano 5932 (CONC 73087); Última Esperanza, 50³0’S, $74^{\circ} 00^{\prime} \mathrm{W}, 10 \mathrm{~m}$ s.m., XI1949, Magens 53 (CONC 11454); Última Esperanza. Parque Torres del Paine, Cerro Diente, 5047'S, $72^{\circ} 57^{\prime} \mathrm{W}, 550$ m s.m., XII-1985, Kalin Arroyo \& Squeo 850923 (CONC 86520); Última Esperanza. Parque Torres del Paine, Cerro Diente, 50 $47^{\prime} \mathrm{S}$, $72^{\circ} 57^{\prime} \mathrm{W}, 650$ m s.m., XII-1985, Kalin Arroyo \& Squeo 850925 (CONC 86490); Última Esperanza. Canal de las Montañas, 51 $1^{\circ} 38^{\prime} \mathrm{S}, 7^{\circ} 24^{\prime} \mathrm{W}, \mathrm{XI}-1987$, Pisano 6145 (CONC 104426); Última Esperanza. P. Muñoz Gamero, Bahía Año Nuevo, 52¹2'S, 73³2'W, XI-1983, Pisano \& Dollenz 5812 (CONC 137305); Última Esperanza. Parque Torres del Paine, Cerro Diente, $50^{\circ} 47^{\prime} \mathrm{S}$, 7257'W, 700 m s.m., I-1986, Kalin Arroyo \& Squeo 860093 (CONC 86794); Última Esperanza. Puerto Bella Vista, 51²8'S, 73¹6' W, I-1996, Pisano et al. 8395 (CONC 142776); Puerto Bella Vista, 51 $21^{\prime} \mathrm{S}, 7^{\circ} 16^{\prime} \mathrm{W}$, I-1996, Pisano et al. 8533 (CONC 142787); Magallanes. Punta Arenas, 20-I-1904, Hicken 5 (SI 14540); Magallanes, Río de las Minas, 20-II-1908, Skottsberg s.n. (SGO 58791; BA 41786); Magallanes. Punta Arenas, 5309' $\mathrm{S}$, 7055'W, 300 m s.m., 24-I-1936, H. Behn s.n. (CONC 21689);

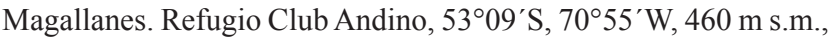
II-1949, Pisano 2161 (CONC 143810); Magallanes, Vegas de

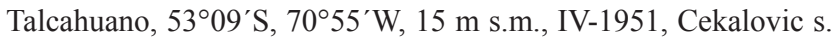
n. (CONC 108193); Magallanes, Isla Riesco, Río Palos, 5242’S, 7146’ W, 20 m s.m., 4-I-1952, Pfister \& Ricardi s.n. (CONC

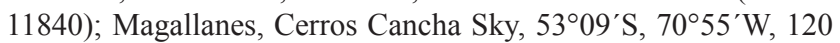
m s.m., 31-XII-1952, Pfister \& Ricardi s.n. (CONC 11725);

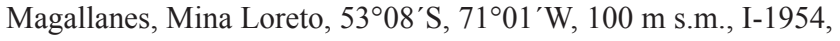
Magens 57 (CONC 108145); Magallanes, Estrecho de Magallanes,

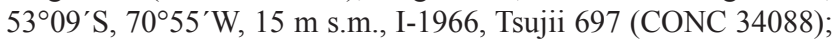
Magallanes, Puerto Gray, 48 $55^{\prime} \mathrm{S}, 7^{\circ} 20^{\prime} \mathrm{W}, 19-\mathrm{II}-1967$, Anliot

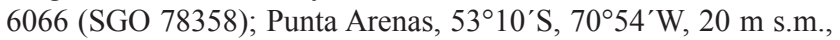
I-1951, Barrientos 26 (CONC 108128); Punta Arenas, Monte Fenton, $53^{\circ} 09^{\prime} \mathrm{S}, 71^{\circ} 03^{\prime} \mathrm{W}$, I-1952, Barrientos 323 (CONC

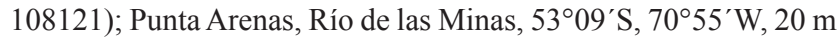
s.m., I-1952, Barrientos 324 (CONC 108157); Punta Arenas, Río Tres Puentes, 2-II-1921, Pastore 60 (SI); Magallanes, Río Caleta, Seno Otway, $53^{\circ} 14^{\prime} \mathrm{S}, 71^{\circ} 35^{\prime} \mathrm{W}, 10 \mathrm{~m}$ s.m., I-1979, Cárdenas 13 (CONC 141831); Magallanes, Los Tres Morros, 531' $8^{\prime} \mathrm{S}, 71^{\circ} 15^{\prime} \mathrm{W}$, 500 m s.m., II- 1974, Dollenz 182 (CONC 108202); San Nicolás, Península Brunswick, 5350`S, 71 ${ }^{\circ} 06^{\prime} \mathrm{W}$, XII-1971, Pisano 3262 (CONC 108197); Magallanes, Río Santa María, 60 km camino sur, 5340'S, 7059'W, II-1972, Pisano 3520 (CONC 137655);

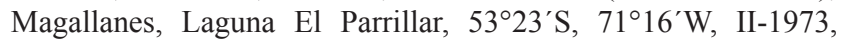
Pisano 3920 (CONC 137234); Magallanes. Bahía del Indio, Lote San Isidro, 5349'S, $71^{\circ} 02^{\prime} \mathrm{W}$, II-1973, Pisano 3990 (CONC 137574).

18. Valeriana laxiflora DC., Prodr. 4: 638. 1830. TIPO: Chile, partes altas de las montañas entre Pilque y Antuco, I-1829, Poeppig 825 (holotipo, G, = fot. F 20547 ex M!).

Valeriana rupicola Poepp. \& Endl., Nov. Gen. Spec. Pl. 3: 16, tab. 217. 1845.TIPO: Chile. Andes Antucensis, Pico de Pilque, III-1829, Poeppig s.n. (holotipo, G).

Valeriana laxiflora DC. var. cardaminifolia Poepp. \& Endl., Nov. Gen. Spec. Pl. 3: 17, tab. 218. 1845. TIPO: Chile, Poeppig s.n. (holotipo, G).

Valeriana sparsiflora Clos, in Gay, Hist. Chile, Bot. 3: 218. 1847. TIPO: Chile. Gay s.n. (holotipo, $\mathrm{P},=$ fot. $\mathrm{F}$ 37129 !).

Valeriana laxa Phil., Linnaea 28: 701. 1858. TIPO: Chile. Provincia de Ñuble, Cordillera de Chillán, XII-1855, Germain s.n. (holotipo, SGO 56935!).

Valeriana foliosa Phil., Linnaea 28: 698. 1858. TIPO: Chile. Provincia de Ñuble, Cordillera de Chillán, XII-1855, Germain s.n. (holotipo, SGO 56936!).

Valeriana lyrata Phil., Linnaea 33:103. 1864-65. TIPO: Chile. Provincia de Colchagua, Simons s.n. (holotipo, SGO 56937!).

Valeriana pearcei Phil., Linnaea 33:101-2. 1864-65. TIPO: Chile. Provincia de Valdivia, Andes de Ranco, Pearce s.n. (holotipo, SGO 56939!).

Hierba perenne de hasta $80 \mathrm{~cm}$ alt., simple o ramificada, densamente foliada en la base. Rizoma subleñoso con numerosas raicillas filiformes. Hojas basales enteras o pinnatilobadas de $20 \times 1,5-3,5 \mathrm{~cm}$; láminas oblongas, ovadas o elípticas, sinuadas, marcadamente nervadas, subglabras con pelos dispersos, a veces más notables en las nervaduras y márgenes; papiráceas; pecíolos hasta $7 \mathrm{~cm}$. Hojas superiores de $1.5-10 \mathrm{~cm}$, pinnatisectas o pinnatilobadas; segmentos oblongos u obovados. Inflorescencias laxas, con largos pedúnculos. Brácteas de 8-15 x $1 \mathrm{~mm}$, enteras, oblongo-lanceoladas o lineares, glabras. Bractéolas de 2,5-5 x $1 \mathrm{~mm}$, oblongo-lanceoladas o lineares. Flor hermafrodita: corola de 3,5-7 $\mathrm{mm}$, infundibuliforme-campanulada, gibosa; tubo arqueado, lóbulos oblongos; estambres inclusos; ovario elipsoide. Flor femenina: corola de 2,5-3 mm, campanulada, con 
giba notable; lóbulos oblongos; estilo exerto. Fruto de 5 x $2 \mathrm{~mm}$, lageniforme, ligeramente cóncavo-convexo, con lóculos estériles incipientes en la cara trinervada del fértil, glabro; pappus formado por 10-13 setas.

ILUSTRACIONES: Borsini, 1944: tab. 130; 1999: 457.

CARACTERÍSTICAS Distintivas: Hierba con numerosas hojas basales, cuya forma es muy variable de enteras a pinnatilobadas, marcadamente nervadas, papiráceas, color verde oscuro, brillantes; hojas superiores pinnatisectas; inflorescencias laxas, pedúnculos largos; fruto de $5 \times 2 \mathrm{~mm}$, lageniforme, arqueado, glabro; con pappus.

Fenología: Florece de noviembre a enero y fructifica en febrero y marzo.

DisTRIBUCIÓN Y HÁBITAT: Habita en las montañas del centro y sur de Chile desde Quillota a Coihaique (Regiones V, M, VI, VIII, IX, XIV, X y XI), entre los 100-2.000 m s.m.; en Argentina en las provincias de Neuquén, Río Negro, Chubut y Santa Cruz, entre los 0-1.800 m s.m.; crece en áreas boscosas densas, sombrías o en claros del bosque, en sectores cercanos a afloramientos rocosos.

Valeriana laxiflora es afín a $V$. hebecarpa, de la cual se diferencia por sus frutos de mayor tamaño, con lóculos estériles incipientes y superficie totalmente glabra.

Material adicional examinado: ARGentina. Chubut. Dpto. Futaleufú: RN N ${ }^{\circ} 258$, lago Futalaufquen, 26-XI-1983, Correa et al. 8966 (BAB); Región del Río Corcovado, Illín 126 (SI); PN Los Alerces, frente al lago Futalaufquen, 2-XII-1990, Correa et al. 10438 (BAB); PN Los Alerces, Cerro Cocinero, 27-III-2004,

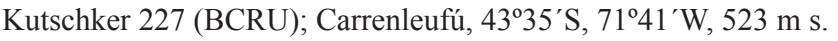
m., 20-III-2008, Kutschker 806 (BCRU). Neuquén. Quetrihué, 5XI- 1950, Diem 1652 (SI); Dpto. Aluminé: R.P. N 11, 23 km al N del lago Ñorquinco hacia paso de Icalma, 1800 m s.m., 17-II-1990, Correa et al. 10053 (BAB); RP N ${ }^{\circ} 11,23 \mathrm{~km}$ al N lago Norquinco hacia Paso de Icalma, 17-II-1990, Correa et al. 10050 (BAB); Dpto. Huiliches: PN Lanín, 21-II-1974, Correa et al. 5798 (BAB); Dpto. Lácar: lago Queñi, picada a los baños termales, 15-I-1984, Gómez Cadret et al. 2101 (BAB); lago Quillén, 25-XII-1947, Krapovickas 3736 (BAB 70533); Límite entre Dpto. Lácar y Los Lagos, Paso del Córdoba, 17-I-1984, Gómez Cadret et al. 2134 (BAB); cordón del Chapelco, 1500 m s.m., 2-I-1980, M. \& P. Gentili 849 (BAB); Dpto. Los Lagos: PN Nahuel Huapi, picada Los Cántaros, 6-I-1952, Boelcke \& Correa 5279 (SI; BAB); PN Nahuel Huapi, Isla Victoria, Laguna Mercedes, 2-XII-1951, Diem 1955 (BAB); Subida al Cerro de Los Angeles, 7-II-1948, Dawson \& Schwabe 2602 (BAB). Río Negro. PN Nahuel Huapi, valle Río Frías, 13-I-1952, Boelcke \& Correa 5548 (SI; BAB); PN Nahuel Huapi, picada Lago Manzano - Lago Martín, 28-I-1952, Boelcke \& Correa 6107 (SI; BAB); PN Nahuel Huapi, faldeo Cerro Santa Elena, 31-I-1952, Boelcke \& Correa 6220 (SI; BAB); Dpto. Bariloche: Cerro Otto, 3-I-1957, Mazzucconi 1188 (BAB); RN N ${ }^{\circ}$ 258, Cascada de La Virgen, 15-XII-1986, Gómez Cadret et al. 735
(BAB); PN Nahuel Huapi, Cerro López, 970 m s.m., 22-X-1949, Boelcke \& Hunziker 3326 (BAB); PN Nahuel Huapi, costa E del lago Gutiérrez, 28-X-1949, Boelcke \& Hunziker 3423 (BAB); Bariloche, Cerro Otto, ladera sur, picada hacia Villa Arelauquen en bosque de lenga, 13-II-1994, Chiapella \& Pillado 332 (BCRU); Bariloche, Bahía López, sobre pared de piedra, 29-X-1994, Brion \& Barthelemy s.n. (BCRU); Bariloche: Refugio Challhuaco, bosque de lenga, 11-II-1993, Ezcurra \& Clayton 612 (BCRU); Bariloche, Villa Pañil, XI-1990, Chiapella s.n. (BCRU); Bariloche, Puerto Blest, primer mirador cascada, 21-XI-1986, Brion \& Puntieri s.n. (BCRU); Bariloche. Llao Llao, costa del Lago Moreno, 800 m s.m., 11-X-1974, Rechencq s.n. (BCRU); Bariloche. Cerro Catedral, $A^{\circ}$ Casa de Piedra, 28-X-1973, Gómez s.n. (BCRU); Bariloche. Picada de las Nubes, 900-950 m s.m., 15-I1976, Rechencq s.n. (BCRU); Bariloche. Castaño Overo, 910 m s.m., 10-XI-1975, Rubulis s.n. (BCRU). Santa Cruz. Dpto. Magallanes: 20 km sur de San Julián, RN N³ 3, 21-XI-1963, Correa et al. 2688 (BAB). CHILE. V Región de Valparaíso. Quillota. Cerro Cruz, $33^{\circ} 06^{\prime} \mathrm{S}, 71^{\circ} 16^{\prime} \mathrm{W}, 900 \mathrm{~m}$ s.m., VIII-1928, Garaventa 1203 (CONC 54275). Región Metropolitana. Santiago. San Gabriel, Río Maipo, 3346'S, 70¹4’W, 1500 m s.m., X-1962, Schlegel 4412 (CONC 54314). VIII Región del Bío-Bío. Concepción. Fundo Collico, $5 \mathrm{~km}$ antes de Florida, 36 ${ }^{\circ} 49^{\prime} \mathrm{S}$, 7243'W, 230 m s.m., X-1976, Oehrens s.n. (CONC 54336); Nuble. Cordillera de Chillán, Shangri-La, $36^{\circ} 52^{\prime} \mathrm{S}, 71^{\circ} 30^{\prime} \mathrm{W}, 1500$ m s.m., XII-1992, Rodríguez y Marticorena 2937 (CONC 135058); Nuble. Chillán, Atacalco, 3653'S, 71³8' W, 650 m s.m., 6-I1935, Pfister s.n. (CONC 3596); Ñuble. Termas de Chillán, $36^{\circ} 54^{\prime} \mathrm{S}, 7^{\circ} 24^{\prime} \mathrm{W}, 2000 \mathrm{~m}$ s.m., 13-XII-1940, H. Behn s.n.

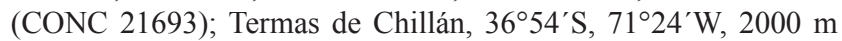
s.m., I-1940, Pfister s.n. (CONC 4253); Termas de Chillán, $36^{\circ} 54^{\prime}$ S, $71^{\circ} 24^{\prime} \mathrm{W}, 2000$ m s.m., XII-1930, Gulland s.n. (CONC

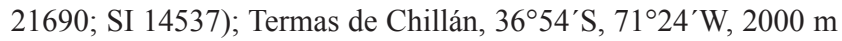
s.m., II-1931, Deltor 2004 (CONC 54262); Termas de Chillán, $36^{\circ} 54^{\prime} \mathrm{S}, 71^{\circ} 24^{\prime} \mathrm{W}, 2000$ m s.m., 20-II-1953, Pfister s.n. (CONC 13761); Termas de Chillán, Camino Garganta del Diablo, $36^{\circ} 54^{\prime} \mathrm{S}$, $71^{\circ} 27^{\prime} \mathrm{W}, 1200 \mathrm{~m}$ s.m., III-1966, Gleisner 155 (CONC 54335);

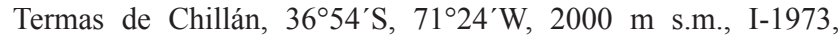
Zoellner 6257 (CONC 108229); Camino Termas de Chillán, refugio el aserradero, $36^{\circ} 55^{\prime} \mathrm{S}, 71^{\circ} 27^{\prime} \mathrm{W}, 1240 \mathrm{~m}$ s.m., XI-1986, Basualto et al. 145 (CONC 105519); Camino Termas de Chillán, Refugio Aserradero-cascada, $36^{\circ} 54^{\prime} \mathrm{S}, 71^{\circ} 28^{\prime} \mathrm{W}, 1300 \mathrm{~m}$ s.m., XII-1992, Rodríguez \& Marticorena 3032 (CONC 135087); Termas de Chillán, $36^{\circ} 54^{\prime} \mathrm{S}, 7^{\circ} 31^{\prime} \mathrm{W}, 1720$ m s.m., XII-1995, Godoy 332 (CONC 135498); Nuble. Nevados de Chillán, Pirigallo, 36 $55^{\prime} \mathrm{S}, \quad 71^{\circ} 24^{\prime} \mathrm{W}, 2000 \mathrm{~m}$ s.m., XII-1992, Rodríguez \& Marticorena 3006 (CONC 135048); Bío-Bío, Yungay, Fundo Baquedano-Santa Lucía, 3705'S, 71³8'W, 1200 m s.m., 4/9-II1957, Artigas s.n. (CONC 19577); Nuble, Sierra de Polcura, $37^{\circ} 15^{\prime} \mathrm{S}, 71^{\circ} 20^{\prime} \mathrm{W}, 1000 \mathrm{~m}$ s.m., 1-II-1972, Zoellner 5560 (CONC 108278); Bío-Bío, Parque Nacional Laguna del Laja, $37^{\circ} 25^{\prime} \mathrm{S}$,

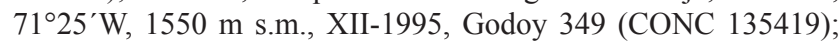
Arauco, Cordillera de Nahuelbuta, Reserva Forestal Pino Hachado,

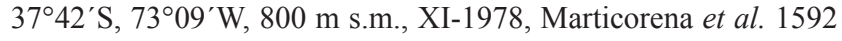
(CONC 54306); Arauco, Parque de Nahuelbuta, Laguna Las Totoras, $37^{\circ} 43^{\prime} \mathrm{S}, 7^{\circ} 02^{\prime} \mathrm{W}, 1250 \mathrm{~m}$ s.m., XI-1987, Baeza 23 (CONC 103124); Arauco, Cordillera de Nahuelbuta, Bajo Pino Huacho, $37^{\circ} 43^{\prime} \mathrm{S}, 7^{\circ} 06^{\prime} \mathrm{W}, 1270$ m s.m., XII-1982, Marticorena et al. 1717 (CONC 54050); Arauco, Parque de Nahuelbuta, $37^{\circ} 48^{\prime} \mathrm{S}, 7^{\circ} 01^{\prime} \mathrm{W}, 1460$ m s.m., I-1967, Montaldo 4397 (CONC 
108228); Cordillera de Nahuelbuta, Piedra del Aguila, $37^{\circ} 49^{\prime} \mathrm{S}$, $73^{\circ} 08^{\prime} \mathrm{W}, 1100 \mathrm{~m}$ s.m., 6-XII-1953, Smith \& Sparre 144 (CONC 17525); Parque de Nahuelbuta, Piedra del Aguila, $37^{\circ} 49^{\prime} \mathrm{S}$, $73^{\circ} 08^{\prime} \mathrm{W}, 1350$ m s.m., I-1968, Ricardi et al. 1979 (CONC 54203); Bío-Bío, Las Huellas, SE de Bío-Bío, 3756'S , 71³2’W, 1500 m s.m., I-1989, Marticorena \& Rodríguez 9983 (CONC 112766); Ñuble, Baños de Chillán, II-1862, s.col. (SGO 57088); Cautín, Lonquimay, Cord. Las Raíces, 2-III-1939, Burkart 9550 (SI); Ñuble, Montaña de Chillán, 1863, s.col. (SGO 56967); Bío-Bío, Río Bío-Bío, Valle Superior, s.col. (SGO 56989); Camino entre centro de ski Arenales Park y centro de ski Corralco, 27-XI-2008, Morrone 5981 (SI). IX Región de la Araucanía. Malleco, Tolhuaca, s.col. (SGO 61101); Malleco, Nahuelbuta, Volckmann s.n. (SGO 43450-43461); Malleco, PN Nahuelbuta. Cerro Anai, 1400 m s.m., 29-XI-1987, Meza \& Barrera 1590 (SGO 113588); Araucanía, Volckmann s.n. (SGO 56968); PN de Nahuelbuta, 3743'S, 7302'W, 1000 m s.m., XI-1964, Montero 6966 (CONC 100858); PN de Nahuelbuta, $37^{\circ} 43^{\prime} \mathrm{S}, 7^{\circ} 02^{\prime} \mathrm{W}, 1000$ m s.m., XII-1964, Montero 7018 (CONC 100857); Angol, PN de Nahuelbuta, 3743'S, 7302'W, 1400 m s.m., 6-XI-1981, Montero 12089 (CONC 101071); PN de Nahuelbuta, 37²4'S, 7302' W, $1250 \mathrm{~m}$ s.m., XII-1968, Ricardi \& Marticorena 5695 (CONC 54293); PN de Nahuelbuta, 3749'S, 72 58'W, 1200 m s.m., XII-1978, Rodríguez G. 263 (CONC 54304); Malleco, PN Contulmo, $38^{\circ} 00^{\prime} \mathrm{S}, 73^{\circ} 11^{\prime} \mathrm{W}, 150 \mathrm{~m}$ s.m., XII-1983, Matthei \& Quezada 94 (CONC 55866); Malleco, Tolhuaca, $38^{\circ} 14^{\prime} \mathrm{S}, 71^{\circ} 44^{\prime} \mathrm{W}, 1250 \mathrm{~m}$ s.m., I-1939, Pfister s.n. (CONC 108125); Malleco, Termas de Tolhuaca, $38^{\circ} 14^{\prime} \mathrm{S}, 71^{\circ} 44^{\prime} \mathrm{W}, 1250 \mathrm{~m}$ s.m., I-1939, Pfister s.n. (CONC 4152); Termas de Tolhuaca, Cerro Buena Vista, $38^{\circ} 14^{\prime} \mathrm{S}$, 7144’W, 1250 m s.m., XII-1956, Pfister s.n. (CONC 19209); Malleco, Paso de Lonquimay, $38^{\circ} 22^{\prime} \mathrm{S}, 71^{\circ} 34^{\prime} \mathrm{W}, 1600 \mathrm{~m}$ s.m., I1974, Zoellner 7678 (CONC 108227); Refugio Volcán Lonquimay, 38²5'S, 71³5'W, 1570 m s.m., XII-1995, Godoy 385 (CONC 135432); Malleco, Cordillera Las Raíces, LonquimayMalalcahuello, $38^{\circ} 26^{\prime} \mathrm{S}, \quad 71^{\circ} 29^{\prime} \mathrm{W}, 1560 \mathrm{~m}$ s.m., I-1977, Marticorena et al. 1289 (CONC 54195); Malleco, Camino a Lonquimay, Cordillera Las Raíces, $38^{\circ} 26^{\prime} \mathrm{S}, 7^{\circ} 29^{\prime} \mathrm{W}, 1300 \mathrm{~m} \mathrm{~s}$. m., I-1947, Pfister s.n. (CONC 7207); Malleco, Camino de Curacautín a Lonquimay, km 46, 38²7'S, $71^{\circ} 26^{\prime} \mathrm{W}, 1600$ m s.m., XII-1968, Ricardi \& Marticorena 5643 (CONC 54292); Malleco, $15 \mathrm{~km}$ camino Termas de Manzanares-Lonquimay, $38^{\circ} 28^{\prime} \mathrm{S}$, 71³2’W, 980 m s.m., XII-1967, Ricardi 5418 (CONC 32863); Malleco, Termas Río Blanco, 38³4'S, 71³4’W, 1200 m s.m., I1935, Montero 2039 (CONC 100859); Termas Río Blanco, 38³4'S, 71³4'W, 1060 m s.m., I-1975, Montero 9610 (CONC 100854); Malleco, Parque Nacional Galletué, $38^{\circ} 38^{\prime} \mathrm{S}, 71^{\circ} 25^{\prime} \mathrm{W}$, 1250 m s.m., I-1977, Marticorena et al. 1453 (CONC 54193);

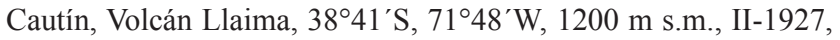
Werdermann 1278 (CONC 56360; SI); Cautín, China Muerta, $38^{\circ} 42^{\prime} \mathrm{S}, 71^{\circ} 31^{\prime} \mathrm{W}, 1800 \mathrm{~m}$ s.m., I-1958, Montero 5811 (CONC 100860); Cautín, Carahue. La Cabaña, 38²9'S, $71^{\circ} 14^{\prime} \mathrm{W}, 800 \mathrm{~m}$ s.m., XII-1972, Montero 8878 (CONC 100861); Cautín, Volcán Llaima, 3842'S, 7144'W, 1200 m s.m., I-1942, Gunckel 12285 (CONC 108115); Volcán Llaima, 1250 m s.m., I-1942, Gunckel

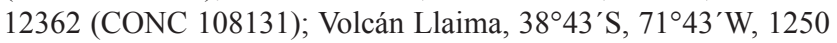
m s.m., 17-XII-1953, Smith \& Sparre 240 (CONC 17526); Volcán Llaima, refugio, $38^{\circ} 43^{\prime} \mathrm{S}, 71^{\circ} 43^{\prime} \mathrm{W}, 2000 \mathrm{~m}$ s.m., I-1942, Montero 4329 (CONC 100855); Volcán Llaima, 3843'S, 7143' W, $1250 \mathrm{~m}$ s.m., 14-III-1954, Smith \& Constance 10675 (CONC 17527); Cautín, Quebrada frente al refugio del Llaima, $38^{\circ} 43^{\prime} \mathrm{S}, 71^{\circ} 43^{\prime} \mathrm{W}$,
1450 m s.m., II-1956, Garaventa 5586 (CONC 54276); Cautín, Laguna Verde, Parque Nacional Huerquehue, $39^{\circ} 08^{\prime} \mathrm{S}, 71^{\circ} 43^{\prime} \mathrm{W}$, 1300 m s.m., XII- 1995, Godoy 415 (CONC 135462). XI Región de Aisén. Coihaique, Parque Nacional Trapananda, Reserva Mano Negra, 45²5'S, 7158'W, 900 m s.m., 8-III-1977, Schlegel 6977 (CONC 115628).

19. Valeriana lepidota Clos in Gay, Hist. Chile, Bot. 3: 230. 1847. TIPO: Chile. Provincia de Colchagua, Talcarague, II-1831. Gay s.n. (holotipo, P, = fot. F 37113 ! = fot. MO 1312387 !)

Valeriana colchaguensis Phil., Linnaea 33: 104. 1864-5. TIPO: Chile. Provincia de Colchagua. Landbeck s.n. (lectotipo, designado por Borsini (1966: 397), SGO 43499!)

Valeriana maipoana Rav., Onira 11 (13): 37. 2008. TIPO: Chile. Santiago, ladera N arriba del valle del Río Maipo, camino a Torrecillas del Manzano, XI-2006. Ravenna 5438 (holotipo, BAB; isotipo, SI 89816!)

Hierba perenne hasta $80 \mathrm{~cm}$ de alt. Tallos aéreos hojosos en la parte inferior, con pelos cortos en la base, glabros hacia el ápice. Hojas basales lobadas, liradas o pinnatipartidas, de 3,5-4 x $1 \mathrm{~cm}$, con el segmento terminal más desarrollado, ligeramente pubescentes, carnosas. Hojas superiores pinnatipartidas. Inflorescencias laxas, paucifloras. Brácteas de 7-9 mm, oblongas o lineares, frecuentemente auriculadas, márgenes con pelos glandulosos. Bractéolas de 3-4 mm, oblongas, ovado-lanceoladas u ovado agudas. Flor hermafrodita: corola de 2,5-3 mm, infundibuliforme; lóbulos oblongos; anteras elipsoides. Flor femenina: corola de 1,8-2 mm, campanulada, gibosa; lóbulos ovados o suborbiculares; estilo exerto; estigmas lamelados. Fruto de 3-3,8 x 2-3,5 mm, ovoide, aplanado, con nervaduras gruesas; lóculos estériles reducidos a esbozos en el ápice de la cara trinervada, glabro; pappus formado por 11-13 setas plumosas.

ILUSTRACIONES: Borsini, 1966: 463.

CARACTERÍSTICAS DISTINTIVAS: Hojas inferiores formando seudorosetas, lobadas, liradas, o pinnatilobadas, con el segmento terminal más desarrollado, carnosas. Hojas superiores pinnatipartidas o pinnatisectas. Inflorescencias laxas, paucifloras; fruto de 3-3,8 mm, ovoide, con bordes gruesos en la cara trinervada, glabro; con pappus.

Fenología: Florece en enero y fructifica a fin de verano.

DistriBUCiÓN Y HÁBITAT: Es endémica de las provincias centrales de Chile: Santiago y Colchagua (Regiones M y VI). Habita en zonas montañosas, entre los 1.000-2.300 m s.m.

Valeriana lepidota es afín a $V$. obtusifolia, de la cual se diferencia por su mayor altura, la inflorescencia pauciflora 
y el fruto que presenta los lóculos estériles reducidos a esbozos.

Material adicional examinado: CHILE. Región Metropolitana. Santiago, Cordillera de las Arañas, X-1856, s.col. (SGO 56986); Santiago, Cordillera de Las Arañas, XI-1861, Philippi 975 (SGO 43489); Santiago, Salto de agua, X-1879, Philippi 968a (SGO 43483); Santiago, Cordillera de Popeta, I-1881, Philippi s.n. (SGO 43484); Santiago, San Ramón, XI-1883, s.col. (SGO 56985); Santiago, Cordillera del Abanico, $33^{\circ} 29^{\prime} \mathrm{S}, 7^{\circ} 29^{\prime} \mathrm{W}, 2300 \mathrm{~m}$ s.m., XII-1928, Garaventa 204 (CONC 54271); Santiago, Cerro Abanico, $33^{\circ} 29^{\prime} \mathrm{S}, 7^{\circ} 29^{\prime} \mathrm{W}, 1800$ m s.m., XII-1949, Barros s.n. (CONC 108205); Santiago, San José de Maipú, Cajón del Río Morales, $33^{\circ} 30^{\prime} \mathrm{S}, 7^{\circ} 00^{\prime} \mathrm{W}$, Saavedra y Pauchard 274 (SGO 133139). VI Región de O'Higgins. Colchagua, Talcaragüe, s.col. (SGO 56966); Colchagua, Talcaragüe, Philippi 965b (SGO 43462).

20. Valeriana leucocarpa DC., Prodr. 4: 638. 1830. TIPO: Chile. Andes Antucensis, Sierra Velluda, I-1829, Poeppig 847 (holotipo, G, = Microfilm Prodr. 638.53!; fot. F 20546 ex M!).

Valeriana chubutensis Speg., Anales Mus. Nac. Buenos Aires 7: 279-298. 1902. TIPO: Argentina. Chubut, Carrenleufú, I-1900, Illin s.n. (holotipo, LP 11860!).

Hierba perenne de hasta $1 \mathrm{~m}$ alt., simple o ramificada en la base y densamente foliada. Rizoma horizontal, con numerosas raicillas. Tallos tetrágonos. Hojas basales enteras, hasta $20 \mathrm{~cm}$; láminas de 7-14 x 1-4 cm, oblongo-lanceoladas, márgenes ligeramente sinuados, atenuados en un largo pecíolo de 9-11 cm, membranáceas. Hojas superiores pinnatipartidas a pinnatisectas, de $6-9 \mathrm{~cm}$, cortamente pecioladas, crenuladas, pelos dispersos. Nudos y axilas de las hojas pubescentes, con pelos más abundantes en las hojas superiores. Inflorescencias de $50 \mathrm{~cm}$ aprox. Brácteas hasta 10 mm y bractéolas de $3 \mathrm{~mm}$, lineares o lanceoladas, auriculadas, con abundantes pelos hirsutos. Flor hermafrodita: corola de 1,5-3,5 mm, infundibuliforme-campanulada, tubo giboso en la base; estambres inclusos, anteras elipsoides. Fruto de 2-3 x 1,5-2 mm, elipsoide, nervaduras gruesas; lóculos estériles reducidos a esbozos incipientes, glabro; pappus formado por 10-12 setas plumosas.

Ilustraciones: Borsini, 1944: tab. 141 (sub. Valeriana chubutensis); 1966: 451; 1999: 459.

CARACTERÍSTICAS DISTINTIVAS: Hojas basales enteras, oblongolanceoladas, membranáceas; hojas superiores pinnatilobadas a pinnatisectas; nudos y axilas de las hojas pubescentes; inflorescencias contraídas de $\pm 50 \mathrm{~cm}$; fruto de $2-3 \mathrm{~mm}$, elipsoide, nervaduras gruesas, lóculos estériles incipientes, glabro; con pappus plumoso.

FENOLOGía: Florece de octubre a diciembre y fructifica en verano, en enero y febrero.
DiSTRIBUCIÓN Y HÁBITAT: Habita en cordilleras de las provincias del centro y sur de Chile, de Colchagua hasta Magallanes (Regiones VI, VIII, IX y XII); en Argentina en las provincias de Neuquén, Río Negro y Chubut, entre los 900 y 2.000 m s.m.

Valeriana leucocarpa se asemeja a $V$. borsinii, de la cual se diferencia por presentar frutos glabros.

Material adicional examinado: ARGEnTINA. Chubut: Río Aisén, XI-1900, Burmeister s.n. (BAB 5163); Laguna Blanca, verano 1903-04, Koslowsky s.n. (BAB 12481). Neuquén. Dpto. Huiliches: lago Tromen, laguna Escondida, 1000 m s.m., 28-XI1967, Schajovskoy s.n. (BAB); Dpto. Lácar: huella entre Hua Hum y lago Queñi, 22-XI- 1983, Correa et al. 8884 (BAB). Río Negro. Dpto. Bariloche: Mallín entrada Valle Castaño Overo, 17-XII-1975, Rechencq s.n. (BCRU); Bariloche, Mallín km 25, camino a Tronador, 14-V-1975, Rechencq s.n. (BCRU); Bariloche, Rápidos Río Alerce, 900 m s.m., 27-XI-1974, Rechencq s.n. (BCRU); Bariloche, Cerro Tronador, picada al paso de las Nubes, 900 m s.m., 16-I-1975, Rechencq s.n. (BCRU); Bariloche, Llao Llao, bosque de coihue cerca de Soria Moria, 26-I-1997, Chiapella \& Wardle s.n. (BCRU). CHILE. VI Región de O'Higgins. Colchagua, Cordillera de Colchagua, XII-1870, Landbeck s.n. (SGO 57026). VIII Región del Bío-Bío. Ñuble, Hotel en Termas de Chillán, $36^{\circ} 54^{\prime} \mathrm{S}, 71^{\circ} 24^{\prime} \mathrm{W}, 1600$ m s.m., XI-1990, Taylor et al. 10288 (CONC 123316); Nahuelbuta, Volckmann s.n. (SGO 57027-43432). IX Región de la Araucanía. Malleco, Parque de Nahuelbuta, sector Coimallin, $37^{\circ} 43^{\prime} \mathrm{S}, 73^{\circ} 02^{\prime} \mathrm{W}, 1250 \mathrm{~m}$ s.m., XI-1987, Baeza 37 (CONC 101257). XII Región de Magallanes. Última Esperanza, Fiordo Falcon, 49³3'S, 7350'W, XII-1988, Pisano 6482 (CONC 104532); Provincia de Magallanes, Isla Piazzi, Caleta Ocasión, 5144'S, $74^{\circ} 01^{\prime} \mathrm{W}, 17-\mathrm{I}-1976$, Dollenz et al. TBPA-fit. 1029 (BAB).

21. Valeriana macrorhiza DC., Prodr. 4: 635. 1830. TIPO: Phyllactis macrorhiza (DC.) Wedd. Chloris Andina 2: 33. 1859. TIPO: Chile. Andes Antucensis, Poeppig 918 (holotipo, G, = fot. F 20548 ex M!).

Betckea gilliesii Hook. \& Arn., Bot. Misc. 3: 366. 1833. Phyllactis gilliesii (Hook. \& Arn.) Wedd. Chloris Andina 2: 33.1859. Valeriana gilliesii (Hook. \& Arn.) Stuck. \& Briq., Ann. Conserv. Jard. Bot. Genève 20: 439.1919. TIPO: Argentina. Andes de Mendoza, Casa de Piedra, Gillies 192 (holotipo, fot. K!).

Phyllactis macrorhiza (DC.) Wedd. var. pumila Speg., Revista Fac. Agr. Univ. L.P. 3: 607. 1897. Valeriana macrorhiza DC. var. pumila Speg. Anales Mus. Nac. Buenos Aires 7: 299. 1902. TIPO: Argentina. Chubut, Carrenleufú, 1889, Moyano s.n. (holotipo, LP 11859!).

Hierba perenne hasta $25 \mathrm{~cm}$ alt. Rizoma grueso, carnoso. Hojas enteras, hasta $16 \mathrm{~cm}$, espatuladas; láminas de 3,515 x 1-4 cm, obovadas, márgenes enteros, membranáceas; pecíolos de 2-11 cm. Inflorescencias espiciformes, contraídas. Brácteas de $5 \mathrm{~mm}$, sésiles, enteras, oblongas o linear-oblongas. Bractéolas de 2-3 mm, oblongas obtusas. 
Plantas polígamo-trioicas. Flor hermafrodita: corola de 4,5-5 mm, infundibuliforme-campanulada, gibosa; lóbulos oblongos; estambres exertos; ovario oblongo. Flor femenina: pequeña, corola de $0,5-1,5 \mathrm{~mm}$, campanulada; estilo exerto. Flor masculina: corola de 2-2,5 mm, campanulada o infundibuliforme-campanulada; lóbulos oblongos, papilosos exteriormente; estambres exertos; anteras subglobosas o elipsoides. Fruto de 3,5-4 mm, elipsoide, lóculos estériles no desarrollados, glabro; cáliz no desarrollado en pappus plumoso.

ILUSTRACIONES: Borsini, 1944: tab. 147 (sub. Valeriana gilliesii); 1966: 469; 1999: 459.

CARACTERÍSTICAS Distintivas: Raíz fuertemente desarrollada, carnosa; hojas basales enteras, espatuladas, largamente pecioladas; inflorescencias espiciformes; fruto de 3,5-4 $\mathrm{mm}$, elipsoide, glabro; sin pappus plumoso.

Fenología: Florece de enero a febrero, fructifica a fin de verano.

DiSTRIBUCIÓN Y HÁBITAT: Habita en las provincias centrales y sur de Chile, en las cordilleras entre 1.600 y 2.500 m s.m. (Regiones VI, VII, VIII, IX y X). En Argentina en las provincias de Mendoza, Neuquén, Río Negro, Chubut y Santa Cruz entre los 1.500 y 2.700 m s.m. Crece en las zonas altas de las montañas, en planicies húmedas, vegas herbáceas o en pedregales altoandinos.

Valeriana macrorhiza se asemeja a $V$. dinorrhiza, $V$. munozii y $V$. ruizlealii en la morfología de las hojas que conforman una roseta basal y del fruto que en todas las especies carece de pappus plumoso. Asimismo presenta una inflorescencia espiciforme similar a $V$. ruizlealii.

Material adicional examinado: ARGENTINA. Mendoza. Valle del Yeso, 2000-2500 m s.m., 12-II-1900, Gerling s.n. (SI). Neuquén. Dpto. Minas: confluencia de los ríos Pichi-Neuquén y Neuquén, Cerro de Las Yeguas, 23-I-1970, Boelcke et al. 13789 (BAB); Sierra de Cochicó, Cajón de la Botica, 2500-2700 m s.m., 29-I1970, Boelcke et al. 14112 (BAB); Cajón vecino al Paso Portillo, 2000 m s.m., 31-I-1970, Boelcke et al. 14195 (BAB). Dpto. Norquín: Copahue $\pm 2 \mathrm{~km} O$ del camping, 18-II-1992, Rossow 4648/4659 (BAB); Copahue, serranía rocosa al O del pueblo, 2050-2150 m s.m., 8-II-1994, Ezcurra et al. 778/843/854 (BCRU); Copahue, camino al volcán, ca. 2250 m s.m., 9-II-1994, Ezcurra et al. 878/882 (BCRU); Serranía al NO del pueblo Copahue, ca. 2100 m s.m., 16-I-1995, Ezcurra et al. 1294 (BCRU); Río Negro. Dpto. Bariloche: Cerro Catedral, 2000 m s.m., III-1943, Soriano 197 (BAB); PN Nahuel Huapi, Cerro Meta, ladera S, 1790 m s.m., 14-III-1993, Ferreyra 132 (BCRU); Cerro Meta, ladera E, 1750 m s.m., 19-XII-1993, Ferreyra 160 (BCRU); Cerro Meta, 1700 m s.m., 22-XII-1993, Ezcurra et al. 723 (BCRU); PN Nahuel Huapi, Cerro Catedral, 1900 m s.m., 25-II-1997, Ferreyra \& Ezcurra 605 (BCRU); Bariloche, Cerro Catedral, próximo a terminación de cablecarril, aprox. 1800 m s.m., XII-1999, Puntieri s.n. (BCRU). Santa Cruz. Montañas altas al sur del Lago Buenos Aires, Río Zeballos, 16-XII-1908, Skottsberg s.n. (SGO 58787). CHILE. VII Región del Maule. Talca, laguna del Maule, 30-I-1963, Boelcke et al. 10349 (BAB); Talca, Paso Pehuenche, 3559'S, 70²4' W, 2450 m s.m., 30-I-1994, Villagrán et al. 8209 (CONC 129337); Curicó, Alrededores de Laguna de Teno, 35ำ' $10^{\prime} \mathrm{S}, 70^{\circ} 33^{\prime} \mathrm{W}, 2560$ m s.m., 29-III-1973, Marticorena et al. 10 (CONC 54189); Curicó, Laguna de Teno, 35² $10^{\prime} \mathrm{S}, 70^{\circ} 35^{\prime} \mathrm{W}, 2500 \mathrm{~m}$ s.m., II-1967, F. Behn

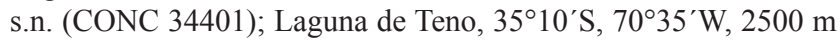
s.m., 10-III-1967, Marticorena \& Matthei 880 (CONC 31841); Linares, Valle Aguirre, $36^{\circ} 10^{\prime} \mathrm{S}, 70^{\circ} 32^{\prime} \mathrm{W}, 2300 \mathrm{~m}$ s.m., 20-I1961, Schlegel 3562 (CONC 54320). VIII Región del Bío-Bío. Chillán, Valle de las Aguas Calientes, 27-II-1862. s. col. (SGO 57020-43433); Baños de Chillán, XII- 1893, Valenzuela s.n. (SGO 43435); Nuble, Chillán, Sage s.n. (SGO 43434); Nuble, Termas de Chillán, Las Fumarolas y Valle de las Nieblas, 36 $54^{\circ} \mathrm{S}, 71^{\circ} 23^{\prime} \mathrm{W}$, 1800-2300 m s.m., 23-XI-1990, Taylor et al. 10294 (CONC 123315); Termas de Chillán, Nieblas, $36^{\circ} 54^{\prime} \mathrm{S}, 71^{\circ} 24^{\prime} \mathrm{W}, 2200 \mathrm{~m}$ s.m., III-1927, Werdermann 1324 (CONC 56378; SI); Nuble, Valle de Las Nieblas, 3654'S, 71²4'W, 1900 m s.m., 17-I-1991, De Vore 1478 (CONC 128674); Camino Termas de Chillán, Valle de Nieblas, 3654'S, 71³1'W, 2000 m s.m., 23-XI-1990, Von Bohlen 1031 (CONC 131369); Termas de Chillán, Valle de Las Nieblas, 36 $54^{\prime} \mathrm{S}, 71^{\circ} 31^{\prime} \mathrm{W}, 2000 \mathrm{~m}$ s.m., 10-II-1986, Pacheco et al. 1279 (CONC 125548); Termas de Chillán, Valle de Las Nieblas, $36^{\circ} 54^{\prime} \mathrm{S}, 71^{\circ} 31^{\prime} \mathrm{W}, 2000 \mathrm{~m}$ s.m., I-1948, Pfister s.n. (CONC 4151); Termas de Chillán, Cerro Pirigallo, $36^{\circ} 55^{\prime} \mathrm{S}, 71^{\circ} 24^{\prime} \mathrm{W}$, 2200 m s.m., 1-III-1979, Rodríguez 1142 (CONC 51178); Bío-Bío,

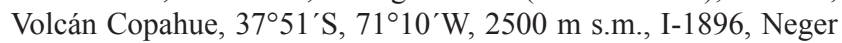
s.n. (CONC 100977); Malleco, Tolhuaca, I-1908, s.col. (SGO 61119); Malleco, Pemehue, 3748'S, $71^{\circ} 45^{\prime} \mathrm{W}, 1650$ m s.m., $18-$ I-1946, Kunkel s.n. (CONC 100165). IX Región de la Araucanía. Araucanía, Pitrunquinia, Sage s.n. (SGO 43436); Malleco, Termas de Río Blanco, Curacautín, 38³5'S, 71³7’ W, 1680 m s.m., 3I-1948, F. Behn s.n. (CONC 7945); Malleco, Lago Conguillio, Sierra Nevada, $38^{\circ} 45^{\prime} \mathrm{S}, 71^{\circ} 40^{\prime} \mathrm{W}, 1700$ m s.m., II-1977, Montero 10477 (CONC 101089); Malleco, Camino Paso Pino Hachado, Lonquimay, 38³9'S, 7054'W, 1750 m s.m., 10-I-1948, Pfister s.n. (CONC 8091); Paso Pino Hachado, ladera exposición sur, 38 $40^{\prime}$ S, $70^{\circ} 54^{\prime} \mathrm{W}, 1920$ m s.m., 13-I-1996, Marticorena et al. 417 (CONC 135270); Malleco, Estero El Saltillo, 3840'S, 7058'W, 1780 m s.m., 10-I-1977, Marticorena et al. 1424 (CONC 45797); Malleco, El Saltillo, $2 \mathrm{~km}$ antes Paso Pino Hachado, $38^{\circ} 40^{\prime} \mathrm{S}$, $70^{\circ} 48^{\prime}$ W, 1800 m s.m., 27-XII-1968, Ricardi \& Marticorena 5679 (CONC 35614); Paso Pino Hachado, camino a Liucura, Ruta 181, Reserva Nacional Alto Bío-Bío, 18-XI-2006, Morrone 5519 (SI).

22. Valeriana moyanoi Speg., Revista Fac. Agr. Univ. Nac. de L. P. 3: 607. 1897. TIPO: Argentina. Chubut, Río Corcovado, 2-III-1900, llín s.n. (holotipo, BAB 5150!).

Valeriana fonckii Phil. var spiciformis Dusén, Rep. Princeton Univ. Exped. Patagonia 3: 250, tab.3. 1914. TIPO: Argentina. Santa Cruz, Boquete Zeballos, entre Lago Buenos Aires y Lago Ghio, 1700 m s.m., 17-XII-1908, Skottsberg s.n. (neotipo, designado aquí, SGO 58789!).

Valeriana radicalis Clos var. patagonica Hicken, Darwiniana 2 (2-3): 70. 1930. TIPO: Argentina. Santa Cruz, 300 m s.m., 14-X-1929, Donat 168 (holotipo, SI 346!). 
Hierba perenne hasta $20 \mathrm{~cm}$ de alt. Rizoma de 1,5 cm diám, grisáceo, rugoso transversalmente; escapo central simple, erecto, carnoso. Hojas basales arrosetadas, densas, hasta $6 \mathrm{~cm}$, sésiles o pecioladas; lámina de 1-1,5 cm, obovada, espatulada o lanceolada, inciso-dentada o irregularmente lobada, carnosas; pecíolo notablemente nervado, 2 ó 3 veces más largo que la lámina. Inflorescencias espiciformes, densas; los glomérulos de las cimas se disponen alternadamente en la axila de pequeñas hojas enteras o divididas. Brácteas de 8 $\mathrm{mm}$ y bractéolas de $5 \mathrm{~mm}$, oblongo-lineares, generalmente de bordes pubescentes. Flor hermafrodita: hasta $\pm 8 \mathrm{~mm}$; corola de 3,5-6 mm, anchamente infundibuliforme, gibosa en la base; lóbulos oblongos o anchamente ovados; estambres inclusos; anteras elipsoides; estigma trífido. Flor femenina: corola de 2-2,5 mm, campanulada, gibosa; lóbulos ovados, obtusos.; estilo exerto, engrosado en el ápice. Fruto de 3-4 $\mathrm{mm}$, piriforme, con máculas y pubescencia corta; pappus formado por 11-15 setas gruesas.

ILUSTRACIONES: Borsini, 1944: tab. 136; 1999: 459.

CARACTERÍsticas Distintivas: Hemicriptófito pequeño; rizoma corto, rugoso transversalmente; hojas pinnatilobadas a pinnatisectas, constituyendo una roseta basal densa, de la cual surge un escapo floral cilíndrico, carnoso, en general densamente florífero; inflorescencias espiciformes; fruto de 3-4 mm, piriforme, maculado, cortamente pubescente; con pappus.

Fenología: Florece de octubre a diciembre y fructifica en verano, en enero y febrero.

DistriBUCIÓN Y HÁBITAT: Especie que habita en Patagonia argentina, en las provincias de Neuquén, Río Negro, Chubut y Santa Cruz, entre los 1.000 y 2.500 m s.m. Ha sido registrada en la Región XI de Chile (Saldivia \& Rojas 2006). Se la encuentra formando pequeños manchones en pedregales de altura, como así también en lomadas de la estepa patagónica.

Valeriana moyanoi se asemeja en la morfología de las hojas basales a $V$. papilla, pero se diferencia notablemente en el porte de la planta y en el tipo de inflorescencia.

Observación: En el caso de Valeriana fonckii Phil. var spiciformis Dusén la necesidad de designar un neotipo se fundamenta en la pérdida total del material original. Se designa aquí al ejemplar de Skottsberg s.n. como neotipo.

Material adicional examinado: ARGEnTINA. Chubut. Dpto. Futaleufú: Cerro Huemules Sur, 1580 m s.m., 16-XI-2001, Kutschker 150 (BCRU); Cerro Huemules Sur, 42 $47^{\prime} \mathrm{S}, 71^{\circ} 29^{\prime} \mathrm{W}$, 1581 m s.m., 16-III-2008, Kutschker 804 (BCRU); Dpto. Languiñeo: Estancia La Blanche, 25 km S de Tecka, 9-XII-1946, Soriano 2251 (BAB); Estancia Pampa Chica, en los Cerros junto al Río Tecka, 22-I-1947, Soriano 2453 (BAB); Dpto. Senguerr: $\mathrm{RPN}^{\circ} 272$ a $110 \mathrm{~km}$ O de Río Mayo, 6-XII-1976, Arroyo et al. 308 (BAB); Valle de Laguna Blanca, 15-XI-1901, Koslowsky 59 (SI); Dpto. Tehuelches: Río Frías, Putrachoique, I-1899, Illín s.n. (BAB 5149). Neuquén. Dpto. Lácar: San Martín de los Andes, Cerro Chapelco Chico, 1700 m s.m., 22-I-1974, Gentili 190 (BAB); Dpto. Los Lagos: Cerro Saihueque, 1900 m s.m., 27-I-1964, Diem 3218 (SI; BAB); Estancia Fortín Chacabuco, 4-XI-1949, Hunziker \& Boelcke 3537 (BAB). Río Negro. Dpto. Bariloche: mallín en Cerro Nireco, 1600 m s.m., II-1946, Bernasconi s.n. (SI 15933); PN Nahuel Huapi, CerroVentana, 1900 m s.m., 28-X-1949, Boelcke \& Hunziker 3400 (BAB); Cerro Meta, ca. 2000 m s.m., 10-III-1993, Ferreyra 94 (BCRU); Cerro López, picada desde el refugio Cerro López hacia la cumbre, ladera exposición N, 1900 m s.m., 19-II-1994, Chiapella et al. 620 (BCRU); PN Nahuel Huapi. Travesía Cerro Ñireco-Cerro Challhuaco, 1700-2200 m s.m., 18-II-1996, Núñez \& Puente 106 (BCRU); PN Nahuel Huapi, Cerro Carbón, ladera SO, 1500 m s.m., 10-XI-2001, Puntieri s.n. (BCRU); Dpto. Pilcaniyeu: a $5 \mathrm{~km}$ del cruce de las rutas $23 \mathrm{y}$ 237, 23-XI-1967, Constance et al. 3816a (BAB); Dpto. Valcheta: Somuncurá, camino laguna Raimunda-laguna Paraguay, 23-XI1975, Correa et al. 6280 (BAB); 9 de Julio, RP 60, a 65,5 km S del puesto policial, cerca del Cerro Corona (e/ $\mathrm{C}^{\mathrm{o}}$ Corona Grande y Chico), 21-XII-2006, Zanotti 25 (SI). Santa Cruz. Dpto. Lago Buenos Aires: meseta del lago, $42 \mathrm{~km}$ NO del casco de la Estancia La Vizcaína, \pm 1350 m s.m., 10-XII-1986, Gómez et al. 570/572 (BAB); Lago Buenos Aires, camino a Los Antiguos, 15,6-21 km N Paso Roballos, 19-I-2007, Zanotti 131 (SI); Monumento Natural Bosques Petrificados, 23-X-2001, Zoratti 185 (BCRU); La Bajada, 14-III-1914, Hicken 800 (SI); Dpto. Güer Aike: Estancia Las Vizcachas, Cerro Las Vizcachas, 25-I-1977, Arroyo et al. TBPAfit 2435 (BAB); Estancia Guakenken Aike, 14-XI-1977, Roig \& Méndez TBPA-fit 2476 (BAB). CHILE. XI Región de Aisén. Provincia de Aisén, Cerro Rosado, 45²2'S, 7207'W, $1.400 \mathrm{~m}$ s.m., 2-I-2003, Saldivia s.n. (SGO 152417); Aisén, Cerro Rosado, $45^{\circ} 22^{\prime}$ S, $72^{\circ} 07^{\prime} \mathrm{W}, 1.400 \mathrm{~m}$ s.m., 2-III-2004, Saldivia s.n. (SGO 152416); Provincia del General Carrera, Comuna de Chile Chico, Reserva Nacional Lago Jeinimeni, 46 50 'S, $72^{\circ} 01^{\prime}$ W, $1.600 \mathrm{~m}$ s.m., 18-I-2003, Rojas \& Saldivia s.n. (SGO 152418).

23. Valeriana munozii Borsini, Gen. et Sp. P1. Arg. 2: 275372. 1944. TIPO: Argentina. Mendoza, Tres Esquinas, 2200 m s.m., I-1921, Carette 395 (holotipo, SI!).

Hierba perenne hasta $30 \mathrm{~cm}$ de alt. Rizoma 2-2,5 cm, con restos foliares escamosos. Hojas basales enteras, lámina de 2-5 x 1-1,5 cm, obovada o espatulada, decusadas, concrescentes en la base; pecíolo 2-2,5 veces más largo que la lámina. Hojas superiores sésiles de 1-2,5 cm, pinnatipartidas. Inflorescencias terminales contraídas. Brácteas de 3-3,5 mm. Bractéolas de 2-3,5 mm, oblongo-espatuladas. Flor hermafrodita: corola de 3-3,5 mm, infundibuliforme, con giba notable en la mitad del tubo, replegándose en la base formando un anillo; lóbulos oblongos, obtusos, papilosos en la parte interna de los bordes; estambres exertos; ovario curvado longitudinalmente. Flor femenina: corola de $1 \mathrm{~mm}$, campanulada, con replieque basal; lóbulos suborbiculares; ovario oblongo; estilo exerto; estigmas libres, aplanados. 
Fruto triquetro de 4-5,5 x $2 \mathrm{~mm}$, falcado, curvado longitudinalmente, alado en los bordes, glabro; cáliz nulo en la madurez, no desarrollado en pappus plumoso.

Ilustraciones: Borsini, 1944: tab. 148.

CARActerísticas distintivas: Hojas basales enteras, espatuladas, largamente pecioladas; hojas superiores pinnatipartidas; inflorescencias terminales, contraídas; fruto triquetro, de 4-5,5 × $2 \mathrm{~mm}$, ovoide, arqueado longitudinalmente, glabro; sin pappus.

Fenología: Florece de octubre a diciembre y fructifica en verano, en enero y febrero.

DistribuCión Y hÁBITAT: Es una especie endémica de Mendoza, Argentina. Habita en zonas montañosas entre los 2.000 y $3.500 \mathrm{~m}$ s.m.

Valeriana munozii se asemeja a $V$. macrorhiza y $V$. dinorrhiza en la morfología de las hojas y frutos, y se diferencia por su inflorescencia terminal capituliforme, contraída.

Material adicional examinado: ARGEntina. Mendoza: Loncoche, XI-1911, Girth s.n. (SI 14529); Nacimiento del Maipo, I-1921, Carette 72 (SI).

24. Valeriana obtusifolia DC., Prodr. 4: 635. 1830. TIPO: Chile. Poeppig 640 (holotipo, G, = Microfilm Prodr. 635.32!, fot. F 32675 ex V!).

Valeriana obovata Clos in Gay, Hist. Chile, 3: 221. 1847 non DC., 1830. TIPO: Chile. Gay s.n. (holotipo, $\mathrm{P},=$ fot. $\mathrm{F}$ 37116 !, = isotipo fot. $\mathrm{K}$ !).

Valeriana aegilitis Phil., Anales Univ. Chile 85: 741. 1893 4. TIPO: Chile. Valparaíso, Curauma, X-1885, Philippi 2050 (holotipo, SGO 56957!).

Valeriana araucana Phil., Anales Univ. Chile 85: 744. 1893-4. TIPO: Chile. Entre Temuco y Lautaro, XI-1887, s.col. (holotipo, SGO 56963!).

Valeriana crassicaulis Phil., Anales Univ. Chile 85: 746. 1893-4. TIPO: Chile. Ñuble, X-1878, Poza s.n. (holotipo, SGO 56938!).

Hierba perenne de aprox. $40 \mathrm{~cm}$ de alt., con pelos cortos glandulosos. Rizoma de 1-7 x 1-1,5 cm, carnoso, fusiforme, rugoso transversalmente, con numerosas raicillas secundarias. Tallo simple o ramificado. Hojas basales de 4,5-9 x 2-5 cm, enteras, subcarnosas; láminas ovadas, elípticas, márgenes irregularmente dentados o lacerados, crespos; o bien pinnatisectas, con 3 pares de segmentos, el terminal de mayor tamaño; pecíolo de 2$7 \mathrm{~cm}$, engrosado, pubescente. Hojas superiores enteras o partidas. Inflorescencias densifloras, con abundantes pelos glandulosos. Brácteas de $-5 \mathrm{~mm}$, lineares. Bractéolas de 1,5-2,5 mm, ovado-lanceoladas, pubescentes en la superficie y márgenes. Flor hermafrodita: corola de 33,5 $\mathrm{mm}$, infundibuliforme, pubescente interiormente; estambres inclusos; ovario elipsoide; estigmas lamelados. Flor femenina: corola de 1-1,2 mm, campanulada, gibosa; tubo estrecho; lóbulos oblongos u ovados; estilo exerto, engrosado en el ápice. Fruto con lóculo fértil de 2-3 x 1,5-2 $\mathrm{mm}$, elipsoide, plano; lóculos estériles bien desarrollados en la parte central del fértil, separados por un pequeño surco; glabro; pappus formado por 9 setas plumosas.

ILUSTRACIONES: Borsini, 1966: 466.

Características distintivas: Tallos engrosados en su base; hojas basales enteras, subcarnosas, bordes dentados o lacerados, o bien pinnatisectas, en este caso con el segmento terminal notablemente más desarrollado; hojas superiores enteras o partidas; inflorescencias densifloras, con abundantes pelos glandulosos; fruto con un lóculo fértil aplanado; los estériles subglobosos; glabro; con pappus.

FenOlogía: Florece de septiembre a noviembre, fructifica en los meses de verano.

DistribuCión: Habita en las provincias del centro y sur de Chile (Regiones V, VII, VIII, y IX).

Valeriana obtusifolia es afín a Valeriana bridgesii de la cual se separa por su inflorescencia menos desarrollada y por el fruto que tiene el lóculo fértil plano. También presenta afinidad con $V$. lepidota, de la cual se distingue por la inflorescencia densiflora y por el fruto elipsoide, con lóculos estériles bien desarrollados.

Material adicional examinado: CHILE. VII Región del Maule. Linares, Cordillera de Linares, I-1856, Germain s.n. (SGO 43446/57054). VIII Región del Bío-Bío. Ñuble, Camino Termas de Chillán, 36 53'S, 71³3'W, 950 m s.m., XI-1944, Pfister s.n. (CONC 4156); Nuble, Atacalco, Cerro Castillo, 36 ${ }^{\circ} 53^{\prime} \mathrm{S}, 71^{\circ} 37^{\prime} \mathrm{W}$, 1100 m s.m., 29-XI-1944, Pfister s.n. (CONC 4157/4158); BíoBío, Los Angeles, Fundo San Carlos de Purén, 37³5'S, $72^{\circ} 16^{\prime} \mathrm{W}$, 140 m s.m., 19-IX-1936, Junge s.n. (CONC 5763); Los Angeles, Fundo Natalia, 37³5'S, 72 $17^{\prime} \mathrm{W}, 200$ m s.m., 5-VIII-1939, Junge s.n. (CONC 6665); Bío-Bío, Mulchén, Cerro Coronado, 3743'S, $72^{\circ} 13^{\prime} \mathrm{W}, 180$ m s.m., 3-XI-1957, Aránguiz s.n. (CONC 23763). XIV Región de Los Ríos.Valdivia, San Juan, s.col. (SGO 43447); Malleco, Mininco, 3747'S, $72^{\circ} 28^{\prime} \mathrm{W}, 190$ m s.m., IX1952, Schwabe s.n. (CONC 12626); Malleco, Collipulli, 3757'S, $72^{\circ} 26^{\prime} \mathrm{W}, 150 \mathrm{~m}$ s.m., Baeza s.n. (CONC 54266); Cautín, Temuco, 38 $44^{\prime}$ S, 72³5'W, 110 m s.m., XII-1927, Joseph s.n. (CONC 108171); Cautín, Pillanlelbum, 38³8'S, $72^{\circ} 27^{\prime} \mathrm{W}, 165$ m s.m., 15-X-1962, Montero 6595 (CONC 100849).

25. Valeriana papilla Bertero ex DC., Prodr. 4: 638. 1830. TIPO: Chile. Cachapoal, San Joaquim, 1828/9, Bertero 
742 (holotipo, G,= fot. F 27197 ex P!; isotipos, fot. MPU!, $\mathrm{MO}$ !).

Valeriana berterii Colla, Mem. Acc. Torin. 38 (4): 21. 1835. TIPO: Chile. Cachapoal, 1830, Bertero s.n. (holotipo, $\mathrm{G).}$

Valeriana papilla DC var. andicola Clos in Gay, Hist. Chile, Bot. 3: 222. 1847. TIPO: Chile. Santiago, Cordillera de Las Arañas, X-1853, Philippi s.n. (neotipo, designado aquí, SGO 57036!).

Hierba perenne de 15-20 cm alt., simple o ramificada en la base. Rizoma grueso, carnoso. Tallo glabrescente o hirsuto. Hojas basales enteras o pinnatipartidas, hasta 16-21 x 2,5$4 \mathrm{~cm}$; segmentos oblongos, el terminal de mayor tamaño, carnosos; pecíolo dilatado. Hojas superiores enteras o pinnatisectas, de 4-8 cm. Inflorescencias de aprox. $11 \mathrm{~cm}$, contraídas o desarrolladas en seudopanículas. Brácteas de $1 \mathrm{~cm}$, enteras o profundamente recortadas. Bractéolas de 2,5-9 mm, oblongas o lineares, ensanchadas en la base. Flor hermafrodita: corola de 6-6,5 mm, infundibuliforme, pubescente interiormente y en su parte basal externa; estambres exertos. Fruto de 5-7 x $4 \mathrm{~mm}$, ovoide, escotado en la base, hirsuto, pelos distribuidos en toda la superficie, especialmente sobre las nervaduras que son muy engrosadas y divergentes en el ápice; pappus formado por 16-18 setas plumosas.

ILUSTRACIONES: Borsini, 1966: 458.

CARActerísticas distintivas: Rizoma grueso, carnoso; hojas basales enteras o divididas; en este caso con segmentos laterales oblongos, delgados y lóbulo terminal de mayor tamaño, redondeado; hojas superiores en general pinnatisectas; inflorescencias muy desarrolladas, fruto de 5$7 \mathrm{~mm}$, ovoide con lóculos estériles no desarrollados, hirsuto, con pappus.

Fenología: Florece desde agosto a septiembre, fructifica en verano.

DisTRIBUCIÓN Y HÁBITAT: Habita en las montañas y zonas costeras de las provincias centrales de Chile: Santiago, O’Higgins, Valparaíso (Regiones IV, V, M y VI), entre los 200 y 2000 m s.m.

\section{Nombre COMÚN: papilla}

Valeriana papilla se asemeja a $V$. moyanoi en la morfología de las hojas basales, pero se diferencia en el mayor porte de la planta, en la morfología de la inflorescencia que es paniculiforme y en el fruto densamente pubescente.

Observación: Ante la pérdida total del material en que se basó la descripción original de Valeriana papilla var. andicola, se designa aquí un neotipo que corresponde al ejemplar de Philippi s.n.depositado en SGO.

Material adicional examinado: CHILE. IV Región de Coquimbo. Coquimbo. Illapel, XII-1890, Geisse s.n. (SGO 72777); Illapel, Cuesta de los Hornos, Geisse s.n. (SGO 57038); Limarí. Cuesta El Espino, $31^{\circ} 17^{\prime} \mathrm{S}, 71^{\circ} 05^{\prime} \mathrm{W}, 1500$ m s.m., X-1963, Marticorena \& Matthei 411 (CONC 54298); Choapa. Fundo El Mollar, Cerro Cuchilla Blanca, 3156'S, 71²2'W, 990 m s.m., VIII-1961, Schlegel 3806 (CONC 51336). V Región de Valparaíso. San Felipe. Cerro Caquisito, $32^{\circ} 45^{\prime} \mathrm{S}, 71^{\circ} 05^{\prime} \mathrm{W}, 1000 \mathrm{~m}$ s.m., IX-1954, Schlegel 197 (CONC 51318); Quillota. Cerro El Roble, 32 ${ }^{\circ} 58^{\prime} \mathrm{S}$, $71^{\circ} 00^{\prime} \mathrm{W}, 1800 \mathrm{~m}$ s.m., IX-1971, Garaventa 5921 (CONC 54267); Quillota. El Roble, 32 $58^{\circ} \mathrm{S}, 7^{\circ} 02^{\prime} \mathrm{W}, 1500 \mathrm{~m}$ s.m., IX-1911, Rudolph s.n. (CONC 108231); Valparaíso. Viña del Mar, Salto, $33^{\circ} 02^{\prime} \mathrm{S}, 71^{\circ} 33^{\prime} \mathrm{W}, 230$ m s.m., 3-IX-1932, K. Behn s.n. (CONC

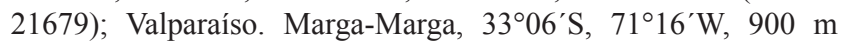
s.m., IX-1916, Jaffuel s.n. (CONC 54261); Marga-Marga, Cerro de la Cruz, $33^{\circ} 06^{\prime} \mathrm{S}, 71^{\circ} 16^{\prime} \mathrm{W}, 900$ m s.m., IX-1932, Jaffuel 3024 (CONC 54260). Región Metropolitana. Santiago, Salto de agua, XI-1862, Philippi 980 (SGO 43448); Santiago, Salto de agua, XI-1883, s.col. (SGO 43449); Santiago, Salto San Ramón, IX1891, s.col. (SGO 61675); Santiago, Tiltil, $33^{\circ} 05^{\prime} \mathrm{S}, 70^{\circ} 56^{\prime} \mathrm{W}, 580$ m s.m., IX-1911, Horst s.n. (CONC 108230); Santiago, Mina de Las Arañas, 331' ${ }^{\prime} \mathrm{S}, 70^{\circ} 28^{\prime} \mathrm{W}, 2000$ m s.m., XI-1937, Grandjot s.n. (CONC 108243); Santiago, Cerro de Manquehue, 33⒉ ${ }^{\prime} \mathrm{S}$, 70³5'W, 1800 m s.m., IX-1957, Gunckel 40809 (CONC 108241); Comuna de La Reina, Quebrada de San Ramón, 3326 ' S, 70³0’W, 800-1200 m s.m., 10-IX-2000, Tomé 315 (CONC 156960); Maipo,

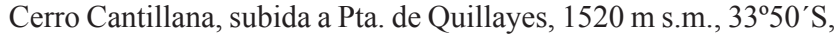
7056' W, 15-IX-2003, A. Marticorena 585 (CONC 165496). VI Región de O'Higgins. Cachapoal, Cordillera de Cauquenes, X1907, s.col. (SGO 61104).

26. Valeriana peltata Clos in Gay, Hist. Chile, Bot. 3: 229. 1847. TIPO: Chile. Coquimbo, 1839, Gay s.n. (holotipo, P, $=$ fot. F 37117 !)

Hierba perenne de $25-70 \mathrm{~cm}$ alt. Rizoma simple o bifurcado, tortuoso, estriado transversalmente.Tallos simples o ramificados, pubescentes. Hojas basales de $6 \mathrm{~cm}$, enteras, liradas a pinnatilobadas, lámina orbicular o reniforme, base escotada; en las hojas divididas los segmentos son lineares, oblongos, obovados, márgenes sinuados o irregularmente dentados, membranáceos; pecíolo de $6 \mathrm{~cm}$, pubescente en su base y márgenes. Inflorescencias hasta $30 \mathrm{~cm}$, densifloras. Brácteas de 3-8 mm, linear-oblongas, base auriculada. Bractéolas de 2,5-4 x 1-2 mm, lineares, oblongas, obovadas u oblanceoladas, ápice mucronado, pubescentes en la base y márgenes. Flor hermafrodita: corola de $3 \mathrm{~mm}$, infundibuliforme, gibosa en la base; lóbulos ovados $\mathrm{u}$ obovado-obtusos; estambres inclusos. Flor femenina: corola de $2 \mathrm{~mm}$, campanulada, gibosa; ovario elipsoide. Fruto de 2,5 mm, piriforme, lóculo fértil hirsuto y lóculos estériles bien desarrollados, glabros; pappus formado por 8-11 setas.

ILUSTRACIONES: Borsini, 1966: 447. 
CARacterísticas distintivas: Rizoma tortuoso, arrugado transversalmente, tallos pubescentes notablemente adelgazados en su base; hojas enteras a pinnatilobadas, membranáceas. Inflorescencias densifloras, contraídas o laxas; fruto de 2,5 mm, piriforme, el lóculo fértil hirsuto y los estériles bien desarrollados, glabros; con pappus.

Fenología: Florece de septiembre a noviembre, fructifica en verano.

Distribución y hÁBItat: Especie endémica de Chile, se distribuye en las Regiones III, IV y V. Habita entre 0 y 500 m s.m.

Valeriana peltata es afín a $V$. bridgesii de la cual se diferencia por la lámina foliar o segmento terminal de la hoja de base escotada y por el fruto piriforme y con el lóculo fértil hirsuto.

Material adicional examinado: CHILE. III Región. Huayco, Camino Carrizalillo a Domeyko, km 14, 2901' S, $71^{\circ} 15^{\prime} \mathrm{W}, 400 \mathrm{~m}$ s.m., X-1971, Marticorena et al. 1813 (CONC 54199). IV Región de Coquimbo. Elqui, El Molle, 2959'S, 7057'W, 350 m s.m., IX-1961, Jiles 3829 (CONC 54331); Elqui, Camino Mineral La Higuera, $29^{\circ} 29^{\prime} \mathrm{S}, 71^{\circ} 13^{\prime} \mathrm{W}, 450 \mathrm{~m}$ s.m., X-1963, Marticorena \& Matthei 170 (CONC 28141); Elqui, Punta Teatinos, 2949'S, 71¹9’W, 5 m s.m., IX-1965, F. Behn s.n. (CONC 54301); Elqui. Carretera Panamericana al sur de La Serena, km 440, 3007'S, 71²2’W, 10 m s.m., IX-1965, Gleisner 97 (CONC 34507); Limarí, Fray Jorge , $30^{\circ} 40^{\prime} \mathrm{S}, 71^{\circ} 40^{\prime} \mathrm{W}, 450 \mathrm{~m}$ s.m., 21-IX-1952, Ricardi

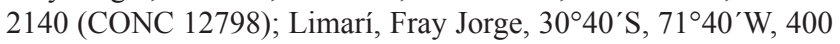
m s.m., IX-1952, Ricardi 2127 (CONC 12786); Limarí, Fray Jorge, IX-1934, Grandjot 339 (SGO 60153); Limarí, Fray Jorge, IX-1934, Grandjot 458 (SGO 60152); Limarí, Fray Jorge, IX-1935, Muñoz P. s.n. (SGO 58458); Limarí, Fray Jorge, 26-IX-1935, Muñoz P. 247 (SGO 57697); Limarí, Desembocadura del Río Limarí, 12IX-1942, Muñoz P. 3419 (SGO 58371); Limarí, Estancia Talca,

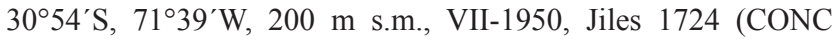
54326). V Región de Valparaíso. Chañarcito, IX-1885, s.col. (SGO 57050); Chañarcito, en carrizal, IX-1885, Philippi 2051 (SGO 43451); Quillota, Valle de Ocoa, 32 $50^{\prime} \mathrm{S}, 71^{\circ} 07^{\prime} \mathrm{W}, 300 \mathrm{~m}$ s.m., IX-1958, Schlegel 1191 (CONC 54318).

27. Valeriana philippiana Briq., Ann. Conserv. Jard. Bot. Genève 17: 333. 1911-1913 =

Valeriana pulchella Phil., Linnaea 33:102. 186465, non Marl. \& Gal., 1844. TIPO: Chile. Provincia de Valdivia, Andes de Ranco, 1676 m s.m., Pearce s.n. (lectotipo, designado por Borsini (1966: 420), SGO 43500!; isolectotipo fot. $\mathrm{K}$ !).

Hierba perenne de hasta $20 \mathrm{~cm}$ alt., simple o ramificada. Rizoma de hasta $14 \mathrm{~cm}$, subleñoso, cilíndrico, a veces estolonífero. Tallos con entrenudos muy cortos, formando una seudorroseta basal. Hojas inferiores pinnatilobadas a pinnatisectas, de ámbito oblongo, hasta $8 \mathrm{~cm}$; segmentos de 4-8 x 3-7 mm, orbiculares u obovados, atenuados en la base, superpuestos, papilosos, glabros, carnosos; pecíolo canaliculado, pubescente. Hojas superiores de 6-10 × 3,5 mm, enteras, oblongas. Inflorescencias terminales contraídas. Brácteas de $7 \mathrm{~mm}$, enteras, oblongas, glabras. Bractéolas de 2,5-4,5 mm, oblongas, glabras. Flor hermafrodita: corola de $4 \mathrm{~mm}$, infundibuliforme-campanulada, gibosa; lóbulos oblongos u obovados; estambres exertos; estigmas lamelados. Fruto de 3-4 × $2 \mathrm{~mm}$, elipsoide, con lóculos estériles incipientes, pubescente; pappus formado por 11-13 setas plumosas.

ILUSTRACIONES: Borsini, 1944: tab. 129; 1999, 461.

CARacterísticas distintivas: Planta pequeña, entrenudos cortos generando una seudorroseta basal; hojas basales pinnatisectas, con segmentos obovados u orbiculares, superpuestos; hojas superiores enteras; inflorescencia terminal contraída; fruto de 3-4 mm, elipsoide, pubescente; con pappus.

Fenología: Florece de octubre a diciembre y fructifica en verano, en enero y febrero.

DistRIBUCIÓN Y HÁBITAT: Habita en las provincias del sur de Chile (Regiones X y XI); en Argentina en las provincias de Neuquén, Río Negro y Chubut, entre los 1.000-2.400 m s.m. Crece en zonas de montaña, en pedregales altoandinos, particularmente entre rocas o en grietas de las mismas.

Valeriana philippiana es afín a $V$. clarionifolia, de la cual se diferencia por su menor desarrollo en altura, por los segmentos de las hojas basales superpuestos y por los frutos elipsoides y pubescentes.

Observación: Valeriana philippiana Briq. (1911-1913) fue publicado como nomen novum de V. pulchella Phil. (186465), un homónimo ilegítimo de V. pulchella Marl. \& Gal. (1844). Siguiendo el Código Internacional de Nomenclatura Botánica (CINB) (Viena, 2006: Cap. II, Sec. 2, Art. 7.3), el tipo de $V$. philippiana es entonces el tipo de $V$. pulchella Phil. (non Marl. \& Gal.), que corresponde en este caso a Pearce s.n.

Material adicional examinado: ARGEnTINA. Chubut. Dpto.

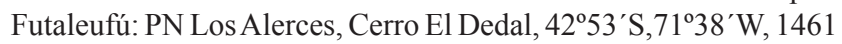
m s.m., 24-III-2008, Kutschker 809 (BCRU); Dpto. Tehuelches: Lago General Paz, 1200 m s.m., I-1945, s.col. (SI); Dpto. Senguerr: Lago Fontana, 1896, Koslowsky s.n. (LP). Neuquén. Dpto. Aluminé: parte O. del cordón de Rucachoroi, $\pm 2200 \mathrm{~m}$ s.m., 20-I-1982, Carrique et al. 1342 (BAB); Dpto. Huiliches: PN Lanín, subida al filo del Cerro de Los Angeles, picada al S, ext. E Lago Epulaufquen, en ladera, 20-II-1974, Correa et al. 5830 (BAB); ladera S del volcán Lanín, 1420 m s.m., 17-II-1974, Correa et al. 5708 (BAB); Dpto. Lácar: Cerro Chapelco, 17-XII- 
1986, Gómez et al. 826 (BAB); Cerro Chapelco, en el fillo encima del refugio, 1800-1870 m s.m., 23-II-1974, Correa et al. 5945 (BAB); Cordón del Chapelco, arroyo Chapelco Grande, $1800 \mathrm{~m}$ s.m., 23-I-1979, M. Gentili \& P. Gentili 759 (BAB); Cordón del Chapelco, nacientes del arroyo Trabunco, 27-III-1978, M. Gentili \& P. Gentili 747 (BAB); Chenque Pehuén, Cerro Butahuao, ladera $\mathrm{S}, \pm 2400$ m s.m., 15-I-1982, Carrique et al. 1082 (BAB); Chenque Pehuén, Cerro Butahuao, $38^{\circ} 10^{\prime} \mathrm{S}, 71^{\circ} 00^{\prime} \mathrm{W}, 2400 \mathrm{~m}$ s.m., 15-I1982, Rossow et al. 1082 (CONC 65198); Dpto. Los Lagos: PN Nahuel Huapi, entre Puerto Manzano y lago Traful, nacimiento arroyo s/nombre, 14-II-1953, Boelcke \& Correa 6908 (BAB); Villa Puerto Manzano, subida al Cerro Centenario, 1650 m s.m., 23-II1970, Diem 3380 (BAB); Cerro Bayo, cerca de Villa La Angostura, $40^{\circ} 45^{\prime} \mathrm{S}, 71^{\circ} 36^{\prime} \mathrm{W}, 1600-1800 \mathrm{~m}$ s.m., 12-I-2002, Weigend \& Weigend 6854 (BCRU); Dpto. Ñorquín: Copahue, $\pm 2 \mathrm{~km} \mathrm{O}$ del camping, 18-II-1992, Rossow 4635 (BAB); Copahue, serranía rocosa al O del pueblo 2050-2150 m s.m., 8-II-1994, Ezcurra et al. 826 (BCRU). Río Negro. PN Nahuel Huapi, Cerro López, 1700 m s.m., 28-I-1946, Boelcke 1996 (SI); PN Nahuel Huapi, Picada al Rigi, 11-I-1952, Boelcke \& Correa 5456 (SI; BAB); PN Nahuel Huapi, Cerro López, 2100 m s.m., 1-II-1944, Montiel s.n. (SI); PN Nahuel Huapi, Cerro Tronador, 17-I-1952, Boelcke \& Correa 5736 (SI); Cerro Catedral, Refugio Frey, 1780 m s.m., 14-I-1994, Ferreyra \& Clayton 212 (BCRU); Cerro Catedral, 2000 m s.m., III1943, Soriano 209 (BAB); PN Nahuel Huapi, Cerro Tronador, 17I-1952, Boelcke \& Correa 5735 (BAB); Cerro Tronador, pedreros húmedos debajo del refugio, ca. 1850 m s.m., 23-II-1997, Ezcurra 2315/2316 (BCRU); Dpto. Pilcaniyeu, a $5 \mathrm{~km}$ del cruce de rutas 23 y 237, 23-XI-1967, Correa et al. 3816 (BAB); Bariloche, Cerro López, 2000 m s.m., 1-III-1993, Ferreyra 22 (BCRU); Cerro López, desde refugio hasta aprox. $1950 \mathrm{~m}$ s.m., 21-III-1993, Ferreyra 145 (BCRU); Cerro López, picada desde el Refugio Cerro López hacia la cumbre, ladera exposición NE, 1900 m s.m., 19-II-1994, Chiapella et al. 611 (BCRU); Bariloche, Cumbre Cerro López, I2000, Puntieri s.n. (BCRU); Bariloche, Cerro Catedral, aprox. 1800 m s.m., 1-I-2000, Puntieri s.n. (BCRU); Cerro Ventisqueros, Río Manso Inferior, 1700-2000 m s.m., 3-III-1996, Núñez \& Puente 116 (BCRU); Bariloche, Cerro Nireco, ladera exposición N, 1650 m s.m., 21-XII-1994, Cadillo \& Posse s.n. (BCRU); Bariloche, Castaño Overo, chaparral de lenga, 1450 m s.m., 21-III-1976, s.col. (BCRU); Bariloche, Cerro Tronador, 4-I-1975, Rubulis s.n. (BCRU); Tronador, refugio viejo, 1-III-2002, D'Átri s.n. (BCRU). CHILE. X Región de Los Lagos. Lago de Todos los Santos, Cerro Santo Domingo, 5-II-1917, s.col. (SI 14534); Osorno, Puyehue,

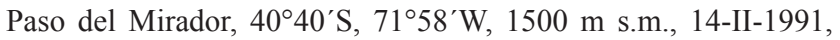

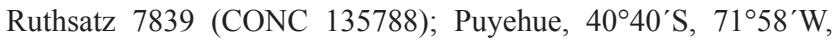
1400 m s.m., 19-III-1954, Sparre \& Constance 10825 (CONC 17529); Llanquihue, Parque Nacional V. Pérez Rosales, $41^{\circ} 10^{\prime} \mathrm{S}$, 72³0’W, 200 m s.m. 10-I-1986, Gardner 3451 (CONC 107129).

28. Valeriana polemoniifolia Phil., Anales Univ. Chile 85: 743-4. 1893-4. Chile. Valdivia, Cordillera de Ranco, Chaihuin, I-1887, Philippi 2158 (lectotipo, designado por Borsini (1966: 414), SGO 56953!).

Valeriana pilosa Phil., Linnaea 28: 702. 1858, non Ruiz \& Pav., 1798. = Valeriana germainii Briq., Ann. Conserv. Jard. Bot. Genève 17: 336. 1919. TIPO: Chile. Valparaíso, Quillota, Germain s.n. (holotipo, SGO 56947!).

Valeriana pugae Phil., Anales Univ. Chile 85: 746.
1893-4. TIPO: Chile. Provincia de Ñuble, Laguna del Baño, Olico, 1887, Puga s.n. (lectotipo, designado por Borsini (1966: 414), SGO 56958!).

Valeriana caudata Phil., Anales Univ. Chile 85: 743. 1893-4. TIPO: Chile. Arauco. Curanilahue, s.col. (holotipo, SGO 56941!).

Hierba perenne hasta $85 \mathrm{~cm}$ alt., simple o ramificada desde la base, glabra o escasamente pubescente. Raíz de 2-5 mm diám., frecuentemente con numerosas ramificaciones. Tallo tetrágono, hueco, con escasa pubescencia, cubierto por restos foliares en la base. Hojas basales de $17 \times 7$ $\mathrm{cm}$, pinnatilobadas o pinnatisectas, de ámbito oblongo, segmentos ovados, oblongos, lanceolado-elípticos, obtusos o agudos hasta caudados, márgenes dentados o sinuados; subglabras o pubescentes, pelos más abundantes en el haz y base de los pecíolos, membranáceas; pecíolo de $2-5 \mathrm{~cm}$. Hojas superiores pinnatisectas, segmentos lanceoladolineares. Inflorescencia terminal de $-35 \mathrm{~cm}$, pauciflora, grácil; pedúnculos axilares tenues, filiformes. Brácteas de 4-8 mm x 0,5 mm, enteras, lineares u oblongo-lineares, algo ensanchadas en la base, con pelos en las axilas. Bractéolas de 1,5-2 x 0,5 mm, oblongo agudas o lineares, auriculadas, generalmente glabras o con pelos cortos. Flor hermafrodita: corola de 1-1,5 mm, campanulada, gibosa; lóbulos ovados; estambres inclusos. Fruto de 1,5-2 x $1 \mathrm{~mm}$, ovoide aplanado, con lóculos estériles reducidos a esbozos, nervadura marginal doblada sobre la cara trinervada, papiloso, cortamente pubescente; pappus de $2 \mathrm{~mm}$, formado por 10-11 setas.

Ilustraciones: Borsini, 1966: 455 (sub. Valeriana lobata); $1999,464$.

CARACTERÍSTICAS Distintivas: Hojas basales pinnatilobadas a pinnatisectas, lóbulo terminal más desarrollado; hojas superiores pinnatisectas; inflorescencias paucifloras, gráciles; fruto unilocular, de 1,5-2 x $1 \mathrm{~mm}$, ovoide, con lóculos estériles reducidos a esbozos en el ápice de la cara trinervada, papiloso, escasa y cortamente pubescente; con pappus.

Fenología: Florece de diciembre a enero, fructifica en febrero y marzo.

DisTRIBUCIÓN Y HÁBITAT: Habita en las provincias del sur de Chile, desde Talca hasta Osorno (Regiones VII, VIII, IX, XIV y X); en Argentina en las provincias de Neuquén, Río Negro y Chubut, entre los 0 y 1500 m s.m. Crece en bosques húmedos, sombríos.

Valeriana polemoniifolia es afín a $V$. velutina, de la cual se diferencia por los segmentos de las hojas basales elípticos y por la flor hermafrodita campanulada. 
Observación: Los ejemplares identificados como Valeriana lobata en los herbarios generalmente corresponden a $\mathrm{V}$. polemoniifolia.

Material adicional examinado: ARGEnTINA. Chubut. Dpto. Cushamen: Lago Puelo, picada entre puesto de gendarmería y límite con Chile, 18-I-1982, Rossow 2184 (BAB); Picada al anexo Puelo, 14-XII-1986, Gómez et al. 727 (BAB); Valle del Río Puelo, II1896, Reiche s.n. (SGO 56991). Neuquén. Dpto. Lácar: PN Lanín, Sección Ñorquinco, Cusato 2951 (BAB). Río Negro. Bariloche, Puerto Blest, a $100 \mathrm{~m}$ del Hotel hacia Frías, 6-XII-1999, Puntieri s.n. (BCRU). CHILE. VII Región del Maule. Talca, Constitución, XII-1891, s.col. (SGO 56990). VIII Región del Bío-Bío. Ñuble, Atacalco, 36 $6^{\circ} 53^{\prime} \mathrm{S}, 71^{\circ} 38^{\prime} \mathrm{W}, 900$ m s.m., 19-IX-1939, Pfister s.n. (CONC 3407); Nuble, Termas de Chillán, camino aserraderoGarganta del Diablo, 3654'S, 71²6'W, 1500 m s.m., 13-II-1966, Gleisner 154 (CONC 54186); Nuble, Fundo El Rosario, RecintoTermas de Chillán, $36^{\circ} 52^{\prime} \mathrm{S}, 7^{\circ} 36^{\prime} \mathrm{W}, 600$ m s.m., 26-X-1974, R. Rodríguez 603 (CONC 54310); Ñuble, Río Renegado, a 2 km de Los Lleuques, 3652'S, 71³8'W, 700 m s.m., 7-XI-1978, G. Rodríguez 206 (CONC 54303); Nuble, Los Lleuques, camino a Termas de Chillán, 3651'S, $71^{\circ} 38^{\prime} \mathrm{W}, 800$ m s.m., 9-XI-1979, R. Rodríguez \& G. Rodríguez 1293 (CONC 54486); Nuble, Los Lleuques, camino a Termas de Chillán, 3651'S, 71³8’W, 800 m s.m., 26-X-1979, R. Rodríguez \& G. Rodríguez 1307 (CONC 54487); Nuble, Termas de Chillán, Refugio El aserradero, 36 ${ }^{\circ} 54^{\prime} \mathrm{S}, 7^{\circ} 27^{\prime} \mathrm{W}, 1250-1700$ m s.m., 22-XI-1990, Taylor et al. 10255 (CONC 123317); Nuble, Camino Termas de Chillán, R. Aserradero-Cascada, 36 54'S, 71²8'W, 1300 m s.m., 7-XII-1992, Rodríguez \& Marticorena 3023 (CONC 135049); Bío-Bío, Santa Julia, 37³1'S, 72²2’W, 125 m s.m., XII-1895, Neger 4176 (CONC 100978); Arauco, Camino Curanilahue-Cañete, Quebrada Río Trongol, 373' $\mathrm{S}, 7^{\circ} 23^{\prime} \mathrm{W}$, 170 m s.m., 11-I-1972, Quezada et al. 47 (CONC 54289); Arauco, Cordillera de Nahuelbuta, Reserva Forestal Pino Huacho, $37^{\circ} 42^{\prime} \mathrm{S}$, 7309'W, 800 m s.m., 24-XI-1978, Marticorena et al. 1599 (CONC 54196); Bío-Bío, Camino Bío-Bío a Copahue, Estero Epun, 3752’S, $71^{\circ} 27^{\prime} \mathrm{W}, 1260 \mathrm{~m}$ s.m., 13-III-1976, Marticorena et al. 973 (CONC 55397). IX Región de la Araucanía. Malleco, Camino Termas de

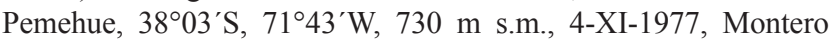
10575 (CONC 101091); Malleco, Reserva Forestal Malleco, Río Niblinto, $38^{\circ} 10^{\prime} \mathrm{S}, 71^{\circ} 45^{\prime} \mathrm{W}, 940$ m s.m., 29-X-1977, Marticorena \& Quezada 1530 (CONC 54008); Malleco, Capitán Pastene, $38^{\circ} 11^{\prime}$ S, $72^{\circ} 59^{\prime} \mathrm{W}, 400$ m s.m., 9-XII-1934, Montero 2269 (CONC 100871); Malleco, Laguna Malleco, 38¹3'S, 71²9'W, 900 m s.m., 1-I-1947, Pfister s.n. (CONC 7181); Malleco, Termas de Tolhuaca, $38^{\circ} 14^{\prime} \mathrm{S}, 71^{\circ} 44^{\prime} \mathrm{W}, 1250 \mathrm{~m}$ s.m., 2-I-1947, Pfister s.n. (CONC 7192); Termas de Tolhuaca, $38^{\circ} 14^{\prime} \mathrm{S}, 71^{\circ} 44^{\prime} \mathrm{W}, 1200 \mathrm{~m}$ s.m., 4I-1947, Gunckel 16365 (CONC 108162); Malleco, Malalcahuello, 38²8'S, 71³5'W, 950 m s.m., 4-I-1974, Zoellner 7726 (CONC 108196); Malleco, Salto de la Gloria o de la Princesa, $38^{\circ} 29^{\prime} \mathrm{S}$, 7147’W, 900 m s.m., 8-I-1977, Marticorena et al. 1229 (CONC 54194); Malleco, Termas de Río Blanco, 38³4'S, 71³8’ W, 1100 m s.m., XII-1947, Pfister s.n. (CONC 7819); Malleco, Tolhuaca, I1908, s.col. (SGO 61121); Cautín, Cunco, 38 ${ }^{\circ} 55^{\prime} \mathrm{S}, 7^{\circ} 02^{\prime} \mathrm{W}, 200$ m s.m., XI-1920, Hollermayer 309d (CONC 108178). XIV Región de Los Ríos. Valdivia, entre Lanco y Panguipulli, Purulon, 39²8'S, $72^{\circ} 41^{\prime} \mathrm{W}, 100$ m s.m., 12-I-1976, Marticorena et al. 224 (CONC 54307); Valdivia, Pilmaiquén, 39³8'S, $72^{\circ} 38^{\prime} \mathrm{W}, 180$ m s.m., 24-I-1928, Hollermayer s.n. (CONC 108177); Valdivia, Riñihue, $39^{\circ} 50^{\prime} \mathrm{S}, 7^{\circ} 25^{\prime} \mathrm{W}, 115$ m s.m., 6-XII-1958, Kunkel 389 (CONC
108181); Valdivia, Los Lagos, $39^{\circ} 52^{\prime} \mathrm{S}, 7^{\circ}{ }^{\circ} 49^{\prime} \mathrm{W}, 30$ m s.m., 14-X1933, Junge 335 (CONC 2835); Valdivia, Corral, Cerro de la Marina, 3953'S, 732 $5^{\prime}$ W, 30 m s.m., 17-X-1929, Gunckel 669 (CONC 108174); Corral, Pampa de Paredes, 3953'S, 7326'W, 25 m s.m., 3-XI-1929, Gunckel 1442 (CONC 108211); Valdivia. San Juan, 3955'S, 72³5'W, 35 m s.m., 8-II-1930, Gunckel 9151 (CONC 108217); Valdivia, Amargos, $39^{\circ} 52^{\prime} \mathrm{S}, 7^{\circ} 25^{\prime} \mathrm{W}, 25 \mathrm{~m}$ s.m., 16-III1930, Gunckel 9150 (CONC 108135); Corral, 3953'S, 73²6’ W, 50 m s.m., 23-XI-1930, Gunckel 1863 (CONC 108216); Corral, Mal Paso, 3953'S, 73²6’ W, 25 m s.m., Gunckel 2476 (CONC 108164); Valdivia. La Rama, $39^{\circ} 54^{\prime} \mathrm{S}, 7^{\circ} 24^{\prime} \mathrm{W}, 50 \mathrm{~m}$ s.m., 22-XI1931, Gunckel 36605 (CONC 108185); Corral, Mal Paso, 3953'S, 732ㄷ' W, 10 m s.m., 8-XII-1934, Gunckel 4940 (CONC 108176); Valdivia, Chaihuin, 3956'S, 73³3'W, 100 m s.m., 3-VI-1935, Gunckel 15617 (CONC 108209); Valdivia. Llancacura, 40¹8'S,

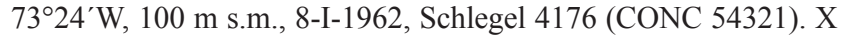
Región de Los Lagos. Osorno, Trumao, 40²1'S, 73¹0’W, $100 \mathrm{~m}$ s.m., X-1933, Hollermayer 309c (CONC 108184); Llanquihue, La

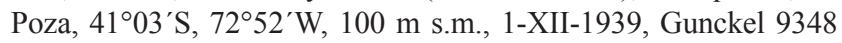
(CONC 108163); Llanquihue, Lago Todos Los Santos, $41^{\circ} 08^{\prime} \mathrm{S}$, $72^{\circ} 25^{\prime} \mathrm{W}, 185$ m s.m., III-1974, Castillo s.n. (CONC 108255); Llanquihue, Chilcon, Lago Todos Los Santos, $41^{\circ} 08^{\prime} \mathrm{S}, 72^{\circ} 25^{\prime} \mathrm{W}$, 180 m s.m., 21-I-1951, Pfister s.n. (CONC 10410); Chiloé, Rolecha, 41 ${ }^{\circ} 55^{\prime} \mathrm{S}, 7^{\circ} 50^{\prime} \mathrm{W}, 10 \mathrm{~m}$ s.m., 5-I-1951, Pfister s.n. (CONC 10319); Parque Nacional Puyehue, 6-XII-1998, Grosfeld s.n. (BCRU).

29. Valeriana polystachya Sm., Pl. Icon. Ined. 3: 51. 1791. TIPO: Argentina. Buenos Aires, Commerson 62 (holotipo, $\mathrm{P}$; isotipo, fot. MO 1629350!).

Hierba perenne de hasta $1,50 \mathrm{~m}$ alt., tallo simple o densamente ramificado y foliado. Rizoma leñoso hasta $5 \mathrm{~cm}$, a veces estolonífero. Tallos glabros. Hojas basales enteras o divididas, de aprox. $18 \mathrm{~cm}$; las enteras de lámina oblongo-lanceolada o lanceolada, aguda, dentada o aserrada, peciolada; las pinnatisectas, con 3-7 pares de segmentos opuestos, subopuestos o alternos, lineares, oblongos, obtusos o agudos. Inflorescencias en panículas espiciformes hasta $30 \mathrm{~cm}$. Brácteas de $6 \mathrm{~mm}$, enteras o divididas, lanceoladas. Bractéolas de 2,5-3 mm, triangulares, ovadas u ovado-lanceoladas. Brácteas y bractéolas pubescentes en las axilas. Flor masculina: de 3-3,5 mm; corola de 22,5 $\mathrm{mm}$, infundibuliforme-campanulada, gibosa; lóbulos ovados u oblongos; estambres inclusos. Flor femenina: de 1,5-2 mm; corola de $\pm 1-1,5 \mathrm{~mm}$, campanulada, gibosa en la base; estigma trífido. Fruto de 2-2,5 mm, oblongo, triquetro, glabro; caliz no desarrollado en pappus plumoso.

ILUSTRACIONES: Borsini, 1944: tab.153; 1999, 461.

Características distintivas: Hierba perenne de hasta 1,5 $\mathrm{m}$ alt.; rizoma leñoso; hojas basales enteras o generalmente pinnatisectas, con segmentos lineales, polimorfas; inflorescencias axilares y terminales en panículas espiciformes; fruto de 2-2,5 mm, oblongo, triquetro, glabro; sin pappus plumoso. 
Fenología: Florece de octubre a diciembre, fructifica en enero y febrero.

DistRIBUCIÓN: Especie nativa que se distribuye en Argentina, en las provincias de Buenos Aires y Río Negro, entre los 0 y 1000 m s.m. Está presente también en Uruguay (Borsini 1944, 1946) y SE de Brasil (Lörcher 1990).

Valeriana polystachya es afín a $V$. ferax (especie endémica del centro de Argentina, no incluida en este estudio), de la cual se diferencia por los tallos cilíndrico y por el fruto triquetro elipsoide u oblongo.

Material adicional examinado: ARGEnTINA. Buenos Aires. Tandil, Los Leones, 22-XI-1937, Pastore s.n. (SI 1214); Tandil, 3-XI-1928, Burkart 2800 (SI); Punta Chica, 2-X-1900, Hicken s.n. (SI 14518); Punta Chica (a orillas del Río de la Plata), 8-XI1951, Boelcke 6385 (SI); Mar del Plata, 11-XII-1913, Valentini 54 (SI 14548); Camino San Fernando, a orillas Río las Conchas, 13-XI-1952, Boelcke 6644 (SI); Partido de Tornquist, Sierra de la Ventana, 8-XI-1938, Cabrera 4704 (SI); Partido de Tornquist, Sierra de la Ventana, XI-1904, Dusén 6329 (SI); Sierra de la Ventana, 7-XI-1907, Hicken s.n. (SI 14522); Barrancas al sud, 23X-1902, Venturi 201 (SI); Capital Federal, Palermo, Hicken 1897 (SI 14521); San Fernando, Permington s.n. (SI 14519); A $^{\circ}$ Las Brusquitas, entre Dionisia y Chapadmalal, 25-I-1929, Hicken s.n. (SI 22708); Bosquecillo Bajo Belgrano, 30-X-1924, Millán 143 (SI); Palermo, X-1925, Burkart 430 (SI); Quilmes, costa del río, 3-XII-1899, Hicken s.n.(SI 14520); San Isidro, XI-1950, Hunziker 4615 (BAB); Isla Martín García, alrededores de La Cantera, 6-X2003, Hurrell 5336 (SI); Escobar, camino a Paraná de Las Palmas, puente sobre el río Luján, 31-X-2004, Hurrell 5797 (SI). Río Negro. Dpto. Adolfo Alsina: $100 \mathrm{~km}$ del puente Viedma-Patagones, 19-II1990, Botta \& Correa 10123 (BAB); finca Ya Verán, a orillas del Río Negro, 8-XI-1988, Correa et al. 9553 (BAB). BRASIL. Río Grande do Sul, Colonia do Erval, 9 km SO de Mariano Pimentel, aprox. 300 m s.m., 14-X-1978, Weberling 6356. URUGUAY. Cerro Largo y A ${ }^{\circ}$ Palleros, 8-I-1936, Rosengurtt 2141 (MVM 5678); Dpto. Montevideo: Punta Gorda, 10-XI-1912, Osten 6390 (MVM); Florida, Cerro Colorado, Estancia San Pedro, X-1942, s.col. (LIL 100173); Colonia, alrededores de Nueva Helvecia, Colonia Suiza, 15-X-1941, Legrand 2925 (MVM); El Durazno, Molles, 20-X1901, Osten 4260 (MVM); Dpto. Rivera: Tranqueras, XI-1899, Arechavaleta s.n. (MVM); Dpto. Canelones: Atlántida, 14-XII1919, Osten 15263 (MVM); La Floresta, Cañada, 10-XI-1929, Osten s.n. (MVM).

30. Valeriana radicalis Clos, in Gay, Hist. Polít. Chile, Bot. 3: 215. 1847. TIPO: Chile. 1839, Gay 1095 (holotipo, $\mathrm{P},=$ fot. F 37122! ).

Valeriana andina Meigen, Bot. Jahrb. 17: 293. 1893. TIPO: Chile. Santiago, Cajón de Yerba Loca, 3000-3300 m s.m., II-1892, s.col. (isotipo, SGO 56959!).

Hierba perenne de 5-20 $\mathrm{cm}$ alt., grácil, glabra o con pelos escasos. Tallo rizomatoso, leñoso, con hojas aglomeradas en la base formando rosetas. Hojas basales de 10-12 x 8-10 mm, espatuladas, ovadas, elípticas, u orbiculares obtusas, levemente crenuladas, pubescentes en su haz, subcarnosas; pecíolo hasta $8 \mathrm{~cm}$. Hojas superiores pequeñas, lineares. Inflorescencias terminales, contraídas o laxas. Pedúnculos débiles. Brácteas de $7 \times 2 \mathrm{~mm}$, enteras, oblongo-lanceoladas. Bractéolas de 2,5-4 x 1-1,5 mm, oblongas o lineares, glabras o con pelos aislados en sus márgenes. Flor hermafrodita: corola de 2,5-3 mm, infundibuliforme; estambres exertos. Flor femenina: corola de $2 \mathrm{~mm}$. Fruto unilocular de $4 \mathrm{~mm}$, estrechamente elipsoide, aplanado, lóculos estériles no desarrollados, glabro; pappus de 3,5-4 mm, formado por 12-16 setas.

ILUSTRACIONES: Borsini, 1966: 450.

CARActerísticas distintivas: Planta herbácea grácil; hojas basales espatuladas, ovadas u orbiculares, con largo pecíolo; hojas superiores pequeñas, lineares; inflorescencia terminal contraída o laxa; fruto de $4 \mathrm{~mm}$, estrechamente elipsoide, glabro; con pappus.

Fenología: Florece de diciembre a enero, fructifica a fin de verano.

DistRIBUCIÓN Y HÁBITAT: Habita en las montañas del centro de Chile, en la Provincia de Santiago (Región M), entre los 2.000 y $3.400 \mathrm{~m}$ s.m.

Valeriana radicalis se asemeja a $V$. boelckei en la morfología de las hojas basales, y se distingue por el rizoma leñoso y el fruto elipsoide de menor tamaño.

Material adicional examinado: CHILE. Región Metropolitana. Santiago, Cajón de la Yerba Loca, II-1891, Philippi s.n. (SGO 57058-57060); Santuario de la Naturaleza Yerba Loca, cuenca

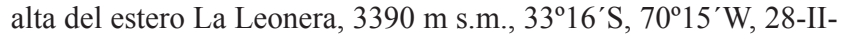
2000, Kalin Arroyo et al. 201442 (CONC 162967); Las Condes, $33^{\circ} 15^{\prime}$ S, $70^{\circ} 22^{\prime} \mathrm{W}, 2000$ m s.m., XII-1950, Morales s.n. (CONC 108206).

31. Valeriana ruizlealii Borsini, in Descole Gen. et Sp. Pl. Arg. 2: 349-350. 1944. TIPO: Argentina. Mendoza, Dpto. San Carlos, Estancia Llaucha, 2250 m s.m., 17-I-1941, Ruiz Leal 715 (holotipo, LIL!).

Hierba perenne de hasta $1 \mathrm{~m}$ alt. Rizoma de 2-7 cm, con restos foliares. Tallos simples o múltiples, densamente foliados. Hojas basales enteras hasta $32 \mathrm{~cm}$, espatuladas, obovadolanceoladas, obtusas o ligeramente acuminadas; lámina hasta 24 x 5,5 cm; pecíolo de 5-13 cm. Hojas superiores de 2-2,5 $\mathrm{cm}$, enteras o frecuentemente partidas hacia la base, sésiles. Inflorescencias espiciformes de hasta $50 \mathrm{~cm}$. Brácteas de 2,5-5 mm, pubescentes en las axilas. Bractéolas de 1-2,5 $\mathrm{mm}$. Flor hermafrodita: corola de $2 \mathrm{~mm}$, infundibuliforme; lóbulos oblongos; estambres inclusos; estigma trífido. Flor masculina: corola de 1,5-3 mm, infundibuliforme, gibosa 
en la parte media; lóbulos ovados u oblongos, obtusos; estambres iguales o más cortos que los lóbulos de la corola. Flor femenina: corola mucho más pequeña que las anteriores; lóbulos ovados, acuminados; estilo exerto. Fruto de 2-2,5 $\mathrm{mm}$, ovoide, curvado longitudinalmente, pubescente; cáliz no desarrollado en vilano plumoso.

ILUSTRACIONES: Borsini, 1944: tab. 151.

CARACTerísticas distintivas: Hojas basales de láminas enteras, espatuladas, obovado-lanceoladas, elípticas o suborbiculares; pecioladas; hojas superiores sésiles, enteras o frecuentemente partidas en la base; inflorescencias espiciformes; fruto de 2-2,5 mm, curvado longitudinalmente, pubescente; sin pappus.

Fenología: Florece de octubre a diciembre, fructifica en enero y febrero.

Distribución: Especie que habita en las provincias de Mendoza, La Rioja, Salta y San Juan, entre los 1500-4100 m s.m.

Valeriana ruizlealii se asemeja a $V$. macrorhiza en la morfología de las hojas basales y a $V$. polystachya por la inflorescencia glomeruliforme discontinua. Asimismo presenta frutos triquetros arqueados longitudinalmente similares a $V$. dinorrhiza.

Material adicional examinado: ARGentina. Mendoza. Dpto. Luján de Cuyo: La Crucesita, Cerro Verde, 20-XII-1938, Ruiz Leal 5379 (Herb. Ruiz Leal); Cuesta de las Chilcas, 15-X-1939, Ruiz Leal 6229 (Herb. Ruiz Leal); Dpto. Tunuyán: Rincón Colorado en la precordillera, 3000 m s.m., 8-III-1933, Ruiz Leal 1277 (Herb. Ruiz Leal); Malargüe, II-1940, Lombordozi s.n. (Herb. Ruiz Leal 8077). La Rioja. Dpto. Famatina: entre Los Corrales y Cueva de Pérez, 3600 m s.m., 13-I-1976, Cabrera et al. 27166 (SI). Salta. Cerro del Cajón, 4100 m s.m., 30-I-1914, Rodríguez 1377 (SI). San Juan. Angaco, Pie de Palo, camino a Mogote Corralitos, 6-II2000, Kiesling 9361 (SI).

32. Valeriana samolifolia (DC.) Colla, P1. rar. chil. Mem. Accad. Sci. Torino 33: 1835. Betckea samolifolia DC. Prodr. 4: 642. 1830. Plectritis samolifolia (DC.) Höck, Bot. Jahrb. 3: 37.1882. Valerianella samolifolia A. Gray, Proc. Amer. Acad. XIX, 83. 1883. TIPO: Chile. Punta de Cortés, Bertero s.n. (holotipo, $\mathrm{G}$, = fot. MO 137124!).

Plectritis samolifolia (DC.) Höck var. pusilla Speg., Nova Add. Fl. Pat. Mus. Nac. Buenos Aires 7: 299. 1902. TIPO: Argentina. Chubut, Carrenleufú, 1901, Illín s.n. (holotipo, BA 50824!).

Planta anual hasta $28 \mathrm{~cm}$ alt., simple o ramificada. Raíz pequeña, delgada. Tallos erguidos, paucifoliados. Hojas inferiores y superiores enteras, de $0,6 \times 3 \mathrm{~cm}$; láminas obovadas, u oblongas, obtusas o brevemente acuminadas, pubescentes en las axilas y márgenes, sésiles o pecioladas. Inflorescencias paucifloras, contraídas. Brácteas de 4-5 mm. Bractéolas de 1-4 mm, lanceoladas, lineares o filiformes. Brácteas y bractéolas con pelos en márgenes y axilas. Flor hermafrodita: cáliz subnulo; corola de $1.5-2 \mathrm{~mm}$, campanulada o infundibuliforme, gibosa, exteriormente pubescente; estambres inclusos; estigma 3-lobulado. Fruto de 2-2,5 x 1-1,2 mm, triquetro, ovoide, glabro; cáliz a la madurez no desarrollado en pappus plumoso.

ILUSTRACIONES: Borsini, 1944: tab. 125; 1999: 464.

CARacterísticas distintivas: Tallos poco foliados, hojas basales enteras, espatuladas, atenuadas en un pecíolo o sésiles, las superiores oblongas, sésiles; inflorescencia terminal o axilar, pauciflora; fruto unilocular, de 2-2,5 x 1-1,2 mm, triquetro, ovoide, glabro; sin pappus.

Fenología: Florece de octubre a diciembre, fructifica en enero y febrero.

DistribuCiÓn: Habita en las provincias centrales y sur de Chile, entre los 0 y $1.200 \mathrm{~m}$ s.m. (Regiones V, M, VI, VII, VIII y IX); en Argentina en la provincia de Chubut, entre los 500 y 1000 m s.m.

Valeriana samolifolia se asemeja a $V$. corymbulosa (especie del noroeste argentino, no incluida en este estudio) en el aspecto de la planta y el fruto, y se diferencia por ser una planta anual, con tallos tetrágonos y corola de la flor hermafrodita campanulada.

Material adicional examinado: ARGEnTina. Chubut. Río Corcovado, 1903, Illin s.n. (BAB). CHILE. Región Metropolitana. Santiago, Cerro San Cristóbal, X-1862, Philippi s.n. (SGO 57077); San Cristóbal, 15-IX-1878, s.col. (SGO 57078); Santiago, Cerro San Cristóbal, $33^{\circ} 25^{\prime} \mathrm{S}, 70^{\circ} 38^{\prime} \mathrm{W}, 800$ m s.m., X-1914, Baeza s.n. (CONC 45950); Cuesta de Lo Prado, 3329'S, 7057’ W, 800 m s.m., X-1932, Jaffuel s.n. (CONC 45951); Santiago, Cuesta de Lo Prado, 33⒉ $9^{\prime} \mathrm{S}, 70^{\circ} 57^{\prime} \mathrm{W}, 800$ m s.m., IX-1951, Levi 524 (CONC 108159); Santiago. Cerro Negro, San Bernardo, 33³7'S, $70^{\circ} 40^{\prime} \mathrm{W}, 600$ m s.m., X-1951, Gunckel 25617 (CONC 100449);

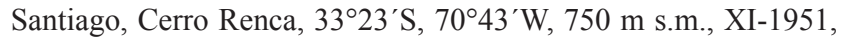
Gunckel 22588 (CONC 100443); Cerro San Cristóbal, 33²5'S, 70³8’ W, 550 m s.m., X-1952, Gunckel 40780 (CONC 108183); Santiago, Fundo de la Rinconada, 3330'S, 7052'W, 840 m s.m., IX-1955, Levi 2639 (CONC 108158); Santiago, La Rinconada, Maipú, Quebrada La Plata, 550 m s.m., 6-IX-1958, Schlegel 1694 (SGO 73362); Santiago, Rinconada Lo Cerda, Quebrada La Plata, 33²9’S, 7056'W, 860 m s.m., IX-1960, Schlegel 2943 (CONC

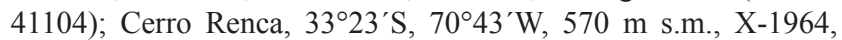
Montero 6864 (CONC 100865); Santiago, San Cristóbal, IX/X1978, s.col. (SGO 43490); Comuna de la Reina, Quebrada de Ramón, 33²6’S, 70³0’W, 800-1200 m s.m., 30-IX-2000, Tomé 230 (CONC 157296). V Región de Valparaíso. Petorca, Zapallar, $32^{\circ} 33^{\prime} \mathrm{S}, 71^{\circ} 28^{\prime} \mathrm{W}, 35 \mathrm{~m}$ s.m., IX-1908, Johow s.n. (CONC 
10448); Zapallar, Tigre, $32^{\circ} 33^{\prime} \mathrm{S}, 7^{\circ} 28^{\prime} \mathrm{W}, 20$ m s.m., IX-1923, K. Behn s.n. (CONC 103978); Petorca, Papudo, Quebrada El Salado, 32 $31^{\prime} \mathrm{S}, 71^{\circ} 25^{\prime} \mathrm{W}, 50$ m s.m., IX-1937, Montero 3206 (CONC 101090); Valparaíso. Quintero, $32^{\circ} 46^{\prime} \mathrm{S}, 71^{\circ} 32^{\prime} \mathrm{W}, 30$ m s.m., 8-XII-1950, Gunckel 19385 (CONC 100452); Quillota, Cerro Comunidad, Maitenes, 32 $59^{\prime} \mathrm{S}, 7^{\circ} 15^{\prime} \mathrm{W}, 120 \mathrm{~m}$ s.m., IX1929, Garaventa 402 (CONC 49847); Valparaíso, Marga-Marga, $33^{\circ} 06^{\prime} \mathrm{S}, 71^{\circ} 05^{\prime} \mathrm{W}, 150 \mathrm{~m}$ s.m., IX-1931, Jaffuel 3125 (CONC 45263); Quillota, Cerro Cruz, 3306' S, $71^{\circ} 16^{\prime} \mathrm{W}, 900$ m s.m., IX1929, Garaventa 437 (CONC 49518). VI Región de O’Higgins.

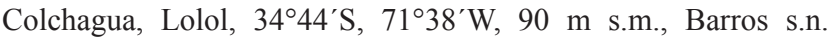

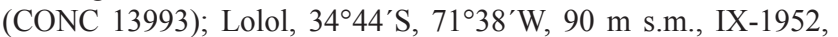
Barros s.n. (CONC 13962); Cardenal Caro. Alcántara, 3446'S, 71 ${ }^{\circ} 55^{\prime} \mathrm{W}, 50$ m s.m., IX-1951, Barros s.n. (CONC 13957). VII Región del Maule. Talca, Constitución, Cerro Matran, X-1890,

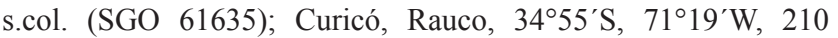
m s.m., IX-1920, Barros 855 (CONC 100450); Curicó, Cerro Condell, 345' ${ }^{\circ}$, $71^{\circ} 13^{\prime} \mathrm{W}, 290$ m s.m., IX-1925, Barros 998 (CONC 100444); Talca, Constitución, $35^{\circ} 20^{\prime} \mathrm{S}, 72^{\circ} 25^{\prime} \mathrm{W}, 50 \mathrm{~m}$ s.m., IX-1953, Gunckel 40783 (CONC 100446). VIII Región del Bío-Bío. Bío-Bío, San Rosendo, 37²16'S, 7243’W, 45 m s.m., IX-1926, Joseph 4387 (CONC 100447); Bío-Bío, Candelaria, Los Setenta, $37^{\circ} 22^{\prime} \mathrm{S}, 72^{\circ} 29^{\prime} \mathrm{W}, 100$ m s.m., XI-1935, Junge s.n. (CONC 5580); Bío-Bío, Antuco, 37²0’ S, 7141'W, 650 m s.m., X-1937, Barros s.n. (CONC 13991); Bío-Bío, Pangal del Laja, $37^{\circ} 10^{\prime}$ S, $72^{\circ} 12^{\prime} \mathrm{W}, 180$ m s.m., X-1959, Ricardi \& Marticorena

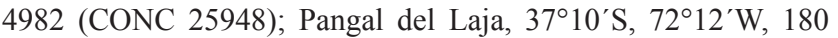
m s.m., X-1962, Ricardi 5215 (CONC 28339). IX Región de la Araucanía. Malleco, Lumaco, Puente del Cura, $38^{\circ} 10^{\prime} \mathrm{S}, 72^{\circ} 54^{\prime} \mathrm{W}$, 75 m s.m., X-1958, Kunkel 558 (CONC 100451).

33. Valeriana sedifolia d'Urv., Fl. Iles Malouines, Mem. Soc. Linn. 4: 612. 1826. Phyllactis sedifolia (d'Urv.) Wedd., Chloris Andina 2: 31. 1859. Aretiastrum sedifolium (d'Urv.) Graebn., Bot. Jahrb. 37: 373-563. 1906. TIPO: Argentina. Islas Malvinas, Monte Chatellaux, XI/X-1822, d'Urville s.n. (holotipo, P; isotipo, fragm. fot. MO!).

Valeriana sedoides Hombr. \& Jacq., Voy. Pole Sud, tab. 16 A. 1852. TIPO: Estrecho de Magallanes, 1837-1840, Hombron \& Jacquinot s.n. (holotipo, P).

Valeriana magellanica Decne. in Hombr. \& Jacquinot, Voy. Pole Sud, tab. 16 B. 1852. Phyllactis magellanica (Decne.) Speg., An. Soc. Cient. Argent. 48: 172 1899. TIPO: Estrecho de Magallanes, 1837-1840, Hombron \& Jacquinot s.n. (holotipo, P).

Phyllactis magellanica (Decne.) Speg. var. azorelloides Speg. An. Soc. Cient. Argent. 48:172 1899. Valeriana magellanica Decne. var. azorelloides (Speg.) Macloskie. Skott Exp. Patag. 748. 1903-06. TIPO: Karr-aik, Lago Argentino, III-1898, C. Ameghino s.n. (holotipo, LP ex LPS 11861 !).

Hierba perenne de 1-4 cm alt., ramificada, formando densos cojines. Raíces filiformes y rizoma hasta $2,5 \mathrm{~cm}$. Hojas enteras de 4-8 mm, lingüiformes, imbricadas, ápice engrosado, papiloso, coriáceas, sésiles. Inflorescencias paucifloras, agrupadas en la porción apical de las ramas, contraídas.
Flor masculina: corola de 2,5 mm, infundibuliforme; tubo giboso en la base; lóbulos obovados; estambres inclusos. Flor femenina: corola de 1-1,5 mm, campanulada. Fruto de -2 mm, ovoide, lóculos estériles no desarrollados, glabro; pappus formado por 8-10 setas plumosas.

ILustraciones: Borsini, 1944: tab. 137; 1999, 464.

CARACterísticas Distintivas: Planta pequeña, cespitosa, glabra; hojas enteras, imbricadas, aglomeradas, de ápice obtuso, redondeado y papiloso; inflorescencias terminales contraídas, que apenas sobrepasan la longitud de las hojas; fruto de $-2 \mathrm{~mm}$, ovoide, glabro; con pappus.

FenOlogía: Florece en enero y fructifica en febrero.

DisTRIBUCIÓN Y HÁBITAT: Habita en peñascos húmedos, en la zona del Estrecho de Magallanes e Islas Malvinas. En Chile en la Región XII; en Argentina en las provincias de Santa Cruz y Tierra del Fuego, entre los 500 y 1.500 m s.m.

Valeriana sedifolia es afín a $V$. descolei, de la cual se diferencia por sus hojas linguiformes, coriáceas e imbricadas y por el fruto glabro con pappus plumoso.

Material adicional examinado: ARGENTINA. Santa Cruz. Dpto. Guer Aike: Valle Superior del Río Turbio, 51 ${ }^{\circ} 27^{\prime} \mathrm{S}, 7^{\circ} 05^{\prime} \mathrm{W}, 980$ m s.m., 5-II-1978, Ambrosetti \& Méndez 531 (CONC 52155); Estancia Stag River, $51^{\circ} 34^{\prime} \mathrm{S}, 72^{\circ} 01^{\prime} \mathrm{W}, 750 \mathrm{~m}$ s.m., 15-II-1978, TBPA 3256 (CONC 52156); Patagonia, Cerro Mocho, 1000 m s.m., II-1900, s.col. (SGO 57061); Lago Argentino, El Calafate, Ea La Anita, Cerro Huiliche exc 4x4, Laberinto 2, 14-XI-2001, Guerrido 440 (SI). Tierra del Fuego. Dpto. Río Grande: Estancia El Salvador, $\pm 60 \mathrm{~km}$ NO de Río Grande, 20-XI-1971, Boelcke et al. 15105 (BAB); Río Grande, Estancia San Julio, Cerro Hongo, 18-V-1972, Goodall 4282 (BAB); Estancia Sarmiento, 17-XII-1972, Goodall 4381 (BAB); Islas Falkland, cima del Monte Adam, 715 m s.m., 13-XII-1907, Skottsberg 78 (SGO 58721; BA 41802). CHILE. XII Región de Magallanes. Última Esperanza, Sierra Baguales, Estancia La Cumbre, frontera Chile-Argentina, 50 $37^{\prime} \mathrm{S}, 7^{\circ} 23^{\prime} \mathrm{W}, 1100 \mathrm{~m}$ s.m., 2-XII-1986, Landero 639 (CONC 93192); Última Esperanza, Sierra Baguales, Cerro Santa Lucía, 5044'S, 72²0’W, 1000 m s.m., 1-XII-1984, Kalin Arroyo et al. 841027 (CONC 76912); Sierra Baguales, Cerro Santa Lucía, 5044’S, 72²0’W, 1100 m s.m., 23XII-1984, Kalin Arroyo 841126 (CONC 76900); Última Esperanza, Cerro Donoso, Río de Las Chinas, 5044’ S, $72^{\circ} 31^{\prime} \mathrm{W}, 900$ m s.m., 9/11-II-1987, Kalin Arroyo et al. 870263 (CONC 86617); Mitad de camino entre Caleta Clarencia-Cerro Sombrero, 52 $54^{\prime} \mathrm{S}, 70^{\circ} 08^{\prime} \mathrm{W}$, 20 m s.m., XI-1957, Magens 1108 (CONC 23705).

34. Valeriana sphaerocarpa Phil., Anales Univ. Chile 41: 732. 1872. TIPO: Chile. Aconcagua, Purutum, IX-1865, Philippi 988 (lectotipo, designado por Borsini (1966: 429), SGO 43507!).

Hierba anual hasta $2 \mathrm{~m}$ de alt. Tallos aéreos fistulosos. Hojas basales pinnatisectas, de $8-10 \mathrm{~cm}$; con 2-3 pares de 
lóbulos laterales, ovado-lanceolados, y el lóbulo terminal de mayor tamaño, márgenes aserrados o crenados; pecioladas. Inflorescencias muy desarrolladas, laxas. Brácteas de 4-8 $\mathrm{mm}$. Bractéolas de 2 × 0,5 mm, lanceoladas o lineares, con pelos aislados en sus márgenes. Flor hermafrodita: corola de $1 \mathrm{~mm}$, rotácea, lóbulos ovados. Flor femenina: corola muy pequeña; estilo exerto. Fruto trilocular, lóculo fértil de de 1 x $1 \mathrm{~mm}$ y los estériles de 1,5 x 1,2-1,5 mm, globoso, los lóculos estériles están tan desarrollados como el fértil, densamente pubescente; pappus formado por 12-14 setas plumosas.

ILUSTRACIONES: Borsini, 1966: 466.

CARACTERÍsticas Distintivas: Planta de hasta $2 \mathrm{~m}$ de alt., hojas basales y superiores pinnatisectas, con segmento terminal de mayor tamaño y 2-3 pares de segmentos laterales; inflorescencias muy laxas; fruto globoso, densamente pubescente; con pappus.

Fenología: Florece de septiembre a octubre, fructifica en los meses de verano.

Distribución Y HÁBITAT: Es una especie endémica de la Provincia de Aconcagua, en Chile (Región V). Crece en zonas de matorral.

Valeriana sphaerocarpa es afín a $V$. crispa, ambas especies son anuales y se parecen en la morfología de las hojas basales, y se diferencian en el fruto que es globoso y densamente pubescente en $V$. sphaerocarpa y presenta lóculos estériles separados por un surco y es glabro en $V$. crispa.

Material adicional EXAMinado: Sólo se ha observado el ejemplar tipo (SGO).

35. Valeriana stricta Clos in Gay, Hist. Chile, Bot. 3: 235. 1847. TIPO: Chile. Coquimbo, La Serena, 1836, Gay 1990 (holotipo, $\mathrm{P}$, = fot. F 37130!).

Valeriana glauca Poepp. in DC., Prodr. 4: 639. 1830. TIPO: Chile. Poeppig 127 (holotipo, G, = fot. F 37108 ex $\mathrm{P} !)$.

Valeriana elegans Clos in Gay, Fl. Chile 3: 236. 1847. Valeriana glauca DC. var. elegans (Clos) Reiche, Anales Univ. de Chile. 3: 176. 1902. TIPO: Chile. Cordillera de Santiago, 1839, Gay 488 (holotipo, P, = isotipo fot.K!).

Hierba perenne hasta $1 \mathrm{~m}$ alt., ramificada, hirsuta, con pelos densos o aislados. Tallos aéreos con hojas aglomeradas cerca de la base o en la parte media del tallo. Hojas basales pinnatipartidas a pinnatisectas, de 6-15 x 2-4 cm, de ámbito oblongo, lóbulos irregulares, alternos, polimorfos, ovados u oblongos, márgenes enteros o crenulados, carnosas; sésiles o cortamente pecioladas; pecíolo grueso, ensanchado en la base, canaliculado, con pelos hirsutos densos en la cara ventral. Hojas superiores pinnatisectas, de 5-20 mm, segmentos lineares, sésiles. Inflorescencias contraídas o densamente ramificadas y laxas. Pedúnculos con pelos simples. Brácteas de 5-10 $\mathrm{mm}$, enteras, oblongo-lanceoladas. Bractéolas de 1-4 $\mathrm{mm}$, lanceoladas o lineares. Flor hermafrodita: corola de 2,5 mm, infundibuliforme-campanulada, gibosa; lóbulos ovados; estambres exertos; ovario elipsoide, glabro. Flor femenina: corola de 1-1,2 mm, rotácea, gibosa; lóbulos ovados; estilo exerto; estigmas lamelados. Fruto de 2-4,5 x 1,2-1,5 mm, lageniforme, con esbozos de lóculos estériles en el ápice del fértil; bordes gruesos doblados hacia la cara trinervada, glabro, papiloso; pappus formado por 10 setas plumosas.

ILUSTRACIONES: Borsini, 1966: 456.

CARACTERísticas Distintivas: Tallos con hojas aglomeradas en la base o en la parte media del mismo, hojas basales y superiores pinnatisectas, segmentos polimorfos, carnosos; la pubescencia es variable, existiendo ejemplares con hojas glabras, hasta escasa o densamente pubescentes; inflorescencias contraídas o densamente ramificadas y laxas; fruto de 2-4,5 lageniforme, con lóculos estériles reducidos a esbozos en el ápice de la cara trinervada, glabro; con pappus.

FenOloGía: Florece en noviembre a enero.

DiSTRIBUCIÓN Y HÁBITAT: Se distribuye ampliamente en las provincias del norte-centro de Chile (Regiones III, IV, V, M, VI, VII y XIV); en Argentina ha sido recolectada en Mendoza. Habita hasta los 3.300 m s.m.

Valeriana stricta es afín a $V$. vaga, de la cual se diferencia por sus hojas carnosas y frutos lageniformes y papilosos.

Observación: Esta especie estaba registrada como endémica de Chile; aquí se cita para Argentina, existiendo ejemplares de la provincia de Mendoza.

Material adicional examinado: ARGENTINA. Mendoza. Puente del Inca, Cerro base, 2700-2900 m s.m., II/III-1940, Dawson \& Ruiz Leal 98 (SI); Dpto. Malargue: Los Molles, 1900 m s.m., Cabrera et al. 33351 (SI); Alto Valle de El Sosneado, 2700 m s.m., 19-II1942, Burkart et al. s.n. (SI 14309-14310). CHILE. III Región de Atacama. Huasco, Río Laguna Grande, 2853'S, 7008'W, 2400 m s.m., II-1981, Kalin Arroyo 81501 (CONC 53528); Río Laguna Grande, $28^{\circ} 47^{\prime} \mathrm{S}, 70^{\circ} 02^{\prime} \mathrm{W}, 2400 \mathrm{~m}$ s.m., I-1983, Marticorena et al. 83378 (CONC 55090); Río Laguna Grande, $28^{\circ} 45^{\prime} \mathrm{S}, 6^{\circ} 57^{\prime} \mathrm{W}$, 3100 m s.m., I-1983, Marticorena et al. 83395 (CONC 55652); Huasco, Río Chollay, km 14, 2908'S, 7009'W, 2300 m s.m., I1994, Arancio et al. 94153 (CONC 129215); Huasco, Quebrada 
La Totora, en las laderas rocosas, 2500 m.sm., $28^{\circ} 40^{\prime} \mathrm{S}, 70^{\circ} 11^{\prime} \mathrm{W}$, II-2008, Teillier \& Delaunoy 5583 (CONC 166871). IV Región de Coquimbo. Tulahuen, Río Toscadero, 1889/90, Geisse s.n. (SGO 56996); Ovalle, Tulahuen, Río Toscadero, XI-1896, Geisse s.n. (SGO 72776); Coquimbo, Illapel, Cuesta de Los Hornos, XI-1898, Geisse s.n. (SGO 72882); Illapel, Cuesta de los Hornos, $45 \mathrm{~km}$ al N de Illapel, en la cumbre, Muñoz P. 2351 (SGO 112614); Limarí, Cerro Tulahuen, faldeos, $30^{\circ} 59^{\prime} \mathrm{S}, 70^{\circ} 42^{\prime} \mathrm{W}, 1800 \mathrm{~m}$ s.m., 10-X1948, Jiles 1062 (CONC 93674); Limarí, Cabrería, Morro Blanco, 3046'S, 7043'W, 1600 m s.m., X-1949, Jiles 1594 (CONC 54327); Limarí, Cordillera de Ovalle, El Maitén, $30^{\circ} 48^{\prime} \mathrm{S}, 70^{\circ} 36^{\prime} \mathrm{W}$, 1400 m s.m., 27-I-1954, Jiles 2456 (CONC 93675-32218); Limarí, Río Molles, 3043'S, 70³1'W, 1600 m s.m., XII-1955, Jiles 2882 (CONC 54328); Limarí, Cordillera de Ovalle, Quebrada Larga, $30^{\circ} 44^{\prime} \mathrm{S}, 7^{\circ} 23^{\prime} \mathrm{W}, 2700$ m s.m., 8-XII-1957, Jiles 3366 (CONC 93677); Los Molles, $30^{\circ} 43^{\prime} \mathrm{S}, 70^{\circ} 31^{\prime} \mathrm{W}, 2600 \mathrm{~m}$ s.m., I-1966, Jiles 4757 (CONC 32472); Coquimbo, Ovalle, Mantos Grandes, $2600 \mathrm{~m}$ s.m., 10-X-1958, Jiles 3542 (CONC 54324); Coquimbo, Cordillera de Illapel, La Polcura, $31^{\circ} 30^{\prime} \mathrm{S}, 70^{\circ} 40^{\prime} \mathrm{W}, 2300 \mathrm{~m}$ s.m., 16-II1962, Jiles 4256 (CONC 91313); Coquimbo, Cordillera de Ovalle, Mantos Grandes, 3052'S, 70³3'W, 2600 m s.m., 19-I-1972, Jiles 5874 (CONC 103292); Coquimbo, Cuesta del Espino, 31 ${ }^{\circ} 20^{\prime} \mathrm{S}$, 71ํ6'W, 1400 m s.m., 18-X-1963, Marticorena \& Matthei 412 (CONC 54190); Elqui, Río Claro, 30²0’ S, 70²7’ W, 2600 m s.m., XI-1990, Ruthsatz 6436 (CONC 135947). V Región de Valparaíso. Altos del Colliguay, XI-1893, Onel s.n. (SGO 56994); Valparaíso, Cerro Las Vizcachas (sobre Mina de Cu), 7-XII-1951, Hutchinson 112 (SGO 75357); Valparaíso, Limache, Cuesta de La Dormida, 1160 m s.m., 26-X-1941, K. Behn s.n. (CONC 21669-21670); Aconcagua, Los Andes, Río Blanco, 1300 m s.m., 23-XI-1929, K. Behn s.n. (CONC 21685-21686); Los Andes, camino de Los Andes a Portillo-km 46, 1920 m s.m., 15-XI-1970, Marticorena \& Weldt 577 (CONC 35344); Aconcagua, Camino Internacional de Los Andes a Argentina, Juncal, 32 $54^{\prime} \mathrm{S}, 70^{\circ} 13^{\prime} \mathrm{W}, 2200 \mathrm{~m}$ s.m., 16-I-1964, Marticorena \& Matthei 636 (CONC 54191); Aconcagua, Camino Internacional a Portillo, Puente El Peñón, $32^{\circ} 52^{\prime} \mathrm{S}, 70^{\circ} 11^{\prime} \mathrm{W}, 1900 \mathrm{~m}$ s.m., 13-I-1973, Marticorena et al. 640 (CONC 54281); Aconcagua, Juncal, 2300 m s.m., 26-XI1970, Mahu 6479 (CONC 101092); Aconcagua, Jahuel (EL Laja), 12-XI-1955, Barrientos 1763 (CONC 108238); Aconcagua, Río Colorado, Los Maitenes, 2000 m s.m., 28-XI-1969, Zoellner 3569 (CONC 108254). Región Metropolitana. Santiago, Cordillera de Santiago, XII-1856, s.col. (SGO 57109); Cordillera de Santiago, II-1857, s.col. (SGO 57032); Santiago, Salto de Agua, VIII-1854, Germain s.n. (SGO 57023); Salto de Agua, XI-1862, s.col. (SGO 43442); Santiago, Salto San Ramón, IX-1891, s.col. (SGO 61677); Santiago, Cordillera de Las Arañas, X-1853, Philippi s.n. (SGO 57022); Santiago, Cordillera de Santiago, XII-1856, s.col. (SGO 57109); Santiago, Catemu, IX-1860, s.col. (SGO 57025); Santiago, Quebrada de San Ramón, Philippi 984 (SGO 43443); Santiago, Río San Francisco, 2500 m s.m., XII-1924, Werdermann 484 (CONC 108170); Santiago, Stebb 8888 (SGO 139929); Santiago, Peñalolén, Sierra s.n. (SGO 122713); Santiago, Cajón del Maipo, trayecto vega "Las Gualtatas" hasta Bocatoma, Villagrán 8640 (SGO 142735); Santiago, Alta Cordillera de Santiago, X-1920, Jaffuel 457 (CONC 54256); Santiago, Lo Valdés, en cercanías del Refugio alemán, Quebrada Valdés, 20-XI-1940, Garaventa 5665 (CONC 54274); Santiago, Cerro Caleu, $33^{\circ} 00^{\prime} \mathrm{S}, 71^{\circ} 00^{\prime} \mathrm{W}, 1100 \mathrm{~m}$ s.m., 10-IX-1952, Schlegel 118 (CONC 51597); Santiago, Quebrada de Peñalolén, 33²8'S, 70³3’ W, 2000 m s.m., XII-1952, Bravo s.n.
(CONC 108236); Santiago, Cordillera de Las Condes, 3300 m s.m., X-1953, Gunckel 40768 (CONC 108237); Santiago, entre Caldera y Maitenes, 2100 m s.m., 11-XII-1954, Skottsberg \& Sparre 11051 (CONC 18168); Santiago, entre Lo Valdés, Valle de El Morado, 334' S, 7001' W, 2300 m s.m., 15-X-1956, Schlegel 1204 (CONC 54312); Santiago, Cerro Provincia, $33^{\circ} 25^{\prime} \mathrm{S}, 70^{\circ} 25^{\prime} \mathrm{W}, 2160 \mathrm{~m}$ s.m., 30-X-1960, Schlegel 3082 (CONC 54185); Santiago, San José de Maipo, 7-IX-1962, Navas 2921 (SGO 73940); Santiago,

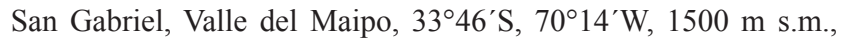
11-X-1962, Schlegel 4408 (CONC 54813); Santiago, Entre Lo Valdés y La Yesera, 3349' S, 7001'W, 2450 m s.m., 11-II-1963, Ricardi et al. 878 (CONC 54204); Santiago, Camino de Santiago a Mina La Disputada, $3 \mathrm{~km}$ antes de Pérez Caldera, 2500 m s.m., 17-I-1964, Marticorena \& Matthei 677 (CONC 54297); Santiago, Cajón del Maipo, Lo Valdés, Cerro Catedral, 2000 m s.m., 6-XII1970, Weldt 709 (CONC 35736); Monumento Natural El Morado, Cajón del Morales, 3349'S, 7005’W, 1900 m s.m., 14-I-1991, Teillier et al. 2306 (SGO 133064; CONC 156691); Comuna de La reina, Quebrada de Ramón, 33²6’S, 70³0’W, 1600-1900 m s.m., 13-I-2001, Tomé 316 (CONC 156961); Santuario de la Naturaleza Yerba Loca, Cajón del estero de Yerba Loca, ladera E, 2100 m s.m., 33ำ $18^{\prime} \mathrm{S}, 70^{\circ} 19^{\prime} \mathrm{W}, 10-\mathrm{XII}-1998$, Kalin Arroyo et al. 980654 (CONC 167045). VI Región de O’Higgins. Colchagua, San Fernando, Vegas del Flaco, Alto de Las Cabras, 2000 m s.m., 10-II-1955, Ricardi 3213 (CONC 18903); Colchagua, Cordillera de Colchagua, Landbeck s.n. (SGO 57024); Colchagua, San Fernando, Termas del Flaco, 1700 m s.m., 31-XII-1974, Montero 9696 (CONC 100868). VII Región del Maule. Curicó, Río Teno, 1000 m s.m., 31-XII-1970, Zoellner 4995 (CONC 108219). XIV Región de Los Ríos. Mal Paso, 13-II-1883, s.col. (SGO 56980); Mal Paso, por Huanto, 13-II-1884, s.col. (SGO 43471); Guardia Vieja, 1600 m s.m., XI-1934, Milner s.n. (CONC 54269).

36. Valeriana vaga Clos in Gay, Hist. Chile, Bot. 3: 227. 1847. TIPO: Chile. Gay s.n. (holotipo, P, = fot. F 37132!; isotipo fot. $\mathrm{K}$ !).

Valeriana muriculata Phil., Linnaea 33: 102. 18645. TIPO: Chile. Cajón del Arrayán, X-1859, Philippi s.n. (lectotipo, designado por Borsini (1966: 419), SGO 56961!; isolectotipo fot. $\mathrm{K}$ !).

Hierba perenne hasta $60 \mathrm{~cm}$ de alt., glabro. Rizoma estriado transversalmente, con raíces tenues o engrosadas, $\mathrm{y}$ restos foliares en la base. Tallos aéreos numerosos, estriados. Hojas pinnatipartidas a pinnatisectas de 6-10 cm; segmentos oblongos, obovados o lineares, el terminal más desarrollado; márgenes enteros, sinuados o dentados; membranáceos. Inflorescencias laxas. Brácteas de $10 \mathrm{~mm}$, enteras o pinnatipartidas. Bractéolas de 2-5 x 0,5-1 mm, lineares u oblongas. Flor hermafrodita: corola de 2-2,2 $\mathrm{mm}$, infundibuliforme, gibosa, glabra, lóbulos ovados; estambres inclusos. Fruto unilocular de 2,5-3 mm, ovoide, cóncavo-convexo, bordes gruesos y curvados hacia la cara trinervada, glabro, muricado; pappus formado por 9-12 setas.

ILUSTRACIONES: Borsini, 1966: 459. 
CARACTERÍSTICAS DisTinTIVAS: Hojas divididas, lóbulo terminal más desarrollado, los demás dispuestos en no más de 4 pares, disminuyen de tamaño hacia la base; membranáceas; inflorescencias axilares y terminales, contraídas o laxas; fruto unilocular, de 2,5-3 mm, ovoide, cóncavo, glabro, y cubierto de protuberancias en toda su superficie (muricado); con pappus.

Fenología: Florece de noviembre a diciembre, fructifica en enero y febrero.

DistribuCión Y hÁBITAT: Especie endémica de Chile que se distribuye en las provincias del centro-norte (Regiones III, IV, V y M) entre los 1.000 y 2.800 m s.m., en valles precordilleranos y montañas bajas.

Valeriana vaga es afín a $V$. stricta, de la cual se diferencia por sus hojas membranáceas y los frutos ovoides, con los bordes doblados hacia la cara trinervada, y muricados.

Material adicional examinado: CHILE. III Región de Atacama. Huasco, Río Laguna Grande, entre Potrero de Toledo y Quebrada Candelilla, 28 $47^{\prime} \mathrm{S}, 7^{\circ} 02^{\prime} \mathrm{W}, 2400-2800 \mathrm{~m}$ s.m., 13-II-1981, Kalin Arroyo 81540 (CONC 53488). IV Región de Coquimbo. Ovalle, Tulahuen, 1889/90, Geisse s.n. (SGO 57069). V Región de Valparaíso. San Felipe, IX-1861, Philippi 981 (SGO 57066); Valparaíso, Cerro Montenegro, entre Llay-Llay y Tiltil, 1200 m s.m., 10-X-1970, Zoellner 4331 (CONC 108235). Región Metropolitana. Santiago, Cerro de Renca, VIII-1854, Germain s.n. (SGO 57068); Santiago, Volckmann s.n. (SGO 43454); Santiago, Catemu, IX-1860, s.col. (SGO 57067); Santiago, Quebrada de Peñalolén, $33^{\circ} 28^{\prime} \mathrm{S}, 70^{\circ} 33^{\prime} \mathrm{W}, 1200$ m s.m., 14-XI-1951, Gunckel 25118 (CONC 108180); Quebrada de Peñalolén, 33²8'S, 70³3'W, 2000 m s.m., XI-1952, Bravo 133 (CONC 108160); Quebrada de Peñalolén, $33^{\circ} 28^{\prime} \mathrm{S}, 7^{\circ} 33^{\prime} \mathrm{W}, 1300$ m s.m., 14-XI1953, Bravo 430 (CONC 108169).

37. Valeriana valdiviana Phil., Linnaea 28: 700. 1858. TIPO: Chile. Araucanía, Renaico, XI-1887, s.col. (neotipo, designado aquí, SGO 56978!; isoneotipo SGO 57093!).

Planta anual hasta $1 \mathrm{~m}$ alt. Tallo tetrágono, hirsuto, particularmente en los nudos. Hojas inferiores pinnatilobadas a pinnatisectas, hasta $28 \mathrm{~cm}$, con 4 pares de segmentos laterales, ovados u oblongos; el segmento terminal de mayor tamaño, hasta $9 \mathrm{~cm}$; márgenes irregularmente dentados o erosados; pubescentes, membranáceas; pecíolos con nervaduras marcadas. Inflorescencias hasta $50 \mathrm{~cm}$, laxas; pedúnculos pubescentes. Brácteas de $5 \mathrm{~mm}$, lineares, auriculadas, pubescentes. Bractéolas de 1,5-2 mm, ovadas u oblongo-lanceoladas, con abundantes pelos. Flor hermafrodita: corola de 1,2$1,5 \mathrm{~mm}$, infundibuliforme, externamente pilosa; lóbulos ovados u oblongos; estambres inclusos; anteras elipsoides. Fruto de 1,5 x $1 \mathrm{~mm}$, elipsoide, bordes doblados hacia la cara trinervada, con lóculos estériles reducidos a esbozos, pubescencia rala, papiloso; pappus formado por 9-11 setas plumosas.

ILUSTRACIONES: Borsini, 1966: 457.

CARACTERísticas Distintivas: Hojas pinnatilobadas a pinnatisectas, membranáceas, pubescentes, el segmento terminal mucho más desarrollado, los restantes, 2-4 pares, disminuyen de tamaño hacia la base; inflorescencias hasta $50 \mathrm{~cm}$; el fruto es uno de los más pequeños, de $1,5 \times 1 \mathrm{~mm}$, elipsoide, con esbozos de dos lóculos estériles en el ápice de la cara trinervada, escasamente pubescente, papiloso; con pappus.

Fenología: Florece de octubre a diciembre, fructifica en enero y febrero.

Distribución: Habita las provincias del centro y sur de Chile (Regiones V, VII, VIII, IX y X).

Valeriana valdiviana es afín a $V$. virescens y $V$. grandifolia, todas anuales; de ambas especies se diferencia por sus frutos elipsoides y glabros.

Observación: La descripción de Philippi está basada en material que él mismo coleccionó. Ante la pérdida total del material original se ha decidido designar un neotipo seleccionado de los materiales depositados en SGO.

Material adicional examinado: CHILE. IX Región de la Araucanía. Cautín, Puerto Saavedra, $38^{\circ} 47^{\prime} \mathrm{S}, 73^{\circ} 23^{\prime} \mathrm{W}, 8 \mathrm{~m}$ s.m., I-1951, Aravena 51 (CONC 54305); Cautín, Temuco, Cerro Nielol, $38^{\circ} 43^{\prime} \mathrm{S}, 72^{\circ} 35^{\prime} \mathrm{W}, 150 \mathrm{~m}$ s.m., I-1962, Montero 6538 (CONC 101087).

38. Valeriana velutina Clos in Gay, Hist. Chile, Bot. 3: 233. 1847. TIPO: Chile. Provincia de Coquimbo, La Serena, 1836, Gay 103 (holotipo, P, = fot. F 37134!).

Hierba perenne de 40-60 $\mathrm{cm}$ de alt., ramificada, densamente pubescente. Tallos tetrágonos, levemente alados. Hojas enteras, liradas, pinnatilobadas o pinnatisectas, hasta 10 $\mathrm{cm}$; segmentos ovado-lanceolados o lanceolados, sésiles, decurrentes hacia el pecíolo; lóbulo terminal peciolado y generalmente más grande, márgenes irregularmente dentados o lobulados; membranáceas. Hojas superiores pinnatisectas. Inflorescencias alargadas, laxas. Brácteas de 5-10 mm, lineares. Bractéolas de 2-5 x 1-1,5 mm, oblongas, enteras o auriculadas. Brácteas y bracteolas con pequeños pelos capitados en la base. Flor hermafrodita: corola de 2 $\mathrm{mm}$, infundibuliforme, gibosa; lóbulos oblongos; estambres inclusos; ovario elipsoide. Flor femenina: corola de 0,8-1,2 $\mathrm{mm}$; estilo exerto. Fruto de 2-2,2 mm, ovoide, aplanado o 
ligeramente cóncavo-convexo, bordes engrosados y doblados hacia la cara trinervada, rugosos y cortamente pubescentes en ambas caras; pappus formado por 9-11 setas.

ILUSTRACIONES: Borsini, 1966: 454.

CARACTERísticas Distintivas: Planta cubierta por tomento blanquecino, denso; hojas enteras, liradas, pinnatilobadas a pinnatisectas; inflorescencias alargadas, laxas; fruto de 2-2,2 $\mathrm{mm}$, anchamente ovoide, escasa y cortamente pubescente en ambas caras; con pappus.

Fenología: Florece de septiembre a octubre, fructifica en noviembre y diciembre.

DistribuCión Y HÁBITAT: Especie endémica de Chile que se distribuye en las provincias centrales (Regiones IV y V); crece en ambientes de montaña, hasta los 2.200 m s.m.

Valeriana velutina es afín a $V$. polemoniifolia, de la cual se diferencia por los segmentos de las hojas basales que son ovados y por la flor hermafrodita que es infundibuliforme, mientras en $V$. polemoniifolia es campanulada.

Material adicional examinado: CHILE. IV Región de Coquimbo. Limarí, Los Molles, 3044'S, 70³6’W, 1500 m s.m., I-1972, Zoellner 6253 (CONC 108245); Coquimbo-La Serena, $3 \mathrm{~km}$ al N-Punta de Teatinos, en sitios rocosos, Muñoz Pizarro 3251 (SGO 118652); Ovalle, Cerro Pan de Azúcar, camino longitudinal a Ovalle, Muñoz Pizarro 3302 (SGO 118699). V Región de Valparaíso. Los Andes, Juncal, Río Blanco, 32 ${ }^{\circ} 53^{\prime} \mathrm{S}, 70^{\circ} 10^{\prime} \mathrm{W}$, 2200 m s.m., XII-1976, Zoellner 9210 (CONC 108239).

39. Valeriana verticillata Clos, in Gay, Hist. Chile, Bot. 3 : 223. 1847. TIPO: Chile. 1839, Gay s.n. (holotipo, $\mathrm{P},=$ fot. F 37135!).

Hierba perenne hasta $60 \mathrm{~cm}$ de alt. Raíz tortuosa. Numerosos tallos gruesos, huecos, estriados, muy hojosos en la base, glabros o con pelos dispersos. Hojas pinnatipartidas a pinnatisectas hasta $11 \mathrm{~cm}$, con 3-6 pares de segmentos oblongos, enteros, dentados o profundamente lobulados, membranáceos; pecíolo ancho. Hojas superiores pinnatisectas con segmentos lineares. Inflorescencias densas, laxas. Brácteas de 15-30 mm, pinnatisectas, segmentos lineares, enteros o dentados, el terminal lobulado. Bractéolas de 2-3 mm, lineares o lanceoladas, soldadas en la base. Flor hermafrodita: corola de $2 \mathrm{~mm}$, infundibuliforme; lóbulos oblongos; estambres apenas exertos. Flor femenina: corola de 1-1,2 mm, infundibuliforme-campanulada; lóbulos oblongos; estilo engrosado en el ápice. Fruto de 2 x $1 \mathrm{~mm}$, ovoide, con lóculos estériles bien desarrollados en la cara trinervada, glabro; pappus formado por 9-11 setas plumosas.
ILUSTRACIONES: Borsini, 1966: 467.

CARActerísticas distintivas: Planta glabra o con pelos dispersos; hojas pinnatisectas; inflorescencias axilares y terminales densas; fruto de $2 \times 1 \mathrm{~mm}$, con lóculo fértil ovoide, y lóculos estériles bien desarrollados, glabro; con pappus.

Fenología: Florece de octubre a noviembre y fructifica en enero y febrero.

DisTRIBUCIÓN Y HÁBITAT: Habita en las provincias centrales de Chile (Regiones V y M), principalmente en las cordilleras bajas.

Valeriana verticillata es similar a $V$. clarionifolia en el aspecto general de la planta, particularmente en la forma de las hojas, se diferencia por el fruto que en $V$. verticillata es ovoide y presenta los lóculos estériles bien desarrollados en la cara trinervada, mientras en $V$. clarionifolia son lageniformes, de mayor tamaño y los lóculos estériles están reducidos a esbozos.

Material adicional examinado: CHILE. V Región de Valparaíso. Valparaíso, Llaillay, IX-1863, s.col. (SGO 43467). Región Metropolitana. Santiago, Valle de Maipo, Mina Cristo, 1869/70, Dávila s.n. (SGO 43469-57071); Santiago, San José de Maipo, Cajón del Río Morales, 3330`S, 7000`W, Saavedra y Pauchard 275 (SGO 133138).

40. Valeriana virescens Clos in Gay, Hist. Chile, Bot. 3: 222. 1847. TIPO: Chile, Gay 27 (holotipo, P, = fot. F 37136!).

Valeriana montteana Phil., Linnaea 30: 191. 1859-60. Valeriana virescens Clos var. montteana (Phil.) Reiche, Anales Univ. Chile 106: 1003. 1900. TIPO: Chile. Puerto Montt, II-1858, Philippi s.n (holotipo, SGO 56962!).

Planta anual hasta $2 \mathrm{~m}$ alt., pubescente. Raíz horizontal poco desarrollada, con numerosas raicillas. Tallo tetrágono, leñoso en la base, con pelos notables en las aristas. Hojas basales enteras, liradas o pinnatisectas, hasta $20 \mathrm{~cm}$; segmentos ovados, elípticos, crenados, el terminal más desarrollado; membranáceas, largamente pecioladas. Hojas superiores de $10 \mathrm{~cm}$, liradas a pinnatipartidas, de ámbito oblongo, sésiles; segmentos oblongo-lanceolados, irregularmente dentados o crenados, decurrentes, pubescentes en la base y axilas. Inflorescencias hasta $70 \mathrm{~cm}$, axilares y terminales, laxas, muy desarrolladas y densifloras. Pedúnculos densamente pubescentes. Brácteas de 2-10 mm, oblongas u oblongalineares, base ensanchada, auriculada, pubescentes en la base, sobre los márgenes y axilas. Bractéolas de 1,5-2,5 $\mathrm{mm}$, oblongas o lineares, pubescentes. Flor hermafrodita: corola de 1,5-2,5 mm, infundibuliforme-campanulada, giba 
pronunciada cerca de la base, exteriormente pubescente; estambres inclusos. Flor femenina: corola de 1,2-1,5 mm, campanulada, gibosa. Ovario elipsoide, pubescente; estilo engrosado en el ápice. Fruto unilocular de 1,5-2 x 1-1,2 mm, con esbozos de 2 lóculos estériles en la porción apical del fértil; ovoide, papiloso, densamente hirsuto en ambas caras; pappus formado por 8-11 setas plumosas.

ILUSTRACIONES: Borsini, 1944: tab. 142; 1999: 464.

CARActerísticas Distintivas: Planta anual que puede alcanzar los $2 \mathrm{~m}$ de alt., raíces escasamente desarrolladas, tallo tetrágono, leñoso en la base, con pelos notables en las aristas; hojas enteras o pinnatisectas, con lóbulos ovados, obtusos, crenados, el terminal mucho más desarrollado; inflorescencias muy desarrolladas, densifloras; fruto de 1,5$2 \mathrm{~mm}$, ovoide, pubescente en ambas caras; con pappus.

Fenología: Florece de diciembre a enero, fructifica a fin de verano.

DISTRIBUCIÓN Y HÁBITAT: Habita en las provincias del sur de Chile, desde Maule hasta Aisén (Regiones VII, VIII, IX, XIV, X y XI); en Argentina en las provincias de Neuquén, Río Negro, Chubut y Santa Cruz, entre los 20 y 1000 m s.m. Crece en sectores de bosque húmedo.

NOMBRE COMÚN y USOS: En mapuche se la denomina "liglolkin"; sus hojas son utilizadas por sus propiedades aromáticas, refrescantes y tónicas (Gusinde 1936).

Valeriana virescens se asemeja a $V$. bracteosa por la morfología de sus hojas, y se diferencia por ser una especie anual, con mayor desarrollo de la inflorescencia y fruto densamente hirsuto. También es afín a $V$. grandifolia y $V$. valdiviana, de las cuales se diferencia por sus frutos ovoides y densamente hirsutos.

Material adicional examinado: ARGEnTINA. Chubut. Dpto. Cushamen: Epuyén, II-1945, Martínez Crovetto 3176 (BAB); Dpto. Futaleufú: Río Corcovado, Illín 39 (SI); Río Corcovado,

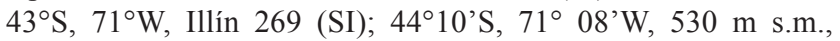
13-I-1902, Hodgberg s.n. (SI 14528); PN Los Alerces, lago Futalaufquen, 9-I-1948, Krapovickas 3951 (BAB); Río Frío, 11I-1948, Soriano 2952 (BAB); Trevelin, Estancia Río Frío, camino a Corcovado, 11-I-1948, Krapovickas 4007 (BAB); Corcovado, Cerro Colorado, 12-I-1948, Krapovickas 4053 (BAB); Carrenleufú, 27-I-2002, Kutschker 172 (BCRU); Carrenleufú, $43^{\circ} 35^{\prime} \mathrm{S}, 71^{\circ} 41^{\prime} \mathrm{W}, 539$ m s.m., 20-III-2008, Kutschker 807 (BCRU); Dpto. Languiñeo: Pampa Chica, 25-I-1947, Soriano 2495 (BAB). Neuquén. Dpto. Aluminé: lago Ñorquinco, arroyo afluente, 19-I-1982, Rossow et al. 1260 (BAB); Dpto. Huiliches: PN Lanín, costa N del lago Huechulaufquen, 13-II-1974, Correa et al. 5540 (BAB); San Martín de los Andes, Cerros al N, 10-XII1946, Dawson 1292 (BAB); Lago Paimún, 5-II-1948, Dawson
\& Schwabe 2527 (BAB); Picada a las termas Carilaufquen, 8-II1948, Dawson \& Schwabe 2678 (BAB); Lago Quillén, Estancia La Ofelia, 20-I-1948, Dawson \& Schwabe 2825 (BAB); Dpto. Lácar: Queñi, II-1889, Philippi s.n. (SGO 56975); Puerto La Elvira, lago Nonthué, 29-I-1948, Dawson \& Schwabe 2301 (BAB); Lago Epulaufquen, 4-II-1948, Dawson \& Schwabe 2413 (BAB); lago Queñi, picada a los Baños termales, 15-I-1984, Gómez et al. 2104 (BAB); RP N²3, camino a los Baños termales del Queñi, 16XII-1985, Correa et al. 9363 (BAB); Lago Queñi, margen O, 15I-1984, Gómez et al. 2035 (BAB); Dpto. Los Lagos: PN Nahuel Huapi, Isla Victoria, 790 m s.m., 9-I-1946, Boelcke 1779 (SI); PN Nahuel Huapi, península Quetrihué, 1-XI-1949, Boelcke \& Hunziker 3463 (BAB); Villa Puerto Manzano, 850 m s.m., 31XII-1969, Diem 3376 (BAB); Ruta “J”, entre Ruca Malén y A ${ }^{\circ}$ La Cantera, 4-XII-1980, Correa et al. 7795 (BAB); $500 \mathrm{~m}$ al N del arroyo Cla-co, 21-II-1981, Rossow \& Gómez 411 (BAB). Río Negro. PN Nahuel Huapi, 1-II-1914, Meunier s.n. (SI 14541); PN Nahuel Huapi, cascada Río Manso, 24-I-1952, Boelcke \& Correa 6002 (BAB); Dpto. Bariloche: RN N 258, cascada de la Virgen, 15-XII-1986, Sánchez et al. 732 (BAB); El Bolsón, Cascada de la Virgen, borde Ruta 258, 27-X-2001, Puntieri s.n. (BCRU). CHILE. VII Región del Maule. Linares, Bullileo, Cordillera Parral, $36^{\circ} 19^{\prime} \mathrm{S}, 71^{\circ} 25^{\prime} \mathrm{W}, 4 / 8-\mathrm{I}-1975$, Villagrán et al. s.n. (CONC 108251). VIII Región del Bío-Bío. Bío-Bío, Tomé, XI1835, Germain s.n. (SGO 56971); Concepción, Isla Quiriquina, 36 $37^{\circ}$ 'S, $73^{\circ} 03^{\prime} \mathrm{W}, 20$ m s.m., 24-XI-1924, Gunckel 9149 (CONC 108213); Arauco, Contulmo, Lago Lanalhue, $38^{\circ} 00^{\prime} \mathrm{S}, 73^{\circ} 14^{\prime} \mathrm{W}$, 30 m s.m., 30-XII-1949, Ricardi s.n. (CONC 9263); Arauco, Isla Mocha, Cordón Central, 38²2'S, 735' W, 280 m s.m., 14III-1971, Weldt \& Rodríguez 1117 (CONC 35345). IX Región de la Araucanía. Cautín, Lonquimay, Cordillera Las Raíces, 2III-1939, Burkart 9488 (SI); Cautín, Freire, 38 $8^{\circ} 7^{\prime} \mathrm{S}, 72^{\circ} 37^{\prime} \mathrm{W}$, 105 m s.m., 24-XII-1913, Baeza s.n. (CONC 108252). XIV Región de Los Ríos. Valdivia, San Juan, XI-1866 (SGO 43475); Valdivia, XI-1903/I-1904, Buchtien s.n. (SI 22713); Valdivia, Krause s.n. (SGO 43474); Niebla, 3951'S, 7324'W, 20 m s.m., 8-XII-1926, Gunckel 68 (CONC 108218); Valdivia, San Carlos, $39^{\circ} 52^{\prime} \mathrm{S}, 7^{\circ} 26^{\prime} \mathrm{W}, 20$ m s.m., 10-X-1928, Gunckel 431 (CONC 108203); Valdivia, Amargos, $39^{\circ} 52^{\prime} \mathrm{S}, 7^{\circ} 25^{\prime} \mathrm{W}, 25 \mathrm{~m}$ s.m., 7I-1930, Gunckel 1185 (CONC 108208); Valdivia, San Juan, 3955'S, 72³5'W, 90 m s.m., 8-II-1930, Gunckel 1492 (CONC 108215); Valdivia, San José de la Mariquina, 39³1'S, $72^{\circ} 58^{\prime} \mathrm{W}$, 25 m s.m., 10-XII-1929, Aravena 194 (CONC 108161); Valdivia, Niebla, 3951'S, $73^{\circ} 24^{\prime} \mathrm{W}, 15$ m s.m. 6-II-1937, Gunckel 17252 (CONC 108204). X Región de Los Lagos. Llanquihue, Punta Larga, $41^{\circ} 10^{\prime} \mathrm{S}, 72^{\circ} 56^{\prime} \mathrm{W}, 60$ m s.m., 2-XII-1939, Gunckel 9337 (CONC 108179); Llanquihue, Ainco, Maullín, Canal de Chacao,

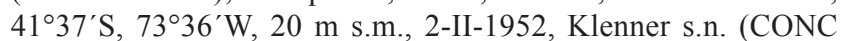
12392); Osorno, Pucatrihue, $40^{\circ} 32^{\prime} \mathrm{S}, 73^{\circ} 41^{\prime} \mathrm{W}, 350 \mathrm{~m}$ s.m., $28-$ XII-1953, Sparre \& Smith 293 (CONC 17532); Chiloé, 1873, Guajardo s.n. (SGO 43472-56972); Chiloé, I-1880, Philippi s.n. (SGO 56970); Chiloé, Ancud, I-1880, Philippi 977d (SGO 43473); Ancud, 6-VII-1925, Pennell 12496 (SGO 59094); Chiloé, Piruquina, $42^{\circ} 24^{\prime} \mathrm{S}, 73^{\circ} 48^{\prime} \mathrm{W}, 25 \mathrm{~m}$ s.m., 25-I-1932, Junge 242 (CONC 1742); Chiloé, $42^{\circ} 15^{\prime} \mathrm{S}, 73^{\circ} 45^{\prime} \mathrm{W}, 180$ m s.m., 1933 , Junge s.n. (CONC 54265). XI Región de Aisén. Aisén, Río Aisén, balseo, 29-XI-1908, Skottsberg s.n. (SGO 58786); Coihaique, 25-I-1934, Espinosa s.n. (SGO 70227); Coihaique, Estero oeste de casas de Coihaique, 7-II-1934, Espinosa s.n. (SGO 70323). 


\section{ESPECIE EXCLUIDA}

\section{Valeriana magna $\mathrm{Clos}$}

Esta especie fue descripta para Chile y considerada un taxón dudoso por Borsini (1966). Debido a que solamente se pudo observar una fotografía del ejemplar tipo de esta especie (Gay s.n., fot. F 37115!), y a que no se encontraron otros ejemplares de herbario que permitieran confirmar a la especie, se excluyó del presente estudio. Por otro lado, se observaron algunos ejemplares de herbario identificados como Valeriana magna Clos, que correspondían a Valeriana vaga Clos.

\section{AGRADECIMIENTOS}

Este estudio es parte de mi tesis doctoral realizada en la Universidad Nacional de la Patagonia San Juan Bosco. Agradezco a Cecilia Ezcurra, mi directora de tesis, por el constante apoyo a mi trabajo. A los directores y curadores de los siguientes herbarios, quienes me brindaron toda la información y material que necesité en oportunidad de visitar dichas instituciones: BAB, BCRU, CONC, SGO y SI, y al personal de los herbarios BA, GL, K, LIL y LP por facilitar mi tarea. Un agradecimiento particular a Kanchi Ghandi de Harvard University Herbaria por su asesoramiento, a los revisores y especialmente a Alicia Marticorena, editora de esta revista.

\section{LITERATURA CITADA}

Adanson, M. 1764. Familles des plantes. Paris. 2 vols.

Aizen, M. \& C. Ezcurra. 1998. High incidence of plant-animal mutualisms in the temperate forest of southern South America, biogeographical origin and present ecological significance. Ecología Austral 8: 217-236.

Alonso, J.R. 1998. Tratado de Fitomedicina. Isis Ediciones, Buenos Aires. 798 pp.

APG III. 2009. An update of the Angiosperm Phylogeny Group classification for the orders and families of flowering plants: APG III. Botanical Journal of the Linnean Society 161: 105-121.

Backlund, A. 1996. Phylogeny of the order Dipsacales. In: C.D. Bell \& M.J. Donoghue, Phylogeny and biogeography of Valerianaceae (Dipsacales) with special reference to the South American valerians. Organisms, Diversity \& Evolution 5(2):147-159.

Backlund, A. \& N. Pyck. 1998. Diervillaceae and Linnaeaceae, two new families of caprifolioids. Taxon 47: 657-661.

Batsch, A. J. 1802. Tabula affinitatum regni vegetabilis, quam delineavit et nune ulterius adumbratam tradit 26: 286.

Bell, C.D. 2003. Systematics of Valerianaceae. In: http://www. phytodiversity.net/ donoghue/ projects/valerian.html, consultado diciembre de 2008.

Bell, C.D. 2004. Preliminary phylogeny of Valerianaceae (Dipsacales) inferred from nuclear and chloroplast DNA sequence data. Molecular Phylogenetics and Evolution 3
(1): 340-350.

Bell, C. D. \& M. J. Donoghue. 2005. Phylogeny and biogeography of Valerianaceae (Dipsacales) with special reference to the South American valerians. Organisms, Diversity \& Evolution 5(2): 147-159.

Bentham, G. \& J. D. Hooker. 1873-1876. Genera Plantarum. 2 (1-8): 1-279.

Boelcke, O. 1981. Plantas Vasculares de la Argentina nativas y exóticas. FECIC, Argentina. 340 pp.

Borsini, O. E. 1942. Valerianáceas de Tucumán. Lilloa 8: 353377.

Borsini, O. E. 1944. Valerianaceae, In: H. Descole (ed.), Genera Species Plantarum Argentina 2: 275-372, 49 lám.

Borsini, O. E. 1946 (1947). Addenda a las Valerianáceas argentinas II. Nuevos materiales consultados. Lilloa 12: 67-85.

Borsini, O. E. 1960. Una nueva Valeriana argentina: Valeriana hunzikeri. Lilloa 30: 361-363.

BorsinI, O. E. 1962. Revisión de las Valerianáceas de Brasil. Lilloa 31: 149-170.

Borsini, O. E. 1966 (1967). Valerianáceas de Chile. Lilloa 32: 375 476.

Borsini, O. E. 1999. Valerianaceae. En: M.N. Correa (dir.), Flora Patagónica. Colección Científica Instituto Nacional de Tecnología Agropecuaria 8(6): 448-471.

Clarke, G. 1978. Pollen morphology and generic relationships in the Valerianaceae. Grana 17: 61-75.

Conticello, L., Gandullo, R., Bustamante, A. \& C. Tartaglia. 1997. El uso de plantas medicinales por la comunidad mapuche de San Martín de los Andes, Provincia de Neuquén (Argentina). Parodiana 10 (1-2): 165-180.

De Candolle, A. P. 1805. In: Lamarck, J.B.A.M. de \& A.P. de Candolle. Flore Francaise. Paris. 2: 600 pp.

De Candolle, A. P. 1830. Prodromus Systematis Naturalis Regni Vegetabilis 4: 623-642.

De Candolle, A. P. 1832. Mémoire sur la famille des Valérianées. Paris. 7: 1-24.

Diez, M.J. 1987 Gentianaceae. En: B. Valdés, M.J. Díez \& I. Fernández (eds.), Atlas Polínico de Andalucía Occidental 1: $246-248$.

Dimitri, M.J. 1974. Pequeña Flora Ilustrada de los Parques Nacionales Andino-Patagónicos. Anales de Parques Nacionales 13: 1-122.

Dimitri, M.J. 1988. Descripción de las Plantas Cultivadas. Enciclopedia Argentina de Agricultura y Jardinería. Ed. Acme, Buenos Aires. 1 (2): 657-1161.

Dufresne, P. 1811. Histoire naturelle et medicale de la famille des Valérianées. Montpellier. 70 pp.

Dumortier, C.B. 1829. Analyse des familles des plantes avec l'indication des principaux genres qui s'y rattachent. 104 pp.

ERIKSEN, B. 1989. Notes on generic and infrageneric delimitation in the Valerianaceae. Nordic Journal of Botany 9: 179-187.

Estomba, D., A. Ladio \& M. Lozada. 2005. Plantas medicinales utilizadas por una comunidad mapuche en las cercanías de Junín de los Andes, Neuquén. Boletín Latinoamericano y del Caribe de Plantas Medicinales y Aromáticas 4(6): 107112.

Estomba, D., A. Ladio \& M. Lozada. 2006. Medicinal wild plant knowledge and gathering patterns in a Mapuche community from North-western Patagonia. Journal of 
Ethnopharmacology 103: 109-119.

Ezcurra, C. 2002. Phylogeny, morphology and biogeography of Chuquiraga, an Andean-Patagonian genus of AsteraceaeBarnadesioideae. In: K.R. Young, C. Ulloa Ulloa, J.L. Luteyn \& S. Knapp (eds.), Plant evolution and endemism in Andean South America. Botanical Review 68 (1): 153-170.

GAY, C. 1847. Historia Física y Política de Chile. Flora de Chile 3: $1-482$.

Graebner, K. O. R. P. P. 1906. Die Gattungen der natürlichen Familie der Valerianaceae. Botanische Jahrbücher Systematik 37: 464-480.

Gusinde, M. 1936. Plantas medicinales que los indios Araucanos recomiendan. Anthropos 31: 555-850.

Hidalgo, O., T. Garnatje, A. Susanna \& J. Mathez. 2004. Phylogeny of Valerianaceae based on matK and ITS markers with reference to matK individual polymorphism. Annals of Botany 93: 283-293.

HinojosA, L.F. 2004. Cambios climáticos y vegetacionales inferidos a partir de las paleofloras mixtas del terciario de Sudamérica. Revista Geológica de Chile 32 (1): 95-115.

Hitchсоск, A.S. \& M.L. Green. 1929. In: Nomen Proposals by British Botanists: 111-199. International Botanical Congress, Cambridge. 1930.

Höck, F. 1882. Beiträge zur Morphologie, Gruppierung und geografischen Verbreitung der Valerianaceen. Botanische Jahrbücher Systematik 3: 1-73.

Höck, F. 1897. Valerianaceae, Engler und Prantl. Die Natürlichen Pflanzenfamilien 4 (4): 172-182.

Höck, F. 1901. Verwandtschftsbeziehungen der Valerianaceen und Dipsacaceen. Botanische Jahrbücher Systematik 31: 405411.

Hoffmann, A., C. Farga, J. Lastra \& E. Veghazi. 1992. Plantas medicinales de uso común en Chile. Ed. Fundación Claudio Gay, Santiago de Chile. 273 pp.

Houghton, P.J. \& J. Manby. 1985. Medicinal plants of the mapuche. Journal of Ethnopharmacology 13(1): 89-103.

Juliet, C. 1962. Plantas medicinales chilenas de las provincias de Llanquihue y Chiloé. Anales de la Universidad de Chile 4 (2): 181-188.

Kunth, K. S. 1819. Nova Genera et Species Plantarum. Sumtibus Librariae, Lutetiae Parisiorum 3(12): 289-384.

KutschKer, A. 2008a. Valerianaceae. En: F. Zuloaga, O. Morrone \& M. Belgrano (eds.). Catálogo de las Plantas Vasculares del Cono Sur. Monographs in Systematic Botany, Missouri Botanical Garden 107 (3): 3091-3101.

KutschKer, A. 2008b. Morfología del fruto en especies de Valeriana (Valerianaceae) de los Andes australes. Darwiniana 46 (1): 17-35.

Kutschker, A. 2009. Valeriana L. (Valerianaceae) en Sudamérica austral: taxonomía, aspectos biogeográficos y fitoquímicos. Tesis Doctoral. Universidad Nacional de la Patagonia S.J.B. Chubut, Argentina. 246 pp.

Kutschker, A., H. Menoyo \& V. Hechem. 2002. Plantas de uso popular en comunidades del oeste de Chubut. GTZ, INTA, Esquel. 139 pp.

Larsen, B.B. 1986. A taxonomic revision of Phyllactis and Valeriana sect Bracteata (Valerianaceae). Nordic Journal of Botany 6: 427-446.

LinNé, C. 1753. Species Plantarum. Stockholm. 1: 31-34.

Mabberley, D.J. 1990. The Plant Book. A portable dictionary of the higher plants. Cambridge University Press, Cambridge. 707 pp.

MANFRED, L. 1991. 7000 recetas botánicas a base de 1300 plantas medicinales americanas. Ed. Kier, Buenos Aires. 650 pp.

Martínez Crovetto, R. 1968. Estudios etnobotánicos IV: Nombres de plantas y su utilidad, según los indios onas de Tierra del Fuego. Etnobiológica (3): 1-20.

Mejía Piñeros, A.L., N. Herreño \& L.M. Pombo. 2005. Análisis farmacognóstico y cromatográfico comparativo del contenido de valepotriatos y ácidos valerénicos entre $V$. officinalis L. y $V$. pavonii Poepp. \& Endl., para establecer parámetros de calidad en la elaboración de fitoterapéuticos. Documenta Clínica 18(1-2): 11-25.

Meyer, E. 1991. Investigaciones palinológicas en especies de Valeriana L. de América Tropical. Tesis Doctoral, Ed. München, Germany.

Miller, P. 1754. Gardeners Dictionary. London. Vol. 3, 584 pp.

Moench, K. 1794. Methodus plantas Horti botanici et agri Marburgensis, a staminum situ describendi. Vol. 8, 780 pp.

Molares, S. \& A. Ladio. 2008. Plantas medicinales en una comunidad Mapuche del NO de la Patagonia. Boletín Latinoamericano y del Caribe de Plantas Medicinales y Aromáticas 7(3): 149-155.

Molares, S., A.H. Ladio \& M.A. Castro. 2007. Etnobotánica, percepciones organolépticas y estructuras secretoras de cinco especies aromáticas de la Patagonia argentina. Boletín Latinoamericano y del Caribe de Plantas Medicinales y Aromáticas 6(5): 209 -210.

Montecino, S. \& A. Conejeros. 1985. Mujeres mapuches, el saber tradicional en la curación de enfermedades comunes. Serie $\mathrm{N}^{\circ} 2$ Mujer y Salud. Ed. CEM, Santiago. 89 pp.

Morrone, J.J. 2001. Biogeografía de América Latina y el Caribe. M\&T-Manuales \& Tesis SEA. Sociedad Entomológica Aragonesa, Zaragoza. 148 pp.

Morrone, J.J. 2004. Panbiogeografía, componentes bióticos y zonas de transición. Revista Brasileira de Entomología 48 (2): 149-162.

Mösbach, E. W. De. 1992. Botánica Indígena de Chile. Ed. Andrés Bello, Santiago de Chile. 140 pp.

NeCKer, N.J. de. 1791. Elementa Botanica. Bossange et Soc. Bibliopol. Paris. 2: 81-83.

Patel, V.C. \& J.J. SkVARLa. 1979. Valerianaceae pollen morphology. Pollen \& Spores 21: 81-103

Persoon, C.H. 1805. Synopsis plantarum. París. Vol.1, 546 pp.

Ratera, E.L. \& M.O. Ratera. 1980. Plantas de la flora argentina empleadas en medicina popular. Ed. Hemisferio Sur, Buenos Aires. 189 pp.

ReIche, K. 1902. Estudios críticos sobre la flora de Chile. Flora de Chile 3:1-425.

Ruggiero, A. \& C. Ezcurra. 2003. Regiones y transiciones biogeográficas: Complementariedad de los análisis en biogeografía histórica y ecológica. En: J.J. Morrone \& J. Llorente (eds.), Una perspectiva latinoamericana de la biogeografía, Las Prensas de Ciencias, UNAM, México. 307 pp.

Saldivia, P. \& G. RoJas. 2006. Valeriana moyanoi Speg. (Valerianaceae), nuevo registro para la flora de Chile. Gayana Botánica 63(2): 183-186.

Stuckert, T. \& J. Briquet. 1916-1919. Enumération des 
Valérianacées de 1'Argentine. Annuaire du Conservatoire et du Jardin Botaniques de Genève 20(18): 428-445.

Tournefort, J.P. 1719. Institutiones Rei Herbariae. París. Vol. 1-3, 694 pp.

Villagrán, C. \& L.F. Hinojosa. 1997. Historia de los bosques del sur de Sudamérica, Análisis fitogeográfico. Revista Chilena de Historia Natural 70: 241-267.

Villagrán, C. \& L.F. Hinojosa. 2005. Esquema biogeográfico de Chile. En: J. Llorente-Bousquets \& J. J. Morrone (eds.), Regionalización biogeográfica en Iberoamérica y tópicos afines. Ediciones de la Universidad Nacional Autónoma de México, Jiménez Editores, México. 577 pp.

WeberLing, F. 1961. Die infloreszenzen der Valerianaceen und ihre systematische Bedeutung. Akademie der Wissenschaften und der Literatur, Mathematisch-Naturwissenschaftliche Klasse 5: 155-189.
Weberling, F. 1965. Typology of inflorescences. Journal of the Linnean Society Botany 59: 215-221.

Weberling, F. 1970. Valerianaceae. In: G. Hegi (ed.), Flora von Mitteleuropa. Parey-Verlag, Berlin. 6(2): 2.

WeberLing, F. 1983. Fundamental features of modern inflorescence morphology. Bothalia 14(3-4): 917-922.

Weddell, H.A. 1859. Essai d'une flore de la Región Alpine des Cordillères de L'Amèrique du Sud. Chloris Andina 2: 1731.

Xena de Enrech, N., J. Mathez \& A. Martin. 1996. Caracterización y fertilidad del polen en el género Fedia Gaertner (Valerianaceae). Orsis 11: 15-40.

Xifreda, C.C. 1999. Valerianaceae. En: F. Zuloaga \& O. Morrone (eds.), Cátalogo de las plantas vasculares de la República Argentina. Monographs in Systematic Botany, Missouri Botanical Garden 74(2): 1130-1134.

ApÉNDICE I. Lista de especies válidas y su distribución por países (Arg.=Argentina, Chi.= Chile).

Appendix I. List of valid species and their distribution by country (Arg. = Argentina, Chi. = Chile).

1. Valeriana boelckei Rossow Arg.-Chi.

2. Valeriana borsinii Rossow Arg.

3. Valeriana bracteosa Phil. Chi.

4. Valeriana bridgesii Hook. \& Arn. Chi.

5. Valeriana carnosa Sm. Arg.-Chi.

6. Valeriana chilensis Borsini Arg.-Chi.

7. Valeriana clarionifolia Phil. Arg.-Chi.

8. Valeriana crispa Ruiz \& Pav. Arg.-Chi.

9. Valeriana descolei Borsini Arg.

10. Valeriana dinorrhiza (Griseb.) Höck Arg.

11. Valeriana fonckii Phil. Arg.-Chi.

12. Valeriana graciliceps Clos Chil.

13. Valeriana grandifolia Phil. Chil.

14. Valeriana hebecarpa DC. Arg.-Chil.

15. Valeriana hornschuchiana Walp. Arg.-Chil.

16. Valeriana hyalinorrhiza Ruiz \& Pav. Chil.

17. Valeriana lapathifolia Vahl Arg.-Chil.

18. Valeriana laxiflora DC. Arg.-Chil.

19. Valeriana lepidota Clos Chil.

20. Valeriana leucocarpa DC. Arg.-Chil.
21. Valeriana macrorhiza DC. Arg.-Chil

22. Valeriana moyanoi Speg. Arg.-Chil.

23. Valeriana munozii Borsini Arg.

24. Valeriana obtusifolia DC. Chil.

25. Valeriana papilla Bertero ex DC. Chil.

26. Valeriana peltata Clos Chil.

27. Valeriana philippiana Briq. Arg.-Chil.

28. Valeriana polemoniifolia Phil. Arg.-Chil.

29. Valeriana polystachya $\mathrm{Sm}$. Arg.

30. Valeriana radicalis Clos Chil.

31. Valeriana ruizlealii Borsini Arg.

32. Valeriana samolifolia (DC.) Colla Arg.-Chil.

33. Valeriana sedifolia d'Urv. Arg.-Chil.

34. Valeriana sphaerocarpa Phil. Chil.

35. Valeriana stricta Clos Arg.-Chil.

36. Valeriana vaga Clos Chil. Chil.

37. Valeriana valdiviana Phil. Chil.

38. Valeriana velutina Clos Chil.

39. Valeriana verticillata Clos Chil.

40. Valeriana virescens Clos Arg.-Chil.

ApÉNDICE II. Índice de exsiccatas. Lista de ejemplares examinados con datos de recolector (en orden alfabético) y número de colección. Se indica entre paréntesis el número de especie a la que pertenece cada ejemplar según la numeración en la lista de especies. Los ejemplares tipo se indican con asterisco $(*)$.

APPENDIX II. Index of exsiccata. List of examined specimens, collector data (in alphabetical order) and collection number. The number between brackets indicates the species to which each specimen belongs according to the numbering in the list of species. The type specimens are indicated with an asterisk $(*)$.

Aguilera \& Elgueta s.n. (8). Ambrosetti \& Méndez 531 (33); 667 (5); TBPA-Fit 3369, 3526, 3739 (5). Ameghino, C. s.n.* (33). Anliot 6066 (17). Arancio et al. 94153 (35). Aranguiz s.n. (24). Aravena 51 (37); 194 (40). Arroyo \& Leuenberger 3406 (5). Arroyo \& Squeo 850925 (17). Arroyo et al. 308 (22); 409 (7); TBPA-Fit 2238, 2273, 2433 (5); 2435 (22); 2517, 2676 (5). Artigas s.n. (14); s.n. (18).

Baeza s.n. (8); s.n. (16); s.n. (24); s.n. (32); s.n. (40); 23 (18); 37 (20). Baeza et al. 3415 (13). Barnier s.n. (8); Barrientos s.n. (5); 26, 323, 324 (17); 356 (5); 1763 (35). Barros s.n. (19); 855
(32); 920 (13); 998 (32). Basualto et al. 145 (18). Beckett et al. 4287 (17); 4346 (11). Behn F. s.n. (5); s.n. (11); s.n. (13); s.n. (21); s.n. (26). Behn H. s.n. (11); s.n. (18); 38, 114 (17). Behn K. s.n. (4); s.n. (8); s.n. (16); s.n. (25); s.n. (32); s.n. (35). Belgrano 41 (5). Bernasconi s.n. (22). Bertero s.n.* (24); s.n.* (31); s.n.* (32); 742* (25). Biganzoli 1854 (7). Boelcke 1692 (5); 1779 (40); 1856 (11); 1996 (27); 6385, 6644 (29). Boelcke \& Correa 5262 (17); 5279 (18); 5406 (17); 5444 (11); 5548 (18); 5456 (27); 5572 , 5638, 5688 (11); 5735, 5736 (27); 5750 (17); 5916, 5935, 5950 (11); 6002 (40); 6058 (17); 6107, 6220 (18); 6866 (11); 6908 (27); 
6942, 7173 (11). Boelcke \& Hunziker 3326 (18); 3379 (5); 3400 (22); 3423 (18); 3463 (40); 3693, 3728 (5); 3729 (7); 7075 (17). Boelcke et al. 10349 (21); 10970, 12758 (5); 13789, 14112, 14195 (21); 15039, 15091(5); 15105 (33); 15725 (5); 16441 (17); TBPAFit 609 (17); 738 (5); 973 (17); 3256, 3331 (5). Borchers s.n. (4); s.n. (5). Botta \& Correa 10123 (29). Bravo s.n. (35); 133 (36); 192 (3); 430 (36). Brion \& Barthelemy s.n. (7); s.n. (18). Brion \& Puntieri s.n. (18). Buchtien s.n. (40). Burkart 430, 2800 (29); 5302 (10); 9488 (40); 9550 (18). Burkart et al. s.n. (5); s.n. (35). Burmeister s.n. (5); s.n. (20).

Cabrera 4704 (29); 34150 (7). Cabrera et al. 27166 (31); 32930, 33093 (7); 33304 (5); 33351 (35). Cadillo \& Posse s.n. (27). Cárdenas 13 (17). Carette 72, 395 (23). Carrique et al. 1082, 1342 (27); 1459, 1472 (5). Castellanos s.n. (10); Castillo s.n. (5); s.n. (8); s.n. (12); s.n. (27); s.n. (28). Cekalovic s.n. (17). Comber 895* (17). Commerson s.n.* (5); s.n.* (17); 62* (29). Consigny s.n. (27). Constance et al. 3816 a (22). Correa 5828 (11). Correa \& Nicora 3328, 3543 (5); 3663 (7). Correa \& Pérez Moreau 1989 (5). Correa et al. 2688 (18); 2835 (5); 3472, 3621, 3795 (7); 3816 (27); 5540 (40); 5676 (11); 5708 (27); 5798 (18); 5830, 5945 (27); 6280 (22); 6341 (5); 7795 (40); 7816 (7); 8884 (20); 8944 (7); 8966 (18); 9341 (7); 9363 (40); 9379 (11); 9553 (29); 9916 (14); 9990 (1); 10050, 10053 (18); 10058 (5); 10062 (11); 10204 (5); 10322 (7); 10343 (5); 10400 (7); 10402 (5); 10438 (18); 10441 (7). Crespo \& Giangualani 2073 (11). Crespo \& Troncoso 1702 (5). Cuming 571* (8); 744* (4). Curato; 2951 (28); 2966 (8). Chiapella s.n. (17); s.n. (18). Chiapella \& Pillado 332 (18). Chiapella \& Wardle s.n. (20). Chiapella et al. 605 (11); 611 (27); 620 (22).

Daniels s.n. (5); s.n. (11); 44 (17). D'Átri s.n. (27). Dávila s.n. (39). Dawson 1292 (40). Dawson \& Ruiz Leal 98 (35). Dawson \& Schwabe 527, 2301, 2413 (40); 2602 (18); 2678 (40); 2760 (17); 2825 (40). Delfin s.n.*, s.n. (17). Delgado \& Ramírez s.n. (17). Deltor 2004 (18); 2034 (5); 2074 (14). De Saint s.n. (11). De Vore 1478 (21). Diem 272 (10); 923 (11); 1652 (18); 1766 (11); 1955 (18); 3218 (22); 3375 (5); 3376 (40); 3378 (17); 3380 (27). Dollenz 182 (17); 203 (5). Dollenz et al. TBPA-fit. 1029 (20). Donat 168* (22); 190a, 190b (7); 350 (5). Dusén 6329 (29). D'Úrville s.n.* (33).

Eskuche 3377 (17). Espinosa s.n. (17); s.n. (40). Eyerdam et al. 24097 (5); 24129 (17); 24385 (5). Ezcurra 1281, 2267 (11); 2315, 2316 (27). Ezcurra \& Clayton 612 (18). Ezcurra et al. 715 (11); 723, 778 (21); 826 (27); 843, 854, 878, 882 (21); 911 (11); 1294 (21).

Ferreyra 22 (27); 94 (22); 132 (21); 145 (27); 160 (21); 35, 131 (11); 181 (11); 396 (1). Ferreyra \& Clayton 212 (27); 213 (11); 293, 438 (5). Ferreyra \& Ezcurra 605 (21). Fortunato 4346 (11); 4895, 4896 (5).

Garaventa s.n. (27); 204 (19); 309 (4); 402, 437 (32); 519 (15); 1202 (4); 1203 (18); 1205 (4); 1484 (3); 1527 (12); 5586 (18); 5665 (35); 5921 (25). García s.n. (14). Gardner 3451 (27). Gardner \& Knees 3817 (17); 3903 (11). Gay s.n.* (4); s.n.* (18); s.n.* (19); s.n.* (24); s.n.* (26); s.n.* (36); s.n.* (39); 27* (40); 103* (38); 305* (4); 488* (35); 1089* (15); 1095* (30); 1096* (12); 1990* (35). Geisse s.n. (25); s.n. (35); s.n. (36). Gentili s.n., 146, 147 (11); 190 (22); 296 (17). Gentili M. \& Gentili P. 747, 759 (27); 849 (18). Gerling s.n. (5); s.n. (17); s.n. (21). Germain s.n.* (7); s.n.* (8.); s.n.*, s.n. (12); s.n.* (18); s.n.* (27); s.n. (24); s.n. (35); s.n. (36); s.n. (40). Gillies 192* (21). Girth s.n. (23). Gleisner 97 (26); 154 (28); 155 (18); 169 (27). Godoy 332, 349, 385, 415 (18). Gómez \& Rossow 361 (17). Gómez et al. 201 (10). Gómez
Cadret et al. s.n. (18); 269 (5); 570, 572 (22); 727 (28); 735 (18); 826. (27); 2035 (40); 2101 (18); 2104 (40); 2134 (18). Goodall 2522, 2548, 4467, 4586 (5); 4282, 4381 (33). Grandjot s.n. (25); s.n., 1215 (12); 339, 458 (26). Grondona 2140 (5). Grosfeld s.n. (28); 558 (11). Guajardo s.n. (40). Guerrido 440 (33); 555 (7); 557 (5). Gulland s.n. (18). Gunckel s.n. (11); 68, 431(40); 669 (28); 1185 (40); 1442 (28); 1492 (40); 1863, 2476 (28); 3011 (17); 4940 (28); 9149 (40); 9150, 9151(28); 9337 (40); 9348 (28); 9375, 9379 (17); 12262 (11); 12285 (18); 12356 (11); 12362 (18); 12387 (11); 15617, 16365, (28); 17252 (40); 19385, 22588 (32); 24655 (13); 25118 (40); 25617 (32); 36601 (8); 36605 (28); 37371 (16); 40768 (35); 40780, 40783 (32); 40809 (25); 52601 (11). Guzmán s.n.* (4).

Hicken s.n. (17); s.n. (29); 5, 95 (17); 125* (5); 276 (17); 800 (22); 1897 (29). Hieronymus 606* (10). Hildebrand-Vogel 17 (11). Hirth s.n. (17). Hodgberg s.n. (40). Hollermayer s.n. (17); s.n. (28); 309 (8); 309c, 309d (28); 412 (11); 493, 684, 699 (17). Hombron \& Jacquinot s.n.* (33). Horst s.n. (17); s.n. (25). Humaña et al. 20013 (6). Hunziker 4615 (29). Hunziker \& Boelcke 3537 (22). Hurrell 5336, 5797 (29). Hutchinson 112 (35).

Igayman \& Muñoz s.n. (8). Illín s.n. (7); s.n.* (20); s.n.* (22); s.n.* (32); 39 (1); 126 (18); 269 (40).

Jaffuel s.n. (27); s.n. (25); s.n. (32); 453 (12); 457 (35); 3024 (25); 3125 (32). James 774, 812 (17). Jiles 725 (27); 1062, 1594 (35); 1724 (26); 1751 (27); 1865 (8); 2008, 2399 (27); 2456, 2882 , 3366, 3542 (35); 3829 (26); 4256 (35); 4606 (4); 4757, 5874 (35). Johnson 629 (17). Johow s.n. (32). Jörgensen s.n. (10). Joseph s.n.* (17); s.n. (25); 2758 (12); 4379 (16); 4387 (32). Junge s.n. (13); s.n. (25); s.n. (32); s.n. (40); 73 (17); 242 (40); 335 (28); 974 (16).

Kalin Arroyo 81501 (35); 81540 (36); 841126 (33). Kalin Arroyo \& Humaña 980630 (15); 991851 (12). Kalin Arroyo \& Squeo 850923, 860093 (17). Kalin Arroyo et al. 44, 69, 90 (5); 201442 (30); 841027, 870263 (33); 980654 (35); 994946 (13); 996187 (6); 996197 (13); 996312 (6). Kiesling 9361 (31). Klenner s.n. (40). King s.n.* (14). Kohler 169, 561, 604 (27). Koslowsky s.n. (20); s.n.*, 59 (22); s.n. (26); 60, 12425 (5). Krapovickas 3736 (18); 3951, 4007, 4053 (40); 4056, 4136 (5). Krause s.n. (11); s.n. (40). Kunkel s.n. (13); s.n. (21); 389 (28); 552 (13); 558 (32); 2438 (8); 2441 (13). Kurtz 9329a, 9414 (9). Kutschker 150 (22); 171 (7); 172 (40); 176 (5); 180 (11); 227 (18); 801 (5); 802 (7); 803 (11); 804 (22); 806 (18); 807 (40); 808 (6); 809 (27); 812 (17).

Landbeck s.n. (12); s.n.* (15); s.n.* (19); s.n. (20); s.n. (35). Landero 639 (33); 701 (5). Lechler 780* (17). Leuenberger \& Arroyo 3656 (5). Levi 524 (32); 705 (3); 2639 (32). Looser 861, 883 (12); 2088* (8); 2090 (3).

Magens s.n., 19 (5); 53, 57 (17); 1108 (33). Mahu 6479 (35). Marticorena \& Matthei 61 (27); 170 (26); 411 (25); 412, 636, 677 (35); 880 (21); 966 (15). Marticorena \& Quezada 1530 (28). Marticorena \& Rodríguez 9983 (18). Marticorena \& Weldt 577 (35). Marticorena et al. s.n. (8); 10 (21); 224 (28); 368 (27); 385 (14); 417 (21); 496 (27); 524 (8); 641 (17); 973, 1229 (28); 1265 (27); 1272 (8); 1289 (18); 1411 (11); 1424 (21); 1453, 1592 (18); 1599 (28); 1717 (18); 1813 (26); 83378, 83395 (35). Marticorena A. 585 (25). Marticorena A. et al. 330, 403 (11); 385 (14); 640 (35). Martínez Crovetto 3176 (40). Matthei 679 (13); Matthei \& Quezada 94 (18); 170 (11). Mazzucconi 1188 (18); 1303 (17). Meunier s.n. (40). Meyen s.n.* (15). Meza \& Barrera 1529 (11); 1542, 1575 (17); 1590 (18). Mihoc 3163 (14). Mihoc et al. 7237 (14). Millán 143 (29); s.n. (35). Montaldo 4397 (18); 4616 (17). Montaldo \& 
Seeger 362 (11). Montero s.n. (11); 1024 (15); 2039 (18); 2052 (11); 2269 (28); 3206 (32); 3673 (11); 4329 (18); 4471, 4901 (11); 5030 (17); 5811 (18); 6538 (37); 6595 (24); 6864 (32); 6966, 7018 (18); 8609 (11); 8665 (5); 8878,9610 (18); 9696 (35); 10335 (5); 10477 (21); 10543 (8); 10734 (5); 11412 (17); 12089 (18). Montiel s.n. (27). Moore 1510 (5). Moore \& Goodall 306 (5). Moore \& Pisano TBPA-fit 1728, 1833 (17). Morales s.n. (30). Moreira Muñoz s.n. (17). Morrone 5519 (21); 5668 (7); 5981 (18); 6090 (8). Moyano s.n.* (21); s.n.* (22). Muñoz P. s.n. (12); s.n.; 247 (26); 2351 (35); 3251, 3302 (38); 3419 (26); 4059 (5); 6225 (17).

Navarro s.n. (4); s.n. (12). Navas 2921 (35). Neger s.n. (5); s.n. (21); 4176 (28). Núñez 175, 201 (11). Núñez \& Daniels 162 (17). Núñez \& Puente 106 (22); 116 (27).

O’Donell 2156 (11). Oehrens s.n. (18); 963 (17). Onel s.n. (35).

Pacheco et al. 1279 (21). Pastore s.n. (29); 60 (17). Pearce s.n. (17); s.n.* (18); s.n.* (27); 71 (11). Pennell 12496 (40). Perez Moreau s.n. (10); s.n. (17). Permington s.n. (29). Pfister s.n. (5); s.n. (8); s.n. (11); s.n. (13); s.n. (14); s.n. (17); s.n. (18); s.n. (21); s.n. (24); s.n. (28). Pfister \& Ricardi s.n. (5); s.n. (17). Philippi s.n.*, s.n. (3); s.n. (8); ); s.n.* (11); s.n.* (13); s.n.*, s.n (17); s.n. (19); s.n.* (25); s.n. (30); s.n. (32); s.n. (35); s.n.* (36); s.n.* (37); s.n.*, s.n. (40); 963 (8); 965b, 968a (19); 970 (3); 972 (8); 975 (19); $978 \mathrm{c} \mathrm{(16);} 980$ (25); 981 (36); 984 (35); 986a, 986c (5); 987a, 987b (16); 988* (34); 991c (8); 992b, 993* (17); 995a* (8); 2050 (24); 2051 (26); 2157 (17); 2158* (28). Pisano 2161 (17); 2319, 2568 (5); 3262, 3520, 3920, 3990 (17); 4138 (5); 5932, 6145, 6314 (17); 6482 (20); 6512 (17). Pisano TBPA-fit 2784, 2871(17). Pisano \& Cárdenas 4809 (5). Pisano \& Colomes 6344 (17). Pisano \& Dollenz 5812 (17). Pisano et al. 8395, 8533 (17). Poblete 106 (8). Poeppig s.n.* (18); 127* (35); 640* (24); 825* (18); 847* (20); 918* (21); 942* (14). Poza s.n.* (24). Puga s.n.* (28). Puntieri s.n. (11); s.n. (21); s.n. (22); s.n. (27); s.n. (28); s.n. (40). Puntieri \& Brion s.n. (17).

Quezada et al. 47 (28).

Rechencq s.n. (17); s.n. (18); s.n. (20). Reiche s.n. (15); s.n. (27). Reinicke s.n. (11). Ricardi s.n. (8); s.n. (40); 1249 (8); 2127 , 2140 (26); 2349 (5); 2439 (12); 2808 (13); 3213, 3213 (35); 5215 (32); 5314 (11); 5335 (17); 5418 (18). Ricardi \& Marticorena 4008 (17); 4982 (32); 5113 (1); 5643 (18); 5679 (21); 5695 (18). Ricardi \& Matthei 78 (5); 5236 (11). Ricardi et al. 878 (35); 899 (12); 1979 (18). Rivera s.n. (8). Rodríguez 1100 (8); 1142 (21); 1370 (10); 1377 (31). Rodríguez G. 206 (28); 263 (18). Rodríguez R. 603 (28); 1038 (17). Rodríguez \& Marticorena 3006 (18); 3023 (28); 3032 (18); 3045 (14). Rodríguez y Marticorena 2937 (18). Rodríguez R. \& Rodríguez G. 1307, 1293 (28). Rohmer s.n. (5). Roig \& Méndez TBPA-fit 2476 (22). Roig. et al. 14659 (7); TBPA-Fit 2980, 3076, 3106 (5); 5117 (17). Rojas \& Valdivia s.n.
(22). Rossow 2184 (28); 4536 (14); 4625 (1); 4635 (27); 4648, 4659 (21). Rossow \& Gómez Cadret 185 (5); 380 (11); 411 (40); 2700* (2); 4590 (1); 4602 (11); 4620 (5). Rossow et al. 234, 851, 886 (11); 1013 (1); 1082 (27); 1262 (7); 1260 (40); 1489 (11); 1955* (1); 2308 (5); 2728 (6); 5521 (2). Rubulis s.n. (11); s.n. (17); s.n. (18); s.n. (27). Rudolph s.n. (25). Ruiz Leal $715 *(31)$. Ruiz \& Pavón s.n.* (8); s.n.* (16). Ruthsatz 6436 (35); 7308 (7); 7630 (1); 7777 (11); 7839 (27).

S. col. (8); S. col.* (24); S. col.* (28); S. col.* (30); S. col.* (32). S. col.* (37). Saa s.n. (27). Saavedra y Pauchard 236 (12); 238 (15); 274 (19); 275 (39). Sage s.n. (14); s.n. (21). Saldivia (22). Sánchez 476 (5). Sánchez et al. 732 (40); 753 (11). Sanzin 136* (9). Schajovskoy s.n. (20). Schlegel 118 (35); 197 (25); 1131 (16); 1191 (27); 1191 (26); 1204 (35); 1694 (32); 2134 (17); 2846 (8); 2943 (32); 3082 (35); 3489 (5); 3562 (21); 3670 (12); 3806 (25); 4061 (4); 4171 (8); 4176 (28); 4182 (17); 4408 (35); 4412 (18); 5834 (5); 6817 (11); 6977 (18); 7204 (5). Schwabe s.n. (11); s.n., 7 (17); s.n. (24). Seibert et al.-TBPA-Fit. 969, 1117, 2095 (5); 2252 (17). Seki 295 (17). Semper s.n. (9). Sierra s.n. (35). Simons s.n.* (4); s.n.* (18). Skottsberg s.n.* (7); s.n. (17); s.n. (21); s.n.* (22); s.n. (40); 78 (33); 142, 143 (17). Skottsberg \& Sparre 11051 (35). Smith \& Constance 10675 (18). Smith \& Sparre 144 (18); 224 (11); 240 (18). Soriano 197 (21); 209 (27); 1498 (5); 2007 (7); 2020 (5); 2251, 2453 (22); 2495 (40); 2587 (5); 2952 (40); 4792,4873 (5). Sparre 10013, 10054 (13). Sparre \& Constance 10648 (11); 10789 (17); 10825 (27). Sparre \& Smith 23* (6); 293 (40); 346 (17); 372 (11); 391 (17). Spegazzini s.n. (10). Stebb 8888 (35); 9046 (15). Steccani s.n. (11). Stuckert 7622* (7). Stuessy \& Baeza 11056 (14).

Taylor 10234 (13). Taylor et al. 10255 (28); 10288 (20); 10294 (21); 10295 (11). TBPA 3256 (33). Teillier \& Delaunoy 5583 (35). Teillier \& Márquez 4282 (17); 5260 (12). Teillier et al. 2306 (35); 2308 (12). Tomé 230 (32); 315 (25); 316 (35). Troncoso \& Bacigalupo s.n. (11). Tsujii 697 (17).

Valentini 54 (29). Valenzuela s.n. (21). Vallerini-Suero 1086 (7). Venturi 201 (30); 3098, 4058, 4695, 4746 (10). Vervoorst 5744 (7). Villagrán 4851 (17); 8640 (35). Villagrán et al. s.n. (40); 6859 (17); 8209 (21). Villagrán \& Kalin Arroyo s.n. (15). Villarroel \& Weldt 108 (8). Volckmann s.n. (5); s.n. (18); s.n. (20); s.n. (36). Von Bohlen 1030 (11); 1031 (21). Von Rentzell 6141 (17); 6148* (11); 6164 (5).

Weisser 1542 (5). Weldt 709 (35). Weldt \& Rodríguez 819 (17); 1117 (40). Werdermann 484 (35); 658 (17); 1278 (18); 1324 (5). Weigend \& Weigend 6854 (27). Witte 46 (5). Wolffhügel s.n. (17).

Zanotti 25, 131 (22). Zoellner s.n. (12); $3569(35) ; 4331$ (36); 4495, 4526 (5); 4995 (35); 5560 (18); 6253 (38); 6257 (18); 6363 (8); 6696 (5); 7678 (18); 7726 (28); 9210 (38); 9425 (5). Zollitsch 261 (11); 284 (17); 285 (11). Zoratti 185 (22).

APÉNDICE III. Índice de nombres científicos (nombres válidos en rectas, sinónimos en bastardilla) y de nombres vulgares.

ApPENDIX III. Index of scientific names (valid names in boldface, synonyms in italics) and common names.

Aretiastrum sedifolium 285

Astrephia chaerophylloides 253

Astrephia lobata 262, 263

Betckea gilliesii 275

Betckea samolifolia, 253, 284

Huahuilque, 254

Liglolkin, 254, 290

Ñamkulawen, 254, 258
Nancolahuen 258

Nanculahuen del monte 261

Papilla 279

Phyllactis dinorrhiza, 264

Phyllactis gilliesii, 275

Phyllactis macrorhiza, 275

Phyllactis macrorhiza var. pumila, 275

Phyllactis magellanica, 285 
Gayana Bot. 68(2), 2011

Phyllactis magellanica var. azorelloides, 285

Phyllactis rigida 253

Phyllactis sedifolia 285

Plectritis congesta 253

Plectritis samolifolia 284

Plectritis samolifolia var. pusilla 284

Valeriana aegilitis 278

Valeriana andina 283

Valeriana andonaegui 270

Valeriana araucana 278

Valeriana berterii 279

Valeriana boelckei 245, 248, 249, 250, 255, 256, 283

Valeriana borsinii 248, 249, 256, 275

Valeriana bracteosa 248, 249, 250, 256, 257, 290

Valeriana bridgesii 248, 250, 257, 278, 280

Valeriana bustillosii 269

Valeriana carnosa 248, 250, 254, 256, 258, 265

Valeriana castellanosi 264

Valeriana caudata 281

Valeriana chaerophylloides 253

Valeriana chilensis 245, 248, 249, 250, 260, 270

Valeriana chubutensis 275

Valeriana clarionifolia 248, 249, 250, 261, 269, 280, 289

Valeriana colchaguensis 274

Valeriana columbaria 268

Valeriana congesta 253

Valeriana cordata 270

Valeriana cordata var. dentata 270

Valeriana corymbulosa 284

Valeriana crassicaulis 278

Valeriana crenata 265

Valeriana crispa 245, 248, 249, 250, 262, 263, 286

Valeriana descolei 248, 249, 263, 264, 285

Valeriana dinorrhiza 248, 249, 250, 264, 276, 278, 284

Valeriana elegans 286

Valeriana excelsa 262

Valeriana ferax 283

Valeriana floribunda 245, 262

Valeriana foliosa 272

Valeriana fonckii 245, 248, 249, 256, 258, 260, 265

Valeriana fonckii var spiciformis 276, 277

Valeriana germainii 245, 281

Valeriana gilliesii 275

Valeriana glauca 286

Valeriana glauca var. elegans 286

Valeriana graciliceps 248, 250, 266

Valeriana grandifolia 248, 250, 267, 270, 288, 290

Valeriana hebecarpa 248, 250, 268, 273

Valeriana hornschuchiana 248, 250, 269

Valeriana hyalinorrhiza 248, 250, 267, 269, 270

Valeriana lapathifolia 248, 250, 254, 270

Valeriana laxa 272

Valeriana laxiflora 248, 250, 268, 272, 273

Valeriana laxiflora var. cardaminifolia 272

Valeriana lepidota 245, 250, 274, 278

Valeriana leucocarpa 248, 250, 256, 275

Valeriana lindaviana 270, 271
Valeriana lobata 245, 262, 263, 282

Valeriana lutescens 266

Valeriana lyrata 272

Valeriana macrorhiza 245, 248, 249, 254, 260, 264, 275, 276, 278,284

Valeriana macrorhiza var. pumila 275

Valeriana magellanica 258, 285

Valeriana magellanica var. azorelloides 285

Valeriana magna 245, 291

Valeriana maipoana 245, 274

Valeriana montteana 289

Valeriana moyanoi 248, 249, 250, 276, 277, 279

Valeriana munozii 248, 249, 276, 277, 278

Valeriana muriculata 287

Valeriana nivalis 264

Valeriana obovata 278

Valeriana obtusifolia 248, 250, 257, 274, 278

Valeriana oreocharis 245, 262

Valeriana papilla 278, 279

Valeriana papilla var. andicola 279

Valeriana parnasiifolia 270

Valeriana pearcei 272

Valeriana peltata 248, 250, 279, 280

Valeriana phellocarpa 257

Valeriana philippiana 248, 249, 250, 261, 280

Valeriana pilosa 245, 281

Valeriana polemoniifolia 245, 248, 249, 250, 281, 282, 289

Valeriana polystachya 249, 250, 282, 283, 284

Valeriana pugae 281

Valeriana pulchella 261, 280

Valeriana radicalis 248, 250, 283

Valeriana radicalis var. patagonica 276

Valeriana regularis 257

Valeriana rigida 253

Valeriana rotundiloba 269

Valeriana ruizlealii 248, 249, 276, 283, 284

Valeriana rupestris 256

Valeriana rupicola 272

Valeriana samolifolia 248, 249, 250, 253, 284

Valeriana sarcophylla 261

Valeriana sedifolia 248, 249, 285

Valeriana sedoides 285

Valeriana simplex 257

Valeriana sparsiflora 272

Valeriana spegazzinii 261

Valeriana sphaerocarpa 248, 250, 285, 286

Valeriana stricta 245, 248, 250, 286, 288

Valeriana vaga 249, 250, 286, 287, 288

Valeriana valdiviana 250, 262, 263, 267, 288, 290

Valeriana velutina 248, 250, 281, 288, 289

Valeriana verticillata 248, 250, 261, 289

Valeriana virescens 248, 249, 250, 254, 257, 288, 289, 290

Valeriana virescens var. montteana 289

Valerianella olitoria 253

Valerianella samolifolia 284

Yerba del aguilucho blanco 254

Recibido: 17.12 .09

Aceptado: 18.03.11 